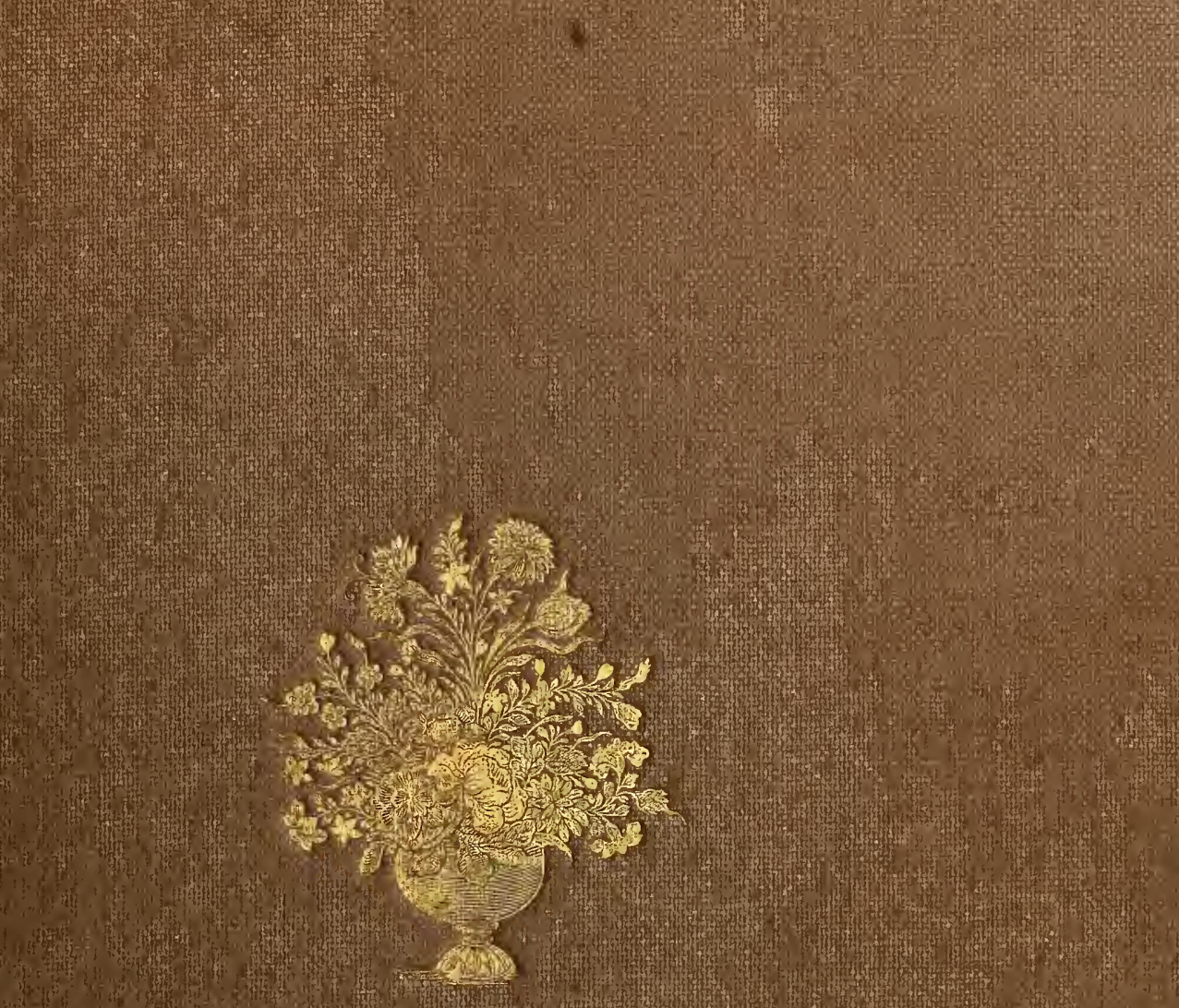





OLD DUTCH POTTERY AND TILES 



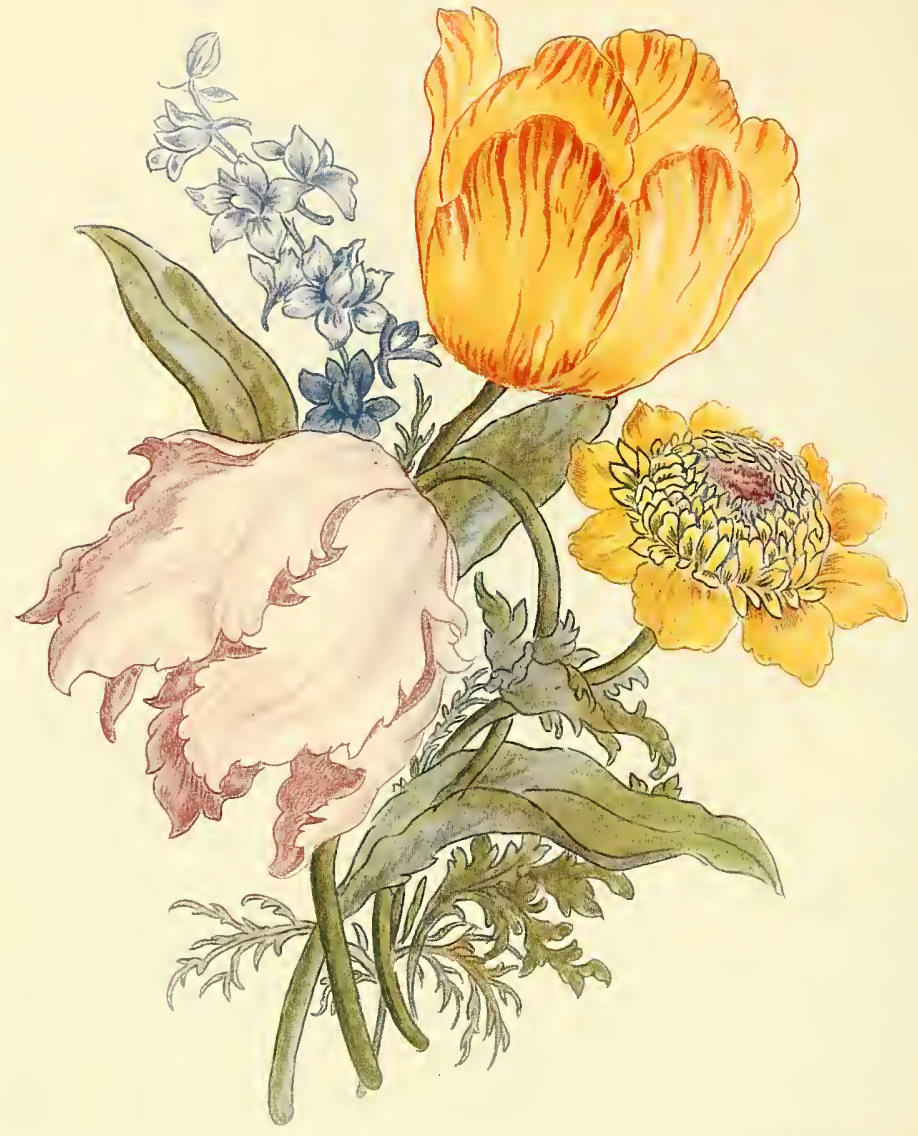


FRONTISPIECE.

PLATE XLI.

Fig. 64. Tile painted with a bouquet of tulips, an anemone and larkspur in yellow, reddish brown, green, blue and manganese-purple of the grand feu on a white ground. Unmarked. Delft; about 1700 . H. 13 ins, $(33 \mathrm{~cm}$.), W. 9 ? ins. $(25 \mathrm{~cm}$.). (See page 98. ) Nederlandsch Museum voor Geschiedenis en Kunst (Rijksmuseum), Amsterdam, No. 339. 



\section{OLD DUTCH \\ POTTERY AND TILES}

BY ELISABETH

NEURDENBURG

LITT. D., READER IN THE HISTORY OF ART AT

THE UNIVERSITY OF GRONINGEN. TRANSLATED WITH ANNOTATIONS BY

BERNARD

RACKHAM

DEPUTY KEEPER, DEPARTMENT

OF CERAMICS, VICTORIA AND

ALBERT MUSEUM

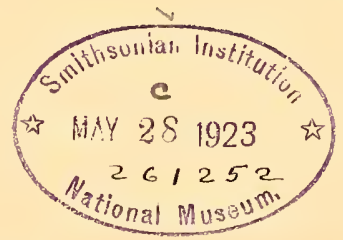

WITH ONE HUNDRED AND TWELVE

ILLUSTRATIONS OF WHICH EIGHT

ARE IN COLOUR

LONDON : BENN BROTHERS, LIMITED

8 BOUVERIE STREET, E.C. 4

1923 
Made and printed in Great Britain at

The Mayflower Press, Plymouth. William Brendon \& Son, Ltd. 
<smiles>C1C[Al]1</smiles>

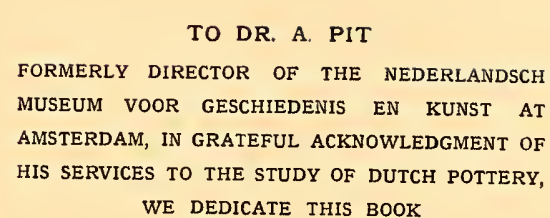





\section{FOREWORD}

This work is to some extent based on the chapters relating to Dutch pottery in the handbook by the authoress on the earthenware in the Nederlandsch Museum voor Geschiedenis en Kunst (Rijksmuseum) at Amsterdam, published under the title Oud Aardewerk, of which the first edition appeared in I9I7 and a second in I920. Acknowledgment is hereby made by the publishers to the Director of that Museum, Mr. M. van Notten, for his kindness in permitting the extensive use that has been made of the Museum publication, and the reproduction of official photographs of the objects in the Museum. The chapter on tiles and the greater part of that on Dutch maiolica are entirely new material, embodying the results of recent researches in these subjects. The chapters on Delft have been considerably amplified by references to specimens in public and private collections in England and on the Continent. The work was written in Dutch specially for the present publishers by $\mathrm{Dr}$. Neurdenburg, and translated with annotations by Mr. Rackham, who has also contributed the chapter on the place of Dutch earthenware in the history of European pottery and helped to choose the illustrations. That these have been drawn in large proportion from specimens in the Nederlandsch Museum (Rijksmuseum) is due to the fact that the authoress has had exceptional opportunities of studying them in her former capacity as Wetenschappeliik Assistente in that Museum.

The authoress and translator desire to express their thanks to Mr. Ferrand Hudig, of the Nederlandsch Museum, to Miss Ida Peelen, of the Lambert van Meerten Museum at Delft, to Mr. A. Hoynck van Papendrecht, of the Museum van Oudheden at Rotterdam, to Dr. H. E. van Gelder, of The Hague, to M. Marcel Laurent, of the Musées du Cinquantenaire at Brussels, to $M$. Frans Claes, of Antwerp, to M. J. de Pas, of St. Omer, to M. Pierre Turpin, of Lille, and to Mr. P. Entwistle, of the Public Museums, Liverpool, for facilities courteously extended to them and for valuable suggestions. They wish also to acknowledge the kindness with which specimens have been placed at their disposal for illustration by M. Th. Clainpanain, of Lille, Mr. J. Schouten, of Delft, M. Michel van Gelder, of Brussels, 


\section{FOREWORD}

Mr. John Tenbosch, of Liverpool, and Mr. Henry A. Cole, Chairman of the Libraries, Museums and Arts Committees, Liverpool. Lastly, their acknowledgments are due for similar privileges to the authorities of the museums already mentioned, and also of the Victoria and Albert and British Museums, London, the Gemeentemuseum at The Hague, the Musée des Arts Décoratifs, Paris, the Musée Céramique, Sèvres, the Schlossmuseum, Berlin, and the Danske Kunstindustrimuseum, Copenhagen; finally, to the Lord Chamberlain for permission to photograph and reproduce a vase at Hampton Court Palace. Crown copyright is also reserved in the case of the photographs reproduced in Figures 7,43 , $45,53,58,68,69,74,84,89$ and $\mathrm{Iog}$. 


\section{CONTENTS}

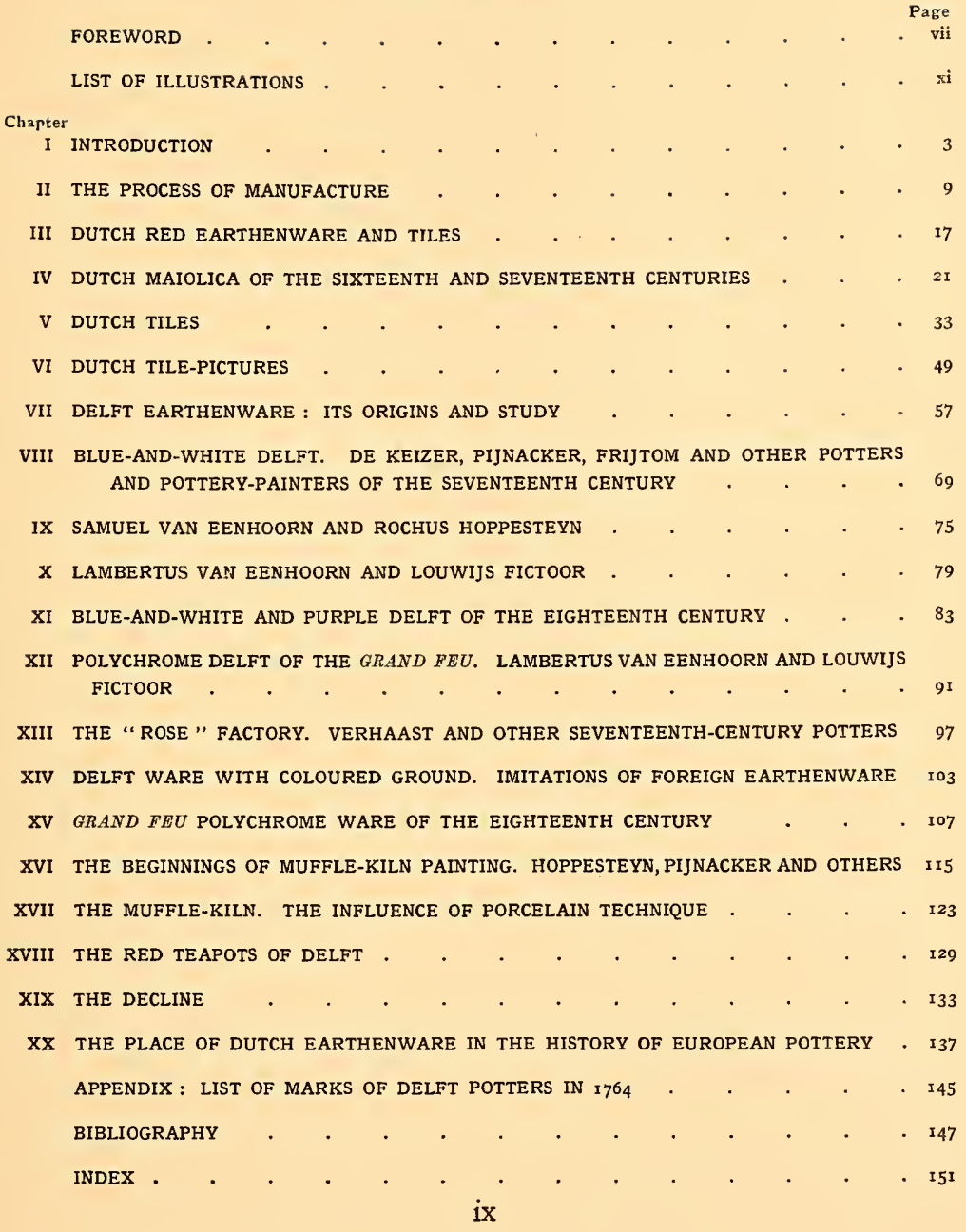





\section{LIST OF ILLUSTRATIONS}

DRUG-POT, DATED I6ro. (In Colours)

Rijksmuseum, Amsterdam.

DISH PAINTED WITH FRUII ON A DISH.

Museum Lambert van Meerten, Delft.

THREE DRUG-POTS FROM MIDDELBURG

Rijksmuseum, Amsterdam.

DISH INSCRIBED EERT GOD

Rijksmuseum, Amsterdam.

DEEP BOWL WITH THE ROMAN CHARITY, DATED I6OI.

Rijksmuseum, Amsterdam.

DISH WITH FIGURES OF VERTUMNUS AND POMONA

Rijksmuseum, Amsterdam.

DISH WITH HERALDIC ROSE

Victoria and Albert Mluseum, London.

PLATE WITH THE MADONNA AND CHILD

MI useum Lambert van MIecrten, Delft.

DISH WITH FRUIT DESIGN

Schouten Collection, Delft.

FOUR TILES WITH ARABESQUES

Museum Lambert van Meerten, Delft.

FOUR TILES WITH IERMINAL FIGURES

Museum Lambert van Mecrten, Delft.

FOUR TILES WITH GEOMETRICAL ORNAMENT

Museum Lambert van Meerten, Delft.

TWELVE TILES WITH LATTICE PATTERN

Museum Lambert van Meerien, Delft.

TWELVE TILES WITH STAR AND LILY MOTIVES

Mf useum Lambert van Meerten, Delft.

NINE TILES WITH VASES OF FLOWERS

Museum Lambert van Meerten, Delft.

TWENTY-FOUR TILES WITH FRUIT AND FLOWERS

Museum Lambert van Meerten, Delft.

TILE WITH FIGURE OF AN ARCHER .

Rijksmuseum, Amsterdam.

FOUR TILES WITH ANIMALS AND BIRDS

Museum Lambert van Meerten, Delft.

FOUR TILES WITH TULIPS

Museum Lambert van Meerten, Delft.

TILE-PICTURE FROM THE HOUSE IN DUYSENT VREESEN

MI useum van Oudheden, Rotterdam.

$\mathrm{xi}$ 


\section{LIST OF ILLUSTRATIONS}

TILE-PICTURE, A VASE OF FLOWERS. (In Colours) .

TILE-PICTURE AFTER JOACHIM UTEWAEL

FOUR TILES WITH FIGURES

MI useum Lambert van Meerten, Delft.

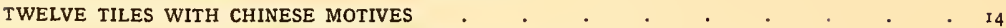

Museum Lambert van Meerten, Delft.

TILE-PICTURE, A TILE-FACTORY AT BOLSWARD. Dated 1737 . $\quad$. . . . . $\quad$ I5 Rijksmuseum, Amsterdam.

TILE-PICTURE, SHIPPING, BY CORNELIS BOUMEESTER OF ROTTERDAM . . . . . I6 Rijksmuseum, Amsterdam.

VASE AND COVER, Mark GK

Cole Collection, Bidston, Birkenhead.

INKSTAND WITH ARMS OF ORANGE

Rijksmuseum, Amsterdam.

TULIP-VASE. Mark AK

$$
\text { Rijksmuseum, Amsterdam. }
$$

JUG WITH RING-SHAPED BODY. Dated 1658 . Rijksmuseum, Amsterdam.

TILE, PORTRAIT OF ROBERTUS JUNIUS. Dated 1660 Rijksmuseum, Amsterdam.

HYACINTH-VASE WITH CIPHER OF WILLIAM III AND QUEEN MARY. Mark AK . . . 2 I Hampton Court Palace.

TILE WITH LANDSCAPE, SIGNED F. V. FRIJTOM Rijksmuseum, Amsterdam.

TILE, VIEW AT DELFT

British Museum, London.

PLAQUE WITH SEA-FIGHT, SIGNED REJNER (?)

Musée Céramique, Sèvres.

PLAQUE WITH VIEW OF CHINESE COAST, SIGNED REINIER $R$. . . . . . $\quad 23$

DI usée Céramique, Sèrres.

TWO PLATES WITH LANDSCAPES, FRIJTOM STYLE Musées du Cinquantenaire, Brussels.

JUG WITH SILVER LID, HOPPESTEYN STYLE Rijksmuseum, Amsterdam.

VASE, FLORAL DESIGN. Mark RHS Rijksmuseum, Amsterdam.

WIG-STAND, CHINESE FIGURES. Mark SVE Victoria and Albert Museum, London.

LARGE VASE AND COVER, CHINESE FIGURES. Mark SVE Danske Kunstindustrimuseum, Copenhagen.

PAIR OF GOURD-SHAPED BOTTLES, FLORAL DECORATION. Mark AK $\quad$. . . $\quad$ - 28 Victoria and Albert Museum, London.

DISH, FLORAL DECORATION. Mark LVE or LF Victoria and Albert Museum, London. 


\section{LIST OF ILLUSTRATIONS}

JUG WITH MUSIC-PARTY. Mark Roos.

Victoria and Albert Museum, London.

PLATE FROM A SET OF THE ZODIAC, SIGNED J. THORNHILL FECIT. DELPH, AUG. 17I1 . 29 British MI useum, London.

DISH WITH SUBJECT OF CHRIST BEFORE CAIAPHAS. Mark IVH . . . . . . 30 Rijksmuseum, Amsterdam.

DISH WITH VIEW OF TWISK, SIGNED $M . v, K U Y K$ and dated 1742 . . . . . . 30 Tenbosch Collectim, Liverpool.

KETTLE AND BRAZIER, CHINESE DESIGN Rijksmuseum, Amsterdam.

DISH, FLOWERS IN PANELS .

Tenbosch Collection, Liverpool.

VIOLIN WITH DANCING SCENES

Rijksmuseum, Amsterdam.

TEAPOT, CHINESE DESIGN, STYLE OF L. $\operatorname{van}$ EENHOORN or L. FICTOOR . . . • 33 Rijksmuseum, Amsterdam.

DISH WITH "LIGHTNING" PATTERN. Mark WK • . . . . . . . . $\quad 33$ Vicloria and Albert Museum, London.

SET OF FIVE VASES, CHINESE DESIGN. Mark LVE or LF . . . . . . . . $\quad$ - 34 Michel van Gelder Collection, Uscle.

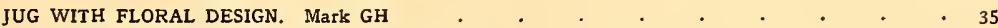
Rijksmuseum, Amsletdam.

COFFEE-POT, FLORAL DESIGN. Mark LF and FDK . . . . . . . . . $\quad$. 35 Rijksmuseum, Amsterdam.

VASE WITH FLORAL ORNAMENT. Mark ROOS. (In Colours) . . . . . . $\quad$. $3^{5}$ Räjosmuseum, Amsterdam.

SET OF THREE VASES AND TWO BEAKERS. Mark ROOS . . . . . . . 37 Victoria and Albert Museum, London.

DISH, FAMILLE VERTE DESIGN . Rijksmuseum, Amsterdam.

DISH, SCATTERED FLOWERS Michel van Gelder Collection, Uccle.

WALL-PLAQUE, CHINESE PLANTS AND BIRDS. Mark IVK. Dated I739 * . . 39 Rijksmuseum, Amsterdam.

PLATE WITH CHINESE FIGURES . Michel van Gelder Collection, Uccle.

TILE WITH GROUP OF PEASANTS, ASCRIBED TO G. VERHAAST . . . . . . . 40 Musée Céramique, Sèrres.

TILE WITH BOUQUET. (Frontispiece, in Colours) Rijksmuseum, Amsterdam.

TEAPOT, DECORATION IN RESERVE ON BLACK GROUND. Mark APK ․ . . $\quad$. 42 Rijksmuseum, Amsterdam.

THREE VASES, DECORATION IN RESERVE ON BLACK GROUND. Mark APK . . 42 Clainpanain Collection, Lille.

WALL-PLAQUE, FLOWERS ON BLACK GROUND. (In Colours) . . . . . . . $\quad$. 43 Victoria and Albert Museum, London. 


\section{LIST OF ILLUSTRATIONS}

TEA-CADDY, CHINESE LANDSCAPES ON BLACK GROUND. Mark LF or LVE in monogram

PLATE, CHINESE LANDSCAPE ON BLACK GROUND

Victoria and Albert MI useum, Lomlon.

JUG, FLOWERS IN YELLOWISH GREEN ON A MAZARINE-BLUE GROUND 45

Gemeentemuseum, The Hague.

PAIR OF VASES, DECORATION ON TURQUOISE-BLUE GROUND. Mark D * . . . $\quad 45$ Rijksmuserm, Amsterdam.

PLATE, DECORATION IN CHINESE STYLE Rijksmuseum, Amsterdam.

WALL-PLAQUE, CHINESE LADIES Rijksmuseum, Amsterdam.

SHALLOW BOWL, CHINESE LADIES Victoria and Albert Museum, London.

DISH, PASTORAL SCENE WITHIN FLORAL BORDER Clainpanain Collection, Lille.

DISH, VASE OF FLOWERS .

Rijksmuseum, Amsterdam.

FIGURE OF A BAGPIPE-PLAYER, Mark an axe Rijksmuseum, Amsterdam.

FIGURE OF A HORSE

Rijhsmuseum, Amsterdam.

PAIR OF SLIPPERS

Rijksmuseum, Amsterdam.

FIGURE OF A COW Rijksmuseum, Ansterdam.

FIGURE OF A PARROT

Clainpanain Collection, Lille.

DISH, FLORAL DESIGN. (In Colours) Rijksmuseum, Amsterdam.

DISH, FLORAL DESIGN

Rijksmuseum, Ansterdam.

BOWL WITH INSCRIPTION COMMEMORATING THE PEACE OF RYSWICK, 1697 . $\quad$. 52 Victoria and Albert Museum, London.

PAIR OF PLAQUES WITH FIGURES OF DRINKERS, ONE INSCRIBED G. SACHTLEEVEN • 53 Rijksmuseum, Amsterdam.

TILE WITH ARMS OF ORANGE. Marked P. VIZEER. Dated I765 * * . . . $\quad$. 53 Rijksmuseum, Amsterdam.

MONEY-BOX, CHINESE FLOWERS

Rijksmuseum, Amsterdam.

PUZZLE-JUG, CHINESE FLOWERS

Rijksmuseum, Amsterdam.

TRAY WITH VASE OF FLOWERS

Victoria and Albert Museum, London. 


\section{LIST OF ILLUSTRATIONS}

JAR, GROUPS OF CHINESE FIGURES, Mark RHS

Rijksmuseum, Amsterdam.

JAR, CHINESE FIGURES. Mark RHS . $\quad$. $\quad$. $\quad$. $\quad$. $\quad$. $\quad$. $\quad$. $\quad$. 57

Schlossmuseum, Berlin.

JUG, CHINESE FIGURES. Mark RHS and a negro's head. (In Colours) . . . . . $\quad$. $5^{8}$ Rijksmuseum, Amsterdam.

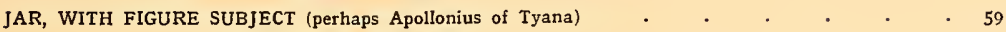

Musées du Cinquantenaire, Brussels.

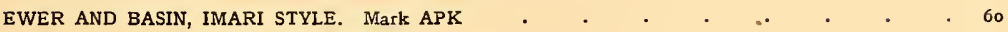

Rijksmuseum, Amsterdam.

DISH, IMARI STYLE. Mark API. (In Colours) . . . . . . . . . . . 61

Rijksmuseum, Amsterdam.

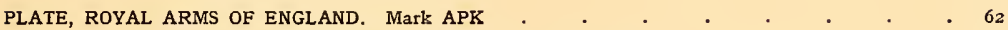
Musée des Arts Décoratifs, Paris.

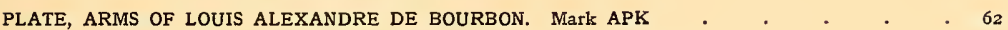
Clainpanain Collection, Lille.

PLATE, ARMS OF FREDERICK THE GREAT OF PRUSSIA. Mark APK . . . . . . $\quad 62$ Gemeentemuseum, The Hague.

JUG, IMARI STYLE. Mark APK . .

Gemeentemuseum, The Hague.

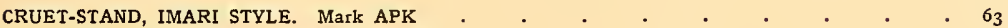

Rijksmuseum, Amsterdam.

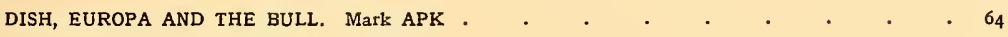
Rijksmuseum, Amsterdam.

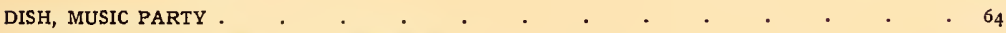

MLusée des Arts Décoratifs, Paris.

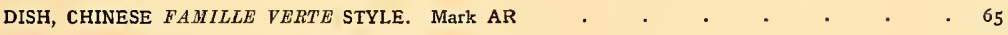

Rijksmuseum, Amsterdam.

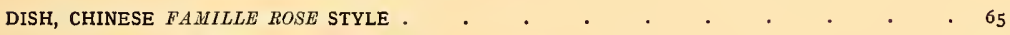

Rijksmuseum, Amsterdam.

MINIATURE SET OF VASES AND BEAKERS, JAPANESE STYLE . . . . . . . . $\quad 66$

Rijksmuseum, Amsterdam.

TEA-TRAY, CHINESE FAMILLE VERTE STYLE . . . . . . . . . . . . 66

Rijksmuseum, Amsterdam.

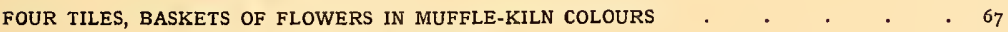

Museum Lambert van Mteerten, Delft.

DISH WITH LANDSCAPE IN MEISSEN STYLE.

Victoria and Albert Museum, London.

WALL-CISTERN AND WASH-BASIN WITH LANDSCAPES $. \quad . \quad . \quad . \quad . \quad$. $\quad$. 68

Rijksmuseum, Amsterdam.

TEAPOT, RED EARTHENWARE. Mark of Ary de Milde . . . . . . . . 69

Rijksmuseum, Amsterdam.

COFFEE-POT, WITH FRUIT AND SCALE BORDER. ARNHEM.$\quad$. . . . . . $\quad$. 69

Clainpanain Collection, Lille. 

INTRODUCTION 



\section{ChAPTER I}

\section{INTRODUCTION}

There is little to be gathered from literary sources about old Dutch earthenware. It is true that quite a number of documents have come down to us relating to the potters and potteries of Delft, Rotterdam and other places, as well as those of Friesland, but we read in them very little about the wares themselves or their technique.

Gerrit Paape, a Dutch author who in the year 1794 published a description of the Delft pottery manufacture, is the only writer who gives us more detailed information, and his work belongs to the very end of the eighteenth century, when Delft earthenware had long passed its prime. Nevertheless, if we wish to get an idea of the processes of manufacture, we shall do well to read Paape's interesting little book entitled De Plateelbakker of Delftsch Aardewerkmaaker ("The Earthenware Potter or Delft-ware Manufacturer"). If we do so, we shall at once meet with an observation that, to us of the twentieth century, accustomed to a more precise use of language, will sound somewhat curious. Delft earthenware, says Paape, is a certain kind of porcelain that was discovered in Holland about the middle of the seventeenth century. And he tells us that the first productions were so successful that they immediately became the rage in different countries. From his further account it appears that he looks upon "delft" entirely as an imitation of what he calls "East Indian porcelain."

The reason why Paape speaks of Delft earthenware as a kind of porcelain will at once be clear to us if we reflect for a moment that, as a matter of fact, at that time all European earthenware with a white ground was a substitute for "a kind of porcelain." The most eager curiosity must have been awakened amongst potters, the Dutch especially, from the sixteenth century right up to the beginning of the eighteenth-till the time, that is, when porcelain began to be made in Europe itself-by the white translucent Chinese porcelain, the splendid homogeneous material that the East India merchants had been bringing with them to Europe since the sixteenth century. What efforts those potters made to imitate this delicate ware, with white body closely united with a 


\section{OLD DUTCH POTTERY AND TILES}

transparent white glaze, and its painted decoration in pure blue or the strong colours of the polychrome palette! They never fully realised their lack of kaolin, which is essential for obtaining a material white throughout its substance. They attempted to imitate this Oriental porcelain with their earthenware, and with such deceptive results that they themselves almost believed they had succeeded; in any case, they called their productions porcelain when painting in blue or colours gave them to the eye an exact resemblance to the Chinese. But their earthenware always consisted of a core, mostly cream-coloured (never white), brittle and readily scratched with a knife, and, overlying this core, clearly separate from it, the layer of enamel, that is glaze owing its whiteness to the presence of tin in its composition. Moreover, body and enamel not being fused into one homogeneous substance, this layer of enamel was liable to crack, and in consequence often shows a network of little fissures, the so-called "crackle"; indeed, it not infrequently flakes right away from the body. Nor is this earthenware ever transparent or translucent like porcelain. Yet the aim of the Dutch potters was undoubtedly to approach as nearly as possible in their productions to the porcelain which was to them such a mystery.

Thus we find the potters of Delft, and equally of Haarlem and other places, when they imitated Chinese porcelain, calling themselves "porcelain potters" (porseleinbakkers) and their earthenware " porcelain." Seen from a distance their work bears a close likeness to porcelain, but its unevenness of surface, its softness to the touch, above all its brittle, tinted body and its easily chipped layer of glaze, prove that all the time they were making "earthenware." That it became customary to look upon delft as a kind of porcelain is clearly shown by the fact that, even as late as 1794, Gerrit Paape (in his work to which reference has been made above) speaks of "porcelain." From this we gather that, from the time when porcelain first became known in Europe right up to the nineteenth century, no distinction such as we now recognise was made between earthenware and porcelain, the boundaries between them having been effaced, so to speak, through the effort to copy Chinese porcelain.

Whilst, therefore, in the nineteenth century delft has again been classified, at least amongst connoisseurs, as earthenware (it is still by no means uncommon to hear people talk of "Delft porcelain"), it has at the same time become customary, with the growth of interest in this class of earthenware, to call everything that shows a correspondence with it "delft." Thus even in England the expression "English and Dutch 


\section{INTRODUCTION}

delft" is generally current, whilst in the Netherlands no distinction is made between the products of the Delft factories and those of other places. And in a certain sense it is indeed convenient to call all such earthenware " delft."

But delft is preceded by an important class of old Dutch earthenware, its forerunners, which has only lately become known. Through the study made of this early ware since the beginning of the nineteenth century, chiefly under the guidance of finds dug up from beneath the soil in various places in the country, we have been brought automatically to a different date for the origin of earthenware in the Netherlands than that of Paape, who in his little book gave it as the middle of the seventeenth century. The discussion, therefore, of old Dutch earthenware and even of delft must begin with these early pieces from the Northern Netherlands, that is to say, with the earthenware that was produced in Holland from the second half of the sixteenth century onwards; it is as yet in no sense an imitation of Chinese porcelain, but displays a peculiar character and a peculiar beautiful warm colouring of its own. 

THE PROCESS OF MANUFACTURE 



\section{Chapter II}

\section{THE PROCESS OF MANUFACTURE}

No description of the technique has come down to us from the early period; we are therefore obliged to make use of Paape's clear survey of the pottery industry in order to picture to ourselves the production of earthenware at Delft and also as well as we can in the older factories. In so doing we shall here pass over receipts for the glaze and other ingredients, names of various shapes of dishes, etc., information that would be of value chiefly to facilitate the reading of inventories. We shall confine ourselves to the description of the method by which the earthenware was made. Nor shall we go into the chemical secrets of the potter-who, indeed, must have kept them to himself as much as possible, although most of them were none the less common property; there is the more reason for omitting these questions in that there is all the difference in composition of body, glaze and pigment between the work of the time of Paape, that is, the end of the eighteenth century, and that of the middle of the seventeenth or the end of the sixteenth century.

The first operation with which the manufacture of earthenware begins is the washing of the clay; that is to say, the clays of the various kinds required are blended into one, repeatedly cleansed with water, kneaded and passed through a strainer. Paape relates that for delft three kinds of clay are required and in these proportions : three ordinary wheelbarrow loads of Tournay clay, three of black or Rhineland clay and two of Delft clay, or greater or less proportions of each of these kinds as the washer judged best from their quality. We know also-although this is not related by Paape, as he deals only with Delft-that elsewhere other clays were used; at Rotterdam, for example, about I630 English clay was also worked in at the same time with other kinds as well.

After the clay had been washed in shallow tanks in the washinggrounds-which were for the most part situated for convenience beside the Schie, the water-course outside Delft-it was dried and then broken away in blocks and taken to the pottery, where the blocks were deposited in pits and kept moist so as to preserve the necessary plasticity.

Before the clay could be used for throwing on the wheel or-in 


\section{OLD DUTCH POTTERY AND TILES}

the case of articles that are not circular-for shaping by pressing into a mould-it was first kneaded afresh by the aardetrapper. ${ }^{1}$ From this Dutch name it is clear that this operation was performed with the feet ; the object was to remove from the clay any hard lumps which would at once be felt by the bare feet. Then the thrower, after the clay has once more been thoroughly kneaded, presses on his potter's wheel as much clay as he requires for the vessel he is going to throw and, setting the wheel in motion by pressing with his feet on the large lower wheel, he shapes with a simple movement of finger and thumb a round vase or bowl on the little spinning disc. Small instruments for measuring and for cutting the vessel from the wheel (for which purpose merely a length of copper wire or a piece of wood is often sufficient), together with a plane for removing after a short drying process any superfluous clay, complete the apparatus of the throwing-bench. We must not forget also the thrower's board, on which the newly thrown pieces are placed to be carried to the drying loft.

For moulded articles the process is as follows. The moulder first makes a model of the objects he has to produce. Around it, leaving a small interval, he builds up a case of clay. Then he pours in plaster to form a mould between the model and the outer case. Sometimes several plaster moulds have to be made for a single article; their number depends upon the more or less complicated nature of the desired object. When the plaster mould or moulds are dry and have been removed from the case, the moulder can press or mould in them one after another the requisite number of pieces. Then the articles are trimmed to give them a smooth surface, a process particularly needful when it has been necessary to use several separate plaster moulds.

The articles are now given their first firing at a moderate temperature. As to the manner in which they are placed in the kiln we shall have something to say shortly when we describe the high-temperature firing.

The next process that the earthenware has to undergo is dipping in the glaze-the white tin enamel. This glaze or enamel, which owes its whiteness and opacity to the introduction of tin-ash, is mixed in the form of a powder with water. The water is absorbed by the dry porous clay, and the enamel remains adhering in a layer on the surface of the ware. If it is desired, in order to economise tin, to cover the back of the article

1 I.e. One who tramples on the clay. In England the process is carried out by "wedging," that is, by lifting the clay in a slab and bringing it down repeatedly with violence on a bench or table. 


\section{THE PROCESS OF MANUFACTURE}

with only a thin layer of enamel, this side is first moistened so that the clay, being already more or less saturated, absorbs the water less rapidly from the enamel mixture; only a thin film of enamel can then be deposited on the surface.

When the enamel is dry, the article is painted. The painter also works with a kind of turning lathe, the "outlining wheel" (profileerwiel), for drawing parallel circles. For painting a number of pieces with the same design, e.g. plates, he uses a stencil, that is, a piece of paper on which the desired pattern is pricked out along all its lines and through which powdered charcoal is rubbed so that the outlines are traced in the powder on the article (specimens of such stencil-papers are preserved in the Museum Huis Lambert van Meerten at Delft, at Rotterdam and elsewhere). The outlines are then painted over in blue pigment with a brush; next comes the shading, dark and light. Painting in polychrome was executed in the same manner. For the laying down and painting of the outlines and the drawing of details within them a dark blue pigment is often used, sometimes purple or black; this is called the trek. As to the composition of this pigment, which, as Paape says, served to make the outlines stand out clearly "above" the blue, directions can be found amongst his receipts for the various kinds of blue and other colours. The pigment, which like the enamel was made up with water only, once laid on the enamel, was, of course, immediately absorbed by it. Thus the painting demanded of the pottery painter a very sure hand.

In very many factories in Italy, Germany and elsewhere the earthenware was fired immediately after painting. At Delft, on the other hand, and (except in the earliest times) at Faenza, we know that the wares, before being put in the kiln, were covered with a second glaze-a thin, clear glaze owing its transparency to lead-to heighten the sheen which the tin enamel will acquire after firing. At Delft this was done on the upper or outer surface only by sprinkling with a brush. The process was called kwaarten.

The earthenware is now ready for the chief firing, that is, at a moderately high temperature. It is next put in the kiln in cylindrical fire-proof boxes or saggars, through holes in which pegs are stuck at intervals in sets of three at the same level; the wares were variously placed according to their form, either suspended on the pegs, as in the case of plates (hence the three rough scars on the back of a plate), or standing on trays, as in the case of cups and other articles. The kiln is then completely bricked up except for inspection holes. The maintenance 


\section{OLD DUTCH POTTERY AND TILES}

of a uniform wood fire was the great art in stoking. According to Paape, low- and high-temperature stokers followed one another as required for the regulation of the heat.

This mode of operations was followed at Delft in its prime both for polychrome and for blue-painted earthenware. But the firing at a high temperature, generally known as the grand feu technique, by which the painting was completely fired into the tin enamel, was not suitable for all colours, and the potter was therefore restricted to a limited palette. Blue is the colour which best endures firing; yellow or brown, green, manganese-purple and brick-red or scarlet also offer a good resistance to the high temperature that the ware has to undergo in the kiln, whilst black also was now and then fired as a grand feu colour.

But there was a demand, especially in the eighteenth century, for intermediate tints and gold, the latter in imitation of Chinese, Japanese and European porcelain. Recourse was therefore had to the technique which was customary for porcelain, and only the colours, blue in particular, most capable of resisting heat were fired in the high-temperature kiln and burnt into the enamel. Colours of less resistance had to be painted on the already-fired ware and subsequently "muffle-fired" at a low temperature. The wares especially that were intended to imitate Meissen ("Dresden") porcelain were for the most part entirely decorated in muffle-kiln colours. But with the adoption of this process both literally and, in the long run, in a figurative sense also, Delft earthenware lost its brilliance. These products of the potter's art are often much sought after for their delicate intermediate tints and gilding, but, regarded from the point of view of technique and also by reason of their much inferior brilliance, they are not to be compared with the older work on which all the colours are fired with and into the glaze, not even with the ware on which at most a little gilding and a single secondary tint has afterwards been added. The muffle colours always have a dull feeling. The wares thus miss precisely all that distinguishes delft from other earthenware, its sheen and its pleasant soft feeling to the touch.

After this description of the manufacture of delft, in which Paape has been our guide, we must add a few remarks about the clay, glaze and methods of decoration not only of delft, but also of the other kinds of old Dutch earthenware.

For we do not find in all old Dutch pottery a fine yellow body and tin enamel as in Delft ware. Indeed, the yellow body and the entire treatment with tin enamel is pre-eminently peculiar to delft. In the 


\section{THE PROCESS OF MANUFACTURE}

older earthenware and also in the so-called schotelgoed ${ }^{1}$-that is, earthenware that was not made in special potteries, but manufactured in tileworks side by side with tiles-we find for the most part a much greyer and coarser body, whilst the dishes show a tin enamel only on the front, and on the back a glaze made with lead and therefore transparent. This use of lead glaze was occasioned not only by the costliness of tin, but also by the manner of firing followed for the schotelgoed; this class of ware was not put in the kiln with so much care as Delft ware, in fireproof boxes or saggars. The lead glaze on the reverse side needed no protecting saggar; the tin enamel on the front was shielded from the fire by piling up the dishes in the kiln and setting them one against another in such a way that only the lead glaze was exposed to the fire, whilst the tin glaze on the front was protected. Small tripods, or "cockspurs," put on the bottom of the dishes, prevented the dishes from getting stuck to one another in the firing. Hence arise the three raw scars in the glaze on the bottom of a dish of this class. They are often quite rough through portions of the cockspurs remaining stuck to the dish. The traces of firing are thus quite different from those on Delft ware, on which three narrow unglazed stripes are to be seen on the back of the rim, the impressions of the pegs on which the ware was suspended in the fireproof saggars.

In the tiles, of which we shall have more to say in Chapter V, we find at a late period an entirely yellow body; whilst often, especially in the older tiles, a reddish tone comes out in the yellow or grey body, and the oldest tiles known to us, of the Middle Ages, display an entirely red body.

We find a red body, however, not only amongst the oldest wares, but also in much later times. Earthenware of red clay is still made and used in the kitchen and for other special purposes. Such red clay also occurs at an earlier date in the Near East and in Italy, covered with a simple lead glaze, a glaze made fusible by means of lead and therefore transparent. The decoration on such wares is as a rule carried out under the glaze on a body that has only been lightly fired, for the most part covered with a white slip in which incised designs can be scratched in the manner of the "sgraffiato " of the Italians. In this way a decoration was obtained in darker lines (the colour of the red body). The slip itself was also used for decoration. It was allowed to run out of a fine funnel

1 Literally, "dish-ware."

2 In Dutch, proenen, derived from the Italian pironi (French, pernettes). 


\section{OLD DUTCH POTTERY AND TILES}

(called ringeloor), so as to trace on the earthenware formal designs and figures which then appeared through a glassy layer of lead glaze. The decoration in this case is therefore executed in an entirely different manner from that in the tin-enamelled earthenware.

As regards this tin enamel, we may observe that its use had already been brought about in earlier periods by the demand for a pure white ground for painting which, though not created, was yet augmented by the influence of Chinese porcelain. For efforts had continually been made towards a white glaze. It appears that in the Near East it had been found possible to obtain an opaque white glaze even without the addition of tin-ash, but by far the most thoroughly opaque white glaze is that containing tin, and the glaze of the delft and older Dutch wares is of that type. Paape therefore devotes a chapter to the method of burning tinash in the Delft potteries. It would, however, take us too far afield to go more closely into this question.

Not only the glaze, but also the pigments used for the painting, which latter were first given their colour by means of metallic oxides, were ground into powder, and in powder form, as we have said already, had merely to be made up with water in order to be ready for use on the ware. The painting on tin-enamelled ware of the grand feu is always applied upon the unfired tin-glaze or enamel. It is absorbed by it and, as it were, amalgamated with it during the firing. 
DUTCH RED EARTHENWARE AND TILES 



\section{ChAPTER III}

\section{DUTCH RED EARTHENWARE AND TILES}

Everything tends to show that the Dutch learned the art of making maiolica from Italy. In any case, the Dutch earthenware with tin enamel of the end of the sixteenth and the beginning of the seventeenth century points towards prototypes from that country, and especially from Faenza. We shall see on a later page how this relationship probably came about.

The pottery produced in Holland before that period, the stoneware jugs known as Jacobakannetjes, do not come within the scope of a work dealing with earthenware.

This is not the case with the red earthenware with coloured slip and lead glaze. The earliest examples are found in the tiles which are combined to form a few portions of fourteenth-century or perhaps even older mosaic pavements from old Utrecht houses, whence they have been removed to the Rijksmuseum at Amsterdam and the Gemeente-museum at Utrecht (the finest are at the latter place). Similar tiles have lately been found in the Dom (the old cathedral) at Utrecht. These and the fifteenthcentury tiles showing an inlay of coloured slip give us at least some idea of the medirval production of floor-tiles in Holland. Quite recently also tiles with lead glaze over relief decoration have come to light-notably at Aduard in the province of Groningen-that seem to be of very early date.

To the class of true peasant art belongs the red earthenware decorated under a lead glaze by means of the ringeloor, a funnel-shaped instrument through which liquid clay is laid on the ware in a thin streak, so that by moving the funnel the potter can draw lines in clay on the surface; we find on it also sgraffiato decoration, that is, designs scratched through the applied clay. Both kinds of decoration were often painted in yellow, green and sometimes blue. The earliest pieces of this kind known to us date from the same period as the early Dutch tin-enamelled earthenware (maiolica). They are found in the ground together with the latter in various places in the country. As regards this class of "slip ware," it is often difficult to say whether we have to deal with German or Dutch work. Examples are to be found in various museums. We may mention a few from the Rijksmuseum at Amsterdam. There are dishes with designs incised through slip and with slip-painting; one of these, bearing 


\section{OLD DUTCH POTTERY AND TILES}

the figure of a man with a glass beaker in his hand, although found in Holland, is probably German (Hessian) and therefore imported ware; whilst other work of this kind may be regarded as Frisian or from Limburg. An example of Frisian earthenware is a dish of heavy build with bottom rounded like a bowl and three small round, shell-shaped feet ; it is decorated with a dove amongst ornamental motives. We may assume that other similar earthenware is to be regarded as of indigenous production, with all the more reason if it shows such simple ornament as yellow and green spots, or is more Dutch than German in character, such as a dish bearing the date 1602 in the Rijksmuseum at Amsterdam.

Some interesting though not altogether beautiful plates from just beyond the frontier belonging to the same museum make such a conspicuous show of their Dutch inscriptions that we must not omit mentioning them amongst Dutch earthenware. They are very large dishes, none of earlier date than the eighteenth century, with sgraffiato decoration; as examples we may take one decorated with a coach and the inscription, "Eenen waegen met paerden,"1 etc., by "Gerrit Eevers potbacker an' het Schaphuysen " (near Crefeld) " anno 1770," and another with a Pietà, signed "Christianus Lappen, I713." Amongst others one on which is represented the Flight into Egypt bears the name of the maker Gerrit Lonnen and the date I728; yet another shows the Madonna of Kevelaar. All these pieces prove the hardy vitality of this peasant pottery with its red body, clay slip and lead glaze, of which the technique was being practised in the early Middle Ages and even before in the Near East; whilst simple examples can still be pointed out in the Dutch kitchens of our own time.

That the decoration was not confined to slip trailed through a funnel or engraving through a slip coating (sgraffiato decoration), but included also modelling in slip, is proved by two small bowls in the Rijksmuseum of the years I609 and I65I, which are both ornamented with relief work and painting in yellow and green.

Amongst earthenware of this and similar types occur also tiles which, together with certain dishes, may be of Limburg provenance. Earthenware of the same kind was purchased across the frontier by pilgrims to Kevelaar and also often imported thence into Holland by boat, so that it will be difficult to point out precisely what is Dutch work and what foreign, even in the case of specimens found beneath the soil in various parts of Holland.

1 "A carriage with horses." 
DUTCH MAIOLICA OF THE SIXTEENTH AND SEVENTEENTH CENTURIES 



\section{Chapter IV}

\section{DUTCH MAIOLICA OF THE SIXTEENTH AND SEVENTEENTH CENTURIES}

Shortly after Igoo attention was first directed to the art of the Dutch maiolica-potter of the sixteenth and the beginning of the seventeenth century, the forerunner of Delft earthenware. Since that time new pieces have continually been coming to light, amongst them especially fragments from excavations. From written documents, however, we knew little or nothing on the subject. An important piece of information is given by Karel van Mander in his book on painters, in the course of his account of Hendrik Cornelissen Vroom, who was born in 1566. Van Mander relates there of Vroom's father that he was a sculptor who devoted himself to the art of making pottery, or "porselein." He had such a mastery of the art that he knew how to turn out drinking vessels so wonderfully constructed that the drinker could not tell where to put his mouth to them for drinking. From this we may almost conclude that he was already making puzzle-jugs such as are familiar to us amongst the works of the later Delft potters. Van Mander further praises Vroom's father for his artistic ability and his fine colours. When we go on to read that Hendrik was forced by his stepfather to take up the potter's craft, and became a pottery painter, we arrive at 1580 at latest as the earliest date afforded by the evidence of Van Mander for the making of maiolica in Holland. At that period, according to his description, this art was well advanced, so that we were able from his account to infer that maiolica potteries already existed in Holland before 1580 , in Haarlem if not elsewhere. This surmise was in agreement with a find of pottery at Middelburg, in Zeeland, on the spot where the hospital of the Premonstratensian abbey formerly stood. The drug-jars excavated there (Fig. 3) must date from before I570, seeing that the abbey was dissolved in that year; to these little jars we shall shortly revert.

Exactly what kind of earthenware was made by Vroom's father we do not know, but Van Mander's praise leads us to suppose that it consisted of articles of more importance than drug-pots. Our thoughts naturally turn to the many dishes, large and small, and especially the 


\section{OLD DUTCH POTTERY AND TILES}

fragments found in such great quantity in Holland, as well as to the early tiles. These drug-jars, dishes and tiles immediately bring to mind the palette of the Italian potter of the fifteenth and the earlier part of the sixteenth century. How the influence thus betokened spread from Italy was not at first obvious. It was known, it is true, from the treatise on maiolica written in 1548 by the Italian potter Piccolpasso, that a potter from Castel Durante named Guido di Savino set up kilns at Antwerp, but nothing was known of any contact with the Northern Netherlands, and the tile-picture of 1547 (representing the Conversion of St. Paul), in the Vleeschhuis section of the Steen Museum at Antwerp, is of a somewhat different character from the old Dutch maiolica.

This was the state of our knowledge until a short time ago. Quite recently references to one Guido Andries as working at Antwerp from I5I2 till his death in I54I were discovered by the same Belgian investigators, who found out for us that as early as 1530 an Italian was making drug-pots-not of stoneware, but of maiolica-in that city. There is little reason to doubt that this Guido Andries is identical with the Guido di Savino mentioned by Piccolpasso. The tile-picture of 1547 is ascribed by the Belgian authorities to the sons of Savino, who are spoken of by Piccolpasso as carrying on their father's work at that very time. If, as seems almost certain, we are right in accepting the surmise that he assumed at Antwerp the name Andries, there can be little doubt that it was one of his sons who set up a pottery at Middelburg. For a document in the Middelburg archives tells us that a pottery was established in the Zeeland city in 1564 by an Antwerp potter, Joris Andriesz by name; we also learn that in 1552 Joris (George), one of the sons of Guido Andries, was enrolled in the Antwerp Guild of St. Luke. From these recent disclosures we may argue that the drug-pots found at Middelburg were probably made on the spot, either by Joris Andriesz, son of Guido di Savino, the Castel Durante potter who migrated to Antwerp, or perhaps by another potter, Adriaen Ingelsz, by name, who worked in Middelburg at the same time. ${ }^{1}$

Tiles are also to be found in Belgium, of later date than the picture of the Conversion of St. Paul, which come much nearer to those found in the last few years in the Northern Netherlands. The question has not yet been thoroughly studied, but we believe that even now we are in

1 Joris Andriesz of Antwerp and Adriaen Ingelsz are both described in the financial records of Middelburg for ${ }^{1565-1567}$ and 1568 as geleyerspottebacker or geleyersbackere, that is, "maiolica-potter." 


\section{MAIOLICA OF THE XVIth AND XVIIth CENTURIES}

a position not only to draw a somewhat closer distinction-even though still with some reserve-between North and South Netherlandish tiles, but also to regard it as almost proved that the connecting link between Italy and Holland is to be sought in the South Netherlands-at Antwerp.

Meanwhile we learn from the account in Van Mander's book of Hendrik Vroom's journeys to Spain and Italy that the Dutch maiolicapotters may also have learned direct from the Italians and their ItaloSpanish fellow-craftsmen. Vroom goes to the South in order to become qualified as a painter in oils, but we find him again repeatedly earning his livelihood by pottery painting. He worked in this manner amongst other places at Seville for an Italian, and at a later date he was again working in a maiolica factory, at Venice. It is, however, to be regretted that we do not hear whether Vroom was still engaged in the potter's craft when he went back to Haarlem. It appears probable that he was able to make his living as an artist by painting shipping subjects; and Van Mander tells us that he also painted ships on tiles. Amongst Dutch tiles there are many with ships on them, also whole pictures in tilework with ships on a large scale, but none of them are so early in date that they could have been painted by Vroom.

We can therefore, from the biography of Hendrik Vroom alone, rightly infer a direct connection between the Dutch pottery painters on the one hand and the Italian potteries on the other. It is certainly a fact of importance that he worked at Seville for an Italian. This could not have been the well-known Niculoso Italiano; the latter lived in the first quarter of the sixteenth century, and Vroom's travels took place in the last quarter. But Vroom must naturally have seen this master's work at Seville, and the Italian for whom he painted pottery was doubtless someone from the school of Niculoso. Where we find Vroom travelling, others may perhaps have gone before, and others again have followed him. Possibly also Italians may have brought the art of tin-enamelled pottery into Holland; but as to this we know nothing.

Van Mander's account of Vroom's travels has of course lost some of its weight, now that we may probably find the connecting link at Antwerp ; but the statement that Vroom's father made such wonderful drinkingvessels remains of importance, as it shows that finely-made articles were produced in maiolica at Haarlem before 1580 .

However this may be, the earthenware itself points to a connection with Italian and particularly Faventine maiolica and with Spanish maiolica of the Italian type (we may compare, for instance, the tile-picture by 


\section{OLD DUTCH POTTERY AND TILES}

Niculoso Italiano in the Rijksmuseum at Amsterdam). The technique is the same. Tin enamel is used on the front and lead glaze on the back of the ware, as on certain types of Italian maiolica; the colours-blue, yellow including orange, brown, green and manganese-purple-correspond exactly as regards their strength and brilliance; whilst the motives also are Italian, although for the most part translated into a Dutch version.

Except in the case of the little drug-pots discussed above, it is not known where the oldest Dutch earthenware with a tin enamel was made. Joris Andriesz and Adriaen Ingelsz are, as far as we know, only mentioned during a few years in the Middelburg archives. That various fragments were found at Delft proves nothing, as no trace of any maiolica pottery of that period is known there. Yet the possibility of such a thing is naturally not excluded. An argument on the other side is that we do not know of maiolica-potters at Delft at so early a date ; as regards Haarlem, however, this is not the case, and it is known that in the beginning of the seventeenth century potters, or at least workmen engaged in the potter's craft, went from Haarlem to Delft. Again, at Rotterdam, in addition to a very large quantity of potsherds, "wasters" of this kind of ware have been found, showing that in any case one or more maiolica-potteries were in operation in that city, whilst at the present time documents and earthenware as well are being brought to light in Friesland also. Meanwhile similar potsherds are being dug up in various other places in Holland, not only at Delft, Middelburg and Rotterdam, but also at Kampen, Hoorn, Leeuwarden and elsewhere. At Cologne, too, some years ago a considerable find was made on a site on which a monastery formerly stood. In England, again, similar wares have been found. From all these facts the evidence steadily grows that we are dealing with an industry that was practised chiefly in the Netherlands, but also in Germany and England; priority belongs in all probability to Antwerp.

From the collection of this class of wares belonging to the Rijksmuseum at Amsterdam, and on the strength of a single date found on a specimen, we can trace the improvement in technique, and finally the use of a beautiful pure white enamel (on both sides of the ware) which is characteristic of "delft." The body, which to begin with is of a warm grey or sometimes brick-red colour, becomes steadily lighter, till it attains the pale ivory colour of delft, although for tiles in particular a coarser red body still continues in frequent use. The finishing off also improves -in the oldest earthenware rough traces of the spurs, used to keep the plates apart from one another in the kiln, are often to be seen stuck fast 


\section{MAIOLICA OF THE XVIth AND XVIITh CENTURIES}

to the surface. Yet it is far from true that with the perfecting of technique Delft earthenware establishes its superiority over the old Dutch maiolica in all respects. It is only necessary to compare the vigorous combinations of warm colour of the plates of the latter class with those of delft in order to prefer the first, from the decorative point of view also. Even a good collection of fragments, such as that in the Museum van Oudheden at Rotterdam, is enough to show the wonderful variety of the maiolica. The Delft ware often betrays most strongly in the most carefully finished pieces the intention of emulating Chinese porcelain, and in so doing repudiating its peculiar character as earthenware.

The oldest pieces belonging to the Rijksmuseum are actually the little drug-pots (Fig. 3) mentioned above, which were dug up on the site formerly occupied by the hospital of the Premonstratensian abbey at Middelburg and probably made on the spot about 1565 . Formerly these pots, or similar ones found in England, were regarded as Italian earthenware, but none have been found in Italy with such simple ornament or of such small dimensions. These drug-vases, one of which is supported on a foot, are decorated with bands, in one case in blue and manganesepurple, in another in blue and yellow, the largest of them in blue with a border of small flame-like ornaments in yellow and manganese-purple; this last motive is reminiscent of Italian albarelli. Many similar drug-jars and pots are also found in other collections, English included; amongst them are some of much larger size.

It is known likewise where some of the fragments of dishes belonging to the Rijksmuseum were found; they are, therefore, although not dated, of more importance for our survey of this class of earthenware than dishes, often in much better condition, which appear from time to time in the hands of dealers. This second group of earthenware was for the most part found during the widening of a canal at Delft. It comprises the following specimens : a fragment of a dish on which are depicted in blue, yellow and green the Virgin and Child in an aureole; two fragments of dishes with linear ornament and one with a running fox, the body of which shows curious reserves such as are seen also in Italian pottery and earlier still in Egypt ; lastly, one with a star-shaped leaf design in which manganese-purple is introduced in addition to the colours appearing together or severally on the pieces previously mentioned-yellow, orange, green and blue. All these pieces show a lead glaze on the back. Having drawn attention to these fragments of dishes all dug up together, we must mention certain dishes in the Kunstgewerbe Museum at Cologne 


\section{OLD DUTCH POTTERY AND TILES}

which were dug up on the spot. One of these shows the same Virgin as the Amsterdam fragment, but with a wide border of check-pattern. A small unbroken plate (Fig. 8) in the Lambert van Meerten Museum at Delft also shows the Virgin represented in precisely the same fashion as on the Amsterdam and Cologne fragments, but here we find already on the rim a pattern copied from Chinese Ming dynasty porcelain. The same combination of incongruous elements occurs on plates in the Musée Céramique at Sèvres and the Musée Dupuis at St. Omer. We must next return to the Rijksmuseum, where our attention is demanded by a very unusual large deep bowl (Fig. 5, a and b), signed both inside and outside with an unknown mark $\mathrm{HV}^{\mathrm{V}}$ and dated I60I. The same mark is found on a tile-picture dated 1606 , with which we shall deal in the chapter on tiles ; this picture is copied from a print after Maerten van Heemskerck, a Dutch painter. The bowl is painted inside with the subject of "the Roman Charity"-Cimon in prison fed by his daughter Pera; the colours used are blue, green, yellow, touches of manganese-purple and, in large quantity, yellowish brown. On the wide, flat rim are grotesque motives reserved on a yellow ground, in blue outline filled in with the same colours as the middle subject; the colours are repeated in the design of flowers on coiled stems on the outside of the bowl. In the combination of colours and the predominance of brown we may perhaps trace the influence of the Italian school in Spain; there is certainly a striking contrast with the predominant orange of Dutch dishes and tiles of slightly later date. The Dutch origin of the bowl is somewhat uncertain, but a comparison of the tile-picture by the same hand with undoubtedly Dutch and Flemish examples suggests Dutch workmanship. The tin enamel on both exterior and interior is occasioned by the form of the bowl, by which neither side is hidden from view.

A deep dish in the British Museum, bearing the mark "C L" in monogram and the date 1583 , must not be allowed to pass unnoticed in this connection. It shows a decided resemblance to the bowl at Amsterdam, the design on the back of which calls to mind the border of formal flowers on its rim; it is painted in the middle with a bust of a lady wearing a ruff and a wide lace cap. The colours used are bright blue, orange, yellow and green, with some manganese-purple on the dress. The lower side of the rim is devoid of ornament. Here, again, it is difficult to decide between a Dutch and a Flemish origin.

Another unusual but undoubtedly Dutch piece, showing a more brilliant surface than the "Roman Charity" bowl, is a small jar with 


\section{MAIOLICA OF THE XVITH AND XVIITH CENTURIES}

handles, bearing a date. This jar (Fig. I), in the Rijksmuseum, displays the arms of Amsterdam and Haarlem and the date I6Io in warm, strong colours that remind us of maiolica from Faenza, whilst, as in Faenza ware also, a lead glaze is used as a coating for the inside. A very decorative dish with fruit ornament, made of a reddish body, and two dishes at Delft (Fig. 2) and Amsterdam (Fig. 4) respectively, painted with a dish of fruit, and with the inscription "Eert God"1 in old Dutch lettering, display the same technique and, with the exception of purple, the same colours as the little jar of I6Io. The predominance of orange is a noteworthy feature. On the rim of the two last pieces the centres of the rosettes are impressed from the back in the mould, so as to stand out as bosses in relief. The same manner of decoration with bosses is to be seen also on dishes painted with a shield of arms and provided with a similar rosette border. A small dish with the date 1630 is a still later and less carefully made example, without relief, of this class, as is also a plate of a not uncommon type in the Victoria and Albert Museum, inscribed with the words "Loof Godt altijt" in Roman capitals. We shall shortly see a seventeenth- or perhaps eighteenth-century Delft descendant of these old Dutch plates, with the same inscription, but modified in colour and technique. They prove that this class of wares long continued to be made, though without the old strength and freshness of colouring - a Delft eighteenth-century version of the old Dutch theme. A dish (Fig. 7), in the Victoria and Albert Museum, is painted in softer colours-greyish blue, brownish yellow, pale green and a dull manganese-red-the result perhaps of faulty firing, unless this modification indicates a somewhat more advanced date; the very effective designa heraldic rose enclosed by a band of lozenge motives and a border of oblique dashes-is paralleled on fragments in the museums at Rotterdam and Leeuwarden. Another type which must have been made in some quantity, as fragments of exported specimens have been found in excavations in London, Colchester, Oxford and elsewhere in England, is that represented by a dish (Fig. 9) in the Schouten Collection at Delft ; the leading motive here consists of formalised fruit in blue, green and orange, the gadroon pattern on the rim being painted in blue only.

To this same group, again, belongs a fragment of a dish, also found at Delft, with a portrait of William the Silent in blue and yellow, that

1 "Honour God." Similar specimens may be seen in the Victoria and Albert Museum, in the Musée Dupuis at St. Omer, and in German museums.

2 "Praise God alway." 


\section{OLD DUTCH POTTERY AND TILES}

already shows a pure white on the front. Another piece perhaps to be included is a rare dish (Fig. 6) on which is depicted, in blue, green, yellow and purple, the story of Vertumnus and Pomona. A plate with chequer-pattern in blue and white (probably intended to represent white blossoms on a blue background) is an example of a pattern found in various colours on dishes in the Rotterdam, Cologne and other museums.

A small plate, corresponding in technique and colouring, but with a design of small buildings of Chinese character, points to the approaching influence of Chinese porcelain, which was already generally known and was indeed imported into Holland in great quantities from the beginning of the seventeenth century onwards. We have already noted dishes with the Virgin and Child enclosed by a border of Chinese (Ming) design.

Meanwhile an example of improved technique is provided by a potsherd also found at Delft-a fragment of a dish with star-shaped ornament-still free from Chinese influence and rather of the Italian type. This piece, dated 1622 , is covered with a splendid white tin enamel on front and back alike. Even as late as this a close correspondence is often found with Italian maiolica.

After these early pieces it is worth turning our attention to a number of representatives of certain groups of earthenware, polychrome as well as blue-and-white, which have only quite recently been distinguished in detail. They comprise productions from various places in Holland. Many specimens of this type have been found at Delft and Rotterdam, but they occur also in Friesland and Limburg, where students are beginning to recognise a distinctive individual character. Earthenware of this class was undoubtedly made, like that of the older type, in different parts of the country, as well as in England and on the Rhine. As regards Friesland we know that at Harlingen, Makkum and Bolsward this ware was made in quantities together with tiles and, in fact, actually in tileworks; it is always tin-enamelled on the front and lead-glazed on the back, with painting in polychrome and also in blue only, but much inferior in quality to the old Dutch maiolica described above. This industry, already mentioned in the Introduction, lasted till far into the nineteenth century-indeed, the Makkum factory still exists; it turned out great quantities of this class of ware for foreign as well as for inland use. The Rijksmuseum only possesses a few pieces; there are specimens also in the Victoria and Albert Museum, London. A good example in the former is a dish in the decoration of which, executed in blue of 


\section{MAIOLICA OF THE XVIth AND XVIITH CENTURIES}

washing-blue tone and manganese, are introduced the words "sta pal." Another specimen is a small plate with an alphabet and the date I722, in manganese with a little blue, yellow and green; on the analogy of a corresponding plate in private possession with the word "Mackom" it may be regarded as a production of Makkum, so that here we have a more precise indication of a definitely Frisian fabrication. The Rijksmuseum has a somewhat better representation of earthenware of this class from Limburg, probably produced at Megelsum and other places in that province.

1 "Stand fast, don't budge." 

DUTCH TILES 



\section{Chapter V}

\section{DUTCH TILES}

The Dutch tiles, painted in blue or several colours on a white tin enamel, have fared the same as the corresponding pottery. All tiles of this kind found in Holland or brought from that country have been regarded as of Delft origin, though they are often called merely "old Dutch tiles." They are known all over the world. The seventeenthcentury Dutch painters, such as De Hoogh and Vermeer, depict them for us in the rooms shown in their pictures, and foreigners also used them to decorate the passages and kitchens of their houses and even their sittingrooms. In Holland they are, or were, to be found everywhere cemented into the walls of old dwellings. By far the greater number have long ago attracted the attention of collectors and antique dealers, and have consequently, by their removal from their position or through demolition of the houses, found their way into museums or private collections. We may note here that they were made only to cover walls, never for paving purposes.

Amongst all these tiles there are, of course, many that were made at Delft, but even more than the pottery they were the product of various factories throughout the country, particularly at Rotterdam. There existed in that city a large number of tileworks, and the municipal Museum van Oudheden possesses an extensive collection of tiles, for the most part taken from old houses in the city. Certain definite types can also be ascribed to Frisian factories.

In the case of tiles also a distinction has to be drawn between the later blue-and-white type and the earlier. The same is true even more of the later tiles with the colour scheme of Delft ware, in which red plays a part and muffle-kiln decoration also occurs, and the tiles with the older palette, which with its blue, brownish yellow, green and occasional manganese-purple shows absolutely the same colouring as the old Dutch maiolica. As regards technique also, there is an exact correspondence. Lastly, the identity of patterns provides even stronger confirmation of the view that the tiles and the corresponding pottery must have been made in the selfsame factories-that is, in tileworks, and that therefore the 


\section{OLD DUTCH POTTERY AND TILES}

history of both runs on absolutely parallel lines. In order to obtain a clear idea of the tile manufacture, we must bear in mind that a distinction has to be made in general between potteries properly so-called, in which Delft was especially rich, and tileworks, which were to be found in various places in Holland.

It has already been explained in the Introduction that the finer earthenware-" delft"-was being made in faience potteries, whilst the tileworks were producing, in addition to tiles, a coarse kind of earthenware (schotelgoed), which could be fired in the same kilns as the tiles, without saggars to protect it. We must therefore bear in mind that the oldest factories made the tiles with the earlier fine colouring and the corresponding pottery, whilst the faience potteries (plateelbakkerijen), properly so-called, in which what we call "delft" was made, are of later date and were not in fact tileworks; the wares produced by them were entirely covered with tin enamel and needed careful protection from the flames in fire-proof saggars. This does not exclude the firing of tiles also in the faience potteries, but such tiles are the later ones of finer quality displaying the colours of the Delft pottery. Tiles of this kind are not nearly so frequently met with as blue-and-white tiles or those with the older polychrome palette. The chief product of the plateelbakkerijen was obviously plateelen-that is, pottery. Hence it is that Paape, who describes for us the firing of Delft earthenware, makes no special mention of the making of tiles, and shows in his illustrations dishes, vases, jugs, etc., and fire-proof saggars, but no tiles; in a tile-picture, on the other hand, in the Rijksmuseum at Amsterdam (Fig. 25), representing a tileworks at Bolsward, we find, apart from tiles, no wares but dishes and notice the absence of saggars.

The course of development appears therefore to be as follows. The oldest factories at first made both pottery and tiles as well, corresponding entirely in colouring and often even in decoration. It was in this early period (the second half of the sixteenth and beginning of the seventeenth century) that their most carefully finished work was turned out. Gradually a finer sort of earthenware, that we generally call " delft," began to be produced in potteries in which tin enamel was used for both back and front of the wares. Delft was above all places the town in which such potteries were established, whence its name is generally applied to this type of ware. The wares of the tilemakers, being of inferior quality, began to play a less important rôle. Less care was inevitably taken in their production; even the tiles steadily declined in artistic merit, perhaps 


\section{DUTCH TILES}

for the reason that the best painters could always find plenty of work in the delft potteries.

Examples, nevertheless, occur of good tile-pictures with the old colouring as late as the middle of the seventeenth century; for instance, a fine large panel depicting a vase of flowers, in the Evenepoel Collection in the Musées du Cinquantenaire at Brussels, bears the date 1647. It shows the old strong colour scheme-blue, yellow, brown, green and manganese-purple. We do not know of any later date than this for this beautiful type of tiles. But this is quite in accordance with the statement of Gerrit Paape, not indeed to be taken in too narrow a sense, that Delft earthenware was invented about the middle of the seventeenth century; for it was, in fact, about that time that the delft potteries (plateelbakkerijen), working with a pure tin enamel, began to attain to a position of great significance, and the tileworks to decline in artistic importance.

Many of these tileworks were endowed with a more robust vitality than the potteries, which, if they survived at all, ceased to produce the technically more refined delft. One such tile-factory is shown in the tile-picture, already mentioned, from Bolsward (Fig. 25), now in the possession of the Rijksmuseum at Amsterdam. Not only is it a very clear picture, but it is of the more importance from the fact that it is executed in tilework. It is painted in blue on a white ground and dated I737, at which period delft was still in its prime, but not so the tileworks ; consequently the tiles are not altogether finely painted. The picture owes its importance to its subject, and also to the fact that it depicts a tile factory at Bolsward in Friesland and was therefore made at that place. It is another reminder to us that the tile-factories were by no means peculiar to Delft, and that tiles were made elsewhere, in Friesland amongst other regions, and especially in Rotterdam, where, in addition to many tiles, a quantity of documents have been found, as well as wasters of tiles and dishes.

In order to give some idea of what such a tile-factory was like, it will be well to describe this picture, which in the illustration suffers somewhat in clearness through reduction in size. At the same time allowance must be made for the fact that, in order to obtain a good pictorial survey of all the processes of tile manufacture, too much has probably been crowded into a small space. But the picture shows very well all that goes on in such an establishment, and we need not stay to consider whether its subdivision is exactly in accordance with the actual facts. It is no doubt correct that the drying lofts were placed in 


\section{OLD DUTCH POTTERY AND TILES}

proximity to the kiln, in order to take the greatest possible advantage of the heat.

The kiln, as the most important part of the factory, is the main feature in the picture. At the bottom, a stoker is seen at work, whilst other men are bringing up wood for the fire. Piles of dishes, large and small, placed in such a manner as to protect one another on the tinenamelled side, are set out on planks in readiness for being put into the kiln. To the right we see horses working the mills in which the various ingredients of glaze and pigment are being finely ground. It is not quite easy to make out what is going on in the room to the left below, of which a glimpse is obtained through an open door, but we can see painters at work there. A not unimportant part of the artistic activity of the factory thus finds a place in the panel.

On the second floor, to left and right, are throwers busy at their wheels making dishes. Other workmen are putting planks with dishes on them upon the drying-racks. Here also stands a boy looking in at the inspection-hole in the kiln, to control the right distribution of the fire.

The uppermost floor is given up to the production of tiles, but tiles are also to be seen a storey lower, piled round the kiln. To the right and left on the top storey men are at work "wedging" the clay, pressing tiles into moulds, trimming them off and smoothing them, in short, preparing them for the kiln. A quantity of tiles are also spread out to dry on planks on the drying-racks.

Having thus obtained from the Bolsward tile-picture an impression of a tile factory, though of a very late period (I737), we may now return to the oldest tiles.

We noted that the Dutch medixval tiles known to us-those of red clay with a slip and a lead glaze-were generally floor-tiles, though some of them also were intended for walls. The tin-enamelled tiles, on the other hand, early and late alike, were, as far as we know, all wall-tiles. They were often used to line the entire walls of corridors, kitchens, cellars and even rooms, and for the fronts of chimney-pieces. Sometimes they were set in rows round white walls or in combination with plain white tiles; this is the case especially with the later tiles. The older tiles, with strong colouring in blue, yellow, brown, green and occasional manganese-purple, were generally set together so as to cover entire wallsurfaces with colour. The later blue-and-white tiles, and, perhaps to a still greater extent, those painted in monochrome purple, were sometimes treated in the same manner. 


\section{DUTCH TILES}

The origin of the wall-tile manufacture is not very easily explained. It looks as though it had stepped forward into the ranks in place of that of the floor-tiles. But the transition from lead-glazed to tin-enamelled tiles must not be regarded as so simple and sudden a process as this. The fact that an identical pattern is found on enamelled tiles and on brown lead-glazed tiles, whilst the latter show a close correspondence with others bearing the date 1556 , points to a closer contact than we should otherwise recognise. Again, the early wall-tiles, displaying patterns in reserve on a coloured ground, call to mind through this peculiarity their lead-glazed forerunners, in which the reserve decoration was effected by means of slip. The wall-tile manufacture, no less than the pottery, may very well owe its tin-enamel technique to Italian, perhaps also to Spanish, influence through Flemish channels. Prototypes of such tiles are certainly to be found in Italy, and their immediate predecessors in Flanders. The connecting link is here more clearly recognisable than in the case of the pottery; it may be identified particularly at Antwerp, as has already been stated above.

The earlier tiles, with strong colouring, are to be regarded as very nearly related to the contemporary pottery. This is indeed proved by the fact, already pointed out, that these tiles have the same colours, and sometimes also the same motives, as this early ware; blue, green, yellow and brown occur on nearly all the tiles with ornamental designs. Manganese-purple must be added to the list in certain types, particularly the tile-pictures. The rough spur-marks of the dishes are not, of course, found on the tiles, as there was no need for cockspurs in the baking of the latter. The tiles, particularly the older amongst them, show in the corners of the upper surface little holes-which have sometimes almost disappeared-caused by the use of a board with nails in it to support the tiles in the process of fabrication. In the vigorous colourscheme the red of later Delft ware is lacking. The later muffle colours naturally find no place in it, as the firing at this period is entirely carried out at the highest temperature. The older tiles may also be recognised by their "body" and their thickness. Even in late tiles an entirely yellow clay is not always seen, but it is chiefly in the older types that a reddish hue is found running through the yellow or grey body, whilst the oldest tiles known, dating from mediæval times, are made of an entirely red clay. As regards thickness, the oldest kinds are about $\frac{5}{8}$ in. ( $\mathrm{I} .5 \mathrm{~cm}$.) thick and often twice as thick as the late tiles, especially those of the eighteenth and early nineteenth centuries. Their surface measures 


\section{OLD DUTCH POTTERY AND TILES}

for the most part about 5 in. (approximately $13 \mathrm{~cm}$.) square. We have sometimes thought that tiles of larger dimensions, amongst others a single type in the Rijksmuseum that also shows a more broadly painted design, should be regarded as Flemish, not Dutch; but tiles do occur larger and even smaller than the normal size which are yet indisputably Dutch.

In approaching a general survey of the tiles we must remark at the very outset that it does not lie within our aim to make it in any sense complete. In fact, the tiles have not yet been exhaustively studied by anyone. Plenty of documents are to be found relating especially to the later tileworks, but here, as in the case of delft, it is generally impossible to connect the documents with the productions of the factories, familiar to us as tiles of the most diverse character and moreover seldom or never showing a distinctive mark. It is true that we know somewhat more about the Rotterdam and Frisian factories and their output, but as regards the oldest classes of tiles, with the fine strong colouring, we are still groping entirely in the dark. Yet a connecting link has been preserved (unfortunately not for the very earliest tiles), which, so far as we know, is lacking in the case of the pottery. It is provided by designs for large as well as small tile-pictures, and especially for individual tiles; they are often perforated with pinpricks and black with charcoal, through having been used as stencils. Such stencils, amongst other things, have been found in Friesland, amongst the plant of an old tile factory, and at Rotterdam a considerable number, including some of great size, are preserved, together with designs for tiles, in the municipal archives. There is something quite attractive about them, especially when they show a careful design pricked through with very fine perforations, and we can understand that if the design were transferred to the tile with some care, a good tile painter might make a really beautiful thing of it.

It will probably be supposed that with the help of these designs for tiles, some of which can be regarded as coming from particular factories, something might be done in the direction of dating and localising more precisely the many tiles known to us. But the results are disappointing. Local attribution is possible up to a certain point. It is undoubtedly interesting to be able to identify certain patterns as from Rotterdam and others as from Frisian tileworks, but for dating purposes the information given by the stencils is not very helpful. The reason for this can easily be explained. The very fact that they are stencils means that they provide no sure ground for dating. In the first place, perforated sheets of stout paper, or even old engravings, could be used for a considerable time, and 


\section{DUTCH TILES}

could be rubbed over again and again with charcoal before becoming unfit for further use. Again, what guarantee have we that the older patterns were not again transferred to new stencils? It is, in fact, remarkable that, so far as it has been possible to trace a few of the watermarks upon them, the stencils appear to be often much more recent in date than would be judged from their patterns.

We find it, therefore, quite impossible to agree with those who seek to classify the tiles by date of production on the evidence of differences of style in their design, and then talk of the earliest and latest classes on the strength of the patterns employed, finding some peculiar significance in every slight variation of pattern. Even when a criterion of date is thought to have been provided by details of costume, etc., in a figuresubject on a tile, the most that can be said is that a terminus post quem is established, seldom, and assuredly never with absolute certainty, that an actual date of origin is indicated.

But what can be said of tiles actually bearing a date? To begin with, they are of great rarity; moreover, much depends on the manner in which the date is introduced. Occasionally it is beyond dispute a clear indication of the date of manufacture-where the numerals on a tile are included in the pattern, or a tile-picture is signed and dated. But when a print has been copied, caution is necessary, just as in the case of dishes and other pottery. Often prints as much as a hundred years old were used, and only when the signature or date of a print has been replaced on a tile by another, or the subject has been supplied with a date, can we be quite sure that the date in question is that of the ware itself and not that of the print used as a model. It is therefore a very difficult matter to find one's way amongst the quantities of tiles in existence, even more so than in the case of the pottery, for which in the later wares, i.e. delft, a basis of classification is provided by marks.

Marks occur on tiles with the utmost rarity. A name is found as signature on at most a few tile-pictures, or on later Delft tiles to which special care was devoted. It is true that a letter or numeral is often seen painted with broad strokes on the back of a tile, but such letters cannot be explained, whilst the numerals may well be serial or class numbers ; the letters may also have the same significance. Meanwhile it may be taken as established that tiles with painting in blue only, like the corresponding pottery, were first made under the influence of blue-andwhite Chinese porcelain. More clearly stated, both tiles and pottery conformed with the fashion for blue-and-white, not earlier than the second 


\section{OLD DUTCH POTTERY AND TILES}

or perhaps even the third decade of the seventeenth century. But even with this knowledge to guide us, we are confronted with the many classes of blue-and-white tiles without any more precise data of a satisfactory nature. In their case, to a much greater degree than with the pottery, the older patterns must have been continually used again in later times, not only for the reason that stencils could be employed so much more readily on the flat surface of tiles, but especially because their use was imposed as a matter of course by the demands of mass-production. For our part, therefore, we can only consent to the assignment of a date in cases where it is possible to establish a clear distinction in the thickness of a tile, the character of the glaze, the colours or a distinctly recognisable deterioration of pattern. Even this last criterion has by no means always the same significance; obviously there will be a difference in the treatment of the same stencilled pattern by a good and a bad painter.

From these considerations is it not clear that distinctions of style will not carry us very far? It is better, therefore, not to venture on this slippery path, and to be content with a description of the finest patterns and with reproductions of a few of them, in the conviction that there may perhaps still be somewhat more that could be related about the tiles, and that many collectors will probably be able to point to other fine patterns in their collection. As it is not possible to set beside one another illustrations of tile-patterns from a variety of sources, we confine ourselves in the main to the new and admirably equipped museum of tiles at Delft, the Lambert van Meerten Museum, which has recently been enriched by the purchase of a splendid collection. It contains fine examples of nearly all patterns. We have borrowed a few from specimens in the Rijksmuseum at Amsterdam, and for important examples of tilepictures we shall include other museums in our survey. Rotterdam also possesses in its Museum van Oudheden a fine collection of tiles and tile-pictures, which unfortunately through lack of space do not receive their due.

The older tiles, and indeed those of later date as well, must be divided into two groups. The first consists of those which combine to form a continuous pattern, extending vertically and horizontally over the wall-surface; generally these tiles when set together in fours make up a continually repeating motive. Next to these come the tiles which show each a separate design-a figure or an animal or flower, with or without a geometrical border, in some cases with corner fillings which form a geometrical connection with the contiguous tiles, as if to reinforce the 


\section{DUTCH TILES}

continuous design. In tiles of this class sometimes the geometrical motives predominate, sometimes the figure-subjects or plant-motives; the pattern displayed by a tiled wall is more or less continuous in accordance with such predominance, but in all cases this rhythmic effect is more or less intended.

The second group, that of tile-pictures, always displays a representation of some kind, a scene, a landscape, a ship at sea, or a vase of flowers, carried over several tiles, sometimes covering a large wall-surface, so that each tile has its individual rôle to play in the great whole. Each tile thus demanded separate handling, but this was also the case with the tiles of a continuous pattern that could be produced with a single stencil. Hence they are never all exactly alike. The outline design was transferred with a stencil on to the tiles, but the painter, according to his greater or less artistic ability, had his own manner of transforming in blue or other colours the charcoal design-in a word, his own style. This is the reason why the tiles vary so widely in artistic merit, quite apart from the fact that they often differ greatly in quality as productions of the tilemaker's craft. At the same time the number and diversity of really beautiful tiles is great enough to ensure much æsthetic enjoyment from a visit to a good collection.

First we will discuss the tiles with the older polychrome colouring, corresponding to that of the old Dutch maiolica. The colours are the familiar blue, yellow, brown, green and manganese-purple; but a distinction is to be observed between the tiles with a continuous pattern and the tile-pictures and figure-subjects painted on tiles. In the latter manganese-purple is seldom wanting; in the former, on the other hand, we rarely meet with its use. In most of these continuous designs a powerful colour effect is obtained with blue, yellow or yellowish brown and green, in which the predominance of one of the colours, and the influence of the colours in juxtaposition upon one another, combine to enrich the colour scheme, though the number of colours remains limited to the same restricted total. The warmth of the colouring is not inferior to, and indeed often surpasses, that of the much richer palette of the delft of later times; it is decidedly superior to that of the muffle-pigments of the eighteenth-century factories.

We deal, then, first with the group of continuous patterns displaying the old colouring. Their manufacture went on well into the seventeenth century-some, indeed, were made as late as the middle of it-but many of them certainly date from the latter years of the sixteenth century. We 


\section{OLD DUTCH POTTERY AND TILES}

can to some extent class in groups the tiles of this type. In our survey we shall constantly refer to examples in the museum at Delft, some of the finest of which are shown in the illustrations. The tiles in that museum are set together in large panels, giving their full value to the patterns.

We shall confine ourselves to tiles that we can regard with tolerable certainty as of Dutch origin, though it may quite possibly be found later that certain kinds must be ascribed to Antwerp. For the present we draw the line, in agreement with certain Belgian authorities, at the point where the clear canary-yellow of the Flemish tiles is no longer to be seen in the designs; we regard as Dutch those tiles in particular with ornament of less strongly pronounced Renaissance character, giving a greater impression of flatness than the Flemish, which call to mind more vividly the scrollwork of grotesque designs. But, as in the case of the pottery, the dividing line cannot as yet be drawn quite definitely.

I. The first class is that of patterns in which geometrical figures predominate, whilst such plant-motives as occur are formally treated. To this class belong simple chequer-patterns, as well as formal fleurs-de-lys in circles and lozenges; geometrical compartments enclosing arabesques ; star-motives combined with formal foliage and rosette-motives with leafornament or foliated arabesques ; lastly, lozenges or circles or compartments of other shapes with formal leaf- or arabesque-ornament. A very interesting pattern recalls, by the filling up of the surface in the form of a cross with arabesques, the old Persian star and cross tiles, although it is carried out over four tiles set together. This motive also occurs on sixteenth-century tiles of red clay with a lead glaze; this fact, combined with the decoration in white reserved on a coloured ground, suggests that the design should be reckoned as one of the earliest types. We may mention some pretty examples of this kind, including a design (Fig. Io) in which each tile is painted with an oblong hexagon set diagonally, flanked by motives in the two angles which combine with similar motives on three other tiles to build up a regular hexagon. Both forms of hexagon are filled with reserved arabesques, in blue, yellow, brown and green. A beautiful and uncommon pattern (Fig. I2) shows kidney-shaped motives reserved against a ground of the same colours surrounded by foliated arabesques, likewise in reserve; the corner-motives form various patterns, such as a rosette, in combination with those on the other tiles. The dominant green, contrasted with orange-brown, gives to this pattern a very pretty effect. The leading motive in green is 


\section{DUTCH TILES}

displayed in its entirety on each tile, but they form a pattern only when set together, in fours or even in larger panels. Another very carefully worked-out example (Fig. I3) consists of a central starmotive in a circle on a white ground, surrounded by stylised leafmotives, whilst the corners of the tiles also form star-motives in conjunction with the adjacent tiles; the whole pattern is enclosed by a framework of oblong motives, traversing the edges of the tiles and decorated with small spirals somewhat reminiscent of Oriental inscriptiondecoration, scratched in reserve through the colour of the ground. Here again the colours are blue, yellow, brown and green. A very different effect is produced by a design (Fig. I4) which nevertheless belongs to this group on account of its motives. It shows, on a white ground telling vividly between the ornament, a starlike rosette in the middle, formal fleurs-de-lys, verging on foliage, in the corners, and simple rosettes with small scrolls on the edges. This fine pattern, painted in the same familiar colours, is marked by strong diagonal lines. Variations of this design occur, as indeed of all those described. These tiles, with their blue, yellow, brown and green on a white ground, give the effect of the particles of coloured glass in a kaleidoscope constantly forming and reforming themselves into different combinations, the patterns thus formed recurring in different variations.

2. We pass to designs still comprising geometrical motives, but with plant forms, naturally rendered or only slightly stylised, as the dominant note. An example is a design, again composed of four tiles, with a fleur-de-lys, rosette or star motive in the middle, and tulips and pomegranates or bunches of grapes radiating from it. There are very fine specimens of this type amongst others in the museum at Delft. An example is a pattern (Fig. I6, also represented in that museum in plain blue and white) showing a four-tile design of radiating tulips, with pomegranates between them and bunches of grapes in the interspaces; here again the effect given by a large number of tiles fitted together is that of strongly accented diagonals. There are many variations; in some of them the grapes play a part in the diagonal bands. The same pattern is found also confined in its entirety to a single tile. Again, the same motives or some of them, particularly the orange, are arranged in pointed quatrefoil compartments, sometimes extended over four tiles. Again, the quatrefoil and its contents may be comprised on a single tile, in which case the four corner ornaments, when the tiles are brought together, form rosettes of arabesque character reserved on a blue ground. The 


\section{OLD DUTCH POTTERY AND TILES}

colours are as usual, but the bright orange-yellow of the tulips and oranges here plays an important part.

3. The last class in the group is that in which a figure of a man or animal, a flower, a flower-vase, a dish of fruit, etc., is the leading feature, usually forming the middle motive and often bordered by a geometrical framework, the corners of which are filled with ornament reserved on a blue ground. Some of the designs approach those of the former group by the manner in which the geometrical border gives a well-marked rhythmic effect in conjunction with the surrounding tiles. A pattern of this type (Fig. I5) has as its central motive a symmetrical bouquet in a vase, somewhat formal in its treatment, in blue, yellow and green; this is enclosed within a pointed quatrefoil surrounded by corner decorations, in which appear foliated arabesques reserved in white on blue, also forming four-sided figures when brought together. The colours are as usual, and many variations of the pattern occur. But in this group, as a general rule, the rhythmic connection between the tiles, although maintained, is less striking than the chief motive, a human figure or portrait bust, an animal, flower or vase of flowers. All these motives occur both with and without corner ornaments, enclosed not only in lozenges but also in circles and oval, lozenge- or quatrefoil-shaped frames. They are exemplified by various tiles at Delft, in the Rijksmuseum and at Rotterdam. In the painting of the figures manganese-purple is sometimes added to the usual colours. In this group each tile forms a much more definite unit by itself, especially when there is no corner decoration of any kind, as in the tiles painted with figures of Roman soldiers (Fig. 17), which moreover fill the tile-surface in a very satisfactory manner. To this class also belong, amongst others, the tiles with mermaids and mermen, on a green sea painted so as to continue through several tiles. A pretty type with figures of animals, often drawn in a very spirited manner, is well represented in Fig. I8. In these the various animals are enclosed in circles with foliage reserved on a blue ground in the corners of the tiles ; they show here and there the use of a little manganese, together with the customary colours (it will be noted that it is generally in figures that this pigment occurs). Lastly, we may mention a pattern (Fig. Ig) of detached flowers (different varieties of tulip), with fleurs-de-lys in the corners and in addition baluster-motives at the sides, all in the four usual colours. A somewhat exceptional pattern, in the same colours, is that (Fig. II) of four tiles forming when put together a rosette of terminal figures radiating from a centre. 


\section{DUTCH TILES}

The patterns of all the well-known types of tiles undoubtedly continued for a long time in use, so we should not be prepared to go further than to say that they were made equally towards the end of the sixteenth century and in the first half of the seventeenth, and to count amongst the earliest the tiles showing the pure reserve technique. Further, less careful execution of a pattern is often a proof of later date, whenever it is obvious that the pattern must be derived from a more firmly drawn original.

4. We have already mentioned a pattern which was carried out in blue only as well as in the old colouring. We will now turn our attention to the tiles executed solely in blue and white. The patterns of the older polychrome types were sometimes produced in blue, but blue tiles as a class only began to be made in the course of the seventeenth century. We shall now deal only with the designs that we do not find in the older colouring, and must take as our fourth group the tiles with figuresubjects, with or without a circular border and corner ornaments. Amongst them we see representations of every class, such as biblical subjects, landscapes, shipping subjects, soldiers on foot or mounted, children playing games, flowers, animals, coats of arms, etc. Chinese influence is perceptible not only in the use of blue alone on a white ground, but also to some extent in the motives. An example is a design (Fig. 24) of leaf-motives forming diagonals enclosing medallions, in which are painted various motives under the influence of Chinese porcelain of the time of Wan $\mathrm{Li}$ (1573-r6Ig). The vogue of "blue-and-white" had a very long life, examples occurring from the early seventeenth until the nineteenth century. Tiles, and especially tile-pictures of this class, were also made at Delft. In so far as we regard them for one reason or another as of Delft origin, or can assign them to individual Delft potters, we shall describe them in a later chapter, on Delft earthenware. We shall refer here only to a few other designs, such as figures in costume of the early seventeenth century, surrounded by ornamental motives filling the corners (Fig. 23).

5. Meanwhile the blue-and-white fashion of the seventeenth century was followed in the eighteenth century by a vogue for purple-and-white, which was not, however, an entirely new development, as painting in manganese-purple had been practised much earlier. An eighteenthcentury rococo pattern in manganese and white in the museum at Delft, consisting of formal foliage and rococo motives, shows that the new styles of ornament did not escape the notice of the tile-maker. 


\section{OLD DUTCH POTTERY AND TILES}

Obviously we have mentioned only a few important designs. The innumerable variations and other combinations have no fresh significance for our survey, any more than the tiles with various subjects, not always applied to the surface with much decorative feeling. They were made in very numerous factories, amongst other places especially in Rotterdam, whilst Friesland also (Harlingen and Bolsward, Fig. 25) provides a contingent in this class of production.

We must, lastly, draw attention to another class of ornamental tiles. The tiles splashed or marbled with purple, so far as they are of later (eighteenth century) date, belong to the same class as those we have just described with painting in purple; but the older type, of thicker tiles, rather brownish purple in tone and more heavily splashed, must be specially mentioned. Tiles of this latter kind have been found amongst others in excavations at Rotterdam, together with factory "wasters," proving that they were made in that city. 


$$
\text { - }
$$




\section{Chapter VI}

\section{DUTCH TILE-PICTURES}

Our consideration is now demanded by tile-pictures showing the old polychrome palette, in which generally manganese-purple is found as well as blue, yellow, brown and green. Here again, as regards the earlier examples, we have for dating purposes only vague criteria to guide us. The most important early tile-picture ${ }^{1}$ is the well-known panel (Fig. 20) which was built into the front of the house of which the name is displayed as well as illustrated by the picture, the House of the Thousand Terrors (In duysent vreesen) at Rotterdam. The panel depicts a lamb standing in the midst of four snarling wild beasts, with a soldier on either flank; a blazing fire is seen in the background. When the house was demolished these tiles were broken away from the position in the facade which they adorned, together with a stone dated I594, and subsequently passed with it into the Museum van Oudheden at Rotterdam. The obvious question, which we are not the first to put forward, is whether this date 1594 is to be regarded as that of the picture. A decisive answer has not yet been found, nor even a satisfactory elucidation of the allegorical representation. But, in view of the fact that the house is already mentioned in legal documents at that period, there is not, in our opinion, any insuperable difficulty in accepting the picture as a fine example of tilework of the end of the sixteenth century. It is, however, certainly somewhat strange that a fine large panel with a vase of flowers of absolutely the same technique and colouring, which the Musées du Cinquantenaire at Brussels possess in the Evenepoel Collection, bears with the mark C.I.V. the date I647; on the analogy of this example we are inclined to assign to a date not earlier than I647 the vase-panel of closely corresponding character in the museum at Rotterdam (Fig. 2I).

I Not long ago four tiles from a panel of twelve, bearing the signature IB and date 1570, were found built into the wall in a house at Delft. The subject is more extensive than that of a picture of 1606 at Amsterdam, which is based on Heemskerck. Are we to infer from it that the Dutch tile-manufacture also goes back as far as 1570 ? It seems too much to believe, but it is not impossible in a country in which Vroom's father was already at this early period making wonderful drinking-vessels of "porcelain" with beautiful colouring. 


\section{OLD DUTCH POTTERY AND TILES}

This latter panel was at one time built into a house since abolished, and entirely agrees in technique and colouring with the Duysent vreesen panel. An unequivocal date is provided by a tile-picture, largely restored, in the Rijksmuseum at Amsterdam, which must surely be of Dutch origin. The subject is the Prodigal Son, based upon a print by Maerten van Heemskerck. In the place where in the print the monogram of the master is seen, we find on the tile-picture an unidentified monogram consisting of the initials $\mathrm{H}^{\mathrm{v} B}$, and the date 1606 . We may therefore accept these figures with certainty as the date of origin of the tiles. They are painted by the same hand as the large bowl of I6or, mentioned on an earlier page, with the subject of the "Roman Charity."

It will be observed that both the dating, and sometimes also the distinction between Dutch and Flemish productions, still present some difficulties, which, however, do not in any way impair the enjoyment afforded to the amateur by the beautiful material and strong, warm colouring of the tile-pictures. We will note here certain fragments of pictures in the Rijksmuseum with the old colouring, showing mounted figures (amongst them Prince Maurice) within an ornamental border, and other fragments in the Lambert van Meerten Museum at Delft. Lastly, we must mention a tile-picture in the latter museum (Fig. 22) with a large figure of a naked boy; it is $5 \mathrm{ft} .6 \frac{1}{2} \mathrm{in.}(\mathrm{I} \cdot 70 \mathrm{~m}$.) high, and is made up of thirteen rows of six tiles each. The painting is carried out chiefly in manganese-purple, with blue, yellow, brown and green. This picture came from Gouda. The painter used as his model, in reverse, a detail from a drawing of 1599 by Joachim Utewael, a design for a painted window in the Groote Kerk in that town. Its subject is the Victory of Conscience over Force. The boy, one of two supporters of a cartouche, is represented in a dancing attitude, and rests his left foot on a heavenly sphere in place of the shield of the original design; in the foreground is a bright green scroll. Whilst the tile-painter will not, from his reproduction of the design, be ranked as a first-rate master, the power of the painting and the size in which he has rendered the figure (equal to that of the window design) justify us in regarding the work as an effective and powerfully painted picture. We do not know who the artist was; he himself perhaps worked at Gouda, but his name is there unknown. We recognise his hand, however-or at least that of a nearly related artist -in another tile-picture, in private possession; it is carried out on the same large scale, and also came from Gouda, being based upon the design for another detail of the same window. The colours of this latter picture 


\section{DUTCH TILE-PICTURES}

are restricted to light and dark manganese-purple, thus providing us with an example of a tile-panel painted in this colour alone, going back to the first half of the seventeenth century (it is dated I640). This clearly established dating proves the need for caution in assigning dates on the evidence of prints used as models. The window designs date from I599. The figure of the boy bespeaks almost certainly the same hand as the tile-picture in purple, and can therefore be assigned to a date not much earlier than 1640.

There is therefore no certainty to our knowledge of the existence of sixteenth-century Dutch tile-pictures. One would, indeed, be inclined to refer to a period not earlier than about 1640 some of the undated pictures already mentioned. To the year 1640 belongs also a large blueand-white panel representing Julius Cæsar, in the Museum van Oudheden at Rotterdam. Figures for the fronts of chimneypieces, painted both in the old colours and in blue alone, are also known dating from about the same time ; examples are to be found in museums and private collections.

There is no great likelihood of our being able to point out older blue-and-white pictures. It is true that the Rijksmuseum at Amsterdam possesses a picture representing a ship at sea, that shows a type of vessel of about 1626 , but the picture may be a later copy of an early print. We may mention also in the same museum (in a room in the basement) a large picture of the battle of the Downs in 1639 (in which a Spanish fleet was defeated by the Dutch under Tromp); it is much damaged, having been broken away from the front of a house in Amsterdam and put together again with some of the tiles in the wrong order. This picture is copied from a print by C. J. Visscher. There is also a large figure of a knight, with the inscription Het Graefscap van Buren.

After the oldest types, executed in colours and at a later stage also in blue only, we must next deal with the tile-pictures with which are associated the names of the well-known Rotterdam craftsmen, Boumeester and Aelmis.

Cornelis Boumeester, tile-painter, who executed large pictures in blue and white, representing especially ships at sea, but also landscapes, signed his works with his full name or with the monogram C.B.M. He worked from about 1675 till shortly after 1700 , and died at an advanced age in I733. Pictures of larger or smaller size by his hand, or fragments of them, are to be found in various museums, for the most part broken away from old houses. We may name amongst others those in the Rijksmuseum at Amsterdam and the Museum van Oudheden at Rotterdam. 


\section{OLD DUTCH POTTERY AND TILES}

Amongst those at Amsterdam is the well-known large panel on which are depicted ships at sea enclosed by a border of small purple tiles; it is marked C. Boumeester. As an example for illustration we have selected a smaller panel from Amsterdam (Fig. 26), with shipping on a stormy sea. Amongst other subjects by his hand we will merely mention a quay for merchandise with a tower, and an Italian landscape with ruins, both at Amsterdam.

The name Aelmis is not that of a single master, but of a family of potters, in which the industry was handed down from father to son through several generations. Of the oldest, Pieter Jansz Aelmis, we know that he bought a tileworks in I692. His son, Jan Pietersz, who died in I755, and the son of the latter, Johannes or Jan (I7I4-I799), were the tilemakers who made the panels known to us, which are moreover usually signed. It is not always clear to which of the two named Jan a panel must be ascribed. Thus the two fine panels painted in blue within a border of splashed purple tiles, which are still to be seen as a chimneypiece in one of the rooms in the Weeshuis (Orphanage) at Rotterdam, were at one time attributed to the son, but in view of the Louis XIV style of the framework it may possibly be that the father was the maker. For our purposes there is no need to make a precise distinction between the pictures of the two; we will merely describe their character as a class. Many of the pictures, including unsigned examples, are executed in purple and white. Evidently they were much sought after. Specimens in purple and white are even to be found at Hamburg, in the Museum für Kunst und Gewerbe, which were broken away from a house in that city and are known to have been ordered from Rotterdam by an Altona merchant in 1765 . They are signed and dated Jan Aalmis a Rotterdam I 764 , and are painted with the subjects of Astronomy, Music and Sculpture, after engravings by Jacopo Amigoni. In the Museum van Oudheden at Rotterdam are to be found, amongst other examples, a tile-picture (much damaged), with a vase of flowers in blue which was the sign of the tileworks of the Aelmis family, called the "Flowerpot" (de Bloempot).

Amongst the designs for tiles and tile-pictures preserved in the Gemeente-Archief (municipal archives) at Rotterdam are several that came from the "Flowerpot" tileworks; they also include stencils for panels executed by that factory. Two panels in the Victoria and Albert Museum are copied from an engraving out of a work entitled De zegepraalende Vecht, published in I7Ig, and represent a country-seat by the Vecht, a waterway near Utrecht, at that time noted for its attractions. 


\section{DUTCH TILE-PICTURES}

They may be ascribed with little hesitation to the "Flowerpot "factory, seeing that another subject borrowed from the same book was found amongst the above-mentioned tile-designs, whilst several similar tilepictures, of identical size, are named in the lists of the stock remaining at the factory when it was sold in I843. These pictures appear, however, to be of later date than the Aelmis management and belong probably to the early nineteenth century.

Apparently enamelled earthenware was also made in the Aelmis tile-factory. The mark and date J. Aelmis I73I C.B., with a star, occur on two square trays with round, projecting corners and four small feet, painted with a party on a terrace, surrounded by an ornamental border with clowns in medallions. These pieces, respectively in the Rijksmuseum and in the Gemeentemuseum at The Hague, were formerly attributed to a Delft factory ; now they are regarded as Rotterdam work. A lozengeshaped wall-plaque, also at Amsterdam, decorated with medallions containing figures of ladies amongst ornament, is signed with a monogram (probably that of Jan Aelmis) and dated I736. It is quite probable that some of the earthenware of fine quality that we ascribe to Delft may have been made at Rotterdam; this is to be inferred from the fact that as early as I6I4 one Claes Wijtmans, when making arrangements for the establishment of a pottery at Rotterdam, applied for a patent " for making all sorts of porcelain, decorated or not, nearly identical with the porcelains that come from distant countries." 1 At the same time we are unable as yet to point out any other piece as certainly of Rotterdam origin, and practically all the other factories at that place were not potteries, but tileworks. Moreover, there seems in general to be a decided difference between the productions of Delft and Rotterdam, since both classes of ware are clearly distinguished in the lists in the old inventories of Rotterdam retailers. The superiority in quality of the Delft wares, with few exceptions, over those of Rotterdam is proved by the quantity of Delft shown by the records to have been sold in the latter city; most of the Rotterdam wares must have been merely schotelgoed, of the later, coarser quality, made in the tile-factories. We have a witness to this superiority in the account given by Bleyswijck, writing in 1667, in his Beschrijvinge der Stadt Delft ("Description of the Town of Delft "). It is, of course, obvious that he would praise the earthenware of his own town, but from his words it seems clear that the productions of Delft

1 "Voor het maken van alle soorten van porselein versierd of niet, bijna overeenkomend met de porseleinen die van verre landen komen." 


\section{OLD DUTCH POTTERY AND TILES}

were really of better quality than those of other places. A certain amount of pottery, he tells us, was made at Haarlem, Gouda and Rotterdam, but of a coarse kind, so that only Delfsche Porceleyn is bought far and wide in Brabant, Flanders, France, Spain and even England. It sometimes went even as far as to the East Indies.

This brings us into the region of the Delft potteries and their work. As already explained, we do not propose now to mention tiles made by potters known or presumed to belong to Delft; they will be discussed in due course when we come to deal with the Delft potters. We will here draw attention only to another example of a large flower-vase panel in blue and white in the Rijksmuseum, that must date from about I700, and may have been made at Delft or perhaps at Rotterdam.

For tiles and tile-pictures showing the polychrome palette of Delft, with red and also black, and for those with the intermediate shades of the muffle-kiln, we refer the reader to the following chapters on Delft earthenware. 
DELFT EARTHENWARE: ITS ORIGINS AND STUDY 



\section{Chapter VII}

\section{DELFT EARTHENWARE : ITS ORIGINS AND STUDY}

When we speak of "delft"-as we have already explained-we confine ourselves to the old meaning of the name, and use it of the tinenamelled earthenware made first and foremost at Delft. Tradition is not without significance, and it is therefore not for nothing that Delft has a name as a town of potteries. That such earthenware was made also at factories elsewhere, and that Rotterdam, for example, produced not only tiles, but also what may be called delft, are facts that have quite recently been set in a clearer light, and rightly so ; they are, however, of less importance to us when there is no mark, such as is found, for example, on the pottery of Arnhem, to prove that certain wares were undoubtedly produced in a certain place, or when the earthenware cannot on technical or other grounds be clearly distinguished from that of Delft. It is true that, even amongst what we call delft, pieces of very diverse character are to be met with, but generally there is nothing to prove that they were made elsewhere than at Delft, seeing that their technique does not point, by a different method of fabrication, to another place of manufacture. We shall therefore regard the term "delft" rather as the name of a class, understanding that the earthenware thus named was, in general, made at Delft. At the same time we are fully convinced that we shall allow to pass as delft, by reason of our scanty knowledge of the products of particular factories, occasional specimens which were made elsewhere, not only at Rotterdam, but also at The Hague or Haarlem, for example, or in Friesland.

We can, as a matter of fact, identify, in a certain class of blue and white, the earthenware of Frisian factories. It is generally called Makkum ware, but this class of pottery was made at other Frisian factories as well. The enamel is of a chalky whiteness, and the blue is duller than in delft ; there is an inferiority in quality also. Specimens are to be seen in the Rijksmuseum and in the Frisian Museum at Leeuwarden.

A special position is also taken by the ware of Arnhem, on the Rhine, which is generally marked with a cock. In contrast with the Frisian wares it often displays such an extreme of refinement that a typical 


\section{OLD DUTCH POTTERY AND TILES}

Arnhem coffee-pot in the Clainpanain Collection at Lille (Fig. II2) competes alike in its enamel and in its painting-in pinkish lilac, yellow, pale blue, green and reddish brown-with genuine porcelain.

Similar pieces, inspired by Meissen or other porcelain, are to be seen in the Evenepoel Collection in the Musées du Cinquantenaire at Brussels, and in the Rijksmuseum at Amsterdam. The factory was established by Johan van Kerckhoff in 1755 and appears not to have continued for long in operation. Its sign, an earthenware panel, painted in blue, may be seen by the curious in the Evenepoel Collection at Brussels ; it displays a group of figures after Lancret, with a view of the factory in the background, and its mark, a cock above a ribbon with the legend ARNHEMSE FABRIQUE. The panel has no great merit as a painting, but is of importance as the first clue to the identification of the Arnhem wares.

We will now turn to Delft. The first Delft potters known to us by name are found mentioned in the Registers of the Guild of St. Luke, and in the Huwelijksboeken (marriage registers) of Delft of about the year I6oo. Their names are of no importance to us, seeing that we know of none of their works. Very probably their earthenware was still of the class which we have described above as "Dutch maiolica," for we know nothing that we can with certainty call "delft" of so early a date. But we have already observed the development from this Dutch maiolica of the more recent product. Pure tin-enamelled blue-and-white we class as delft. No important documents have come down to us from the first period of Delft. We have already referred to the application to the StatesGeneral by Claes Wijtmans, of Rotterdam, between I6I4 and I6I6under the influence of the porcelain imported in the earliest years of the seventeenth century from China-for a patent for making " all sorts of porcelain, decorated or not, nearly identical with the porcelains that come from distant countries." From this we can presume that blue-andwhite earthenware was made at Delft also at the same time, but of this class we may say, even more than of other types of ware, that extant specimens cannot with any certainty be assigned to an earlier date than the third or fourth decades of the seventeenth century.

In the case of Delft we are confronted with an entirely different state of affairs from that of the Dutch maiolica and the majority of the tiles. Our knowledge of its makers is considerable. Even in this case, however, we have to regret the lack of documents, and precisely of 


\section{DELFT EARTHENWARE: ITS ORIGINS AND STUDY}

those most important documents that might bridge over the gulf between the potters and their productions. For obtaining extensive information as to the Delft potteries and the Guild of St. Luke, to which the potters belonged, there is an abundance of material ; not so, however, as regards the earthenware itself. The loss amongst other evidence of any list on which the manufacturers recorded their marks, earlier in date than 1764 , is the chief reason why documents have so much less to teach us about the earthenware than might be thought, in view of the quantity in existence of documents in writing and of marked wares. In I680, it is true, the authorities decided that, as a safeguard against forgery, the potters must register their marks, but this decision held good only for red earthenware teapots. The marks of this list even do not occur, so far as is known, on the teapots themselves. We therefore obtain hardly any certain information before the year 1764 , virtually, that is to say, until the manufacture had passed its prime. There has been preserved a list of that year, consisting of marks registered in compliance with the "by-law against the forging of the signs or marks of the potteries, together with the altering of the aforesaid signs or marks" (Keure tegens het Namaaken der Teeckens of Merken der Plateelbakkerijen mitsgaders het veranderen der voorseijde Teeckens of Merken). But this list is too late to be of any help to us except in the elucidation of certain factory marks, in so far as these are not already known to us.

Havard, the pioneer of the study of Delft earthenware, who gave up to that study an enormous amount of time and patience, attempted to meet this difficulty by making a collection of all the potters' names that he could find in registers of marriages and births, registers of hearthtaxes, guild-books and notarial documents, that is to say, in the archives. In the second edition of his book, published under the title of $L a$ céramique hollandaise in I909, he informs us that he has added more than seven hundred new biographies of potters to the original total of forty. This gain, which is not without significance for our knowledge of the pottery industry, appears greater than it really is for the classification of the wares. For what are the actual facts? Not everyone who called himself a "potter" (plateelbakker) was a potter in the sense that he is of importance to us in the elucidation of marks. Of many amongst this host of potters, all that Havard can tell us is that they were twice or three times married, or recorded the births of numerous children; and when we take into account the propensity shown by many persons to give themselves titles not lower than their actual station in life, we shall be sure to 


\section{OLD DUTCH POTTERY AND TILES}

find included in the designation of potters all the workpeople engaged in the potters' craft, down even to the humblest, unless they were, for example, pottery painters. Thus the kiln-stokers, who were the actual " bakers" of the earthenware, must certainly often have called themselves plateelbakker (" potter "), the more so as the proprietors generally styled themselves meester-plateelbakker (" master-potter ").

The attempt of Havard to explain as far as possible the monograms found by him on the wares with the help of names in his extensive list of potters involved a great danger, the more so because most of the marks are not signatures at all. For in the first place, in the list of $I 764$ there is no mention of the marks of potters (plateelbakkers), but of potteries (plateelbakkerijen). And what is in reality the meaning of the marks on the wares? Factory marks can for the most part easily be distinguished, as most of the factories occurring in the list of $\mathrm{I} 764$ were already in existence in the seventeenth century. If such factory marks are accompanied by a monogram agreeing with the initials of an owner or foreman at a time to which, on stylistic grounds, the object can be assigned, then the question is not a difficult one. But this is by no means always possible, and there are factories, for example, which continued working for a period of 150 years. Again, what are we to say if the earthenware is marked only with one or two letters? The numerals often met with on the wares may naturally be regarded as factory numbers, that is, numbers indicating shape, size or series. But what of the monograms? These may be: (I) factory marks unknown to us, (2) initials of the owner or owners of a factory, (3) initials of a foreman, (4) initials of a pottery painter, (5) a combination of one or more of these four. Who shall distinguish all these, or who knows how long a monogram once adopted continued in existence? Again, who that reflects upon the resolutions against the forging of marks adopted in 1680 and 1764 will venture to tell us how many marks were imitated by contemporaries or successors? It is, indeed, admitted by Havard himself, as regards the AK monogram, that it was counterfeited by several manufacturers. And, viewing the case in its most favourable aspect, ought we not to feel some doubt as to the interpretations that have been given of the various marks in the form of letters, when we see how complicated the interpretation often is of a monogram known to us? In addition to this there is the difficulty that various potters have no proper family name, so that father and son can easily be confused in the monograms. Moreover, they have no fixed signature. 


\section{DELFT EARTHENWARE: ITS ORIGINS AND STUDY}

Again, the factories continually changed owners. The difficulty of connecting the name of an owner of a factory with a particular production is proved by the fact that an individual could own a quarter or half share of one or more factories. From this, and from the curious circumstance that a doctor of medicine, for example, owned three-quarters of a pottery, and that a potter, Jacob Wemmersz Hoppesteyn, was at the same time -in fact, primarily-a cooper, we may conclude that many owners or part-owners had only a financial interest in the factories which they called their property. They were therefore, to use a modern expression, merely shareholders, and did not themselves practise the potter's craft. Indeed, we need not look for any personal activity on the part of an owner. It was, in the eighteenth century especially, a very simple matter. Everyone with money was only too glad to see it invested in the profitable pottery industry, and bought a pottery without having the slightest knowledge of the business, allowing his name to be enrolled in the guild as a winkelhouder (retail dealer). In order to be able actually to carry on the industry, it was only necessary to engage a foreman who satisfied the requirements of the guild.

Foremen and workpeople naturally changed no less rapidly than proprietors. But it is not merely impossible to keep count of these continual changes; we see in the wares also all kinds of confusing variations, probably as a direct consequence of the changes of owners, foremen and workpeople, and perhaps also through competition. Thus we find plates and vases showing identical patterns but different marks; we may cite, for example, dishes with the heron-pattern, peacock-feather plates, drug-vases, and, last but not least, work in the manner of Rochus Hoppesteyn. Again, objects of very divergent character bear an identical mark, as for example the "AR" mark, amongst others. Lastly, there are the difficulties presented by the great mass of unmarked pieces.

However things may be, most marks mean for us less than they would lead us to expect. Only in very few cases are they signatures of factory owners. A comprehensive work such as Havard undertook was necessary in order to arrive at this discovery, but Havard himself did not draw this conclusion from it; in his desire to explain all marks as far as possible, he led those who came after him into many a false track.

But we have a less agreeable criticism to make. Havard's work is full of small and even greater inaccuracies which have given rise, and may continue to give rise, to the greatest confusion. It is just for this reason that we rejoice over the fact that a beginning has been made with 


\section{OLD DUTCH POTTERY AND TILES}

the preparation of an accurate authoritative work. ${ }^{1}$ This work will for the first time put students of earthenware in a position to write a new history of Delft ware, for the teaching of the written documents will stand on surer foundations than those hitherto afforded, chiefly by the publications of Havard. Meanwhile it is possible-indeed, in our opinion, probable-that even then the bridge between Delft ware and its makers will remain to a large extent broken down, and that the publication will be found to have more importance for our knowledge of the pottery industry in general, for which indeed it has been undertaken, than for the study of the wares in particular. We expect from it many rectifications, not, however, a complete revolution in the present study of delft, which naturally yields a large place to stylistic criticism. This is therefore the reason why we see no difficulty in writing even at this stage a new account of Delft earthenware, without having been able to examine the documents as yet unpublished. Our survey of delft is based entirely on the wares themselves. We have therefore grouped them, like the classes of earthenware already described, in so far as the marks yield no clear data, by the characteristics they display in their material and decoration; at the same time we have naturally been glad to make use of the dates we have been able to find upon them. The marks have served us often merely as links between the specimens. We have not tried to explain them. Of course, we have given full weight to the interpretations of which we could be absolutely sure. The writings left by the late Mr. Van der Burgh, which contain such important commentaries for the new publication of documents, are our source for certain matters as to which there was immediate need for emendation. Where, in part as the outcome of the researches of Havard, a tradition was in existence and we were unable to replace it with anything better, we have not thought it necessary to make any alteration, seeing that the names of the manufacturers for the most part are more useful in the classification of various kinds of delft than as a means of identifying the productions of particular factories.

As regards marks, completeness is for the present impossible, and, as already remarked, it is questionable whether completeness will be attainable even after the publication of all the still unpublished material from the archives. We shall not give an extensive list of marks, such as those of Havard, Justice or Pitcairn Knowles, because we have adopted

1 This publication has been undertaken by the Nederlandsch Economisch Historisch Archief. Dr. H. E. van Gelder, of the Hague, has been occupied for some years with the critical examination of the extremely copious material. 


\section{DELFT EARTHENWARE: ITS ORIGINS AND STUDY}

a classification by types rather than by marks; the selection of examples makes no pretence to be exhaustive. The chief reason, however, is our desire to avoid attributions where the data are too slender, or where a critical view of the style of the objects too clearly reveals a discrepancy between the period of a piece and the interpretation of its mark offered by one of the authors named.

So far as opportunities allowed we have chosen our examples for illustrations from collections in various places. Where this is not the case, we shall make our selection from the Nederlandsch Museum voor Geschiedenis en Kunst (Rijksmuseum) at Amsterdam, which, especially since the accession of the Loudon Collection, possesses a very fine assemblage not only of polychrome, but also of blue-and-white delft.

When we engage in the study of Delft ware, we are met by a sense of something contradictory, which forces itself upon us again and again as in the case of no other product of good craftsmanship in earthenware. Whenever we enjoy the fine blue on a white ground, or the beautiful palette of the polychrome wares, the reflection comes upon us sooner or later that we are, as a matter of fact, generally in the presence of an attempt merely to imitate something else, that is, porcelain. But let us look more closely. Some of the pottery painters of the seventeenth as well as the eighteenth century made it their business to copy as closely as possible Chinese, and at a later stage also other, porcelain, and often succeeded wonderfully well in doing so. Others, and on occasion these same potters as well, introduced variety by their choice of colours, their preference for a particular palette, that was sometimes florid and vigorous, sometimes soft or delicately shaded. Some artists achieved the same result by modification of the motives. Others, again, as well as these same artists, painted pottery and tiles also with Dutch landscapes or other subjects which they copied with their brush from prints-generally line for line, but sometimes freely. Their choice in these matters depended perhaps on chance. But the fact, for instance, that a Dutch print or a Chinese subject was chosen, the fact that the article with the copy of a Dutch print was painted in Chinese fashion in blue on a white ground, was not dependent on chance. And as soon as an individual palette is in question, the taste of the painter begins to be of some significance. It is worth noting incidentally that both contemporary and earlier Chinese porcelain 


\section{OLD DUTCH POTTERY AND TILES}

was brought into requisition, and also that subjects were sometimes copied on earthenware from prints that were more than a hundred years old.

The taste of the painter is of still more importance when he is his own designer, albeit his designs, however decorative, are often somewhat rough. Such pieces are important because their decoration is original. But the most carefully executed pieces-and this is typical of the art of the Delft potter-are with few exceptions precisely the adaptations of Chinese floral motives-for example, the dishes and vases with branches of flowers of more or less Chinese character. In these the peculiar character of Delft ware comes out clearly. We see the Delft potters and pottery painters in a perpetual state of wonder in the presence of the fine homogeneous, translucent white material-the mysterious porcelain, that first came from distant lands and was later manufactured in Europe also. To counterfeit it they were not able, as they always lacked the fine kaolin-clay that was needful to give the ware resistance in the kiln, so that under a great heat it could fuse without changing form into a homogeneous white porcelain. They merely endeavoured to approach it in a material that consisted of a brittle core of cream-coloured clay, coated with a covering layer of white tin enamel which in a hot kiln (much less hot, however, than that required for porcelain) fixed itself as a glassy film on the clay body, but without coalescing with it; a consequence of this last characteristic was that a tendency in the enamel to flake off was a defect never absent from delft. This material was at times to the eye quite wonderfully like porcelain, and was then actually called porcelain by the Dutch potters. With it, by adaptation of motives, by their taste for colours and shades, and especially by the warmth of tone of the material itself, they succeeded in evolving a product capable of equalling the original by its artistic worth, though not in its nature, and even of surpassing the original by the glowing quality of its hues and substance. Therein lies the miracle achieved by the potters of Delft!

We shall now deal first with the blue-and-white ware, "blauw Delftsch," which is also actually older, or rather of which the earliest pieces are older, than that class of polychrome ware which is included in the category of "delft." Polychrome ware of the Dutch maiolica type may also have been made at Delft, although we do not know this for certain. In any case, we find at a quite early period of the seventeenth century much blue-and-white, but no polychrome in the sense of what we understand by the term in speaking of "delft." It may be surmised that at that time blue-and-white formed the chief part of the porcelain imported from 


\section{DELFT EARTHENWARE: ITS ORIGINS AND STUDY}

China. Moreover, it is quite possible that here also the influence may have been felt of the tendency or fashion observable in painting and costume, in which a reaction against the wealth of colour prevailing before I620 brought about the adoption of monochrome schemes of colouring.

From blue-and-white we shall pass to polychrome wares, divided, by the technical processes described in an earlier chapter, into three groups, as follows :-

(I) That in which all the colours are of the grand feu, that is, fired with and into the enamel at a high temperature; they comprise blue especially, reddish brown or red, yellow, green, manganese-purple and also black.

(2) That with a few colours (chief amongst them blue) of the grand feu, combined with others which would not sustain any great heat, and were fixed at a later stage by a second firing at a lower temperature, that is, in a muffle-kiln; chief amongst these muffle pigments are bright red, green, gold and also intermediate tints.

(3) That painted only in muffle-kiln pigments, on the already fired enamel. In this last group the firing of the whole decoration in the muffle-kiln was doubtless dictated by convenience; but this method of working was induced by the search for refined colours and shades in the effort to imitate not only Chinese, but also IMeissen and other European polychrome porcelain. This question has already been discussed in the Introduction. 

BLUE-AND-WHITE DELFT. DE KEIZER, PIJNACKER, FRIJTOM AND OTHER POTTERS AND POTTERY PAINTERS OF THE SEVENTEENTH CENTURY 



\section{Chapter VIII}

BLUE-AND-WHITE DELFT. DE KEIZER, PIJNACKER, FRIJTOM AND OTHER POTTERS AND POTTERY PAINTERS OF THE SEVENTEENTH CENTURY

The oldest group of fine carefully painted blue-and-white delft consists of the earthenware with the mark AK. The blue is of good quality, applied to a beautiful clear white enamel. This AK mark (there are also others to be mentioned later) is explained as that of the pottery of Aelbrecht de Keizer, who worked about 1650. Like the majority of marks it is a factory mark, and must have been very long in use after his time, and also, to judge by appearances, counterfeited by his contemporaries. We find amongst the wares bearing it imitations of Chinese porcelain, and even copies of it (as, for example, a vase made to replace a broken one in a set of porcelain vases).

Fine examples of this class are to be found in various collections. When reproduced they so exactly resemble Chinese porcelain that it is hardly necessary to give illustrations of them; we need merely mention one or two examples in the Rijksmuseum, such as a gourd-shaped bottle and some small plates, which have even the thinness and lightness of porcelain. In many such pieces the decoration is outlined in dark blue "trek," and then worked up in lighter blue. The Victoria and Albert Museum possesses, in the Salting Collection, a pair of gourd-shaped vases (Fig. 43) charmingly painted in this manner, with tulips and guelderroses combined with Chinese flowers and borders. Pieces with similar decoration of Chinese style occur with other marks, such as GK and WK in monogram; these marks have been associated respectively with the names of Ghisbrecht Lambrechts Kruyk and his brother-in-law Willem Kleftijus, but these identifications as yet lack confirmation from the archives, and must be regarded as conjectural. In the Victoria and Albert Museum are several pieces bearing the GK monogram, including a large covered vase with Chinese ladies in panels, painted in a noticeably vivid blue, and a pair of gourd-bottles with lotus pattern closely simulating a Chinese type of the reign of $\mathrm{K}^{\prime}$ ang Hsi. The jar illustrated in Fig. 27, 


\section{OLD DUTCH POTTERY AND TILES}

in the Cole Collection at Bidston, Birkenhead, is an example bearing the same mark and decorated in soft blue with darker trek.

We occasionally find on earthenware with the AK mark a black "trek," just as on the ware with the mark of Samuel van Eenhoorn (SVE), described on a later page. Large jars and jugs, sometimes with a cover, puzzle-jugs and various other vessels occur in this group.

In addition to Chinese motives, we also find on earthenware of the factory of Aelbrecht de Keizer and on other pieces of the same type finely executed Dutch landscapes, biblical and other subjects. The Rijksmuseum possesses several examples; amongst them are two oblong brick-shaped tulip-pots showing outlines in bluish black trek, marked AK (Fig. 29), and plates with subjects from the Bible and other books within a border left white in the true seventeenth-century manner. Other examples are two jugs decorated with landscapes and scrollwork, one of which bears the mark of the factory at the sign of the Rose ; again, certain plates with shipping subjects show the type of vessel of the middle of the seventeenth century. Other specimens are characterised by very carefully finished painting. We may mention as examples in the Rijksmuseum a brushback with a figure in the manner of Willem Buytenwech, and two butter-dishes with flower decoration; in the latter yellow is added, probably as a substitute for gilding.

We get more reliable clues to the period in which Delft earthenware was produced from specimens with dates inscribed upon them. We shall adduce here a few dated pieces of the seventeenth century from the Rijksmuseum, and shall include with them those that can be dated either by an inscription upon them or by their decoration, or can be immediately associated with dated work. With their help we may learn to recognise the fine blue painting of the second half of the seventeenth century, a period in which the majority of the most beautiful blue-and-white delft was made. The dated specimens in the museum, in chronological order, are as follows: a tile with a side view of the tomb of William the Silent, at Delft, dated 6/16 I657 and marked Junius, and a corresponding tile with the front view; a jug on a foot, with ring-shaped body enclosing a figure of a running horse, carefully painted with flowers and insects, inscribed Dirck Janse van IJselsteyn and dated I658 (Fig. 30); a small plate with a portrait of little Prince William III (afterwards King William III of England), after Harmanus van Aldewerelt, dated $165^{1}$;

1 A dish in the British Museum with a similar portrait is probably later than the date it bears ( $\mathrm{I} 66 \mathrm{I}$ ). 


\section{DE KEIZER, FRIJTOM AND OTHERS}

a tile on which is depicted Elijah fed by ravens, of the same year; a tile with a rustic scene, a small round plaque with a subject from St. Matthew iv., and a finely painted portrait on a tile of Robertus Junius (Fig. 3I), after an engraving of $I 645$ by C. van Queborn, all three dated I660; a similar portrait, bearing the same date, of Dionysius Spranckhuysen (d. I650), a preacher of Delft, also after an original, of I64I, by the same engraver, obviously belonging to the same series as the lastnamed specimen and betraying the hand of the same painter; two octagonal tiles with church interiors, both dated 1662 ; a jug bearing the arms of Orange and a verse in honour of the House of Orange and of Cornelis Tromp, the great admiral, presumably of 1666 , and relating to the disagreements between him and his rival, Michiel de Ruyter (the oranges in the design are rendered in yellow); a dish with a village school scene after Teniers, dated $\mathrm{I} 670$; a jug with a portrait of William III, a coat-of-arms and an inscription relating to the restoration to health of the Prince of Orange, dated 1674 ; two flat plates with an inscribed cartouche and a monogram with an inscription on the rim, dated $16859 / 19$; a globular jug with twisted handle and adherent spout, decorated with landscapes, dated 1687 ; an inkstand with the arms of Orange, surmounted by two figures of lions supporting shields with the arms of Leiden and Delft, mounted in silver, analagous in decoration with the last example (Fig. 28); a vase in the form of a large beaker, with representations of craftsmen, amongst them a potter, dated on a cartouche 1693.

Exactly ascertainable dating is also afforded by three pairs of hyacinth vases, of exceptionally large dimensions, made to adorn Hampton Court Palace, where they are still preserved. One of them is here reproduced as a specimen (Fig. 32). It is marked AK, and painted in blue outlined in bluish black trek; it is decorated with the combined monogram of the king-stadholder William III and Queen Mary, enclosed within the Garter, alternating with ribbons bearing the Orange motto, "Je maintiendray." These vases must have been made between the accession of William and Mary to the British throne in 1689 and the death of the queen in 1694 . The lambrequin motives in the decoration are entirely of the character of the period of Louis XIV. Of the other two pairs of vases, one also bears the mark $\mathrm{AK}$, whilst the second is unmarked; in the latter a bust of William III is combined in the decoration with a peacock and a boy with a captive heron.

To this same period must also belong a large dish in the Rijksmuseum 


\section{OLD DUTCH POTTERY AND TILES}

with the subject of a family gathered round a cradle; it is analogous in drawing and in its reserved decoration with the vase of 1693 named above. It is an example of the work of the pottery of Adriaen Pijnacker, whose mark was a monogram composed of the letters APK; this factory also produced beautiful polychrome wares, to be described on a later page.

We find, however, on the wares of the seventeenth-century blue-andwhite painters not only factory marks and dates. We know also the full signature of a master amongst pottery painters, Frederik van Frijtom, who dwelt and worked at Delft from about 1658 onwards. As an example we may cite a very large tile in the Rijksmuseum (Fig. 33) with a landscape, bearing the mark $F . V$. Frijtom. Other specimens painted in the manner of Frijtom, but unmarked, are a large tile and two oval plaques in the same museum, all with landscapes. The Musée Céramique at Rouen possesses two large tiles, one with a boar-hunting scene, the other with a particularly pleasing view of a windmill beside a waterway on which is a ferryboat. Two oval plaques in the Musée Céramique at Sèvres (Figs. 35, 36), somewhat similar in type to the work of Frijtom, bear shipping scenes and a signature, impossible of explanation, in which figures the name Reinier; on one are seen Dutch and Chinese vessels off the coast of China, whilst it has been suggested that the other depicts the battle of La Hogue, between the French and the combined Dutch and British fleets in I692. The association by Havard of these plaques with Renier Hey of the factory at the sign of "the Roman" (de Romein) is purely conjectural. A tile in the British Museum (Fig. 34), also very finely painted, calls for mention in this connection; it bears a view of the "Zee-visch-marckt en Vleeshal" at Delft, after an engraving by C. Decker, in Van Bleyswijck's Beschrijvinge der stadt Delft, of I667.

To Frijtom also are ascribed certain small plates of a charming type with exquisitely painted landscapes in the middle, and the rim left plain white. Specimens of these are to be seen, amongst other places, in the British Museum, the Musées du Cinquantenaire at Brussels (Figs. 37, 38) and the Rijksmuseum at Amsterdam; the last-named possesses, in addition to specimens of the small plates, a dish of large size.

A tile of large dimensions in the Rijksmuseum, the work of an unknown hand, less finely but powerfully painted with a picture after Wouwerman, dates from the latter part of the seventeenth century. 
SAMUEL VAN EENHOORN AND ROCHUS HOPPESTEYN 



\section{Chapter IX}

\section{SAMUEL VAN EENHOORN AND ROCHUS HOPPESTEYN}

Another important group of seventeenth-century blue-and-white delft may be placed about I680 or I69o. It shows the mark SVE (for Samuel van Eenhoorn) and that of Rochus Hoppesteyn (RHS). We have already noticed, in the AK group of wares, two small dishes decorated in blue, outlined in black trek, with a very delicately executed Chinese flower design and a border-pattern of foliated stems. An exactly analogous dish in the Rijksmuseum bears the mark SVE; like the AK dishes, it shows a more bluish white tone in the enamel than the foregoing wares. The trek, in black or sometimes in purple, and the bluish yet beautiful creamy enamel, are characteristic of the factory of Samuel van Eenhoorn and even more of that of Rochus Hoppesteyn; another noteworthy point is that the Chinese wares chosen by these, amongst other potters-particularly often by Rochus Hoppesteyn-are of a peculiar late Ming dynasty type. We may refer to tea-caddies of this class with floral decoration or figures, such as a large square one, marked SVE, in the Rijksmuseum, and an example with its lid in the Gemeentemuseum at The Hague ; other pieces of this class in the Rijksmuseum are two flasks, similarly marked, each with four medallions in relief on the body, decorated with Chinese landscapes, panels and borders, the trek being black; a little vase with narrow neck, decorated with a spray of flowers and marked RHS (Fig. 40), and a short, wide vase with floral sprays within pointed foliated borders, the trek black, also marked RHS. A small octagonal jug with silver lid, with black-outlined design of figures and foliage (Fig. 39), though unmarked, is probably from the Hoppesteyn factory Another class of pieces ascribed to this pottery show a delicately drawn purple trek, or purple combined with blue in the painting. The same decoration is shown by a wigstand in the Victoria and Albert Museum, London (Fig. 4I), decorated with Chinese figures in blue outlined in deep purple, and by a large covered vase (Fig. 42) in the Kunstindustrimuseum at Copenhagen, on which is painted in the same colours a crowd of Chinese figures with an elephant amongst them. Both of these pieces bear the monogram of Samuel van Eenhoorn. 

LAMBERTUS VAN EENHOORN AND LOUWIJS FICTOOR 



\section{Chapter X}

\section{LAMBERTUS VAN EENHOORN AND LOUWIJS FICTOOR}

Two factories that were working about I700, and both made also polychrome ware of importance, are those of Louwijs Fictoor and Lambertus van Eenhoorn. Their marks are often indistinguishable. Both used for the purpose the same monogram, which may therefore be read as LVE or LF. Only when they added to their monogram the mark of their factory, DS or DSK, for De Dubbelde Schenkkan " The Double Tankard "), of Louwijs Fictoor, or MP, for De Metalen Pot ("The Metal Pot "), of Lambertus van Eenhoorn, can we arrive at any certainty ; even so, the certainty thus afforded is of relatively slight importance for us, as the work of the two factories-especially their polychrome waresshows great similarity, and may therefore best be regarded as forming a single group. The drawing is for the most part looser and less delicate than in the AK group. The surface is, in general, more filled up with ornament ; less of the enamel is visible. In addition to scattered motives, ornament reserved in white on a blue ground is often found. A very fine example of this type is a large dish with a design of scattered flowers in the Victoria and Albert Museum (Fig. 44), with the mark LVE or LF. The Rijksmuseum possesses a pyramid bearing the same mark, and two smaller ones with the mark LF combined with DS. Small hyacinth or tulip vases also occur with the mark LF or LVE.

To the period about 1700 belong also certain pieces with more or less pronounced modelling in relief, all unmarked; we may name in the Rijksmuseum an oval wall-plaque of cartouche form, on which are two angels holding an armorial shield with the name Gaal below it, also a bust of William III, painted in blue, with two cupids on the pedestal. 

BLUE-AND-WHITE AND PURPLE DELFT OF THE EIGHTEENTH CENTURY 



\section{Chapter XI}

\section{BLUE-AND-WHITE AND PURPLE DELFT OF THE EIGHTEENTH CENTURY}

The eighteenth century has nothing unusual to show as regards technical processes. The early years still come within the period of the prime of Delft ; even at a somewhat later date we find very fine works, but this is exceptional. The decline soon announces its approach in the quality of the enamel and in the painting. Mass-production gives rise to hasty and inferior workmanship. The output, to a much greater extent than in earlier times, wears the aspect of factory work, in which far less care can be bestowed on each production. The enamel often assumes a different colour, of bluish tone, the painting becomes coarser, the blue changes its tint. The shapes of the wares, and especially the decoration, alter in conformity with the evolution of styles in France-Louis Quatorze, Louis Quinze, Louis Seize ; the Delft potter, however, was never a great modeller and adjusted himself only very superficially to the various changes of style.

We may name various pieces bearing dates which belong to the good period of the eighteenth century; some of the later ones are of somewhat inferior quality. A square tea-caddy in the Rijksmuseum, with scenes from the story of Tobit, bears the mark and date D.V.K. boot I700; this refers to the factory of Dirk van der Kest, at the sign of "the Boat" (de Boot).

Mention may here be made of a series of blue-and-white plates in the British Museum of the year I7I I. They are painted in broad, rapid strokes with half-figures symbolising the signs of the Zodiac, and are signed on the back: J. Thornhill fecit. Delph Aug. I7II; the plate representing Cancer is here reproduced (Fig. 46). The tradition is that these plates were actually painted at Delft by the English artist Sir James Thornhill, Sergeant-Painter to George I, and that they were in the possession of his daughter Mary, who married the painter Hogarth. The English spelling "Delph" in the signatures seems to confirm this tradition. If it is correct, the Chinese designs on the rim of the plates must be by another painter. On the other hand, the normal practice in pottery painting 


\section{OLD DUTCH POTTERY AND TILES}

suggests that it is at least possible that the whole decoration is the work of a single brush-that of a ceramic painter of Delft-and that he faithfully copied not only the designs supplied by Thornhill, presumably during a visit to Delft, for the middle of the plates, but also the signature and orthography of that artist.

Passing to other dated specimens in the Rijksmuseum, we come to a plate of I7I2 with a subject from 2 Samuel xiii. I, and a narrow floral border, and two pieces bearing the unidentified signature IVH, namely, a dish of 1725, with Europa and the Bull within an ornamental border, and a square tea-caddy of 1727 , with Daniel in the Lion's Den, Jacob's Dream and other subjects, and on the lid a very fine landscape with a farm-waggon. This mark has been attributed to Johannes Verhagen, recorded as master-potter at the "Young Moor's Head" factory in I759, but as yet evidence in support of this is not forthcoming. The same mark and the date 1728 appear on three dishes, painted one with a rustic festival within an ornamental border, another with a similar subject after David Vingboons and landscapes in medallions on the rim, the third with a similar decoration on the rim and the Building of the Temple at Jerusalem in the middle. Another example of the mark IVH is a finely painted dish, dated I729 (Fig. 47), with the subject of Christ before Caiaphas, after a print of Hendrik Goltzius; round the central subject are medallions with other incidents from the life of Christ, amongst foliage and angels. To the year 1736 belongs a rectangular mirror-frame with foliage decoration in reserve, amongst which are sporting children and four medallions with allegorical female figures; it bears an unidentified mark. On one of two three-handled baskets from the factory at the sign of the "Peacock" (de Paauw), with pierced sides and decoration of vases of flowers in medallions, is the date I740. A carefully executed specimen dated $\mathrm{I} 744$ is a kettle with lamp (Fig. 49), bearing a Chinese design of flowers and birds in a garden. A dish of $\mathrm{I} 748$ is painted with a figure under a portico of Moses with the Tables of the Law, and underneath, the Articles of Faith. Two finely painted oval butter-dishes, decorated with landscapes, a monogram and relief foliage, are dated I750. The next date, $\mathrm{I}_{7} 6_{3}$, is seen on a lozenge-shaped wall-plaque with the Woman taken in Adultery. A puzzle-jug, decorated with a landscape amongst floral ornament, bears the date i 768 amongst the openwork of the neck. An oblong rectangular tobacco-jar, with fluted angles and decoration of landscapes in medallions and floral borders, is marked A.D.W. and dated I769. With these dated specimens at Amsterdam we may include a finely 
painted dish in the Tenbosch Collection at Liverpool (Fig. 48). It is decorated with rustic landscapes in panels against a ground of close stylised foliage. The middle view, of the village of Twisk, near Enkhuizen, on the western shore of the Zuiderzee, is based on an engraving after a drawing dated 1726 by Cornelis Pronk, afterwards published by Isaak Tirion at Amsterdam amongst a set of views of Holland entitled Het verheerlijkt Nederland; on a $\log$ in the foreground is the signature $M$. v. Kuyk and the date I742. The painter is probably the second of three artists, of successive generations, who bore the same name, Michiel van Kuyk.

Another dish (Fig. 50), in the same collection at Liverpool, may be mentioned here on account of the similarity of the groundwork, with small figures of amorini amid close foliated scrollwork, to that of the dish with Passion subjects after Goltzius described above. The panels in this case are painted with Chinese vases and flowers in the style of $\mathrm{K}$ 'ang $\mathrm{Hsi}$ blue-and-white porcelain, but the composition of the whole is so well conceived that one is scarcely conscious of the incongruity of the motives.

Of the undated blue-and-white delft of the eighteenth century, marked as well as unmarked, it is even more true than of the dated specimens that the quality is very unequal, although good pieces are still to be found. The middle and second half of the eighteenth century are the period of decline for this class of delft. Mass-production and the manufacture of every possible shape and class of article are now the chief features. Factories like the "Axe" (de Bijl), the "Claw" (de Klaauw), the "Fortune" ('t Fortuyn), the "Ewer" (de Lampetkan), the "Greek A" or "Alpha" (de Grieksche A), the "Three Ash-barrels" (de drie Astonnen) and many others, competed in output and in variety of wares. Whether it be that they often borrowed patterns from one another, or that they did not scruple to copy one another's work, we find numerous specimens with the same patterns, but made in different potteries. Examples of this are the dishes decorated with a heron, some from the "Ewer" factory, others, somewhat different in execution, from the "Axe"; we know of plates of this class from other factories also, whilst types such as the peacock-feather plates (with a design of feathers springing from a small vase), blue and polychrome as well, and drug-vases of various patterns, were produced in several factories.

We may now mention a few of the best pieces of undated blue-andwhite showing the characteristics of the eighteenth century. Amongst 


\section{OLD DUTCH POTTERY AND TILES}

these are wall-plaques and tiles, as well as dishes and other vessels. The dishes and plates may be clearly distinguished from their seventeenthcentury forerunners by their form, the more frequent presence of a footrim and their greater weight, as well as by their colouring, their drawing and the costume of the figures depicted on them. It is not unprofitable to compare such pieces as two plates in the Rijksmuseum, one of the seventeenth century, the other dated 1753 , with the mark of the factory at the sign of the "Porcelain Axe" (de Porceleyne Bijl) and the initials $\mathrm{HB}^{1}$; both are painted with a ship. A comparison of the two shows clearly the difference between the zenith and the decline. Amongst the eighteenth-century plates with landscape subjects are many series illustrating the twelve months; another series often met with is that of the herring fishery. We find other plates made for purely ornamental purposes, including many with inscriptions, in French and English as well as in Dutch. Examples of such pieces in the Rijksmuseum are nine plates from a series of twelve with subjects from the life of Christ after engravings by Hendrik Goltzius, seven from a series representing the twelve months from the factory at the sign of the "Axe" (de Bijl), and a series of six large dishes with various scenes from the story of the Prodigal Son. In the Tenbosch Collection at Liverpool is a nearly complete set of twelve plates with scenes from the Passion and quatrains of a pious character inscribed on the back. We still find at this period exact copies of Chinese blue-and-white porcelain. A dish of this class, also at Amsterdam, with rising rim and six small feet, painted with a Chinese garden scene, bears the mark CB with a star. This mark has been taken to refer to the factory owned by Cornelis de Berg, at the sign of the "Star"; it has also been attributed to Cornelis Brouwer, but neither attribution has as yet been confirmed from the archives.

We now pass to the great variety of other vessels made in the eighteenth century. Incidentally we may observe that in blue-and-white we do not find so many different shapes as in the polychrome ware, in which we meet also with all kinds of little figures and statuettes in far greater abundance. In blue-and-white we find, in addition to the articles to be specially mentioned, tobacco- and snuff-jars and drug-vases with names to indicate their contents, barber's basins, candlesticks, calendars with revolving disc, small boxes, basins (sometimes with pretty Oriental motives), sauce-boats with rococo decoration, cream-jugs, tea-pots,

1 The mark HB has been ascribed to Hugo Brouwer, but in the list of 1764 he signs his name as proprietor of the Drie Porceleyne Flessies. 
grotesque urns for coffee or other drinks in the shape of a seated man or woman (resembling the Staffordshire "Toby-jugs"), and other articles for household use. Drug-pots, to a large extent, retained even in the eighteenth century their seventeenth-century character, their shape and their white enamel, devoid of painting except for an ornamental panel, for the name of the drug. Apart from drug-pots, the great speciality of the factories of the eighteenth century, particularly that of Van Duyn, were sets or garnitures of vases, beakers and jars. Of all these things there was a gigantic output, but of steadily diminishing significance as the eighteenth century advanced.

We will now mention some of the best specimens, amongst them still a few of fine quality, as, for example, the earthenware violins and a birdcage. On various pieces we find the marks of well-known factories of the eighteenth century, such as the pottery of the Dextra family at the sign of the "Greek A," that of Van Duyn and others. A violin (Fig. 5I, a and b), acquired by the Rijksmuseum as part of the Loudon Collection, is painted on the front with a ballroom scene, and on the back with peasants dancing outside a tavern; from the costumes of the dancers it can be assigned to the second quarter of the eighteenth century. It is one of four such objects in blue-and-white delft which have been the subject of a certain measure of romance in ceramic literature; of the others, two belong respectively to the Evenepoel Collection in the IMusées du Cinquantenaire at Brussels and to the Musée Céramique at Rouen. The painting on the Amsterdam violin closely resembles that of a musicparty on a jug in the Victoria and Albert Museum (Fig. 45); this has the $\mathrm{R}$ mark of the factory at the sign of the "Rose" (de Roos). A hexagonal covered box in the Rijksmuseum may be noted on account of its scenes bordered in black, and a small basket decorated with seated figures of ladies, for its mark, $\mathrm{H}$. A large bowl in the same museum is of interest by reason of its subject, the "Midnight Conversation," from a print by Hogarth; this was a favourite also with the delftware potters of Bristol and the Staffordshire salt-glaze makers. A rare piece at the same place is a birdcage, with decoration of Chinese flowers and birds. A set of three vases and two beakers, also at Amsterdam, all five marked with a $D$ and decorated with Chinese floral ornament or landscapes and figures, was made at the "Greek A " factory during the proprietorship of Jan Theunis Dextra. It is worthy of remark with regard to these pieces that on the list of $\mathrm{I}_{764}$ Dextra deposed as his mark the letters A and ITD, to be placed only "on his best produc- 
tions" (achter mijn beste goederen). In his estimation, therefore, the pieces just enumerated do not belong to that category.

The Rijksmuseum possesses several marked specimens from the factory of Johannes van Duyn and from various other potteries; amongst these are a small basin with vertical openwork rim, painted on the bottom with two figures in a garden, marked H.V.H., and a snuff-box of rococo shape decorated with pastoral scenes, marked G.V.S. (from the factory of Geertruy Verstelle). The same mark appears on a kettle with lamp on high legs of rococo form in the Victoria and Albert Museum. A coffee-pot at Amsterdam, also with rococo ornament surrounding landscapes, bears the mark (W.V.D.B.) of the widow Van den Briel, proprietress of the factory at the sign of "Fortune" (In 't Fortuyn); this is a piece of craftsmanship showing a truly refined feeling for style, such as is seldom met with amongst the Delft potters.

Blue was not the only pigment used alone on the white enamel at Delft. Manganese-purple and even soft brown were also employed for monochrome decoration, but objects so painted are of comparatively rare occurrence. We may mention as examples a small model of a sledge, and a pepper-pot with the mark $A$, in the Rijksmuseum. 
POLYCHROME DELFT OF THE GRAND FEU LAMBERTS VAN EENHOORN AND LOUWIJS FICTOOR 



\section{Chapter XII}

\section{POLYCHROME DELFT OF THE GRAND FEU LAMBERTUS VAN EENHOORN AND LOUWIJS FICTOOR}

When Delft ware was at its zenith, the potters turned their attention to the production of polychrome earthenware, as well as blue-and-white. There is, however, scarcely any connection to be discovered, and certainly no direct connection, between the Dutch polychrome ware of maiolica type and that of Delft. The gulf between them was, in fact, bridged by blue-and-white; that is to say, there was a slow transition, through improvements in technique and under the influence of Chinese porcelain, from the old polychrome earthenware, first to decoration in blue alone on a fine white tin enamel, and subsequently, as a consequence of the importation from China of polychrome porcelain, to painting in fresh colours, amongst them as an entire novelty iron-red, on an enamel of clear white hue; the beautiful "polychrome delft" was evolved. The Delft potters found themselves as a result in the presence, as it were, of an entirely new technical procedure. The difficulties that presented themselves in the use of their polychrome palette were not slight. Most of the colours, if not wholly unsuitable for firing at a high temperature at the same time with the enamel, were only just capable of enduring the heat. The skill shown by the Delft potters in the polychrome ware of the grand feu class is on this account the more remarkable. Hardly less remarkable are their endeavours to achieve more than was possible by these means, although the path on which they thereby set foot-the fixing of pigments by a second firing at a low temperature, as described in the Introductionwas a much easier one to tread.

The class of polychrome wares with grand feu colours, fired with the enamel, may be called, from the technical point of view, the most important made at Delft. The colours suitable for the high-temperature kiln (grand feu) are, in addition to blue (the most heat-resisting of all the pigments), yellow, green, purple, reddish brown or red and, lastly, black. The number is therefore limited, but the variations attainable in the application of this palette are many, and polychrome delft displays 


\section{OLD DUTCH POTTERY AND TILES}

to us, in continually surprising alternations, a colour scheme which is now soft and delicate, now again powerful and florid.

Amongst the most beautiful wares of the grand feu are those of the potteries of Lambertus van Eenhoorn, Louwijs Fictoor and certain others, of which the colouring shows such a close correspondence that they can scarcely be distinguished except by their marks. Even so it is often even less possible than in the case of the blue-and-white produced by these factories to make out whether we have to do with earthenware of Lambertus van Eenhoorn or of Louwijs Fictoor. As we have seen in dealing with the blue-and-white, identification can only be established with certainty in the case of pieces bearing the mark of Fictoor's factory, DS (for de Dubbelde Schenkkan, the "Double Tankard"), or the MP of Van Eenhoorn's "Metal Pot." The specimens often bear a mark that can be read either as LVE (Lambertus van Eenhoorn) or as LF (Louwijs Fictoor). Whether one or the other of these two potters is the maker of a piece is of less importance to us here than the question whether it is the work of a third individual; the type shows a definite character, which differentiates it clearly from the other polychrome wares. As regards the period of production, Lambertus van Eenhoorn and Louwijs Fictoor worked about I700. The dates which we find upon pieces in the Rijksmuseum are 1704 on a pair of small armorial plates and $I 739$ on an oval wall-plaque, so that we can indicate the first forty years of the eighteenth century as the period during which wares of this type were made, to which may with probability be added the last ten years of the seventeenth century. The colours used are soft blue and red, pale green, and purple, on a white ground, generally reeded (the so-called cachemire), a soft colour-combination in which a class of decoration with birds and flowers of Chinese character is carried out. In another type we find the same group of colours in stronger tones and, for the most part, enlivened with a fresh yellow. We may mention in the Rijksmuseum a set of three covered vases and two beakers, all octagonal and reeded, marked LVE, ascribed to Lambertus van Eenhoorn on account of the accompanying mark, IVK in monogram, supposed to be that of Arij van der Kloot, who became foreman to Van Eenhoorn in 1708. A large octagonal reeded vase with cover bears the same mark. Two pyramids in the same museum, marked LF, bear another mark, IP in monogram, ascribed to Jan Pietersz, who is believed to have been foreman in the factory of Fictoor. Other specimens of this type at Amsterdam bear various other marks. A large ribbed bowl is marked WK; these initials 
have been assumed, without proof, to be those of Willem Kleftijus. Two small hyacinth- or tulip-vases, with feet and eight spouts and handles in the form of birds, bear the mark IH. Unmarked specimens are a reeded teapot (Fig. 52), a very fine example of this class, and a very important large set of five pieces in the Van Gelder Collection at Uccle, near Brussels (Fig. 54), comprising a covered vase, two covered beakers and two gourd-shaped bottles, all octagonal and reeded, and decorated with ornamental borders with floral sprays and birds between them. In this set, as in some of the following pieces, yellow is included in the colouring. A similar set, more heavily painted, is in the Rijksmuseum. A coffee-pot with long spout, also reeded, in the same museum (Fig. 56), bears the DS mark of the "Double Tankard" (de Dubbelde Schenkkan), the factory of Louwijs Fictoor. The style of Louwijs Fictoor is seen in a dish painted in red, blue and yellowish green, with scattered flowers, in the Van Gelder Collection (Fig. 60); the design recalls the blue-and-white dish in the Victoria and Albert Museum (Fig. 44) already mentioned. Two oval wall-plaques in the Rijksmuseum with scrolled edge, decorated with Chinese sprays and birds within an ornamental border, differ slightly from one another in the colouring; one of them (Fig. 6r) is dated 7 June 1739 and marked IVK. Two plates with coats-of-arms on a black ground are dated I704. 
THE "ROSE" FACTORY. VERHAAST AND OTHER SEVENTEENTH-CENTURY POTTERS 



\section{Chapter XIII}

\section{THE "ROSE" FACTORY. VERHAAST AND OTHER SEVENTEENTH-CENTURY POTTERS}

One of the few better-known factories is the pottery at the sign of the "Rose" (de Roos). The factory is found mentioned as early as 1675 ; it occurs on the list of 1764 and was still in existence at the beginning of the nineteenth century. It would be difficult to date its productions from the occurrence of the simple word Roos as a mark, were it not for certain circumstances to help us on the list of 1764 . The owner at that time, Dirk van der Does, who also, according to his deposition, used the mark D.V.D.D., deposed as his factory mark a drawing of a rose (really a rosette), and not the word Roos; this word, on the other hand, serves as mark on a blue-and-white jug which we have included, on account of its decoration, amongst the seventeenth-century group of specimens with landscapes, of the class of Aelbrecht de Keizer. For this reason, and by the character of the ware, we may place the good coloured specimens from the factory about the year I700. They bear the mark Roos in full. The colours are light red, blue, green, purple, yellow and also black. It may here be noted that the mark Roos was sometimes shortened to R, as is shown by two plates in the Victoria and Albert Museum from a single series with scriptural subjects; one of them bears the name in full, the other the initial only.

Specimens with the mark Roos in the Rijksmuseum are two large jars with covers painted with Chinese floral decoration in which a fresh, bright red is the leading note of colour, a small plate, slanting on the under side, with a spray of Chinese flowers, and a small ribbed vase with a rare design of flowers of almost Turkish type (Fig. 57). In the Victoria and Albert Museum is a large set of three covered jars and two vases marked Roos (Fig. 58); they are decorated with Chinese flowers in red, blue, green and purple. A dish (restored) in the Rijksmuseum (Fig. 59), with figures of monsters in landscapes and an ornamental border in imitation of a Chinese famille verte design, though unmarked, may be attributed with confidence to the "Rose" factory. Another good example of adaptation from the Chinese famille verte is provided by the plate 
with figures crossing a bridge, from the Van Gelder Collection at Uccle, reproduced in Fig. 62.

In the polychrome ware also we meet with a great master amongst the pottery painters of the seventeenth century, by name Gijsbert Verhaast. He was formerly regarded as an eighteenth-century artist. We now know that Verhaast was working about $I 690$ in the factory of Rochus Hoppesteyn, but also painted in other factories and on his own account. We are acquainted with certain tiles painted by him, marked G. Verhaast. One in the Rijksmuseum shows a landscape in grey ranging from a light to a dark tone, buff and pinkish buff, blue of various tints, brown, yellow and green-in short, in wonderfully rich shades of the Delft colours of the grand feu. The tile here reproduced (Fig. 63) is not signed, but is so clearly from the hand of Verhaast that no doubt is possible as to its authorship; its colours also agree absolutely with those of the signed example at Amsterdam. It is preserved in the Musée Céramique at Sèvres. Another such piece, painted with an interior, is in the Evenepoel Collection at the Musées du Cinquantenaire at Brussels.

We now pass to a number of pieces, dating from the seventeenth, or at latest the beginning of the eighteenth, century, which were made in various factories or cannot be assigned to any known factory.

A charming specimen of unknown origin is a large tile in the Rijksmuseum (Frontispiece, Fig. 64) painted in yellow, reddish brown, green, blue and purple with a bouquet of two tulips, an anemone and a spray of larkspur. In the same collection are a teapot with floral design in red, blue and green, bearing the mark AK with a dot, thus : and a jug with a metal lid (Fig. 55), finely decorated with flowers in the same colours, marked GH. A small plate, also at Amsterdam, bears a portrait in blue of Antonie Leeuwenhoek, the biologist, after a detail of a print of the year I686 by Verkolje.

We may mention here the well-known class of "lightning" plates (bliksembordjes), so called from a conspicuous feature in their design, which is borrowed from Japanese (Imari) porcelain. An example of this type in the Rijksmuseum bears the mark WK, to which reference has already been made. The same mark occurs on an oval dish with this design in the Victoria and Albert Museum (Fig. 53). A large dish at Amsterdam with the mark Tome Swa, not yet satisfactorily explained, bears the subject of the Last Judgment painted in blue with passages of yellow and purple, with small figures of boys amongst the decoration on 


\section{THE " ROSE" FACTORY. VERHAAST AND OTHERS}

the rim; it shows a quite exceptional type of colouring, somewhat recalling that of the Old Dutch maiolica.

Of the so-called "peasant delft" (boerendelftsch), the coarser but often much more decorative and artistic type of delft, we shall have more to say in discussing plates of the eighteenth century; some pieces, however, undoubtedly go back to the seventeenth century, though no dated specimens exist to prove it. We can only name as a piece akin to this class a bowl in the Victoria and Albert Museum (Fig. 84) with an inscription commemorating the Peace of Ryswick and a bird amongst foliage broadly painted in blue, olive-green and lemon-yellow; the legend is as follows: Anno 1697 den 20 september is de vreede gesloten met Hollant spanjen engelant en vrancrijk ("Peace concluded between Holland, Spain, England and France, Sept. 20, I697"). 

DELFT WARE WITH COLOURED GROUND. IMITATIONS OF FOREIGN EARTHENWARE 



\section{Chapter XIV}

\section{DELFT WARE WITH COLOURED GROUND. IMITATIONS OF FOREIGN EARTHENWARE}

A fine black colour has already been mentioned in connection with the earthenware from the "Rose" factory and of the type of the Van Eenhoorn and Fictoor potteries. We must now draw attention to certain pieces with the mark of the Pijnacker factory, in which the ornament is reserved on a black ground. First we will cite a rare set of four small vases in the Clainpanain Collection at Lille; they are of three different shapes, and thus presumably belonged originally to a set of five or perhaps seven pieces. Three are illustrated in Fig. 66. The decoration, painted entirely in underglaze colours, consists of stylised flowers and foliage in red, yellow and greyish green in white reserves on a black ground. A teapot in the Rijksmuseum (Fig. 65), with decoration carried out in precisely the same manner, shows also, in its ornament of cherubs and floral sprays, blue in addition to the other colours; it bears the mark of Adriaen Pijnacker, APK in monogram.

Next to the pieces showing this very unusual reserve technique we come to the class, of more frequent but still rare occurrence, covered with a black enamel on which various colours are applied. The pigments generally used are blue, red, yellow, green and white, as on a teapot with small Chinese scenes and the mark LF or LVE (of Fictoor or Van Eenhoorn), and an oval plaque (Fig. 67), with a Chinese floral design, both in the Victoria and Albert Museum, and on a tea-caddy in the Rijksmuseum; other examples in the latter museum are a small plate decorated with Chinese buildings and sprays in various colours, and a pair of brush-backs. Exceptionally fine decoration, doubtless intended to simulate Chinese lacquer, is displayed by certain small black plates, exemplified in various collections, which are painted only in a fine green and a yellow resembling fine gilding. A good example belongs to the Victoria and Albert Museum (Fig. 69). A tea-caddy similarly painted (Fig. 68), also in that museum-in the Salting Collection,-bears the monogram LF or LVE.

In addition to the pieces with black enamel we find also a few with 


\section{OLD DUTCH POTTERY AND TILES}

an enamel stained mazarine-blue or turquoise-blue. We may mention a small jug in the Gemeentemuseum at The Hague (Fig. 70), with floral ornament in yellow on a mazarine-blue ground (similar to another, in the Clainpanain Collection, at Lille), and, in the Rijksmuseum, a dark blue bottle with painting in white, and a set of three vases with a Chinese design in yellow and white on a dark mazarine-blue ground; all these pieces may be regarded as imitations of the faience of Nevers, in France. A plate, also at Amsterdam, made at the "Fortune" factory, with floral and linear design in white, blue and purple on a light greyish blue ground, appears to be an imitation of Bristol delft; the type is perhaps originally Italian. Two small covered vases (Fig. 7I), bearing the mark D and dating from the eighteenth century, are entirely covered with a turquoise-blue enamel and painted over it with floral sprays in colours. Examples of other coloured enamels are two flower-pots with scattered flowers in colours on a yellow ground, bearing the mark of the "Ewer" (Lampetkan) factory, a small bowl with openwork vertical sides similarly decorated, with the mark of the factory at the sign of the "Three Ash-barrels" (de drie Astonnen), and a teapot with yellow flowers on a brown ground, marked L.V.D.; these initials have been supposed to refer to Lucas van Dale, of the "Fortune" factory.

We have just mentioned certain pieces which are imitations of the productions of other places. We may name a few more examples which indicate that not only Chinese porcelain, but also French faience, was imitated at Delft. We may refer to a pair of finely painted models of slippers (Fig. 79), decorated on a white ground with floral scrollwork in scarlet and blue, in imitation of the rust-red (rouille) and blue of Rouen. Another example is a plate with birds amongst flowering branches and a formal border in red and blue; it is marked with an unknown monogram consisting of the $\mathrm{V}$ and $\mathrm{L}$ combined, with a dot above them, thus : a mark found on other specimens with fresh colouring and reputed to be that of Jan van der Laan, of the factory at the "Three Bells" (de drie Klokken). It appears that there was reciprocity of imitation between the factories of Delft and Rouen. 
GRAND FEU POLYCHROME DELFT WARE OF THE EIGHTEENTH CENTURY 


\section{.}




\section{CHAPTER XV \\ GRAND FEU POLYCHROME DELFT WARE OF THE EIGHTEENTH CENTURY}

When we come to survey the grand feu wares of the eighteenth century we find ourselves confronted by an abundance of dishes and wall-plaques, mostly with strong colouring, diversified with a few equally florid vessels and figures. There is a large group of dishes (examples are to be seen in the Rijksmuseum), painted with a landscape or a scene of rustic genre or from Bible history, in blue, surrounded by a polychrome border, in which sometimes further subjects are introduced in small medallions. The various motives of the borders, such as floral ornament and small figures of cupids, reflect the French styles of Louis XIV, the Regency and Louis XV, and enable us more or less to date these dishes; at the same time we find here again that the Delft potters did not always conform with the style of their own time, so that motives of the French periods must not be pressed so far for dating purposes as to exclude the possibility that various dishes with designs of different styles may have been made about the same time. The same can be said of designs painted after prints or copied from Chinese originals. We must not go to the potters of Delft for lessons in the evolution of style. We greatly prefer their work when it shows real originality, and find much to give pleasure in its flower-like colours and beautiful material.

A good example of the type last referred to is a dish in the Clainpanain Collection (Fig. 75), with a pastoral scene in blue within a border of floral decoration in reddish brown, purple, yellow, green and blue, reserved on a black ground. Amongst dishes with a landscape in blue within a coloured border are two in the Rijksmuseum, bearing the date 1756 . These bring us to the middle of the eighteenth century. Unfortunately, all further indications are lacking, as almost all dishes of this class are unmarked; one at Amsterdam is by exception marked with an axe, the mark of the factory bearing that sign (de Bijl). This is also true of the wall-plaques of the eighteenth century with polychrome decoration; they differ in this respect entirely from the blue-and-white 


\section{OLD DUTCH POTTERY AND TILES}

plaques, which, as we have seen, afford sure evidence of the development of the craft in the shape of dates and often also of marks. A dish in the Rijksmuseum shows, within a border of European design, a Chinese landscape in colours, in place of the Dutch landscape in blue; it is marked with a D, the mark of the Dextra family.

A finer and more important class of dishes is that with floral decoration, after the European style or borrowed from a Far Eastern original, in both cases with a character of its own peculiar to Delft. Amongst pieces of this last type are some in the Rijksmuseum with coloured branches of flowers in which a strong reddish brown predominates. On two dishes (Fig. 72) we see the brightest colours of the Delft palette beautifully distributed against a splendid white ground in a design of flowers and birds. The motives are Chinese, but yet belong by virtue of their rendering wholly to Delft, and to Delft at its best on account of their distinctive combination of colours. Fine examples of colouring, again, are two dishes with subjects of Chinese women and children; their palette is striking, and, though identical in design, they show variations in colouring. A wholly different character is worn by a large shallow bowl in the Victoria and Albert Museum (Fig. 74), on which are depicted four Chinese figures in a garden; the design, painted in dark and pale manganese-purple, dull blue, yellow and green, outlined in red, is borrowed from one of the most distinguished types of famille verte porcelain of the reign of $\mathrm{K}^{t}$ ang $\mathrm{Hsi}$. A companion bowl is in the Musée Céramique at Sèvres.

The dishes and plates (mostly of large size, but occasionally small) which show European designs are decorated with a vase of flowers, and on the rim floral or other ornament. They range in date from the early to the later years of the eighteenth century. An undoubtedly early example is a dish in the Rijksmuseum (Fig. 76) with a preponderance of blue in the decoration, which consists of a vase of flowers within a border of Louis XIV style.

Amongst plates with armorial designs and inscriptions are those with the arms of the Van der Hoeven family, bearing the Dextra mark (D) and still recalling somewhat in their colouring the older armorial plates; examples of these are to be seen in the Rijksmuseum and in the British Museum. A proof also that the old tradition continued to prevail -as we have already pointed out-is a plate in the Rijksmuseum made towards the end of the seventeenth, or more probably as late as the eighteenth, century decorated in blue, yellow and green with the inscription 
Loof Godt altijt ; it shows the same method of decoration, and even the same type of ornament on the rim, as the Dutch maiolica dishes of earlier times.

We may now draw attention to certain dishes and plates of frequent occurrence decorated with all the known grand feu colours, to which we have already referred in dealing with wares of the seventeenth century. They form an extensive group of roughly painted but very decorative and often original pieces, for the most part made in the eighteenth century. This class is usually called boerendelftsch (" peasant delft"). They are often in their simple way more tasteful than the finest Delft copies of Chinese porcelain, as may be seen from the specimens in the Rijksmuseum illustrated in Figs. 82 and 83 . We may mention also in particular a plate in the Victoria and Albert Museum with fruit in colours, in panels reserved on a yellow ground, and a dish in the Rijksmuseum, painted with a basket of fruit, not because they are remarkably fine (the colouring is frankly heavy), but on account of the dates they bear, I770 and 1776 respectively. The latter museum also possesses a nice collection of small plates of this kind, as well as a few more finely painted. Amongst them the so-called "peacock-feather plates," with a design with which we have already met in its blue-and-white version, were produced by various factories.

The wall-plaques may be classified in the same manner as the dishes. We find, for example, several specimens in the Rijksmuseum that are decorated with a pictorial subject in blue enclosed by a border of coloured flowers, in some cases modelled in relief. A large group have a modelled border roughly following the forms of the Louis XIV and Louis XV styles, painted in blue, brown, yellow and green, surrounding a subject in blue, generally a pastoral scene. An example in the Salting Collection at the Victoria and Albert Museum shows a figure-subject borrowed from a French engraving, one of a set of Cris de Paris, by Ravenet after Boucher. Two small oval plaques, forming a pair, in the Rijksmuseum (Fig. 85, a and b) are decorated in soft colouring with charmingly drawn figures of seated men drinking; one of them bears on a band the words $G$. Sachtleeven, probably the name of the engraver of the print which served as a model. On both plaques the figure is enclosed by cartoucheornament in Louis XIV style, with two cupids supporting a shield at the top.

An example of Chinese decoration is afforded by a fine oval plaque in the Rijksmuseum (Fig. 73) with figures of two ladies. Another, with scrolled edge and a sleighing scene, may be mentioned on account of the 


\section{OLD DUTCH POTTERY AND TILES}

date I754 painted on the back; whilst the Victoria and Albert Museum possesses an example, dated 1763 , with a cock among flowering plants in the Chinese manner.

Other wall-plaques show, in deeper or paler tones of the usual colours, a vase of flowers within a border. Such examples as may be seen in the Rijksmuseum belong to the finest works of this class. The fresh colours of the crowded bouquets give a splendidly rich effect. Decoration of this class is seen on a tray in the Victoria and Albert Museum (Fig. 89) with a vase of flowers. Other plaques, again, much inferior in artistic worth, depict a birdcage; such pieces are on the border of "peasant pottery," the so-called boerendelftsch, if not beyond it.

Two tiles in the Rijksmuseum with the arms of William V of Orange are works of quite exceptional charm. The shield is enclosed within the Garter, in reference to the Prince's rank as a Knight of that Order. The tiles are dated, one, which has a green ground, I752, the other (Fig. 86), with a white ground, 1765 ; the latter is also signed in full on the reverse $P$. Vizeer. With their fine painting they prove that, like Verhaast in the seventeenth century, Piet Vizeer in the eighteenth was a true artist amongst pottery painters. It is a curious thing that as yet we know nothing of a painter of this name at Delft in 1765 ; an elder P. Vizeer, perhaps his father, died before that year.

We may notice here a few more dated pieces of polychrome delft in the shape of figures, table wares and other vessels. Two small figures of parrots, with soft colouring, bear the mark I.D.V. and the date I729; a larger pair, with a bolder and at the same time coarser combination of colours and more vigorous modelling, are dated 1784 . Both pairs are in the Rijksmuseum. Being dated, they afford a good opportunity for comparing early and late eighteenth-century work. On a boldly painted puzzle-jug (Fig. 88), with bright colouring, we find the date 1758 on the openwork neck.

Amongst undated specimens in the Rijksmuseum may be named a money-box (Fig. 87) of attractive shape; it displays a quite unusual colouring with only a sparing use of red, the decoration consisting of Chinese floral sprays combined with European motives. In the same museum may be seen two small boxes with lids in the form of fruit bearing the mark IVDB, a melon with that of the factory at the sign of the "Axe" (de Bijl), and a brush-back marked M.D.V. The mark on the first of these has been conjectured to be that of Jan van der Buergen, or Verburg, a painter employed by Lambertus van Eenhoorn 
and later at the "Greek A" and "Star" factories ; that on the last is unknown.

Amongst the figures made at Delft in the eighteenth century some are naturally statuettes for decorative purposes only, whilst others were intended for use as covered bowls, vases or jugs. Examples in the Rijksmuseum are a pair of small Chinese figures from the factory of the "Metal Pot" (de Metalen Pot), a boy blowing a trumpet, and a bagpipeplayer with the mark of the "Axe" factory (Fig. 77). A figure of a parrot, perched on a ring, in the Clainpanain Collection at Lille, is here illustrated (Fig. 8I). We may mention also, in the Rijksmuseum, a cock with the mark LC, a pair of small horses (Fig. 78) and a cow (Fig. 80).

The Rijksmuseum possesses also two small vases in the form of cocks, of bright colouring, with the mark, ITD, of Jan Theunis Dextra; a hen and ducks forming covered bowls; jugs for coffee and other beverages in the shape of seated figures, such as one with the mark of the factory at the sign of the "Claw" (de Klaauw), and another marked Van Duyn. Monkeys are generally chosen to form small milk-jugs. We find also amongst these modelled pieces quite literal copies of Chinese work. For instance, we can point to Chinese originals for the parrots and for an ape intended as a milk-jug. In such pieces a quaint transformation has often resulted in the hands of the Delft potter. We may mention here, lastly, a modelled bowl or basket in the Rijksmuseum with rococo decoration and pale colouring, probably intended to hold flowers, which bears the mark HVH, perhaps for Hendrik van Hoorn, of the Drie Astonne ("Three Ash-barrels") factory.

Having discussed all the more important types of polychrome ware of the grand feu class, we may mention, as examples of the skill of the Delft potters in another class of work, two large tile-pictures in the Rijksmuseum (Fig. 90), probably dating from the beginning of the eighteenth century. One is painted with a Chinese figure-subject, presumably based on woodcuts, in which are introduced negroes in a fine black pigment; the other is decorated with a vase of flowers. In both panels, as in all polychrome delft, it is the splendour of the fresh colours that chiefly calls forth our admiration. 

THE BEGINNINGS OF MUFFLE-KILN PAINTING HOPPESTEYN, PIJNACKER AND OTHERS

I 



\section{Chapter XVI}

\section{THE BEGINNINGS OF MUFFLE-KILN PAINTING HOPPESTEYN, PIJNACKER AND OTHERS}

The need was already felt in the seventeenth century for an extension of the range of colours, in order to make possible the reproduction of every class of Chinese and Japanese porcelain. By using only grand feu pigments, that could be fired with the enamel, the potters had attained to blue, yellow, green, manganese-purple, red and black. But we are led to suppose that the red was not absolutely fire-resisting and caused much difficulty. In those instances, at least, in which the palette extends to gold, we find the red as well as the gold fired in the muffle-kiln. This is the case with the productions of the potteries of Rochus Hoppesteyn and Adriaen Pijnacker, who worked at the same time as Lambertus van Eenhoorn and Louwijs Fictoor, or perhaps even earlier. The blue in their work is fired with the enamel, at a high temperature, whilst the remaining colours and the gilding are fired subsequently, in the muffle-kiln.

We here mention Rochus Hoppesteyn and Adriaen Pijnacker together, but in so doing we have indicated their only point of correspondence. Their work was totally different. The factory of Rochus produced wares of an entirely distinctive class of its own, with a peculiar palette, which must be specially commended not only for its splendid brilliance and fine scale of colours, but also on account of its exceptionally good and technically almost unaccountable gilding. As in the case of the blue-andwhite, we get the impression from the polychrome wares of this factory that the Chinese porcelain which served as a model for them was of the late Ming and not of the $K^{\prime}$ ang Hsi type, and that it was blue-andwhite which the earthenware painter translated in his own manner into colours. As an example of the wares of the Hoppesteyn factory we may quote first a small jar in the Rijksmuseum (Fig. 9I), marked RHS, on which are small groups of Chinese figures in blue, red, green, black and a splendidly fine gold; we find in the painting also the black trek or outline with which we have already met in the blue-painted wares of the Hoppesteyn pottery. A fine covered jar (Fig. 92), with a Chinese figure-subject and borders of foliage, belongs to the Schlossmuseum in 


\section{OLD DUTCH POTTERY AND TILES}

Berlin; it also bears the mark of Rochus Hoppesteyn. A jug in the Rijksmuseum at Amsterdam (Fig. 93) is of especial importance, as it bears, in addition to the monogram RHS, the mark of a Moor's head; this is the rarely seen factory mark of the pottery of Rochus, at the sign of the "Moor's Head" (het Moriaanshooft). The true Hoppesteyn technique, and the same border designs as on the jar and jug, are shown by an unmarked plate, painted in the same colours, although the red approaches brown in tone.

A group of wares of frequent occurrence, showing altogether the character of the Hoppesteyn productions, consists of vases, jars and dishes painted with a figure-subject in blue, enclosed by ornament in the typical colours with touches of gilding. These pieces, found in various collections, always bear the mark IW in monogram, thus: An example is a large jar (Fig. 94), in the Musées du Cinquan-

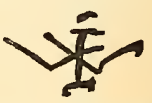
tenaire at Brussels, with a subject perhaps representing a scene in the life of Apollonius of Tyana; the same museum possesses other vases of the same type, all painted in blue between ornamental borders in colours, including a large jar with, amongst other subjects, the death of the children of Niobe. The British Museum possesses a dish with the same kind of colouring, bearing on the rim the arms of the Elector of Brunswick. In the middle is a subject from Roman history, with soldiers building a palisade, painted in blue only. Another dish from the same service, painted with the Rape of the Sabines, is exhibited on loan at the Victoria and Albert Museum. In the Städtisches Museum at Halle is a vase decorated solely with polychrome painting. Two vases in the Rijksmuseum painted with Chinese figures in medallions display the normal colouring and manner of decoration of this class, but on an enamel of chalky white tone.

The IW mark was formerly regarded as the signature of the father of Rochus, Jacob Wemmersz Hoppesteyn (I627-167I). We shall have to look upon it rather as the mark of one of those who worked in the factory of Rochus Hoppesteyn after his time, or possibly together with him, or of a pottery painter who was employed by Rochus and by other proprietors as well. Three different marks are found on earthenware showing in all respects the character of the work of Rochus Hoppesteyn, viz. RHS, IW and AK. Havard saw in these wares a consecutive series of productions of a single factory, that of the "Old Moor's Head" (het oude Moriaanshooft), in which, in succession to the father and son, Jacob Wemmersz and Rochus Hoppesteyn, a late owner, Anthonie Kruyswegh, II 6 


\section{HOPPESTEYN, PIJNACKER AND OTHERS}

was able to keep up the old tradition, with flying colours, until after the middle of the eighteenth century. What are the actual facts? As regards the RHS monogram, its occurrence in combination with a negro's head proves that it may be regarded as in very truth the mark of Rochus Hoppesteyn. The mark IW, on the other hand, is even less to be attributed to his father, Jacob Wemmersz, than AK to Anthonie Kruyswegh. In explanation of the monogram IW, Havard assumed that the potter in question only adopted the name Hoppesteyn when he came into better circumstances; this assumption, however, is entirely at variance with what we learn from the written documents, in view of the fact that in various deeds this man is always referred to by the name Hoppesteyn. He is therefore not likely to have signed his productions with the initials of his Christian names only. But there is other evidence. The large vase in the Städtisches Museum für Kunst und Gewerbe at Halle, bearing the IW mark, with a cover added at the Thuringian faience factory of Dorotheental, near Arnstadt, shows a design of a party drinking tea which is unthinkable in the lifetime of Jacob Wemmersz Hoppesteyn $(1627-167 I)$; for we find in it a detail of costume, the high cap worn by ladies, known as a fontange, which came into fashion at the French court only about 1680, and first occurs in Holland in prints of about 1700 , appearing on earthenware even as late as 1727 .

As regards the AK mark, Havard, undisturbed by the fact that he distributed wares of precisely similar character over a period of about a century, argued as follows : One of the owners of the "Old Moor's Head" pottery was named Kruyswegh; he occurs without Christian name on the list of 1759 , but in certain deeds we read the name Anthonie Kruyswegh. Mr. A. H. H. van der Burgh, however, informs us, on the authority of various deeds, that the Kruyswegh who was the owner of the "Moor's Head" factory was named Jacobus; Anthonie would seem to have been a brother of Jacobus and a wine-merchant.

If we now turn our attention solely to the character of the wares bearing the three different marks, RHS, IW and AK, we shall be obliged to consider them all as work made in the lifetime of Rochus Hoppesteyn and later, showing the same technical methods and painted with a common type of ornament. It will therefore be best to speak of the "Hoppesteyn group," or of wares in the Hoppesteyn style. Certainly these wares are not the work of early, middle and late periods of a factory that flourished for a hundred years, and continuously turned out wares of one single 


\section{OLD DUTCH POTTERY AND TILES}

type of decoration and technique. That was a thing unheard of in the Delft pottery industry.

Before leaving the Hoppesteyn group of wares we must refer to a jug in the Rijksmuseum displaying all their characteristics, with decoration wholly carried out in pigments fired with the enamel-blue, brown, yellow and green; we have here perhaps an example of the grand feu technique employed at this factory, which may be said to have turned out some of the best work known to come from Delft. In connection with all these carefully executed wares we may mention the name of Gijsbert Verhaast, already discussed above, who worked at the Hoppesteyn factory; we do not, however, know whether he was, in fact, the painter of them.

The earthenware of the factory of Adriaen Pijnacker, marked with the monogram APK, belongs to the best known of all classes of delft. It was obviously intended to imitate a definite type of Japanese porcelain, the Imari ware of the Arita kilns, but the preponderance of bright red as compared with blue and gold indicates a modification of the motives of decoration. This has given to the earthenware a character quite its own, somewhat strengthened by the fact that the palette is completed by other colours, such as green, yellow and occasionally a small proportion of black and more delicate tints, like pink and grey. The character of the work of Pijnacker is shared by many unmarked pieces, and also by the wares with the monogram AR; these letters are usually explained as the mark of Augustijn Reijgens. This potter, however, worked about I66o, and the pieces marked AR are certainly of later date. They all show, in addition to red, blue and gold, green and occasionally yellow.

As specimens of the factory of Adriaen Pijnacker in the Rijksmuseum we may name two large jars with flat cover and two with a knob on the cover; various plates and dishes, such as that illustrated in Fig. 96, painted with figures or a vase of flowers and an ornamental border, some with green, some without; a finely painted cruet-stand with bottles for oil and vinegar (Fig. Ior), a small bowl with ribs coloured alternately blue and gold, and two tea-caddies with screw covers. The museum also possesses a wash-basin with its accompanying ewer (Fig. 95, a and b), articles which rarely survive together unbroken. Amongst various jugs is one decorated with a musician in European costume of the time of Louis XIV amid Japanese flowering sprays. The Salting Collection in the Victoria and Albert Museum includes several fine specimens of Pijnacker's work. 


\section{HOPPESTEYN, PIJNACKER AND OTHERS}

We now come to the pieces with European subjects or heraldry enclosed by an ornamental border, painted with the same colours as those named above. A good example is a plate in the Clainpanain Collection at Lille (Fig. 98), with the arms of Louis Alexandre de Bourbon, comte de Toulouse, as Admiral of France, painted in red, blue, gold and black, with touches of green. A plate in the Musée des Arts Décoratifs in Paris (Fig. 97) is decorated in dark blue, red, turquoise-blue and gold with the royal arms of the Hanoverian Kings of Great Britain and Ireland, as borne from the accession of George I in I7I4 until the end of the year I800. Another, in the Gemeentemuseum at The Hague (Fig. 99), bears in the centre the arms of Frederick the Great, and on the rim the black and red eagles of Prussia and Brandenburg alternately, separated by the royal monogram; the whole is painted in blue, red, green, purple, black and gold. Even more extensive is the palette shown by a large dish in the Rijksmuseum (Fig. I02) with the subject of Europa and the Bull, after a print by Goltzius, enclosed by a decorative border on the rim. From the colours-red, blue, green, yellow, black, pink, lilac, grey and gold-we are led to regard this rare dish as a late production of the factory of Pijnacker, though, like the armorial pieces just mentioned, it is unmarked.

A place apart is occupied by wares in which the green is so markedly predominant and the other colours, with the exception of red, are so sparingly applied, that the intention seems to have been to imitate a fine piece of Chinese famille verte. A covered jug (Fig. 100) in the Gemeentemuseum at The Hague is a fine example of this class of Pijnacker's work, in which, be it noted, all the pigments are fired at a second operation in the muffle-kiln.

The mark AR appears on several pieces in the Rijksmuseum. In most of these the enamel is of less fine quality than in the work of the Pijnacker factory. Many specimens with the Pijnacker technique bear no mark. We shall make no attempt to assign them to a particular factory, as other factories may perhaps have made this class of ware, just as Pijnacker himself also produced both blue-and-white and polychrome ware of the grand feu. It is quite possible even that specimens marked APK may comprise imitations of Pijnacker's work made in other factories. There are many such pieces with very fine painting in the Rijksmuseum, amongst them a dozen plates with a small landscape surrounded by swags of flowers within a border, noteworthy as a complete set, and a small figure of the spinario, a variant of the well-known antique, which 


\section{OLD DUTCH POTTERY AND TILES}

is incidentally another proof that modelling was not the strong point with the potters of Delft. Sometimes we find yellow in addition to red, blue, green and gold. Certain small plates with the arms of Hoekke, of which there are specimens both in the Rijksmuseum and in the Clainpanain Collection at Lille, show also pink and black. This extensive palette makes it unlikely that the date introduced on these plates beneath the shield, I7I9, is to be taken as that of their production; they show the influence of the Chinese famille rose, with which the Delft potters cannot have been acquainted until some years after the date in question.

A miniature set of five jars and beakers in the Rijksmuseum (Fig. I06) wears a different character from the work of Pijnacker on account of its bluish white enamel, but shows in other respects the same technique and the same colours. The same is true of a small pair of shoes, marked AB. Other pieces of the Pijnacker group show clearly the influence of Japanese porcelain. 
THE MUFFLE-KILN. THE INFLUENCE OF PORCELAIN TECHNIQUE 



\section{Chapter XVII}

\section{THE MUFFLE-KILN. THE INFLUENCE OF PORCELAIN TECHNIQUE}

As we have seen, Pijnacker and Hoppesteyn made use of a second firing, at a lower temperature, in order to introduce on their earthenware more delicate colours and gilding, and in this manner to imitate Chinese and Japanese porcelain. In the course of the eighteenth century the colours of Chinese porcelain became more refined, and the so-called famille verte, and especially the famille rose, porcelain made their way to Europe; at the same time porcelain began to be made in Europe itself. These developments pointed the direction in which the Delft potters were bound to follow. It was essential that they should have an extensive palette at their command. In porcelain painting, in which blue and copper-red were practically the only colours that could be fired with the glaze (the temperature being too high for other pigments), the mufflekiln technique came into use as a matter of course. In this manner the porcelain painter was able to use whatever colours he wished. His palette was almost unlimited. At Delft the potters were seized with the desire to copy this Chinese and European porcelain (and what did they not imitate!), and the way first pointed out by Pijnacker and Hoppesteyn was now pursued. The practice of firing the blue only, of which now there was less need, in the high-temperature kiln was given up, and, with the definite object of simulating porcelain, earthenware was made, which was painted entirely in overglaze pigments fired in the muffle-kiln. The effect was quite different on the colours themselves, including blue, which, when fired in the muffle-kiln, is always lighter and somewhat purplish in tone. Technically this class of ware is of less significance than that in which all the colours are fired at a high temperature, although some pleasure is certainly afforded by the soft, delicate colours, often applied with great care to the fine white enamel. It is a curious fact that not a single one of the many specimens of this type in the Rijksmuseum bears a date. Only in one case is there a signature; in another there is a mark known to us from its occurrence amongst those registered with the authorities by the potters in 1764 . 


\section{OLD DUTCH POTTERY AND TILES}

Here and there also an unknown mark is found, that is all. It is difficult to guess at the reason for this. Most of the muffle-decorated wares must have been made after the middle of the eighteenth century. For other classes of Delft ware also we have few data of this period, but it is certainly singular that marks are almost entirely lacking on pieces in other respects so carefully finished, seeing that in 1764 the potters were obliged to report their marks to the authorities.

There are two points of contact by which wares of this class, with painting in overglaze muffle pigments, link themselves on to the Pijnacker group. The first is of a technical nature; even here now and then there is to be seen a narrow border in blue fired with the enamel, placing such pieces technically on an identical footing with the work of the Pijnacker factory. The second point is that the small jug with the APK mark, in the museum at The Hague, already described, exemplifies the occurrence at this early period of decoration wholly painted in overglaze pigments on wares of the Pijnacker group, and that two dishes in the Rijksmuseum, similarly painted to imitate Chinese porcelain (Fig. I04), bear the letters $\mathrm{AR}$, which mark is known to us also on pieces of the same group. These dishes, on which is depicted a mounted lady accompanied by four servingmen on foot, enclosed within a narrow ornamental border, are almost exact copies of what is called famille verte; the palette shows precisely the colours of that class of Chinese porcelain. The same colours, but a little brighter, are seen on a tray (Fig. 107) painted with Chinese figures in a garden. The translation into Dutch of the design, certainly not intended, gives it a somewhat odd effect.

The purplish pink of the famille rose class of porcelain appears at this stage to have become the fashionable colour at Delft, whilst the blue is always the peculiar pale violet-blue to which we have already referred. A pair of very charming plates in the Rijksmuseum (Fig. I05), decorated with sprays of flowers, birds and, in the background, two figures, would call to mind famille rose porcelain were it not for the intrusion of too much brownish red and gold amongst the colours; they are another case of the quite individual manner in which the Delft potters modified Oriental themes. Another noteworthy specimen of muffle-painted ware in the same museum is a puzzle-jug marked $S$, beautifully painted with Chinese figures. We pass now to a dish in the Musée des Arts Décoratifs in Paris (Fig. I03), on which is a painting in red, green, yellow, grey, blue, purple and gold of three figures in a garden, a lady and gentleman dancing to the music of a hurdy-gurdy played by the third. Several 


\section{THE INFLUENCE OF PORCELAIN TECHNIQUE}

small plates in the Rijksmuseum, with coloured bouquets in a vase or a basket, include one which bears, in addition to baskets of flowers in reserved compartments, small Chinese subjects; with its red painting on a gold ground this piece is marked by a character of its own more reminiscent of Chinese porcelain.

We find also tiles distinguished by this technique and colouring, decorated with a basket of flowers in a medallion and ornamental motives in the angles, just as on the tiles of the earlier type. Examples are in the possession of the Lambert van Meerten Museum at Delft (Fig. I08).

A set of three vases in the Rijksmuseum are of a peculiar twisted shape with the head of a Chinese lady to form the knob of the cover; they are important not only as imitations of the so-called "Harlequin porcelain " of China, but also chiefly because their mark has been identified and thus enables us to give an approximate date to the set. The letters $\mathrm{A}$ and IH which they bear occur on the list of marks registered with the authorities in 1764 in pursuance of the bye-law already mentioned; they are there given as the mark of Jacobus Halder, who succeeded Jan Theunis Dextra about that year as proprietor of the "Greek A" pottery (de Grieksche A). This set of vases cannot therefore have been made before 1764 .

We have to deal lastly with the earthenware in which the Delft potters borrowed both form and decoration from European porcelain, especially that of Meissen. A good example of this type is a wall-cistern with a wash-hand basin in the Rijksmuseum (Fig. IIO); they are decorated in various colours with landscapes surrounded by very finely painted floral borders. Here again we have the usual pigments, including especially a beautiful pale violet, heightened with gilding, whilst here and there an effective groundwork is obtained by alternations of blue stippling with small red coils; the colours, moreover, are applied in varying shades. A large soup-tureen in the same museum is decorated with detached flowers, in addition to landscapes; one of these is identical with that on a fine dish in the Victoria and Albert Museum in London (Fig. I09). Amongst various other pieces of the same class at Amsterdam is a small basket with an incised $F$, perhaps the mark of the workman (vormer) who shaped the article in the mould. A more subdued colouring is shown by a pair of sauce-boats and two butter-dishes, all in the same place, each of which bears the mark VA; they are decorated with small landscapes in which a deep violet is the prevailing tone.

The Rijksmuseum possesses a large tile-picture with a vintage scene 


\section{OLD DUTCH POTTERY AND TILES}

painted with the same palette of colours. It is marked $M: V: K u y k$, I: Baen, a Delft 5.29.I744. We have already met with the signature of this painter on a blue-and-white plate dated 1742 in the Tenbosch Collection. Late as it is, this picture is not devoid of a certain liveliness of effect, thanks to a fresh red and green in the painting. It is exhibited in the museum in a position in which it is instructive to compare it, with its muffle pigments, with the tile-pictures already mentioned, fine examples of the earthenware of the grand feu, which was, above all, the great glory of the potters of Delft. 
THE RED TEAPOTS OF DELFT 



\section{Chapter XVIII}

\section{THE RED TEAPOTS OF DELFT}

In addition to enamelled earthenware, unglazed red earthenware teapots were also made at Delft in imitation of the Chinese stoneware of Yi-hsing Hsien. The Victoria and Albert Museum possesses a specimen with the mark of Ary de Milde (an oval stamp with his name and a figure of a running fox); it is decorated with small applied rosettes and bud-like ornaments. We may name also two examples from the collection of the Rijksmuseum; one of these (Fig. III) bears the same mark of De Milde, the other that of Jacobus de Caluwe.

Whether De Milde really made red stoneware or only teapots of fine red earthenware like that in the Rijksmuseum is a question which has again come to the fore in recent years. If the first claim is true, Ary de Milde played a very important rôle in the development of the potter's craft, since he may be regarded as the discoverer, as far as Europe is concerned, of the red stoneware which was also called " red porcelain," so named because, in common with porcelain properly so-termed, it consists of a fusible and an infusible substance combined under a very high temperature (higher, that is to say, than earthenware could support) into a homogeneous stone-like material. Such red stoneware is, in any case, regarded as the forerunner of white porcelain. However this may be, to Ary de Milde belongs without doubt the merit of having anticipated Böttger, the inventor of European hard-paste porcelain and founder of the Meissen factory, in the production of red teapots of the Chinese type. For as early as 1680 he registered with the authorities at Delft the mark which was to protect him against counterfeit imitations of his teapots; it is to be noted that he is described as Mr. Theepotbacker ("Master Teapot-maker"). From the fact that such protection was necessary, and that several makers registered their mark at the same time with De Milde, it appears that the manufacture of teapots of this kind was an important industry at Delft. A very similar manufacture was being carried on about this time by two Dutch potters, John Philip and David Elers, at Bradwell Wood in Staffordshire.

The manufacture of these wares, in Holland and England alike, was 


\section{OLD DUTCH POTTERY AND TILES}

occasioned by the introduction from China of tea-drinking. In China, teapots of boccaro ware are believed to be more suitable for making tea than those in any other material. At first they were imported with the tea itself into Europe, but it is not surprising that European potters soon found a source of profit in obviating, by the production of imitative wares, the risk and expense of transport from the East. 
THE DECLINE 



\section{Chapter XIX}

\section{THE DECLINE}

We have now seen what was produced by the Delft potters at their prime. We have also noticed a few products of the period of decline, earthenware having still been produced in large quantity at that time. But there was an end even to this stage of the industry. Paape writes in 1794 that not more than ten potteries were surviving at that date, and that these ten "were nearly all in a state approaching extinction." What was the reason for this? Every kind of art has its rise, its time of prosperity and its decline, but in this instance all kinds of external causes were contributory. One of the chief of these was certainly the invention and distribution in the eighteenth century of European porcelain. As a result of this, delft became steadily degraded to a less sought-after and therefore less costly commodity. In spite of this it was still being produced all the time in great quantities. A more important agent in the total ruin of the Delft ware industry was the establishment in England of factories for fine earthenwares such as "Queen's ware," "cream-coloured ware," "salt-glazed ware" and the like, a new invention generally known in Holland as Engels steen. A cheap and much more durable material, a species of hard, non-porous earthenware such as this was, taking up a position, as it were, between porcelain and delft, was bound to drive delft off the market. And just as in a former age delft had banished pewter as an article of household use-as may be learned from the inscription on a plate in the Rijksmuseum ${ }^{1}$-so in turn it was itself driven out by the English steen. The results of this change are seen in the numerous plates and other articles of English earthenware with Dutch inscriptions. ${ }^{2}$ A Delft ware panel in the Rijksmuseum,

1 Tinne borden sijn niet goet, Om dat men se schuuren moet;

Maar een bord van porceleijn [i.e. delft]

Word van 't wassen wit en rein;

Daarom set vrij op den dis

Een bord dat wel geschilderd is.
Pewter platters are no good, You must scour them after food ;

But a plate of porcelain Comes with washing white and clean, Then on the table set, I pray, A plate of delft with painting gay.

2 Examples are the pieces, such as a soup-tureen in the Victoria and Albert Museum, with portraits of William V, Prince of Orange, and his wife Frederica Wilhelmina, and the 


\section{OLD DUTCH POTTERY AND TILES}

intended as an advertisement board, is eloquent of this state of affairs. We read there, amongst other information, that a single shop offered for sale " all kinds of Delft and English earthenware" (allerhande soorten van Delfts en Engels aardewerk).

From a decorative point of view the delft of the late eighteenth century has very little significance. When a foreign production with very practical qualities drove out of existence also the "useful" ware made at Delft, it was all over with the Delft potteries. To the class of " useful" wares belongs especially what is known as "white delft," much of which has been destroyed. This well-known class of delft, however, includes much that was intended for decoration but was never painted.

At the beginning of the nineteenth century the still surviving potteries ended their days as tile-factories. The nature of the ornamental wares still made at that time may be seen from a set of vases for the sideboard in the Rijksmuseum, from the factory of Jan van Putten. We should have preferred not to draw attention to these productions of a moribund industry, if it were not necessary for the completeness of our survey of Delft earthenware.

sets of plates crudely decorated with paintings illustrating the Sacraments, executed in Holland; on some of these the mark of the Staffordshire potter Turner is impressed. Of better quality are pieces (such as a tureen of Wedgwood's "Queen's ware," inscribed De Vriendschap and dated $\mathrm{I804}$, in the Schreiber Collection at the Victoria and Albert Museum) made and also decorated in England specially for export to the Netherlands. 
THE PLACE OF DUTCH EARTHENWARE IN THE HISTORY OF EUROPEAN POTTERY 



\section{Chapter XX}

\section{THE PLACE OF DUTCH EARTHENWARE IN THE HISTORY OF EUROPEAN POTTERY}

To students and collectors of a former generation Dutch earthenware was synonymous with "Delft," a product of craftsmanship which through some unexplained miracle began life as an adult about the middle of the seventeenth century, and came to the end of its brilliant career some hundred and fifty years later. How this phenomenon came to pass was to some a matter of no concern, whilst to others it was a mystery too difficult to solve. We now know that this was a very inadequate view of the matter. Researches of the last two decades have enabled us to assign to Dutch pottery its appropriate niche in the fabric of ceramic evolution, and to give to it the position of honour to which, on technical, artistic and historical grounds alike, it is justly entitled.

The traditions in the potter's art which were first taken up from Eastern peoples by the Italians were carried on, as we have seen, by the Dutch and handed by them to other nations of the North, the English amongst them. As in the main it is true to say that Italy was the link between the lands of Islam and the rest of Europe, so, as we now know, the Low Countries in turn connected Italy with England, Germany and Scandinavia. If the actual spot at which contact with the maiolica of Italy can be located proves to be Antwerp, and therefore not in the Netherlands as defined in the present day, it was in Holland that the great northern development of tin-enamelled earthenware took place.

With the sundering of the Low Countries which followed the religious wars of the sixteenth century, when Protestant Holland broke away from the Catholic Flemish provinces, Antwerp fell into the background as a centre of ceramic production. The wares of the maiolica class made in Flanders after the close of the sixteenth century are of minor importance, and without effect on the spread of this type of ceramic technique in other countries. It was the great outburst of production in Holland during the times of her prosperity in the seventeenth century which flooded the civilised world with " delft," and spurred on the potters of other lands to emulate the successes of their Dutch fellow-craftsmen. 


\section{OLD DUTCH POTTERY AND TILES}

The origins of enamelled earthenware in England are still veiled in obscurity, but they may be fixed with certainty many years before the word "delft" was added to the English language. Everything tends to show that Dutch tiles, and probably Dutch pottery as well, were being exported over the North Sea before the end of the sixteenth century. A mug of 1618 is the earliest piece certainly English in origin, of ascertainable date, of tin-enamelled earthenware (which in this connection may better be termed "maiolica" than "delft"). That such wares were made by foreign potters, or by Englishmen under the direction of foreigners, may be taken as almost certain, and it seems that the craftsmen who introduced the industry into England were Netherlanders rather than, as has lately been suggested, from Italy. ${ }^{1}$ Most of the earlier English maiolica with painted decoration, whether from Bristol or from the riverside potteries in the neighbourhood of London, shows a decided likeness to the Dutch wares of the same class. Here, as in Holland, polychrome decoration came before blue-and-white. It was only as the seventeenth century advanced that distinctively English types were developed, such as the tulip dishes of Brislington and Bristol, and the blue-and-white winebottles of Lambeth. There was, however, no complete emancipation from Dutch influences, and, until the time when English delft shared the fate of its Dutch congeners, there is no lack of evidence to show that the English potters had to compete with a large trade in pottery and tiles alike from Holland. England was in the seventeenth century more remote than its neighbours from contact with China; consequently polychrome wares of the early type continued there in demand longer than in Holland. But England, too, fell at last under the sway of the vogue of blue-and-white, and to meet its claims there must have been a large importation of Dutch delft. We know also that Dutch potters settled in England to compete with this import trade; in 1671 one John Ariens van Hamme took out a patent for the manufacture at Lambeth of "tiles and porcelain (i.e. delft) after the way practised in Holland." The vases at Hampton Court described on a previous page, and many a production of the Dutch plateelbakkers and tile-makers remaining in old English houses, speak of a fashion which was given a new impetus when in 1689 a Prince of Orange was called to the throne of the Stuarts.

1 Miss Eliza Meteyard (Life of Josiahl Wedgwood, London, I865, vol. i, p. I09) already suggested that the importation of what she termed "Dutch majolica" had a powerful effect as early as the reign of Queen Elizabeth on the development of the pottery manufacture in England. 


\section{THE PLACE OF DUTCH EARTHENWARE}

The English delft wares of the eighteenth century, of Bristol in particular, are often not easy to distinguish from their rivals, especially those made for table use and the similar types known as boerendelftsch. But certain forms seem to be peculiar to England-the two-handled posset-pot, for instance, with cover and sucking-spout-whilst subtle differences in shape or in quality of enamel will usually decide the question. Lettering of inscriptions is sometimes a guide; the triangular arrangement of the initials of a maker, or perhaps owner, sometimes to be seen on the base or back of a piece, appears to be unknown in delft ware of Dutch manufacture.

In Germany events were taking a similar course. In the south, it is true, the making of maiolica was introduced early in the sixteenth century direct from Italy, but its production was small and spasmodic and hardly rose above the level of a peasant craft. In the north also, at Hamburg, the manufacture had begun in the early years of the seventeenth century; its origin is obscure, but may well have been due to potters from the Netherlands. It was only after the end of the Thirty Years' War that tin-enamelled earthenware began to be made on a large scale in Germany, and it was by Dutchmen that the industry was introduced. At Hanau, near Frankfort, in I66r, at Potsdam, where Frederick William, the Great Elector, decided in 1678 to establish a factory of Delftisch Porzellain, at Cassel in 1699 , potteries were founded by immigrants from Holland. From these places in turn men of enterprise went forth, through the length and breadth of Germany, to set up potteries for making earthenware in which the influence of Delft is again and again apparent. From Germany the industry spread to the North. In I722 a Holsteiner named Wolff established at Copenhagen a firm with the title Delfs Porselins eller Hollandsch Steentöys Fabrique; from Copenhagen the same potter passed on to Stockholm, where he founded the still-existing factory of Rörstrand.

These German and Scandinavian delft wares are, as a rule, readily distinguishable from their progenitors; but in the earlier wares especially, with painting in blue alone or in blue with manganese-purple, there is sometimes a marked similarity to the Dutch delft of the Hoppesteyn and "AK" types. The German delft is, however, generally heavier and more massively built ; its painting lacks the delicacy of touch shown by the artists of the town on the Schie.

If Delft ware was, technically speaking, as we have seen, the offspring of Italian maiolica, it was brought to birth and fostered by the social 


\section{OLD DUTCH POTTERY AND TILES}

conditions of the time in which it came into being. The vital struggle with Spain in the sixteenth century, so far from enervating or exhausting the Dutch people, had sharpened their wits and given new power to their energies. Having won for themselves political and religious freedom, they turned their efforts to commerce and culture. Trade with the East brought wealth and a wider outlook on life. Wealth was expended in the increase of comfort and the patronage of art. The Dutch school of painters was the major result, but in the minor arts such as that of the potter the effects of prosperity were no less apparent. The Van Eenhoorns, Hoppesteyn and Frijtom hold a position amongst the great men of their craft hardly less honourable than that of Rembrandt, Hals and Vermeer amongst painters. The pottery decorators may not have been great or original artists-indeed, they drew inspiration for their designs largely from engravings; but they were fine colourists and showed wonderful skill in adaptation and in the handling of the brush. How the pottery industry came to be concentrated in the town of Delft is a question which calls for an answer. The explanation is doubtless to be found in the fact that in the seventeenth century the brewing industry, to which Delft had formerly owed its prosperity, fell into decline, and the buildings left vacant in consequence offered suitable sites for the establishment of potteries. The town was, moreover, well placed, with its port at Delfshaven, for holding the patronage of the wealthy and influential class in Holland, and for the distribution of its wares in other lands. Traditions of craftsmanship accumulated, and Delft rose to a position as a busy focus of the potter's craft which finds its only parallels in the "Kannebäckerländchen" of the Westerwald in Nassau, and in "the Potteries" of Staffordshire.

By the irony of events it was from seed sown by two Dutchmen that a tree sprang up which was to overshadow and at last to take the life from the once so flourishing growth of Delft. The heavy stonewares of Nassau and the Rhineland were no serious rival; they were not of a nature to meet the needs of the new social order. The cost and risks of thousands of miles of transit by sea were an insurance against competition from Chinese porcelain. Nor was great danger to be apprehended from the tin-enamelled wares made in English potteries or in the many factories established directly or indirectly as offshoots from Delft in Germany; they were always markedly inferior in quality. The fate of Delft was decided when, about I69o, the brothers John Philip and David Elers began at Bradwell Wood, near Burslem, with a secrecy they were 


\section{THE PLACE OF DUTCH EARTHENWARE}

unable to keep up, the manufacture of red teapots akin to those of De Caluwe and De Milde. From that moment the Staffordshire potters advanced from supplying crude slip-decorated posset-pots and platters for the markets of the neighbourhood towards the production in mass of articles for table use in a fine and eminently serviceable earthenware which found buyers in all civilised countries. The wares which had been the pride of Holland, possessing in their soft, pleasant enamel and cheerful, harmonious colouring a charm unequalled even by Chinese porcelain, went under before the output of an industry to which Dutch craftsmen had given its start. 


\section{APPENDIX}

LIST OF MARKS OF DELFT POTTERS IN ${ }_{17} 64$ 



\section{APPENDIX}

\section{LIST OF MARKS OF DELFT POTTERS IN I 764}

The marks in the following list were registered with the authorities in pursuance of a by-law against the counterfeiting of tiles; the factory signs were also recorded. As each potter made his declaration on a separate page of a book, and the marks could not be traced from the drawings in this document, we have taken them from Obreen's Archief voor Nederlandsche Kunstgeschiedenis, I.

AK

A. Kiell, factory of the "White Star" (de Witte Ster).

1DI. Jacobus de Milde; the "Peacock" (de Paauw).

ID A Johannes den Appel; the "Golden Boat" (de Vergulde Boot).

DDD or Dirk van der Does; the "Rose" (de Roos).

(1)

Lambertus Sanderus; the "Claw" (de Klaauw)."

10

Willem van der Does; the "Three Bells" (de Drie Klokken). He also used three bells as his mark.

$\frac{\mathbb{A}}{\operatorname{ITD}}$

J. T. Dextra ; the "Greek A" (de Grieksche A).

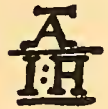

Jacobus Halder, Adr. Zn ; the "Greek A" (de Grieksche A).

Hendrik van Hoorn had as mark the sign of his factory, the "Three Porcelain Ash-barrels" (de drie Porceleijne Astonnen).

MP. Pieter Paree; the "Metal Pot" (de Metale Pot).

1 The form of the mark found on the specimen in the Rijksmuseum is thus 


\section{APPENDIX}

WVDB

R.

站.

Elisabeth Elling, wed, van den Briel; the "Fortune" ('t Fortuijn).

Petrus van Marum; the "Roman" (de Romeijn).

Jan van den Kloot Jansz.; the "Roman" (de Romeijn).

$G: B: S$.

Wed. Jan van der Hagen; the "Young Moor's Head" ('t jonge Moriaanshooft).

Gertruij Verstelle; the "Old Moor's Head" ('t oude Moriaanshooft).

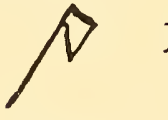

Justus Brouwer; the "Porcelain Axe" (de Porceleijne Bijl).

TR Hugo Brouwer; the "Three Porcelain Flasks" (de drie 11 Porceleijne Flessies).

\section{HVMD}

Hendrik van Middeldijk; the "Heart" ('t Hart).

AP Anth. Pennis; the "Two Little Ships" (de twee Scheepjes).

TDi.j Johannes van Duijn; the "Porcelain Dish" (de Porceleijne Schotel).

DeBlompot

P. Verburg; the "Golden Flowerpot" (de Vergulde Blompot).

PD Pieter van Doorne; the "Porcelain Bottle" (de Porceleijne Fles).

DSK Tomas Spaandonck; the "Double Tankard" (de Dubbelde Schenkkan).

$\angle P K$ Wed. Gerardus Brouwer; the "Ewer" (de Lampetkan). W: V: B Willem van Beek; the "Two Salvage Men" (de Twee Wildemans). 


\section{BIBLIOGRAPHY}

Beets, N. Een schotel van Haarlemsch porselein? Oud-Holland, XXXVI (I918), I70. Bluemlein, C. Delft und seine Fayencen. Hamburg, I899.

Boehlau, Joh. Eine Niederhessische Töpferei des I7en Jahrhunderts. Marburg, I 903.

Bremmer, H. P. Delftsch aardewerk in het Rijksmuseum te Amsterdam. I907.

Bremmer, H. P. Delftsch aardewerk. Amsterdam, no date.

Bremmer, H. P. Delftsch aardewerk, Een practisch aesthetische studie. Amsterdam, I908.

Brinckmann, J. Das Hamburgische Museum für Kunst und Gewerbe, Ein Führer durch die Sammlungen. Leipzig, I894.

Burgh, A. H. H. van der. Delftsche roode theepotten. Oud-Holland, XIX (1901), 99.

Burgh, A. H. H. van der. Aanteekeningen betreffende de oudste Delftsche plateelbakkers. Oud-Holland, XXI (1903), 22.

Chaffers, The New, Marks and Monograms on pottery and porcelain. London, I9I2.

Deneken, F. Die Sammlung niederrheinischer Tonarbeiten, Handbuch des Kaiser WilhelmMuseums in Crefeld. I9I4.

Forrer, R. Geschichte der europäischen Fliesenkeramik vom Mittelalter bis zum Jahre I 900.

Gallois, H. Over Rotterdamsche tegels. Mededeelingen Dienst K. en W., The Hague, I, I8.

Gelder, H. E. van. Een Haagsche Fabriek van "Delftsch Aardewerk." Brediusbundel, Amsterdam, I9I 5, p. 37 .

Geus, C. de. Tegels en tegeltableaux. Oude kunst, I9I9 en I920.

Geus, C. de. The history of the Dutch wall tile as exemplified in the Vis Collection. The Connoisseur (I921).

Havard, H. Catalogue chronologique et raisonné des faiences de Delft composant la collection de M. John F. Loudon. The Hague, 1877.

Havard, H. La céramique hollandaise, Histoire des fayences de Delft, etc. Amsterdam, 1909. 2 Vols.

Hoynck van Papendrecht, A. Oude Noord-Nederlandsche maiolika in het Museum van Oudheden te Rotterdam. Reprinted from Eigen Haard, 5 February, 19I6, nr. 6.

Hoynck van Papendrecht, A. De Rotterdamsche plateel- en tegelbakkers. Rotterdam, I 920.

Knochenhauer, Paul. Niederländische Fliesen-Ornamente. Berlin, no date.

Knowles, W. Pitcairn. Dutch pottery and porcelain. London (1904).

Laurent, M. Guido di Savino and the earthenware of Antwerp. Burlington Magazine, XLI (I922), p. 288.

Mander, Karel van. Het schilderboeck, 1604. Het leven van Hendrick Cornelissen Vroom.

Neurdenburg, Elisabeth. Oud Aardewerk, toegelicht aan de verzamelingen in het Nederlandsch Museum voor Geschiedenis en Kunst te Amsterdam. 2nd edition, I920.

Neurdenburg, Elisabeth. Oude Noord-Nederlandsche Majolika. Bulletin van den Nederlandschen Oudheidkundigen Bond, 1913, p. 228.

Neurdenburg, Elisabeth. De plateelbakkersfamilie Hoppesteyn. Brediusbundel, Amsterdam, I9I 5, p. I9I.

Neurdenburg, Elisabeth. De Verzameling John F. Loudon. Oude Kunst, 1916, pp. 339, 383, 4I I and 19I7, p. I. De techniek van het Oud Delftsch aardewerk. Ibid., I9I7, 


\section{BIBLIOGRAPHY}

p. III. Oud Delftsch aardewerk in het Nederlandsch Museum te Amsterdam. Ibid., I $917, \mathrm{Pp} .149, \mathrm{I} 8 \mathrm{I}$ and 197.

Neurdenburg, Elisabeth. De Verzameling John F. Loudon. Onze Kunst, 1916, p. 72.

Neurdenburg, Elisabeth. De twee majolica-tegels uit het Refugium van de Abdij van Aduard in de stad Groningen. Jaarboek van den Nederlandschen Oudheidkundigen Bond, I922, p. I70.

Neurdenburg, Elisabeth. Twee Rotterdamsche tegeltableaux. Rotterdamsch Jaarboekje, 1923, p. 62.

Notten, M. van. Aanwinsten Nederlandsch Museum, Bulletin van den Nederlandschen Oudheidkundigen Bond, I908, p. 204 and $191 \mathrm{I}$, p. 20.

Obreen, Fr. D. O. Archief voor Nederlandsche Kunstgeschiedenis, I, I, Het Sint LucasGild te Delft; I, 128, Merken van Delftsche Plateelbakkers; VI, 4, Necrologium van Delftsche Kunstenaars, opgemaakt uit de begrafenisboeken in het Archief van Delft, medegedeeld door Mr. J. Soutendam; VII, 28I, Inventaris van eene tegel- en plateelbakkerij in 1627 , medegedeeld door den Heer P. Haverkorn van Rijsewijk; VII, 337, Overeenkomst aangegaan tusschen de Delftsche plateelbakkers op $30 \mathrm{Jan}$., I778, medegedeeld door den Heer A. A. Vorsterman van Oyen.

Ottema, N. Bijdrage tot de kennis van het aardewerk in de Noordelijke Nederlanden in gebruik in het laatste kwart van de I6de eeuw. Reprint from Vrije Fries, XXVI (1918); also Oude Kunst, III (I9I8), pp. 23I, 255, and Verslag Friesch Genootschap, 1918.

Ottema, N. Friesche Majolika, een vergeten hoofdstuk uit de geschiedenis van het Nederlandsch aardewerk. Vrije Fries, XXVII (1920). Jaarverslag Friesch Genootschap, I 918.

Paape, Gerrit. De Plateelbakker of Delftsch aardewerkmaaker. Dordrecht, I794.

Peelen, Ida C. E. Catalogus van de verzameling Nederlandsch aardewerk. Gemeentemuseum, The Hague, I9I7.

Peelen, Ida C. E. Aanwinsten van het Museum Huis Lambert van Meerten te Delft. Bulletin van den Nederlandschen Oudheidkundigen Bond, r 920, p. I 96.

Peelen, Ida C. E. Tegeltableaux uit het midden der XVIIde eeuw. Bulletin van den Nederlandschen Oudheidkundigen Bond, 1920, p. 215.

Pit, A. Oude Noord-Nederlandsche majolika. Oud-Holland, XXVII, I33.

Pit, A. Aanwinsten Nederlandsch Museum. Bulletin van den Nederlandschen Oudheidkundigen Bond, I, 3 ; II, 68, 234 ; III, 262 ; VI, I2.

Pit, A. De apothekerspot of albarello. Het Huis Oud en Nieuw, I905, p. I93. Middeneeuwsch aardewerk. Ibid., I906, pp. 6, I6I.

Rackham, B. Early Dutch maiolica and its English kindred. Burlington Magazine, XXXIII (I9I8), P. II6.

Reinhardt, C. Tschirnhaus oder Böttger? Görlitz, I912.

Riesebieter, O. Frühes Delft. Der Cicerone, IX (I9I7), p. 34I.

Schnorr von Carolsfeld, L. Porzellan der europäischen Fabriken des I 8 Jahrhunderts. Berlin, Igr2.

Verschuer, W. F. K. Baron van. Ary de Milde, Mr. Theepotbacker. Amsterdam, I9I6.

Vlielander Hein, F. E. Over wit Delftsch aardewerk. Het Huis Oud en Nieuw, XI (I9I3).

Vogelsang, W. Versierde borden. Het Huis Oud en Nieuw, 1905, p. 65.

Wiersum, E. De laatste Rotterdamsche tegelbakkerij. Rotterdamsch Jaarboekje, and Series, $X$ (I92I), p. I02.

Willemse, A. Over Oud-Limburgsch e.a. aardewerk. Oude Kunst, I9I7, I9I8, I9I9.

Wylde, C. H. Old English drug and unguent pots found in excavations in London. Burlington Magazine, VII (I 905), 76. 
INDEX 



\section{INDEX}

Names with the prefix "van" will be found under "V," not under the initial of their substantive.

A mark, 88, 125, 145

Aalmis, Jan, signature, 52

Aardetrapper, 10

AB mark, 120

Adriaen Ingelsz, 22, 24

Aduard, I7

Admiral of France, arms, II

Adultery, Woman taken in, subject, 84

ADW mark, 84

Aelmis family, 52, 53

AK mark, 60, 69, $7 \mathrm{I}, 75,116$, I I 7, I 39

AK with dot, mark, 98

AK with star, mark, I 45

Albarelli, 25

Alpha factory (see Greek A)

Alpha mark, I 45

Altona merchant, order for tiles by, 52

Amigoni, Jacopo, subject after, 52

Amsterdam, arms of, on jar, 27

Amsterdam, Rijksmuseum, I7 and passim

Amsterdam, tiles from house in, $5^{\text {I }}$

Andriesz, Guido (see Savino)

Antwerp, 22, 24, 37, 42, I 37

AP mark, 146

APK mark, 72, 103, I 18, 124

Apollonius of Tyana, subject, I 6

AR mark, 6I, I I8, II9, I24

Arita potteries, I I 8

Arnhem pottery, 57

Ash-barrels, Three, factory, 85, I04, I I I, I 45

Astonnendrie (see Ash-barrels)

Axe factory, 85

Axe mark, I 07, I I0, I I I, 146

Axe, Porcelain, factory, 86

Barber's basins, 86

Bells, Three, factory, I04, I 45

Berlin, Schlossmuseum, I 5

Bible history, scenes from, ro?

Bijl, de (see Axe)

Birdcages, 87

Birkenhead (sce Cole Collection)

Black ground, Io3

Bleyswijck (see Van Bleyswijck)

Bliksembordjes, 98

Bloempot factory, 52

Blompot, mark, I 46

Blue-and-white, $45,64,75,83$

Blue enamel ground, I04

Boat factory, 83

Boat, Golden, factory, I 45

Boccaro, ware, I 30

Boerendelftsch, 99, I 09, I I 0, I 39
Bolsward pottery, 28, 34, 35, 46

Boot, de, factory (see Boat)

Bottger, 129

Boucher, design after, ro9

Boumeester, Cornelis, 5 I

Bourbon, Louis Alexandre de, I I

Brabant, 54

Bradwell Wood, 129, 140

Brandenburg, arms of, I I9

Breweries at Delft, I 40

Brouwer, Hugo, 86, 146

Brouwer, Justus, I 46

Brouwer, Weduwe, 146

Brislington ware, 138

Bristol delft, $87,104,138$

British arms, I I9

British Museum, 26, 70, 72, 83, 108, I I6

Brunswick, Elector of, arms, I I 6

Brussels, Musées du Cinquantenaire, $35,49,5^{8}, 72$, 87,98 , I 16

Buren, Graefscap van, 5 I

Burslem, I $4^{\circ}$

Buytenwech, Willem, 70

Cachemire decoration, 92

Calendars, 86

Cassel ware, I39

CB mark, 86

CBM mark, 5 I

Céramique hollandaise, Havard's, 59

Chimneypiece tiles, 5 I

China, coast-scene, 72

Chinese designs, 107,108

Chinese porcelain, influence of, $28,58,64,9$ I ; exact copies of, 86

Chinese stoneware, I29

Christ, scenes from life of, 84,86

Cimon and Pera, subject, 26

Cinquantenaire, Musées du (see Brussels)

CIV mark, 49

CL mark, 26

Clainpanain Collection, 58, I03, I04, I07, I I I, I I9, 120

Claw factory, 85 , I I I, I 45

Clays employed at Delft, 9

Cock mark, 57

Cockspurs, 13,37

Colchester, 27

Cole Collection, 70

Cologne, 25, 26, 28

Copenhagen delft factory, I 39

Copenhagen, Kunstindustrimuseum, 75

Copying between factories, 85 


\section{INDEX}

Cream-coloured ware, 133

Crefeld ware, 18

Cris de Paris engravings, 109

D mark, 87, 104, 108

Daniel in lion's den, subject, 84

Dated Delft ware, 70

Dating of tiles, 39

De Caluwe, Jacobus, 129, I4I

Decker, C., engraver, 72

De Hoogh, 33

De Keizer, Aelbrecht, 69, 97

Delfsch Porceleyn, 54

Delfshaven, port, 140

Delft, arms of, 71

Delft, fragments found at, 24,25

Delft, Huis Lambert van Meerten Museum, I I, 26, 40, 5o, 125

Delft, superiority of productions of, 53

Delft, tile-panel in house at, 49

Delft, view at, 72

"Delft," use of term, 57

"Delph," orthography, 83

De Milde, Ary, 129, I 4 I

De Milde, Jacobus, 145

Den Appel, Johannes, I 45

De Ruyter, Michiel, 7 I

Dextra family, 87, 108

Dextra, Jan Theunis, $87,111,125,145$

Dorotheental, II 7

Double Tankard factory, $79,92,93,146$

Downs, battle of, 51

Dresden (see Meissen)

Drie Astonne (see Ash-barrels)

Drie Klokken (see Bells)

Drie Porceleijne Astonnen (see Porcelain Ash-barrels)

Drie Porceleijne Flessies (see Porcelain Flasks)

Drug-vases, $25,85,86,87$

DS, DSK marks, $79,92,93,146$

Dubbelde Schenkkan (see Double Tankard)

Dupuis, Musée, 26, 27

Dutch maiolica, 138

Duysent vreesen, house, 49

DVDD mark, 97, 145

DVK mark, 83

East Indies, export to, 54

Elers, the brothers, 129 , 141

Elijah, subject, 71

Elling, Elisabeth, 146

Enamel, composition of, Io

Engels steen, 133

England, export to, 54, 138

England, royal arms of, 119

English delft, 4, 24, 138

English pottery, importation of, 133

Enkhuizen, view near, 85

Europa and the Bull, subject, 84,110

Evenepoel Collection, 35, 49, 58, 87, 98

Evolution of Dutch ware, 137

Ewer factory, 85, 104, 146

Faenza, 1 1, I7

Famille rose designs, 120, 123, I24

Famille verte designs, 97, 108, $119,123,124$

Fictoor, Louwijs, 79, 91, 92, 103

Figures, Delft, I 10
Flanders, export to, 54

Flemish maiolica, ${ }_{37}$

Flemish tiles, 50

Fles, Porceleijne, factory, 146

Fontange, in delft paintings, 117

Foremen, status of, $6 \mathrm{r}$

Fortune (' $t$ Fortuijn) factory, $85,88,104,146$

Fox mark, 129

France, Admiral of, arms, 119

Frederica Wilhelmina, Princess, 133

Frederick the Great, arms of, I 19

Frederick William, the Great Elector, 139

French faience, imitations of, 104

Friesland, I8, 24, 28, 33, 38, 46, 57

Frijtom (see Van Frijtom)

Fruit, boxes in shape of, Iro

Gaal, inscription, 79

Garnitures of vases, 87,93

Garter, Order of, 71, 110

GBS mark, 146

Geleyersbackere, 22

George I of England, II

German enamelled earthenware, 24, 137

GH mark, 98

GK mark, 69

Glaze, composition of, I I

Golden Boat factory, 145

Golden Flower-pot factory, I 46

Goltzius, Hendrick, subjects after, 84,86 , I I 9

Gouda, pottery, 54

Gouda, stained glass in Groote Kerk, 50

Gouda, tiles from, 50

Grand feu pigments, 91, 107

Grand feu technique, 12, 14

Greek A factory, 85, 87, 1 1 1, 125, 145

Grieksche $A$ (see Greek A)

Groningen, 17

Guido Andries (see Savino, Guido di)

Guild of St. Luke, Delft, 58

GVS mark, 88

H mark, 87

Haarlem, arms of, 27

Haarlem potteries, 4, 21, 23, 54, 57

Hague, The, Gemeentemuseum, 53, 75, 104 , I I 9

Hague, The, potteries, 57

Halder, Jacobus, 125,145

Halle, Stădtisches Museum, 1 16, I17

Hamburg Museum, $5^{2}$

Hamburg pottery, 139

Hamburg, tiles from house in, 52

Hampton Court, vases at, 71,138

Hanau pottery, I 39

Hanoverian Kings, arms of, $\mathrm{I} r 9$

Harlequin porcelain, 125

Harlingen pottery, 28, 46

Havard, criticism of, 59

HB mark, 86, 146

Heemskerck, M. van (see Van Heemskerck)

Heron pattern, 61,85

Hessian pottery, 18

Hey, Reinier, 72

Hoekke, arms of, 120

Hoorn, pottery found at, 24 


\section{INDEX}

Hogarth, subject from, 87

Hogarth, Mary, 83

Hogue, La, battle, 72

Hoppesteyn group of wares, II7, 140

Hoppesteyn, Jacob Wemmersz, 6I, I 16

Hoppesteyn, Rochus, 75, 98, II5

Huwelijkshoeken, 58

$\mathrm{H}^{\mathrm{V} B}$ mark, 26, 50

HVH mark, 88, 11 I

HVMD mark, 146

Hyacinth-vases, 93

IDA mark, 145

IDM mark, I 45

IDV mark, 1 ro

IH mark, 93, 125, 145

Imari porcelain, 98 , I I 8

Imitations of foreign earthenwares, I04

Indies, export to, 54

Ingelsz, Adriaen, 22, 24

Inscribed specimens, 86

IP mark, 92

Italian infuence, 137

Italian maiolica, 23, 104, 137

Italy, I 3, I7, 23

ITD mark, 87, II I, I 45

IVDB mark, 110

IVDK mark, 146

IVH mark, 84

IVK mark, 92, 93

IW mark, I I 6

\section{Jacobakannetjes, 17}

Jacob's Dream, subject, 84

Japanese porcelain, influence and imitations of, 98 ,

I 18,120

Joris Andriesz, 22, 24

Julius Caesar, tile-picture, 5 I

Junius, mark, 70

Junius, Robertus, portrait, 7 I

Justice cited, 62

Kampen, fragments from, 24

$\mathrm{K}$ 'ang Hsi style, 69, 108,115

Kannebackerländchen, 140

Kevelaar, Madonna of, 18

Kiell, A., 145

Klaauw factory, $85,111,145$

Kleftijus, Willem, 69, 93

Klokken, Drie, factory, 104, 145

Knowles, P., cited, 62

Kruyk, G. L., 69

Kruyswegh, Anthonie, II6, II 7

Kruyswegh, Jacobus, II7

Kwaart, II

Lacquer, imitation of, $\mathrm{IO}_{3}$

Lambert van Meerten Museum (see Delft)

Lambrequin motives, 7 I

Lampetkan factory, 85, 104, 146
Lancret, subject after, 53

Last Judgment, subject, 98

LC mark, III

Leeuwarden, fragments from, 24

Leeuwarder Museum, 27, 57

Leeuwenhoek, Antonie, 98

Leiden, arms of, 71

LF mark, 79, 92, 93, 1 03

Lightning pattern, 98

Lille (see Clainpanain Collection)

Limburg potteries, $18,28,29$

Liverpool (see Tenbosch Collection)

London maiolica, 138

Loudon Collection, 63,87

Louis XIV style, $71,83,107,108,109$

Louis XV style, 83 , 107, 109

Louis XVI style, 83

Louis Alexandre de Bourbon, Ir 9

LPK mark, I 46

LVD mark, 104

LVE mark, 79, 92, 103

Madonna on dishes, $18,25,26,28$

Maiolica, Dutch, 22, 64, 99, 109, 138

Maiolica, English, I 38

Maiolica, Flemish, 22, 137

Maiolica, Italian, 22, 104, 137

Makkum pottery, 28, 57

Manganese-purple in monochrome decoration, 88

Marks on tiles, 39

Marks, register of, 59, 145

Marks, significance of, 60

Marriage registers, $5^{8}$

Mass production, 83,85

Maurice, Prince, picture, 50

Mazarine-blue enamel, 104

MDV mark, I Io

Megelsum pottery, 29

Meissen porcelain, imitations of, $12,58,65,125$

Meissen red stoneware, 129

Metal Pot factory, 79, 92, I I I, I45

Meteyard, Miss E., cited, $I 38$

Middelburg, 2r, 22, 24, 25

Midnight Conversation, Hogarth's, 87

Ming dynasty porcelain, 28, 45, 75, I I 5

Money-box, I Io

Monkey jugs, II I

Monograms, significance of, 60

Moor's head, mark, II 6

Moor's Head, Old, factory, II6, II7, 146

Moor's Head, Young, factory, 84, I46

Moriaanshooft (see Moor's Head)

Moses with Tables of the Law, 84

Moulded wares, ro

MP mark, 79, 92, 145

Muffle-kiln, technique, I2, II 5, 123

Nassau, 140

Nederlandsch Museum (see Rijksmuseum)

Negro's head (see Moor's head)

Nevers faience, imitations of, 104

Niculoso Italiano, 23

Niobe, subject, 116 


\section{INDEX}

Old Moor's Head (see Moor's Head, Old) Orange, arms of, 7 I

Oude Moriaanshooft (see Moor's Head, Old)

Oxford, fragments at, 27

Paape, Gerrit, 3, 9, 35, I 33

Paauw factory (see Peacock)

Paree, Pieter, 145

Paris, Cris de, 109

Paris, Musée des Arts Décoratifs, I 19, 124

Passion series of plates, 86

Peacock factory, 84, I 45

Peacock-feather pattern, 61, 85, 109

Peasant delft, 99, 109, 110

Pennis, Anthoni, 146

Pernettes, 13

Persian tile design, 42

Pewter ousted by deltt, I 33

Piccolpasso cited, 22

Pietersz, Jan, 92

Pijnacker, Adriaen, 72, I03, I I5, I I8, I24

Pironi, 13

Plateelbakker, meaning of, 59

Plateelbakkerijen, 34

PM mark, 146

Polychrome delft, 9 I

"Porcelain," as term for delft ware, 4, 49, 53, 58, 133

Porcelain Ash-barrels, Three, factory, I 45

Porcelain Axe factory, 86, I46

Porcelain Bottle factory, 146

Porcelain, Chinese, 26

Porcelain Dish factory, 146

Porcelain, European, imitations of, 12, 125

Porcelain Flasks, Three, factory, 86, I 46

"Porcelain, red," 120

Porcelain technique, 123

Porceleijne Astonnen (see Porcelain Ash-barrels)

Porceleijne Bijl (see Porcelain Axe)

Porceleijne Fles (see Porcelain Bottle)

Porceleijne Flessies (see Porcelain Flasks)

Porselein, 21

Posset-pot peculiar to England, I 39, I 4 I

Potsdam pottery, I 39

Potteries, The, 140

Prodigal Son, subject, 50, 86

Proenen, I 3

Profileerwiel, I I

Pronk, Cornelis, 85

Prussia, arms of, I 99

Purple-and-white tiles, 45

Puzzle-jugs, 21, 84, I I 0, 124

PVD mark, 146

Queen's ware, I33, I34

R mark, 87,97

Ravenet, engraving, 109

Reactionary tendency in I 7 th-century Dutch art, 65

Red earthenware, 59, 129

Regency style, 107

Registration of marks, 59, I45

Reijgens, Augustijn, I 8
Reinier, signature, 72

RHS mark, 75, 115

Rijksmuseum, 17 and passim

Ringeloor, I 4, I7

Roman Charity, subject, 26, 50

Roman factory, 72, 146

Romeijn, de (see Roman)

Roos factory (see Rose)

Roos mark, 97

Rörstrand pottery, I 39

Rose factory, $70,87,97,103,145$

Rose or rosette, mark, 97, I 45

Rotterdam, fragments found at, 24, 27

Rotterdam, Museum van Oudheden, I I, 28, 40, 44, 49,51

Rotterdam potteries, $33,35,54,57$

Rotterdam tile-makers, 52

Rotterdam tiles, 53

Rotterdam, Weeshuis, tiles in, 52

Rouen falence, imitations of, 104

Rouen, Musée Céramique, 72, 87

Rouille, red, 104

S mark, 124

Sabines, Rape of, subject, I I 6

Sachtleeven, G., rog

Sacraments, sets of plates with paintings of, 134

Saggars, I I, 34

St. Luke, Guild of, 58

St. Omer, Musée Dupuis, 26, 27

St. Paul, Conversion of, tile-picture, 22

Salting Collection, 69, 103, 109, 1 I 8

Salt-glaze ware, 87 , I 33

Salvage Men, Two, factory, 146

Sanderus, L., 145

Savino, Guido di, 22

Scandinavian wares, I 39

Schaphuysen, I 8

Schotelgoed, 13, 34, 53

Schouten Collection, 27

Schreiber Collection, I 34

Seville, 23

Sèvres, Musée Céramique, 26, 72, 98, 108

Sgraffiato ware, 13, I7, I 8

Shareholders in Delft potteries, 61

Shipping subjects, 23,51

Ships, Two Little, factory, 146

Sledge, model of, 88

Slip-decorated wares and tiles, $13,17,36$

Snuff-jars, 86

Sources of design, 63

South Kensington (see Victoria and Albert Museum)

Spaandonck, Tomas, 146

Spain, 23, 26, 54

Spranckhuysen, D., portrait, 71

Star, factory, 86

Star, White, factory, I I I

Ster, Witle, I I I

Staffordshire potteries, 87, 129, I40

Stained glass design in tiles, 50

Stencils for tiles, 38,52

Steen, Engelsch, I 33

Stockholm pottery, I 39

Stoneware, Chinese, 129

SVE mark, 70, 75

Sweden, potteries in, I 39 


\section{INDEX}

Tea-drinking, 130

Teapots, red, 59, I 29, I 4 I

Technique of polychrome wares, 65

Temple, Building of, subject, 84

Tenbosch Collection, $85,86,126$

Teniers, subject after, $7 \mathrm{I}$

Theepotbacker, 129

Thornhill, Sir James, plates with signature of, 83

Thousand Terrors, House of, 49

Three Ash-barrels, factory, I04, I I1, 145

Three Bells factory, 104, I 45

Three Porcelain Ash-barrels, factory, I 45

Three Porcelain Flasks, factory, 86, ${ }_{4} 6$

Tile designs, classification of, 4 I

Tile-factory, view of, 35

Tile-pictures, 35, 4I, 49, III, I25

Tiles, dating of, 39

Tiles, technique of, 33,37

Tirion, Isaak, 85

Tobacco-jars, 84,86

Tobit, scenes from story of, 83

Toby-jugs, 87

Tome Swa, mark, 98

Toulouse, Comte de, arms, I I9

Trek (outline), I I, 69, 70,75, 115

Tromp, Admiral, 5I, 7

Tulip dishes, 138

Turkish type of design, 97

Turner ware, 134

Turquoise-blue enamel, 104

Twisk, view of, 85

Uccle (see Van Gelder)

Utewael, Joachim, 50

Utrecht, tiles, 17

VA mark, I 25

Van Aldewerelt, H., 70

Van Beek, Willem, 146

Van Bleyswijck cited, 53,72

Van Dale, Lucas, 104

Van den Briel, widow, 88, 146

Van den Kloot, Arij, 92

Van den Kloot, Jan, 146

Van der Burgh, Mr., cited, 62

Van der Buergen, Jan, 1 Io

Van der Does, Dirk, 97, I 45

Van der Does, Willem, I45

Van der Hoeven, arms, 108

Van der Kest, Dirk, 83

Van der Laan, J an, I04

Van Doorne, Pieter, I 46

Van Duijn, Johannes, $87,88, I_{46}$

Van Eenhoorn, Lambertus, 79, 91, 92, 93, 103

Van Eenhoorn, Samuel, 70, 75

Van Frijtom, Frederik, 72

Van Gelder Collection, 93,98

Van Gelder, Dr., H. E., 62

Van Hamme, J. A., 138

Van Heemskerck, Maerten, 26, 49, 50

Van Hoorn, Hendrik, III, I 45

Van IJsselsteyn, D., 70

Van Kerckhoff, Johan, 58
Van Kuyk, Michiel, 85, 126

Van Mander, Karel, 2 1, 23

Van Marum, Petrus, 146

Van Middeldijk, Hendrik, 146

Van Putten, Jan, I34

Van Queborn, C., 7 I

Vecht, views of the, 52

Venice, 23

Verburg, Jan, r ro

Verburg, P., 446

Vergulde Blompot, factory, $\mathbf{I}_{4} 6$

Vergulde Boot, factory, I45

Verhaast, Gijsbert, 98, I 10 , 1 I 8

Verhagen, Johannes, 84

Verheerlijkt Nederland, Het, view from, 85

Verkolje, print, 98

Vermeer, 33, 140

Verstelle, Gertruij, 88, 146

Vertumnus and Pomona, subject, 28

Victoria and Albert Museum, 27, 28, 69, 75, 79, 97, $98,99,103,108$, I I0, I I6, I I $, 125,129,133$ I 34

Victory of Conscience over Force, tile-picture, 50

Vingboons, David, 84

Violins, Delft, 87

Visscher, C. J., 5 I

Vizeer, Piet, I I0

VL monogram, 104

Vleeshal, Delft, view of, 72

Vormer, 125

Vroom, H. C., 21, 23, 49

Wall-plaques, 86, 92, 93, 107, 109

Wan $\mathrm{Li}$ designs, 45

"Wasters" from Rotterdam, 46

WD mark, I 45

Wedging of clay, ro

Wedgwood ware, I34

Westerwald, I 40

White delft, I 34

White Star, factory, 145

Wijtmans, Claes, 53,58

Wildemans, Twee, factory, 146

William I (the Silent), portrait, 27

William I (the Silent), tomb of, 70

William III, King, 70, 7 I, 79, I38

William V, I 10, 133

Winkelhouders, $6 \mathbf{r}$

Witte Ster, factory, 145

WK mark, 69, 92, 98

Wolff of Holstein, r 39

Wouverman, subject after, 72

WVB mark, 146

WVDB mark, 88

Yellow enamel ground, 104, rog

Yi-hsing Hsien stoneware, I 29

Zeeland, pottery found in, 2 I

Zeevischmarckt, Delft, view, 72

Zodiac set of plates, 83 


PLATE 1.

Fig. I. Two-handled drug-pot with the arms of Haarlem and Amsterdam, painted in blue, yellow, brown, green and manganese-purple on a greyish white ground. Dutch maiolica; dated I6Io.

H. $5 \frac{1}{6}$ ins. ( $13 \mathrm{~cm}$.). (See page 27. )

Nederlandsch Museum voor Geschiedenis on Kunst

(Rijhs:museum), Amsterdam, No. 135. 


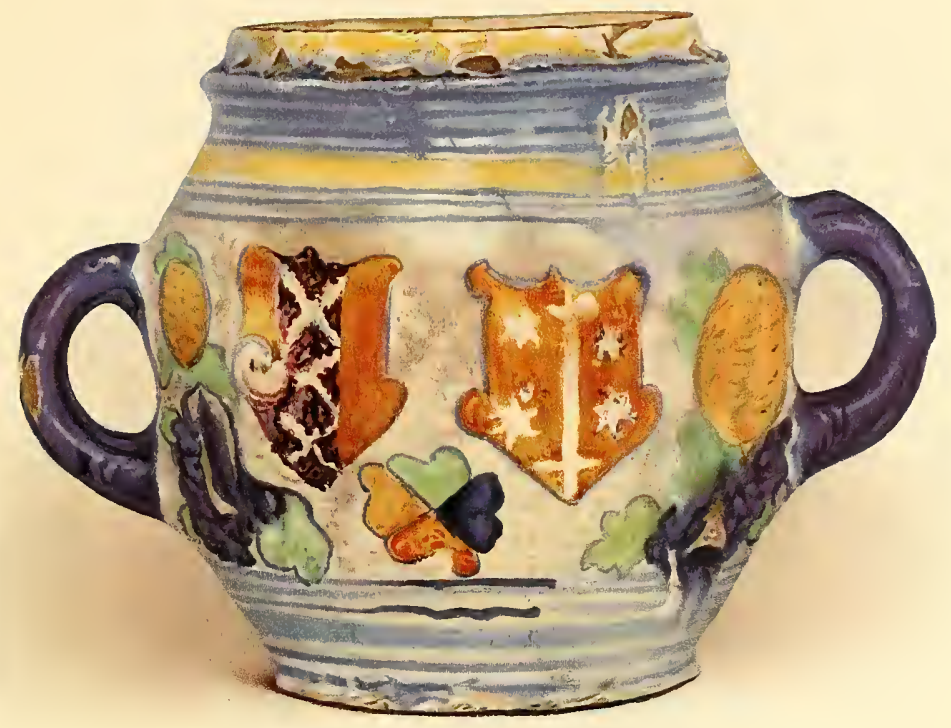




PLATE II.

Fig. 2. Dish painted in blue, orange and green on a white ground with fruit on a dish, and on the rim flowers with embossed centres. Dutch maiolica; early seventeenth century. D. 123 ins. $(32.3 \mathrm{~cm}$.). (See page 27.)

Museum Lambert van Meerten, Delft. 


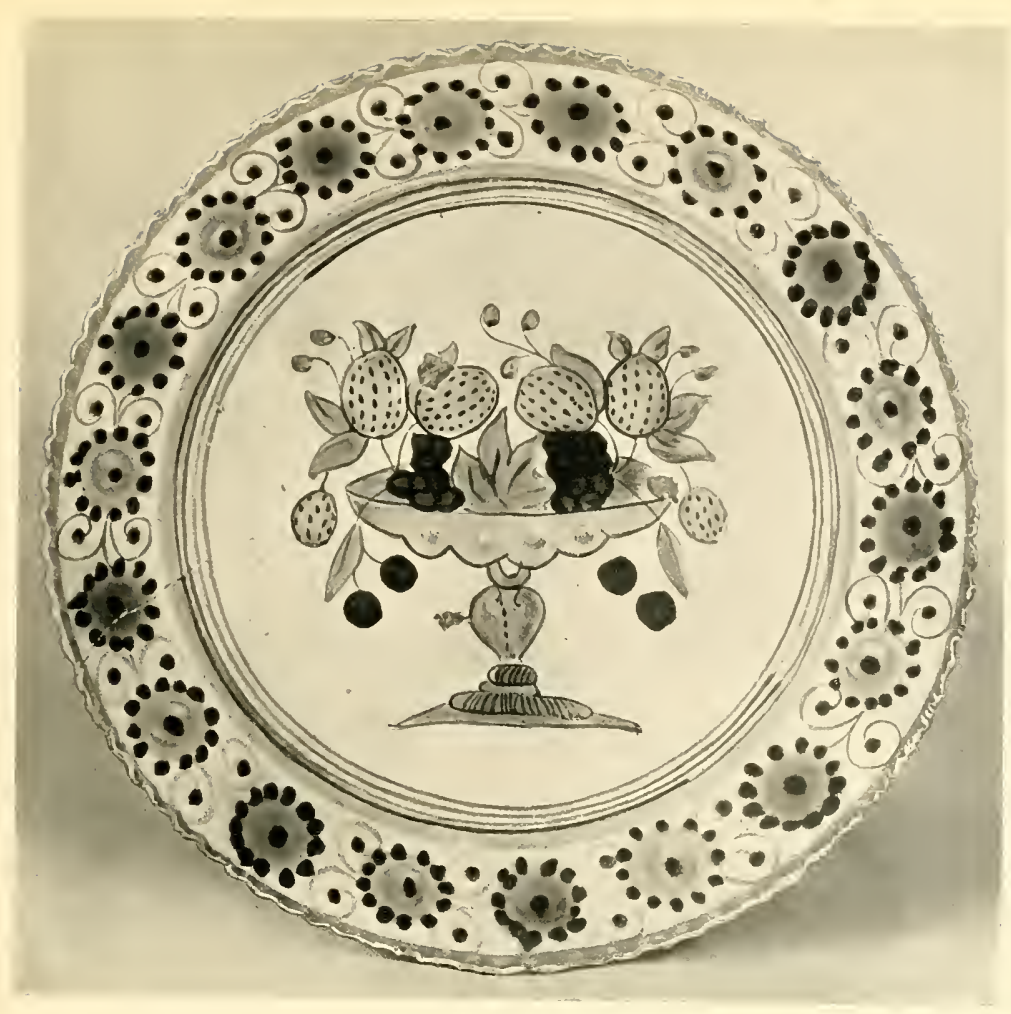




PLATE III.

Fig. 3. Three small drug-pots painted respectively in blue and yellow, blue and manganese-purple, and blue, yellow and manganese-purple on a greyish white ground. Found at Middelburg. Dutch maiolica; about 1565 . H. 2 ins. $(5 \mathrm{~cm}),$.3 ins. $(7.5 \mathrm{~cm}),. 3^{3}$ ins. $(8.5$ cm.). (See pages 21,25 .)

Nederlandsch Aluseum voor Geschiedenis en Kunst

(Rijksnuseum), Amsterdam, No. 129.

Fig. 4. Dish painted in blue, orange and green on a white ground, with the inscription Eert God ("Honour God "), and on the rim flowers with embossed centres. Dutch maiolica; beginning of the seventeenth century. D. I3 ins. $(33 \mathrm{~cm}$.) (See page 27.)

Nederlandsch Museum voor Geschiedenis en Kunst (Rijksmuseum), Amsterdam, No. 139. 

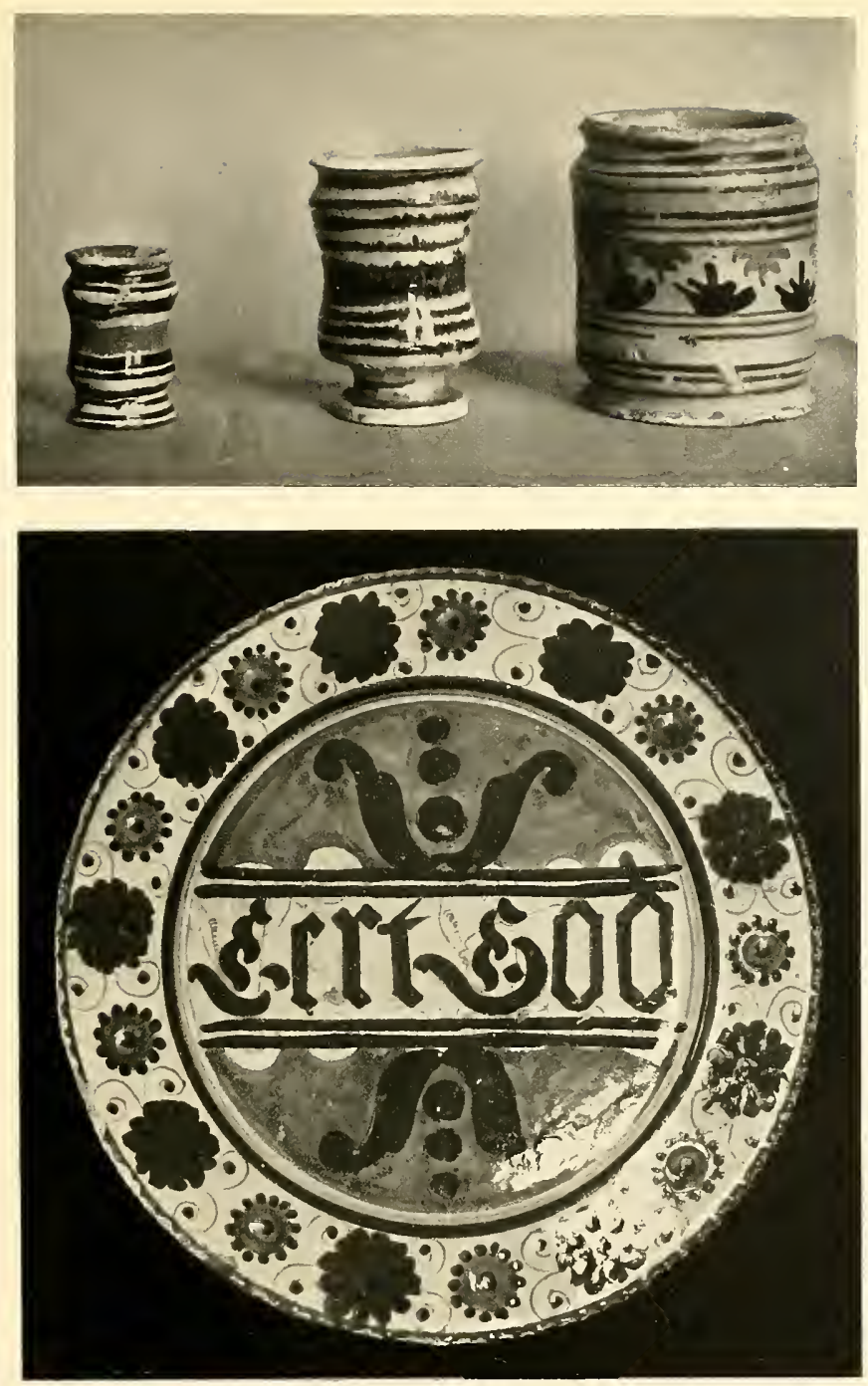



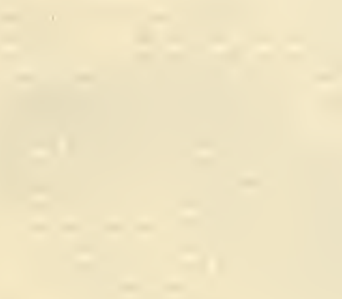


PLATE TV.

Fig. 5, a and b. Deep bowl with the subject of the Roman Charity Cimon in prison fed by his daughter Pera-painted in blue, yellowish brown, yellow, green and manganese-purple. On the rim, in the same colours outlined in blue, grotesque motives reserved on a yellow ground. On the outside, flowers in the same colours with the exception of purple. Signed both inside and under the base with an unidentified mark $\mathrm{H}^{ } \mathrm{B}$. Dutch maiolica; dated I60I.

D. $1^{1}$ ins. $(44 \mathrm{~cm}$.). (See page 26.$)$

Nedprandsch Mrseum voor Geschiedenis en Kunst (Rijkamuscum). Amsterdam. 

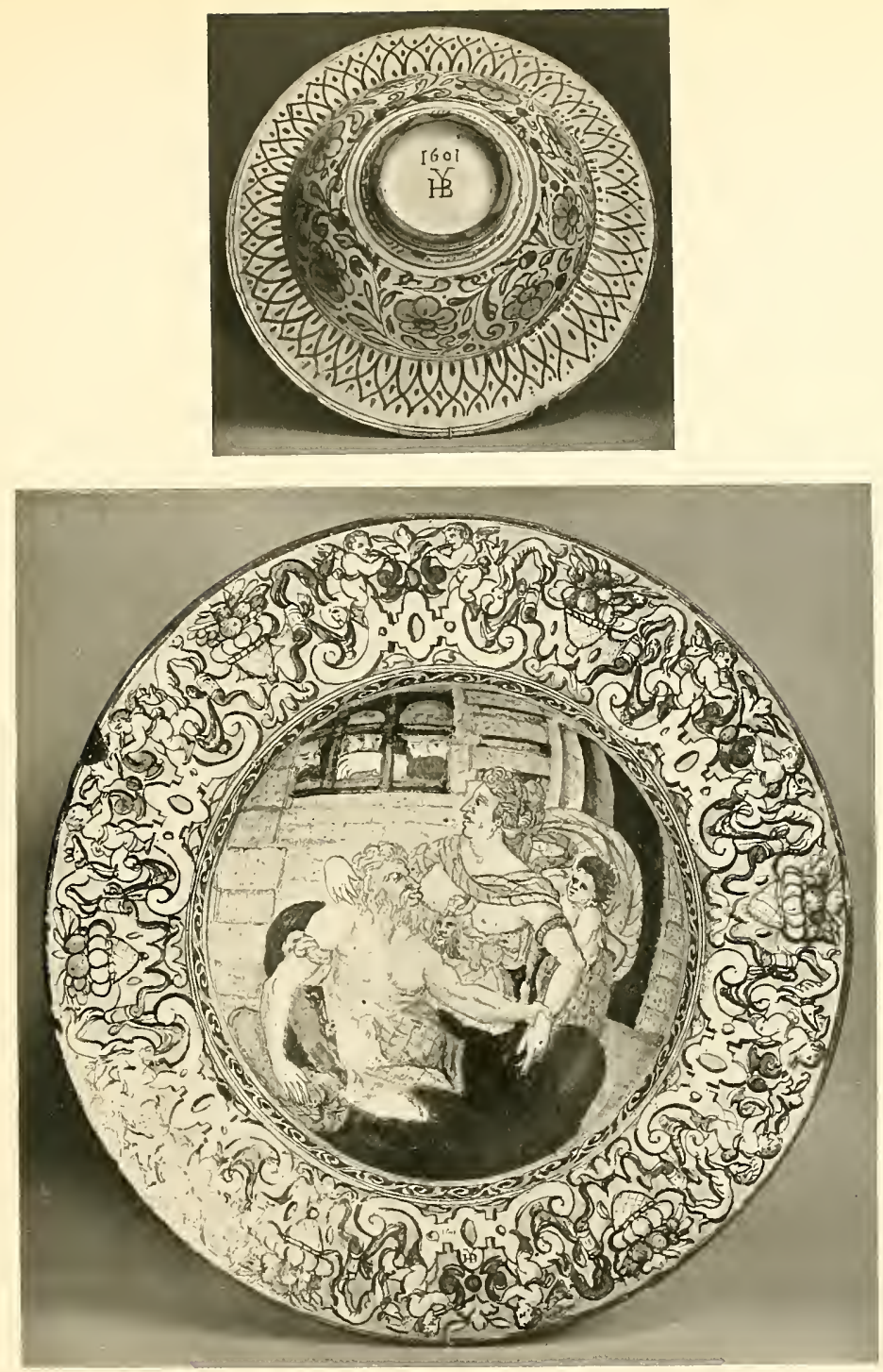




\section{PLATE V.}

Fig. 6. Dish painted in blue, green, yellow, orange and manganese-purple: Vertumnus and Pomona. Dutch maiolica: about $\times 600$. D. $12 \frac{3}{8}$ ins. $(31.5 \mathrm{~cm}$.). (See page 28 .)

Nederlandsch Museum voor Geschiedenis en Kunst (Rijksmuseum), Amsterdam, No. 144.

Fig. 7. Dish painted in greyish blue, brownish yellow, pale green and manganese-red with a heraldic rose and a formal border. Dutch maiolica, early seventeenth century. D. 13.3 ins. $(34.9 \mathrm{~cm}$.). (See page 27.)

Victoria and Albert Museum, London, No. C. 8181920. 

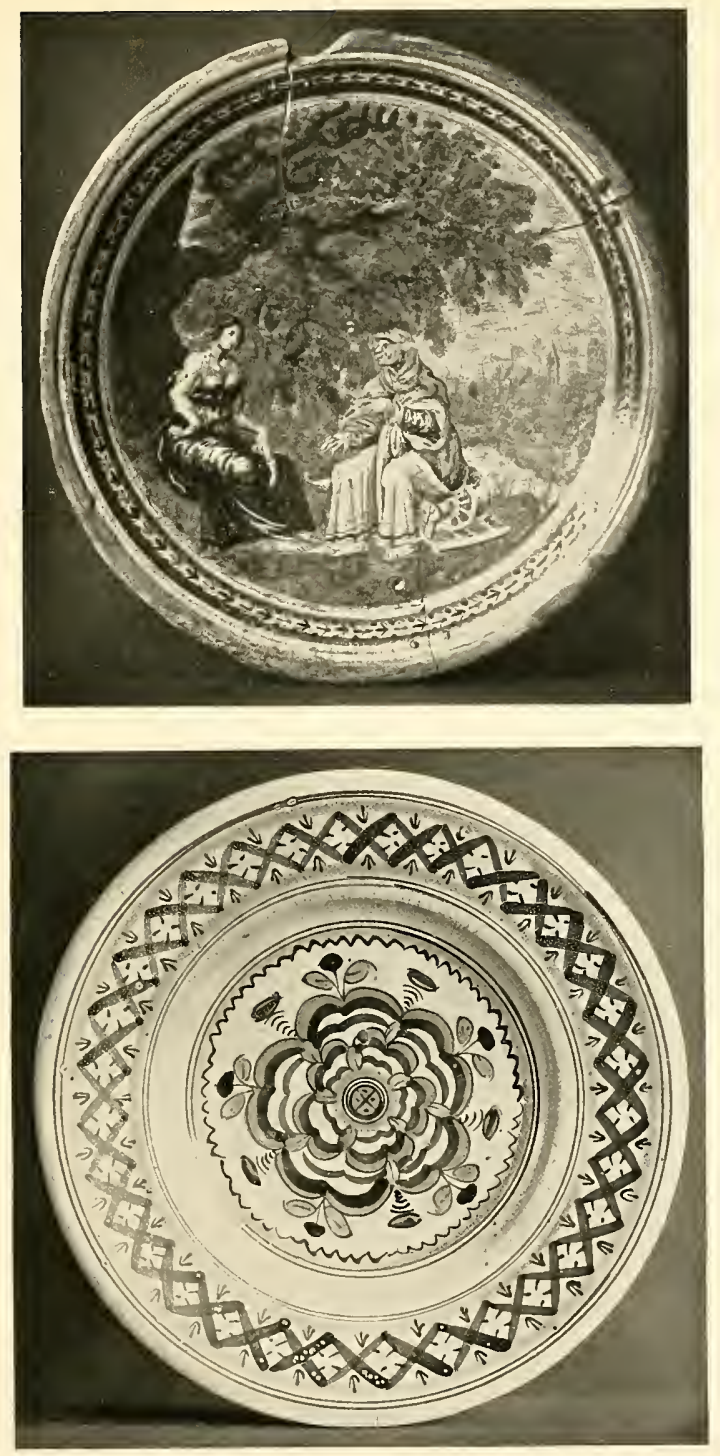


PLATE VI.

Fig. 8. Plate painted in the middle with the Madonna and Child in blue, green and orange, on the rim with panelling in blue in imitation of Chinese porcelain of the late Ming period. Dutch maiolica; early seventeenth century.

D. $7 \frac{1}{2}$ ins. $(19.2 \mathrm{~cm}$.). (See page 26. )

Museum Lambert van Meerlen, Delft.

Fig. 9. Dish painted with stylised fruit in blue, orange and green, and on the rim gadroon ornament in blue. Dutch maiolica; early seventeenth century. D. $12^{3}$ ins. $(31.5 \mathrm{~cm}$.). (See page 27 .) Schouten Collection (lent to the Museum Lambert wan Meerten, Delft). 

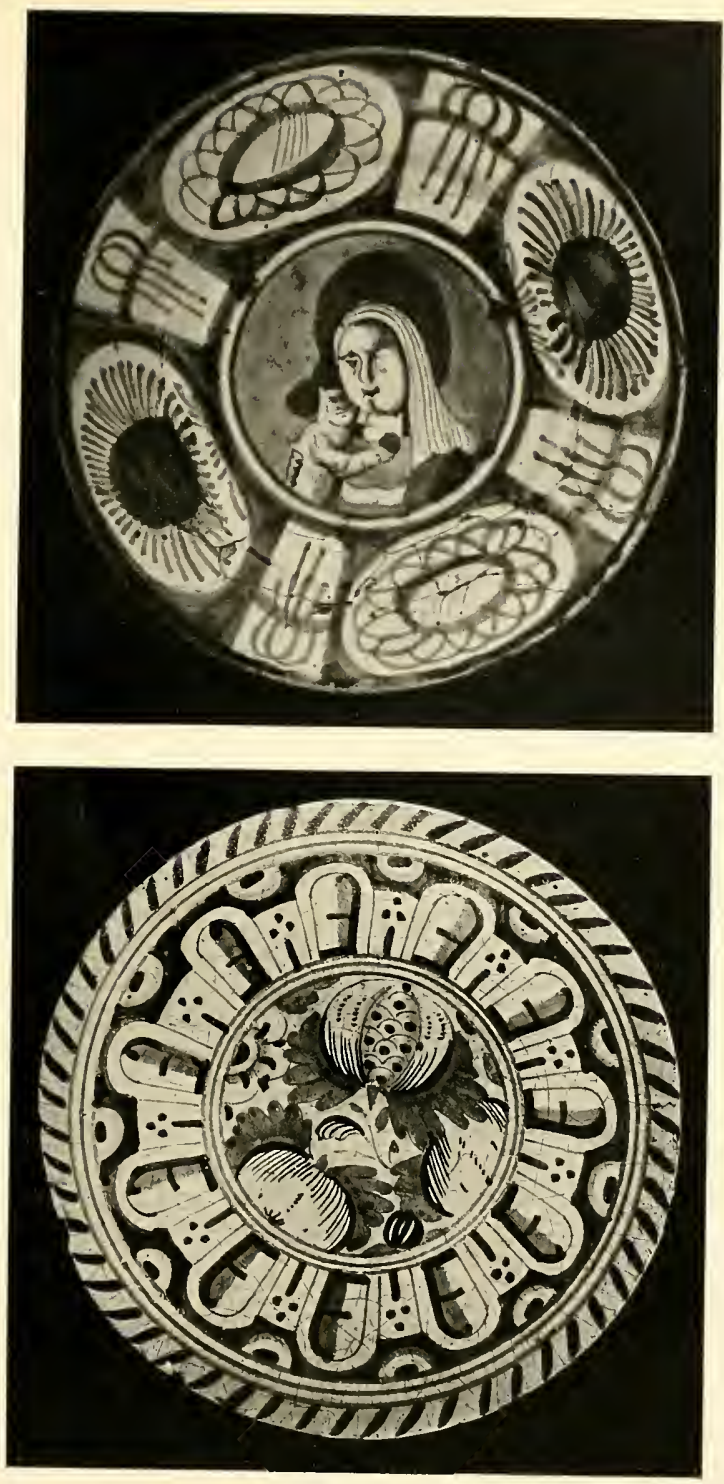

PLATE VII.

Fig. Io. Four tiles with arabesques in geometrical panels in reserve on a ground coloured blue, yellow and brown. Probably Dutch; second half of sixteenth century. (See page 42.)

II useam Lambert van Meerten, Delfl, No, A. 566.

Fig. II. Four tiles forming a rosette of terminal figures, painted in blue, yellow, brown and green. Dutch; about 1600. (See page 44.)

I usenin Lambert van Meerten, Delft, No. A. 826 .
Fig. 12. Four tiles with geometrical and foliated ornament in reserve on a ground coloured blue, yellow, brown and strong green. Dutch; about I600. (See page 42.)

Museum Lambert van Meerten, Delft, No. A. 714. 

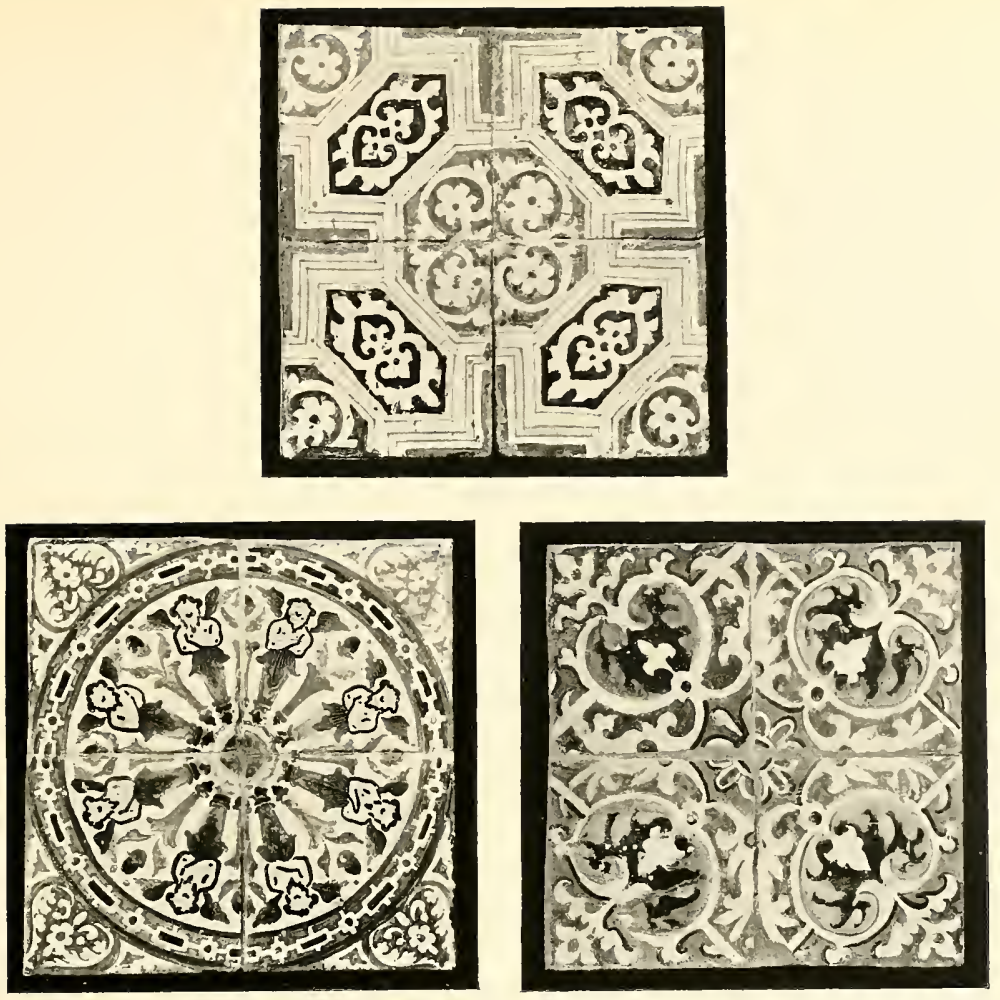


PLATE VIII.

Fig. 13. Twelve tiles with a continuous design

forming a lattice-pattern running

athwart the edges of the tiles, in blue,

yellow, brown and green. Dutch

about 1600 . (See page 43.)

Museum Lambert ran Neerten, Delft, No. A. 721.

Fig. 14. Twelve tiles with a continuous design of star and lily motives in blue, yellow, brown and green. Dutch; first half of seventeenth century. (See page 43. )

II useum Lambert van Meerten, Delfi, No. A. 890. 

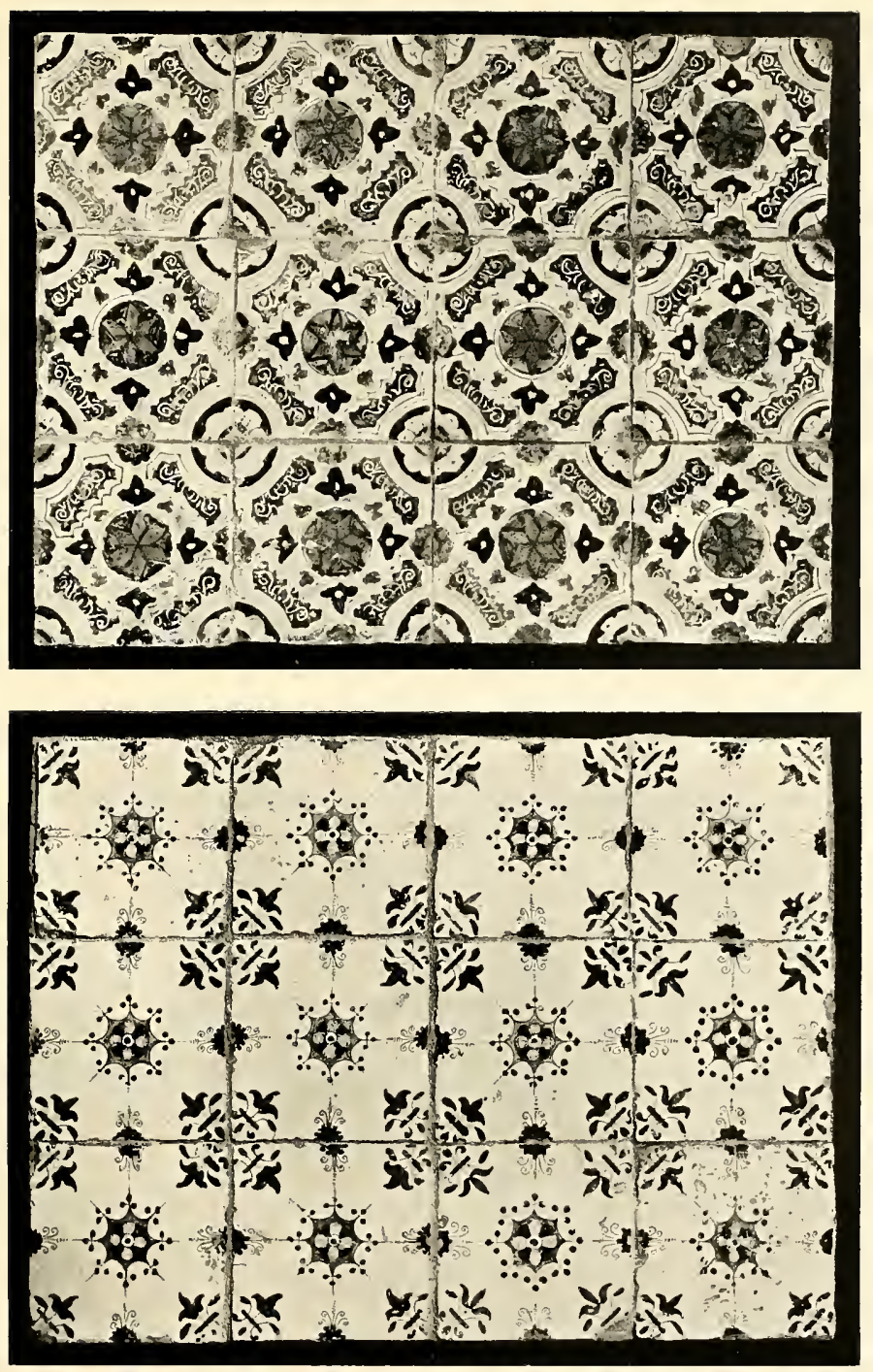



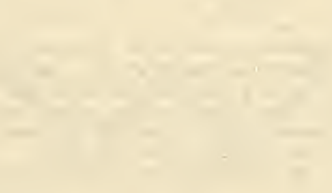

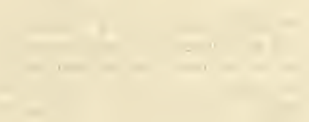


PLATE IX.

Fig. 15. Nine tiles with vases of fowers in quatrefoils, forming a lozenge-pattern continued across the edges of the tiles,

in blue, orange-yellow, brown and green. Dutch; first half of seventeenth century. (See page 44.)

Museum Lambert van Heerten, Delft, No. A. 699.

Fig. 16. Twenty-four tiles with a continuous design of stylised fruit and flowers set together to form star-like motives, in blue, orange-yellow, brown and green. Dutch ; first half of seventeenth century. (See page 43.)

If useum Lambert van Meerten, Delft, No. A. 1000. 

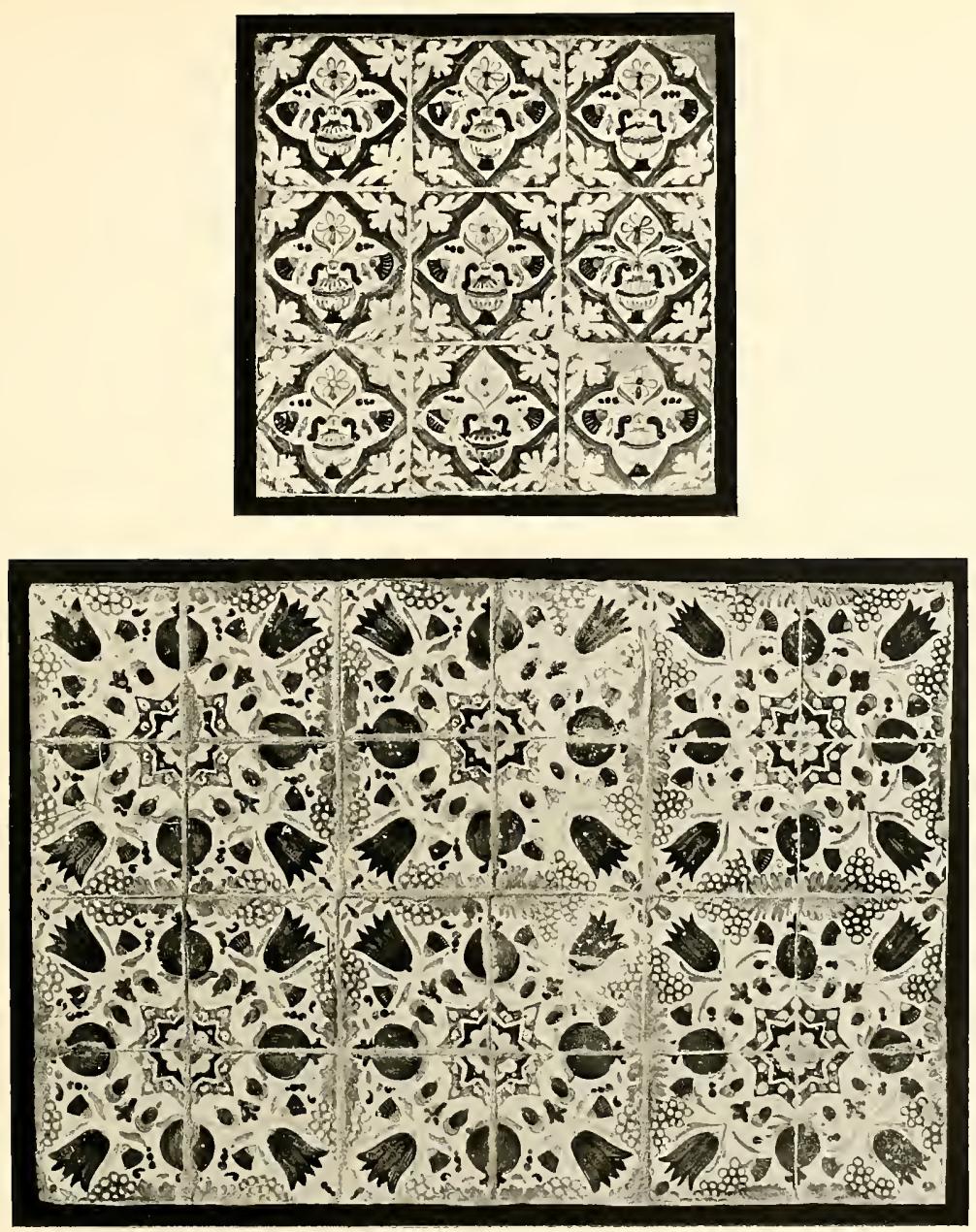



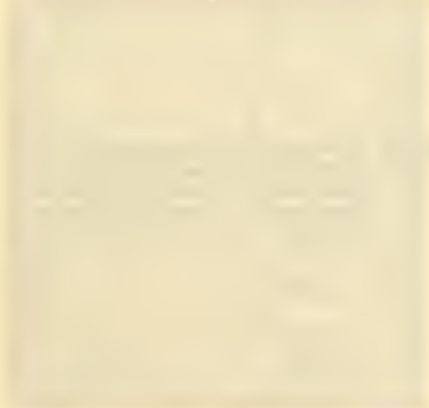


PLATE $X$.

Fig. I7. Tile with a figure of an archer in blue, orange-yellow, manganese-purple and green. Dutch; first half of seventeenth century. (See page 44.)

Nederlandsch Muse um voor Geschiedenis en Kunst

(Rigksmuseum), Amsterdam, No. 153.

Fig. 18. Four tiles with animals and birds in circles and connecting motives in the corners, in blue, yellow, brown, green and inanganese-purple. Dutch; first half of seventeenth century. (See page 44.)

Museum Lambert van Meerlen, Delfi, No. A. 681.
Fig. 19. Four tiles with tulips and, at the edges, baluster-shaped motives in blue, yellow, brown, green and manganese-purple. Dutch; first half of seventeenth century. (See page 44. ) Museum Lambert van Meerten, Delft, No. 910. 

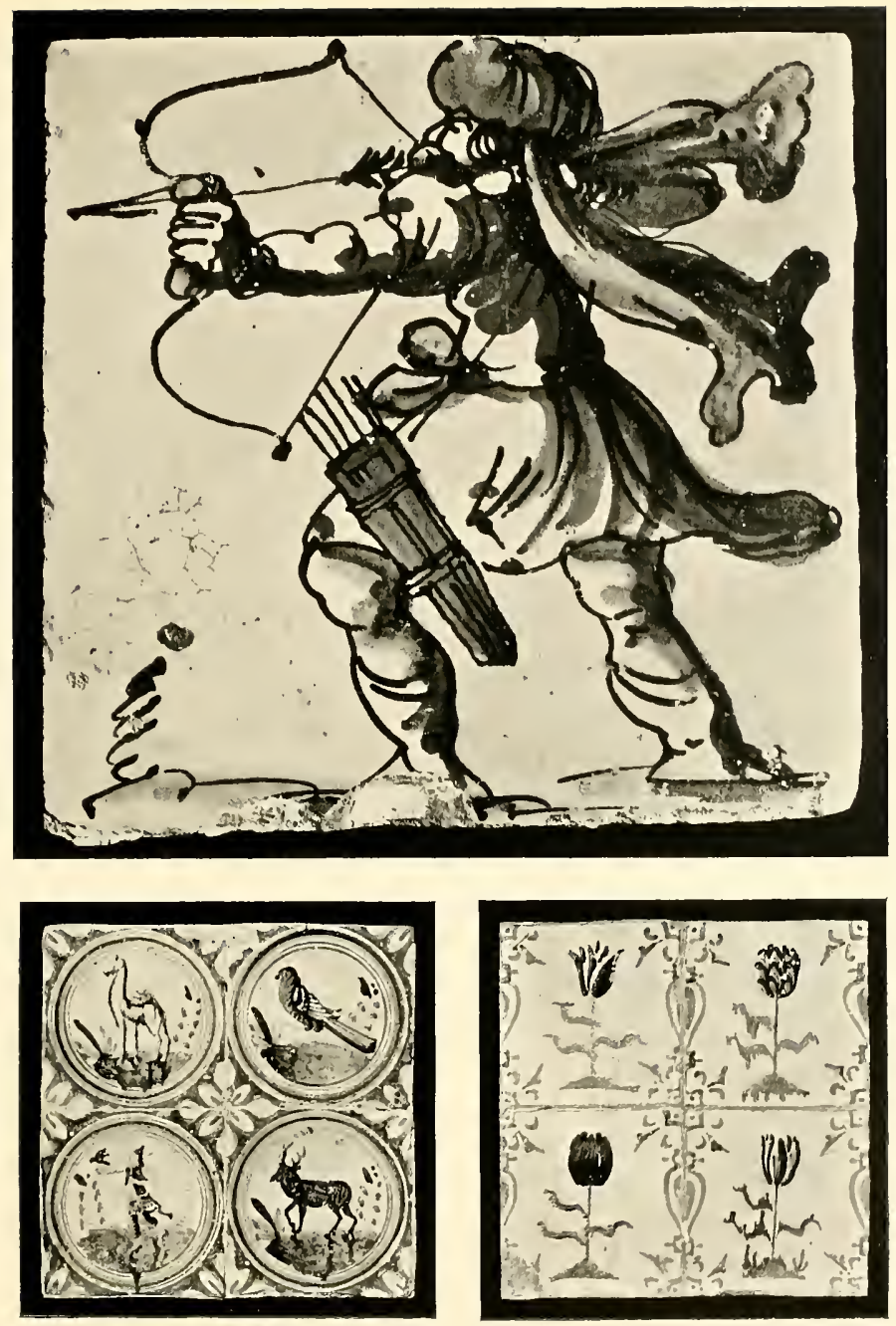

PLATE XI.

Fig. 20. Tile-picture with an allegorical subject, in blue, yellow, brown, green and manganese-purple, formerly built into the front of the house In duysent vreesen at Rotterdam. Dutch; probably dating from the end of the sixteenth century. H. 2 ft. $2 \frac{1}{8}$ ins. $(66.5 \mathrm{~cm}$.). (See page 49.)

II useum van Oudheden, Rotterdum 


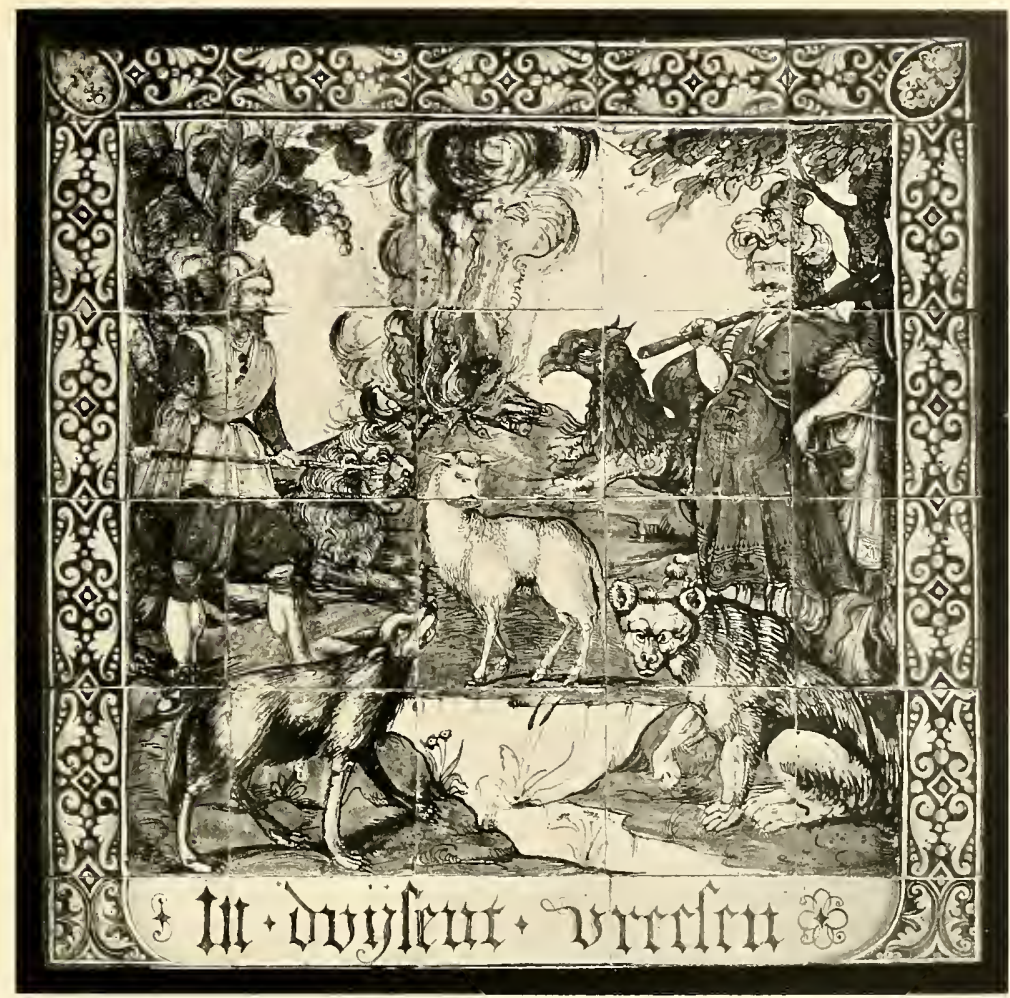




PLATE XII.

Fig. 21. Tile-picture with a vase of flowers, in blue, yellow, brown, green and manganese-purple, formerly in a house in Rotterdam. Dutch; first half of seventeenth century. H. $3 \mathrm{ft}$.

(91.5 cm.). (See page 49. )

Museum van Oudheden, Rotterdam. 


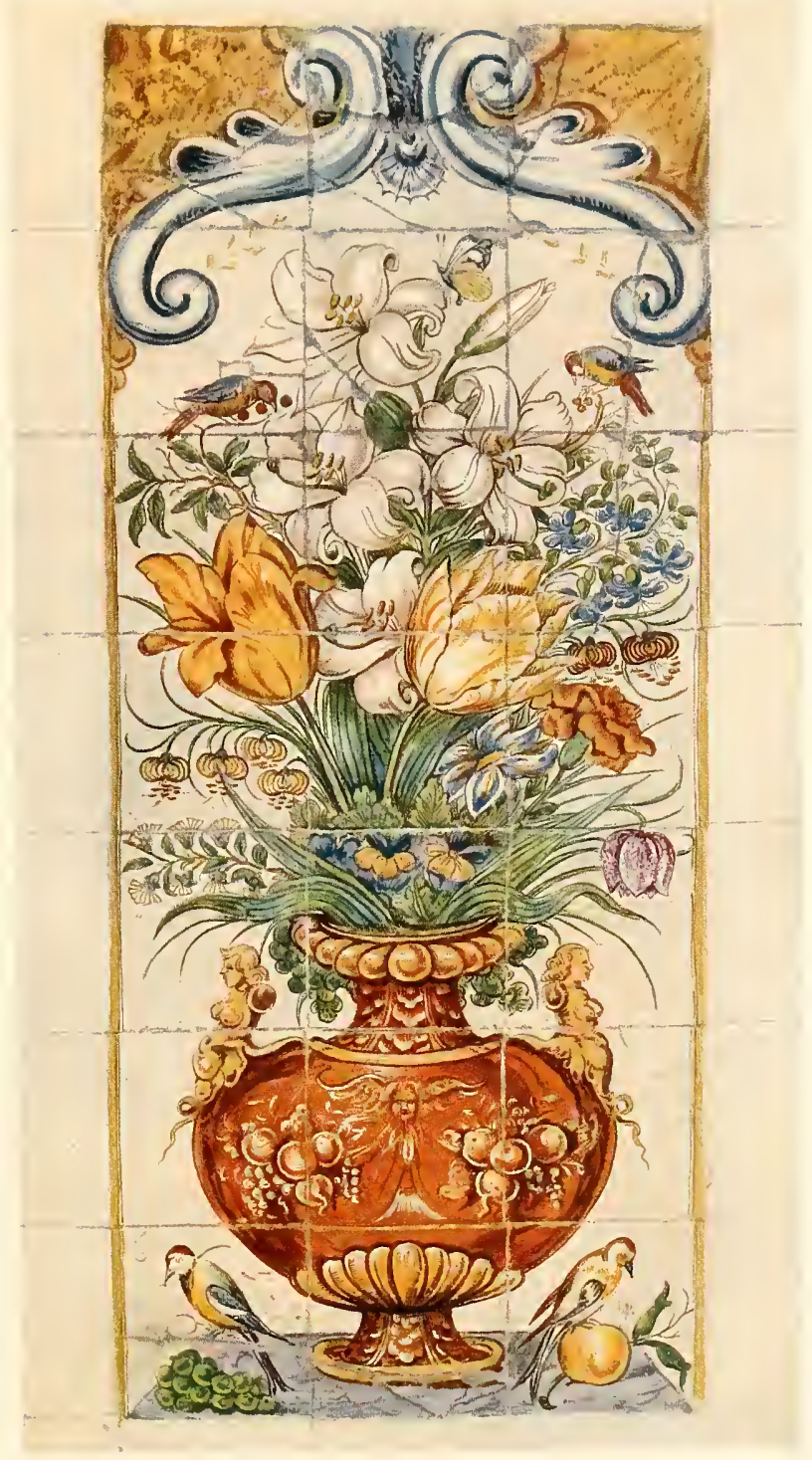




PLATE XIII.

Fig. 22. Tile-picture with a boy resting one foot on a heavenly sphere, in blue, yellow, brown, green and manganesepurple. After a design by Joachim Utewael for a window in the Groote Kerk at Gouda. Dutch; about I640.

H. 5 ft. $6 \frac{1}{2}$ ins. ( $1.70 \mathrm{~m}$.). (See page 50 .) MI useum Lambert van Meerten, Delft, No. A. G18. 


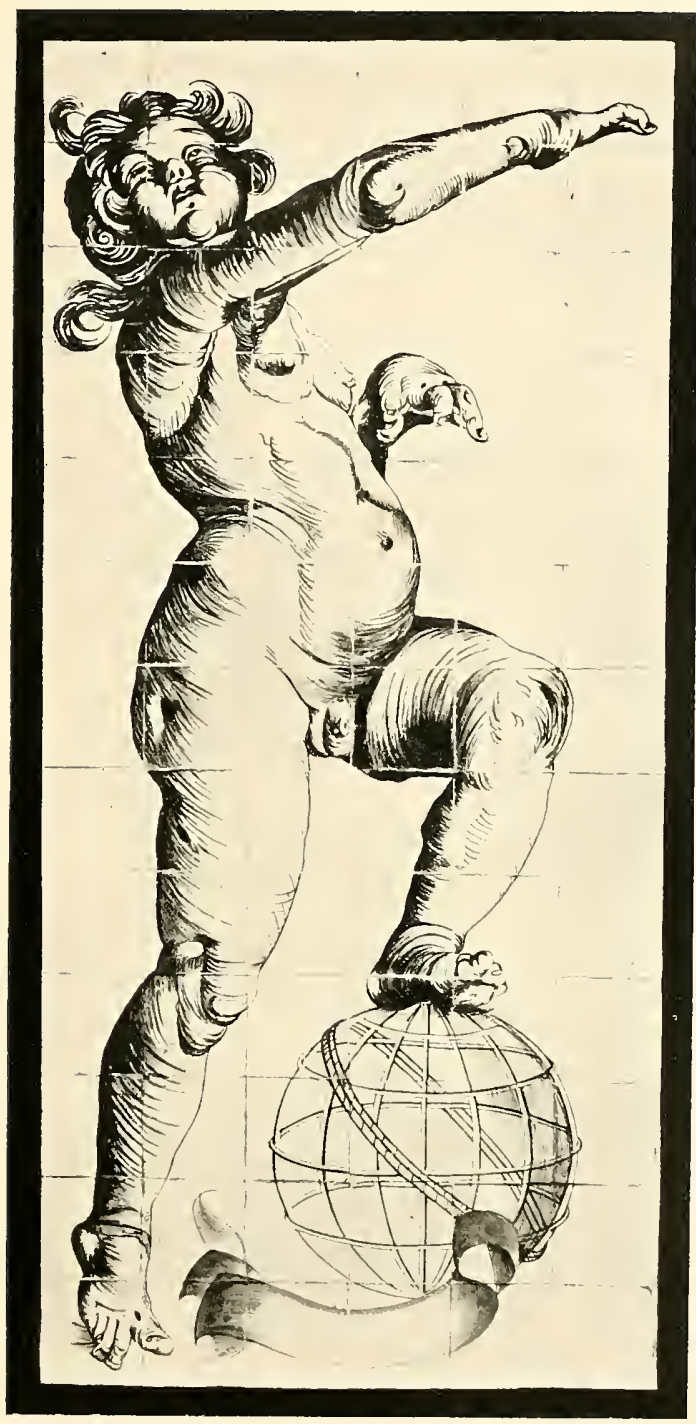




PLATE XIV.

Fig. 23. Four tiles, blue-and-white, with figures

in panels on a ground of diaper. Dutch;

first half of seventeenth century.

(See page 45.)

Museum Lambert van Meerten, Delft, No. A. 961.

Fig. 24. Twelve tiles, blue-and-white, with motives adapted from Chinese

porcelain of the late Ming period.

Dutch; first half of seventeenth

century. (See page 45.)

Museum Lambert van Meerten, Delft, No. A. 975. 

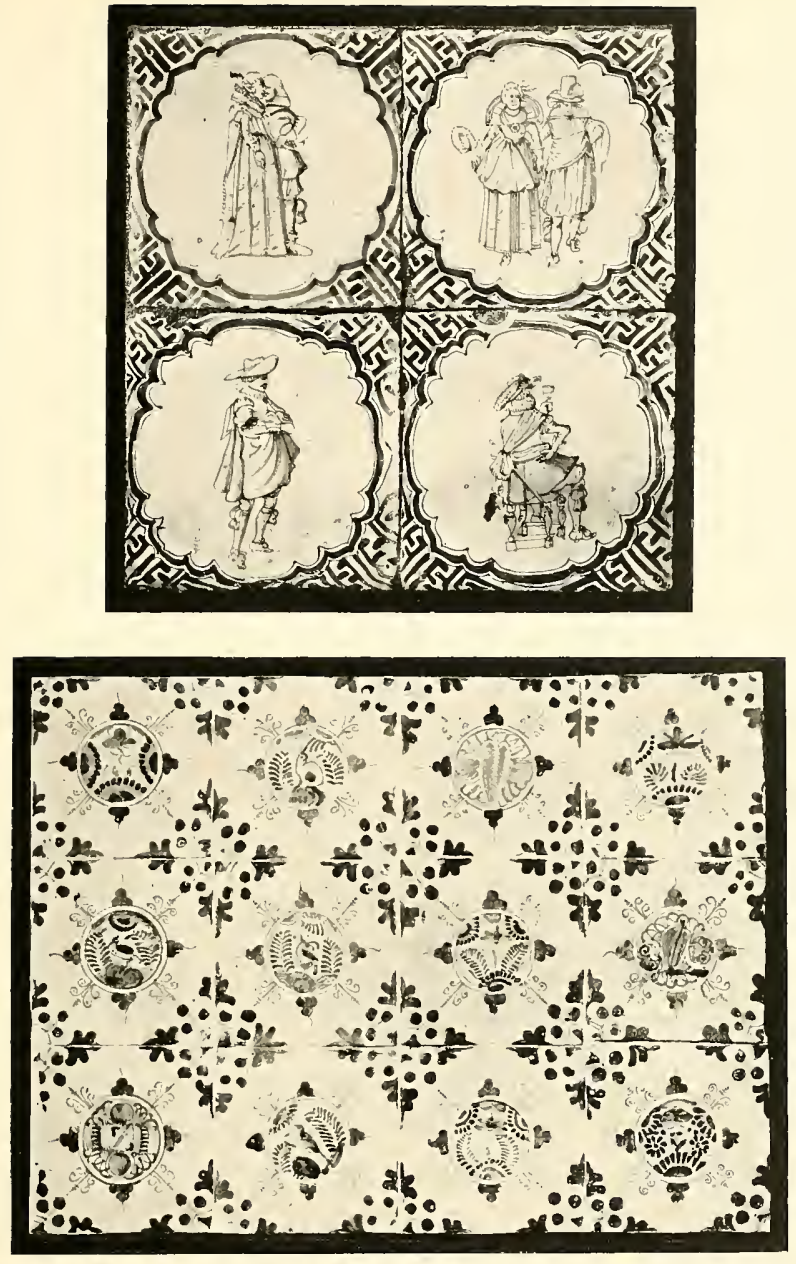


PLATE XV.

Fig. 25. Tile-picture of 154 tiles, blue-andwhite, depicting a tile-factory at Bolsward, Friesland, with the names and arms of its founders. Restored in places; some of the tiles to the right of the pictures set in the wrong order. Formerly at Bolsward. Dated I737. H. $5 \mathrm{ft}$. II $\frac{1}{2}$ ins. (I.82 m.). (See pages $34,35,46$. )

Nederlandsch Huseum voor Geschiedenis en Kunst (Rijksmuseum), Amsterdam. 


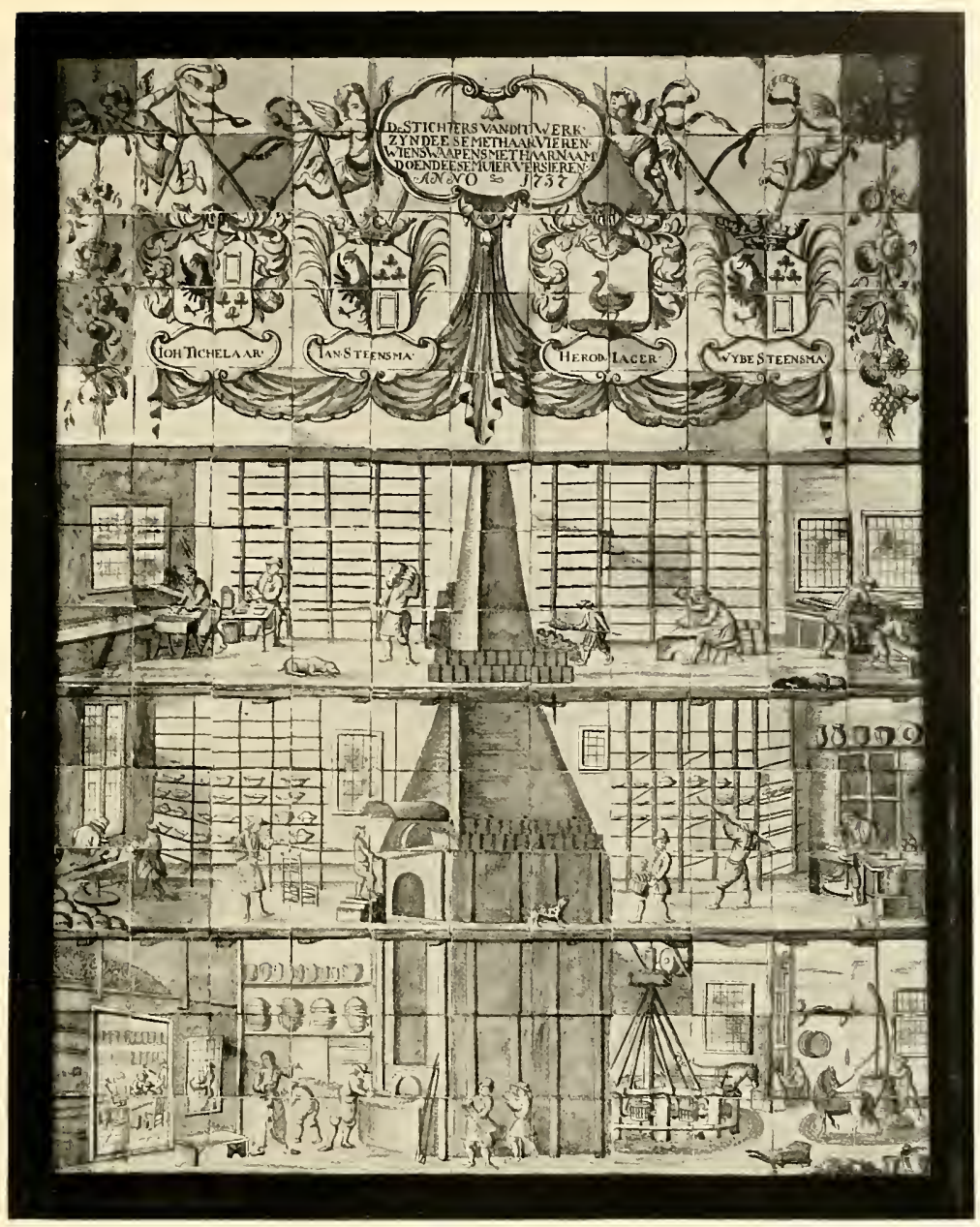




PLATE XVI.

Fig. 26. Tile-picture, blue-and-white, shipping on a stormy sea. Signed C B: M

(Cornelis Boumeester). Rotterdam; second half of seventeenth century.

H. $2 \mathrm{ft}$. 10 ins. $(86 \mathrm{~cm}$.). (See page 52 ).

Nederlandsch Museum voor Geschiedenis en Kunst

(Rijksmuseum), Amsterdam, No. 226.

$\stackrel{C}{B: M}$ 


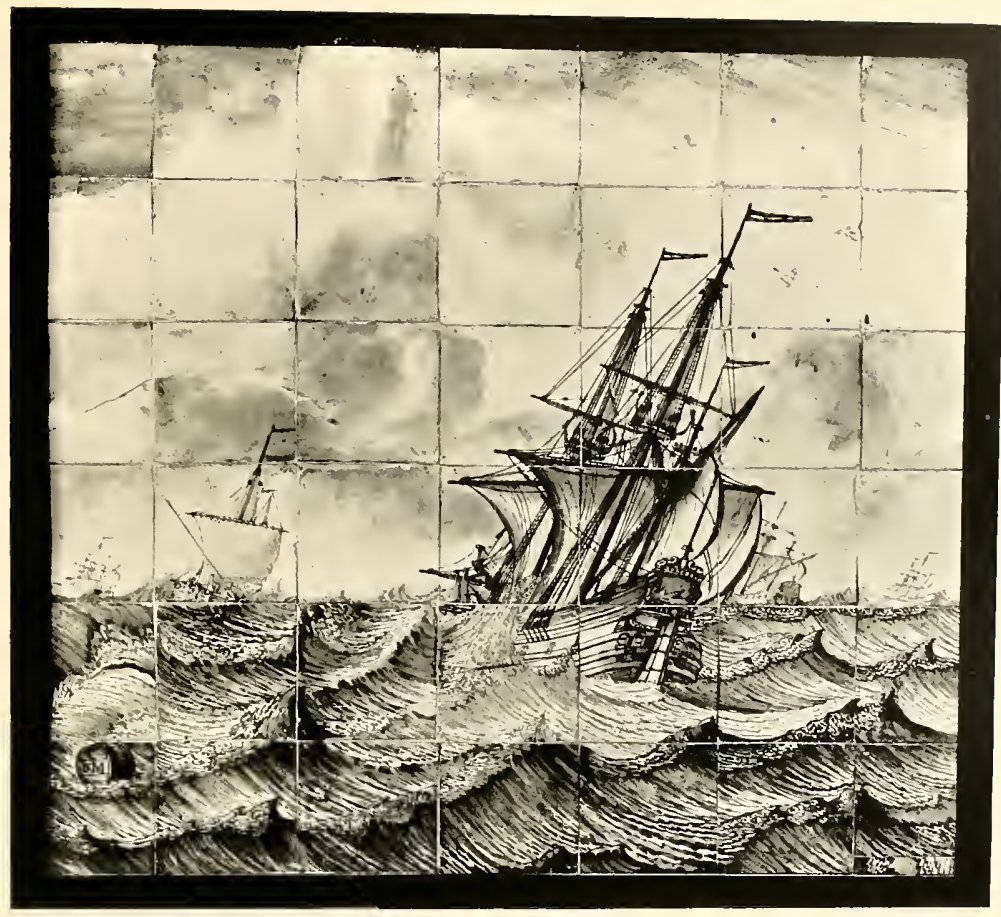




PLATE XVII.

Fig. 27. Vase and Cover, painted in blue, outlined in dark blue trek, with flowers and birds and formal borders in the Chinese style. Mark GK in monogram. Delft; second half of seventeenth century. H. I6 ins. $(40.6 \mathrm{~cm}$.). (See page 69 .)

Cole Collection, Bidston. Birkenhead.

G 


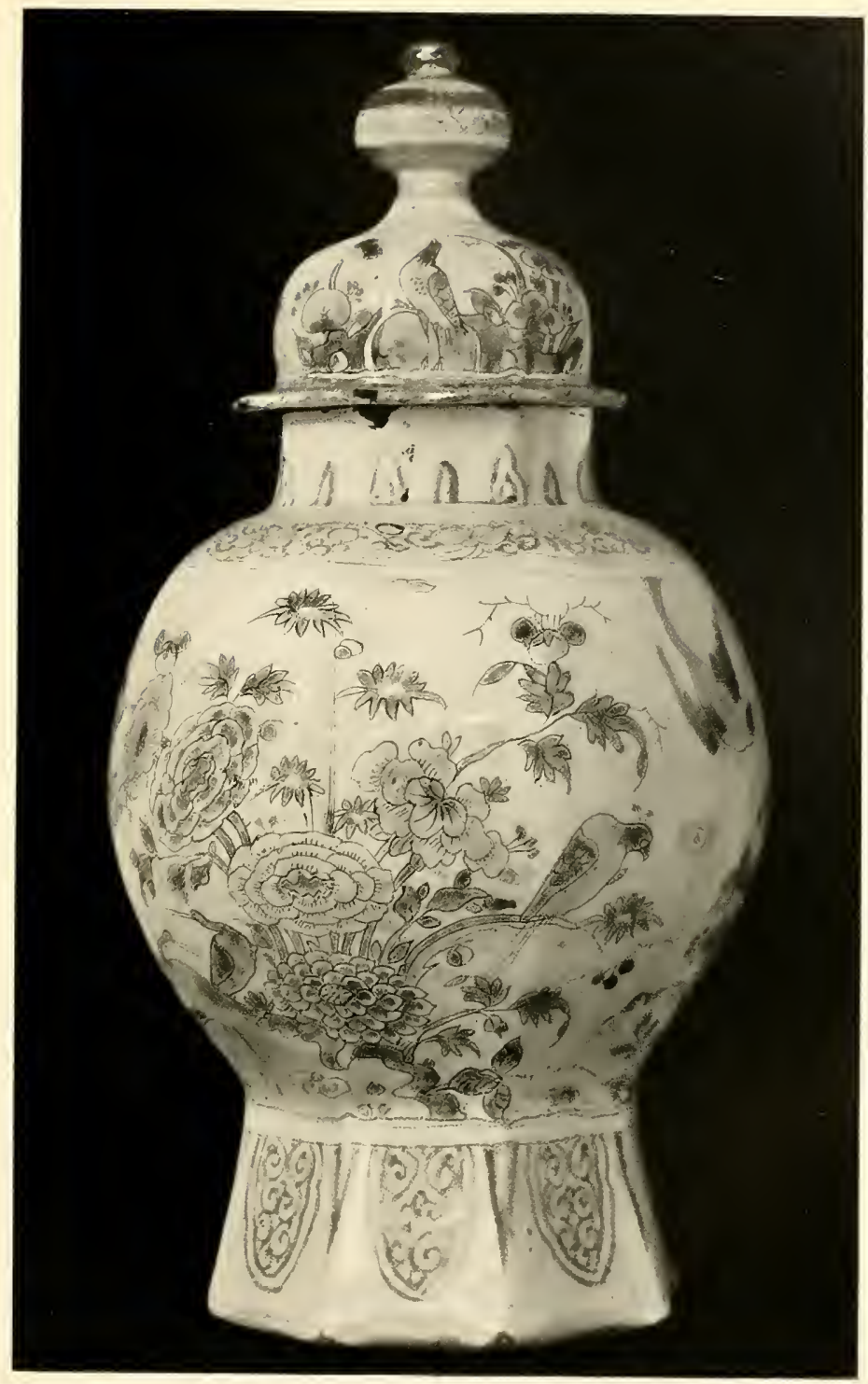




Fig. 28. Inkstand, blue-and-white, painted with the arms of Orange and surmounted by two lions holding shields with the arms of Leiden and Delft. Mounted in silver Unmarked. Delft ; second half of seventeenth century. H. 6 ins. (I5 cm.), W. $8 \frac{1}{2}$ ins. $(21.5 \mathrm{~cm}$.). (See page 71 .)

Nederlandsch Museum voor Geschiedenis en Kunst (Rijlsmuserm), Ansterdam, No. 210 (Loudon Collection).

Fig. 29. Tulip-vase, painted in blue with blackish blue trek with figures in a landscape. Mark, AK in monogram. Delft; second half of seventeenth century. W. Io ins. $(26 \mathrm{~cm}$.). (See page 70.)

Nederlandsch Museum voor Geschiedenis en Kunst (Rijksmuseum), Amsterdam, No. 1.54.

\section{A}



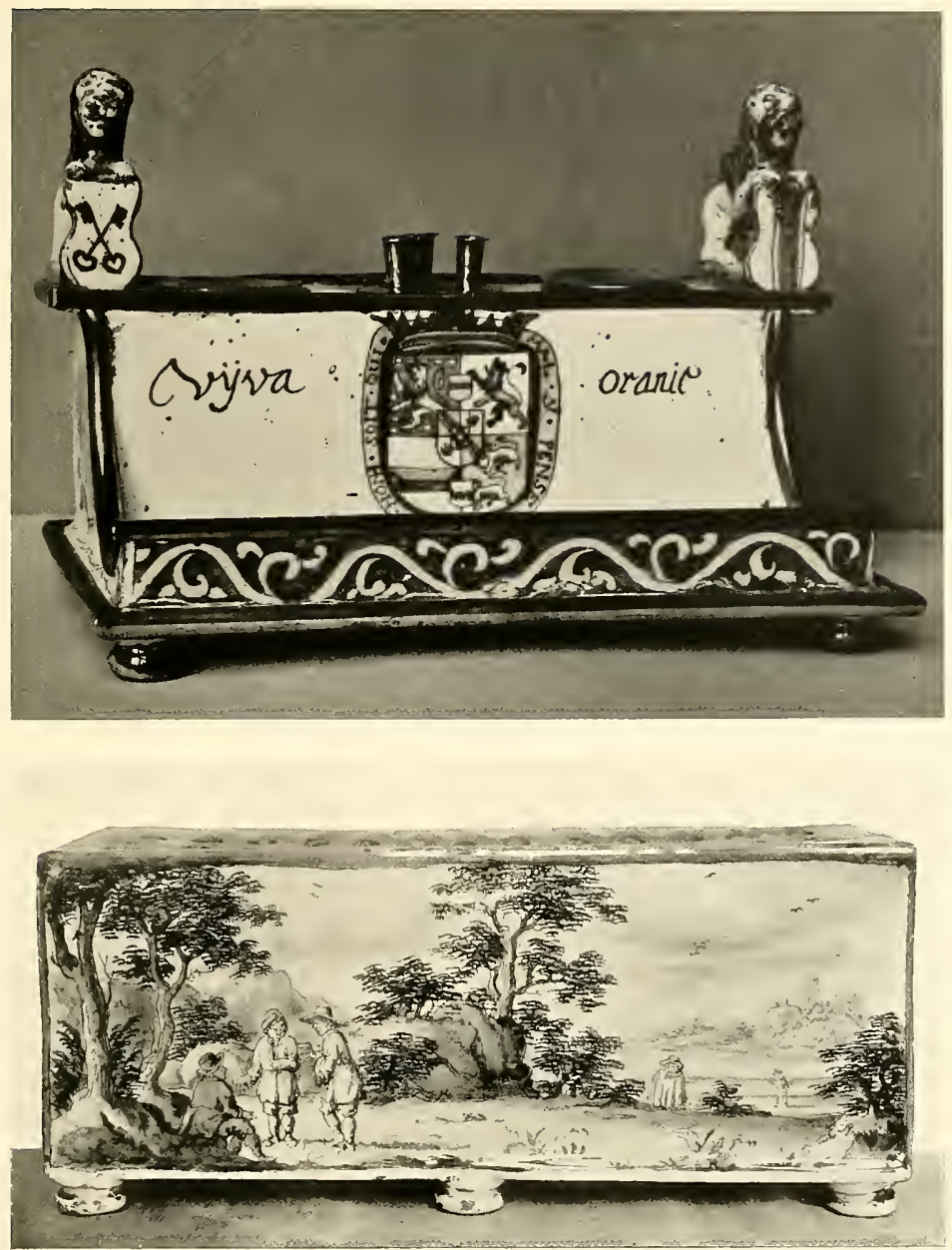


PLATE XIX.

Fig. 30. Jug with ring-shaped body in the middle of which is a figure of a running horse; painted in blue with flowers and insects and the inscription DIRCK JANSE VAN IJSELSTEIJN ANNO

1658. Unmarked. Delft, dated $165^{8}$.

H. 101 ins. $(26 \mathrm{~cm}$.). (See page 70 .)

Nederlandsch 11 useum voor Geschiedenis en Kunst (Rijksmuseum), Amsterdam, No. 195 (Ioudon Collection). 


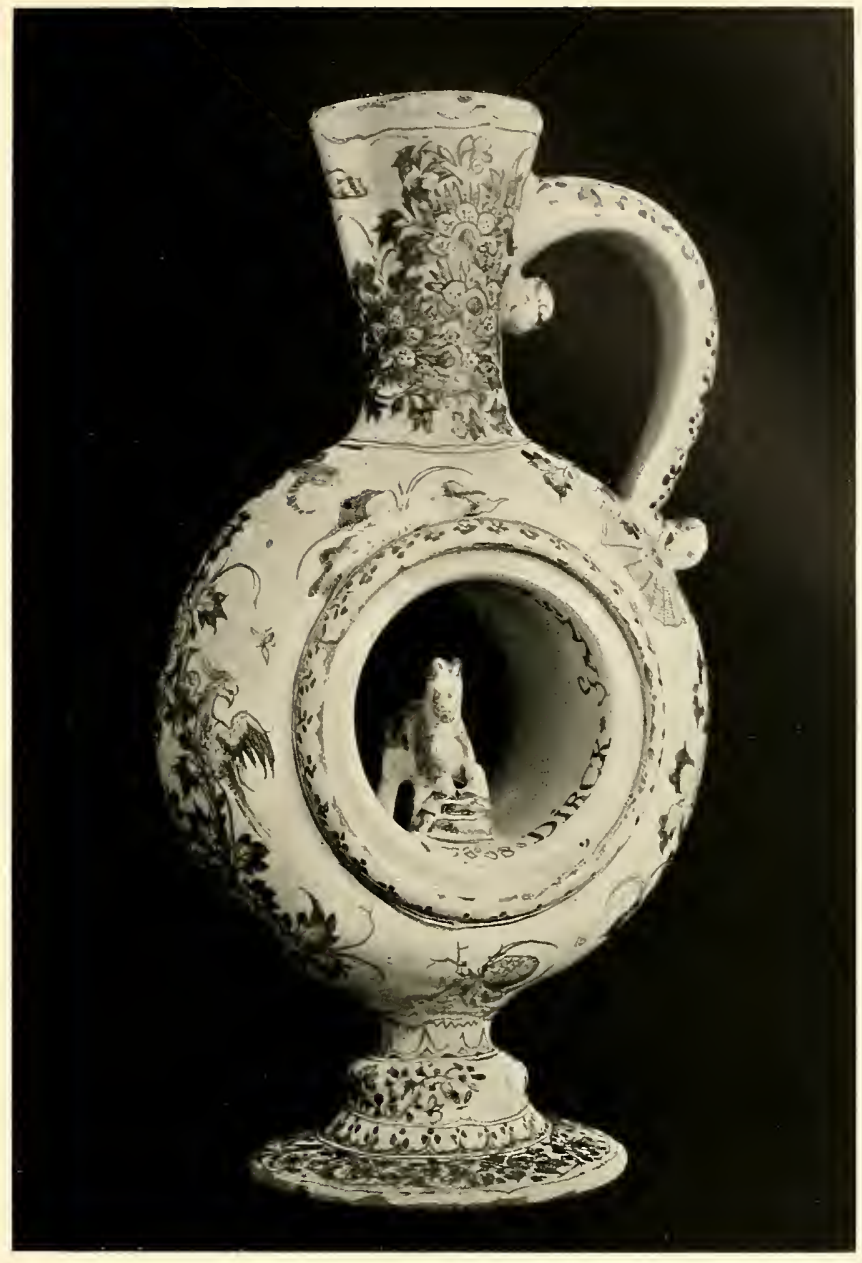




PLATE XX.

Fig. 31. Tile, blue-and-white, with portrait of Robertus Junius, after an engraving

by C. van Queborn of 1645 . Unmarked.

Delft; dated 1660 . H. $7 \frac{1}{4}$ ins. $(18.5$

cm.). (See page 7r.)

Nederlandsch Museum voor Geschiedenis en Kunst (Rijksmuseum), Amsterdam, No. 200. 


$$
\hat{2}
$$




PLATE XX1.

Fig. 32. Large hyacinth-vase, in three sections, one of a pair, painted in blue with manganese-purple trek. The form of the top is based on that of the royal crown of Great Britain and Ireland. Round the lower part, the monogram WMiR (of King William III and Queen Mary) alternates with the motto of the princes of Orange (JE MAINTIENDRAY). Above these are the emblems of England (the rose), France (the fleur-de-lys), Scotland (the thistle) and Ireland (the harp), all repeated. Mark, $A K$ in monogram. Made at Delft between I689 and 1694 for the decoration of Hampton Court Palace, where the pair of vases is still preserved. H. 3 ft. $3 \frac{1}{2}$ ins. ( $1.002 \mathrm{~m}$.). (See page $7 \mathrm{I}$.)

Hampton Court Palace. Copyright of His Majesty the King.

2.j.j.

A 


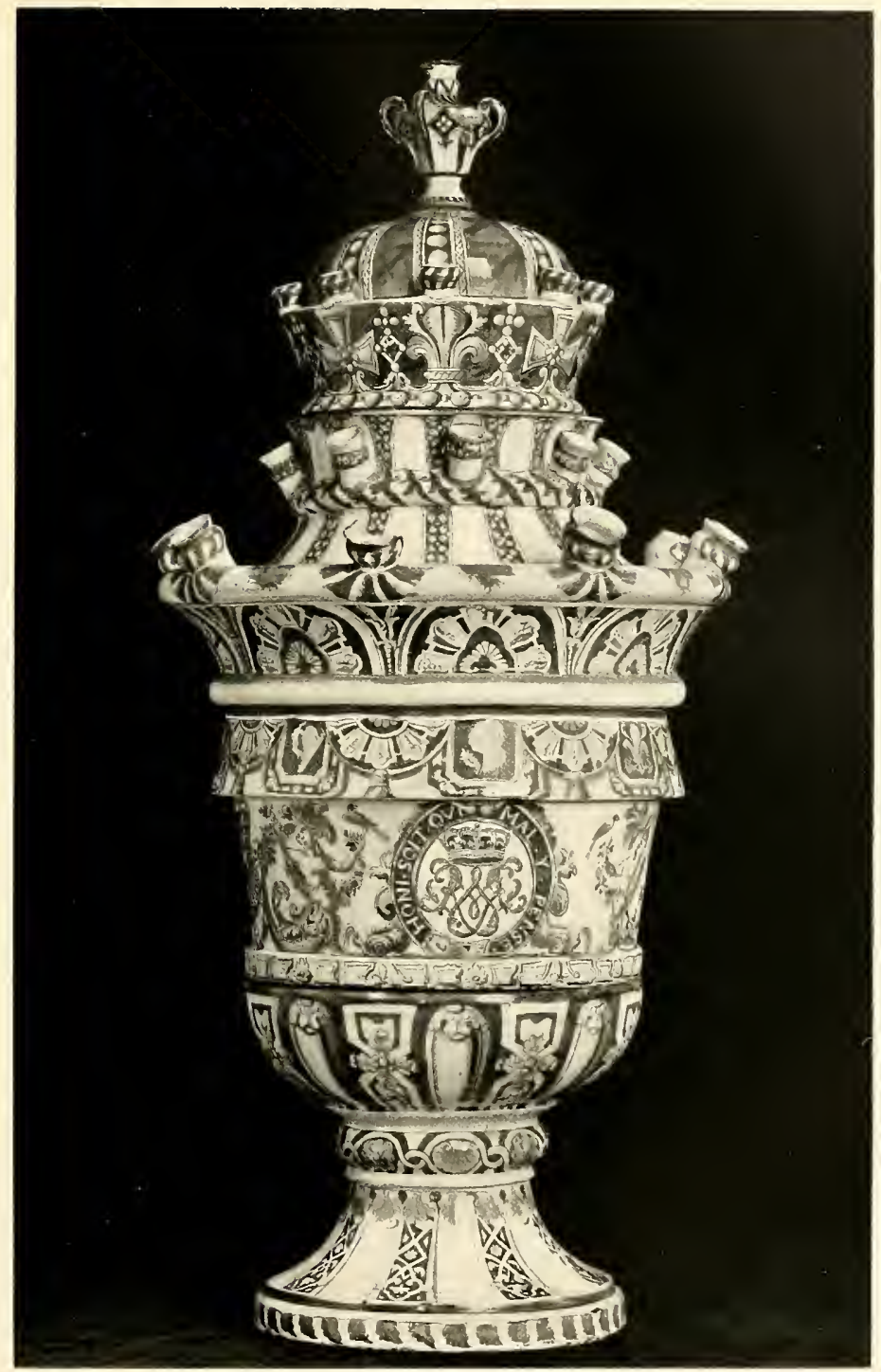




PLATE XXII.

Fig. 33. Large tile, blue-and-white, a landscape with figures, a bridge and distant buildings. Signed $\boldsymbol{F}$. V. Frijtom. Delft; second half of seventeenth century. $2 \mathrm{ft} .0 \frac{1}{2}$ ins. by $3 \mathrm{ft} .4^{\frac{1}{2}}$ ins. (62 by ro $_{3} \mathrm{~cm}$.). (See page 72.)

Nederlandsch Museum voor Geschiedenis en Kunst (Rijksmuseum), No. 213.

\section{F.V. ERYTOM}

Fig. 34. Tile, blue-and-white, with a view of the Fish-market and Meat-market at Delft, with the Old Church in the background. From an engraving by C. Decker in Beschrijvinge der stadt Delft, by Dirck van Bleyswijck, Ist edition, I667. The buildings depicted remain at the present time practically unaltered, apert from restoration and details. Unmarked. Delft; second laalf of seventeenth century. $9 \frac{5}{8}$ ins. by $13 \frac{3}{*}$ ins. $(24.4$ by $33.9 \mathrm{~cm}$.). (See page 72.)

British 11 useum, London. 

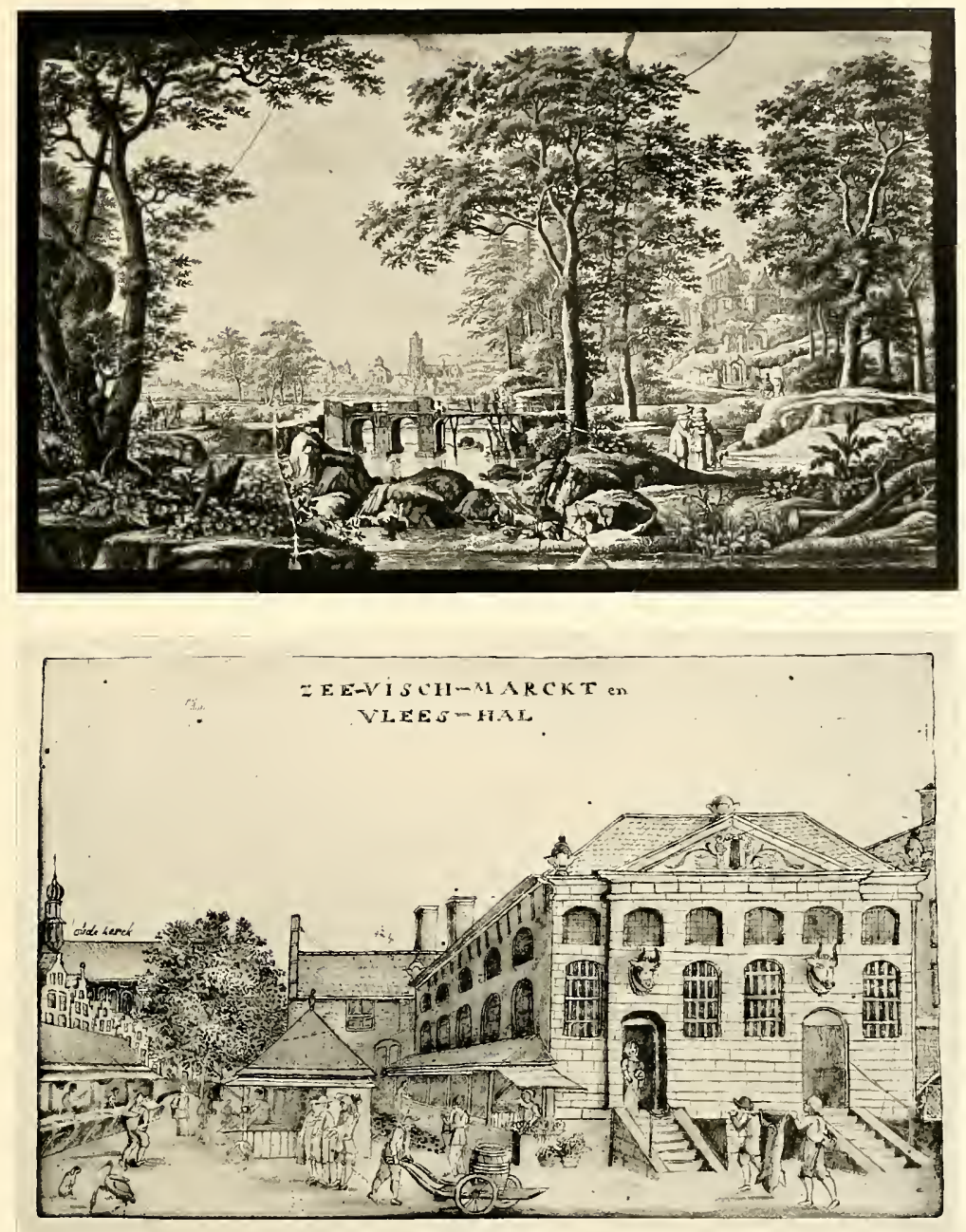


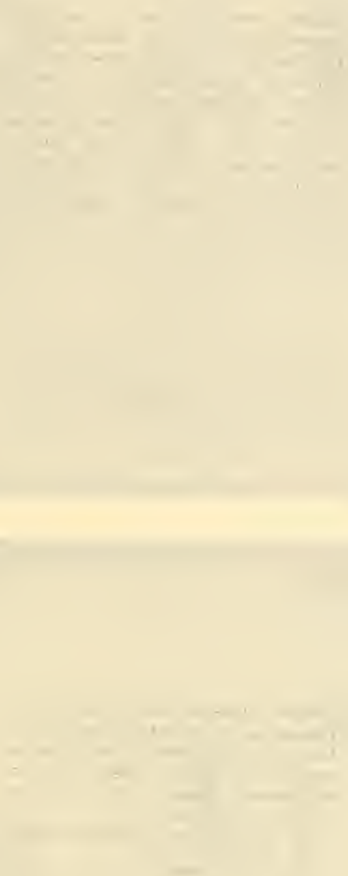
PLATE XXIII.

Fig. 35. Plaque, blue-and-white; a sea-fight, apparently the defeat of the French by the Dutch and English fleets off La Hogue in r692. Signed (on a submerged sail) apparently Rejner; on a plank to the right is also the name 1. Altubon (?). Delft; end of seventeenth century. W. II $1 \frac{1}{4}$ ins. $(28 \mathrm{~cm}$.). (See page 72.)

Musée Céramique, Sèvres, No. 1293.

Fig. 36. Plaque, blue-and-white; Dutch and Chinese sailing vessels off the coast of China, with a fortress. Signed on the back "Rie Reinier." Delft; end of seventeenth century. W. II $\frac{1}{4}$ ins. $(28 \mathrm{~cm}$.$) . (See page 72.)$

II usée Céramique, Sèvres, No. 1292.

Yis

Sietinitr 

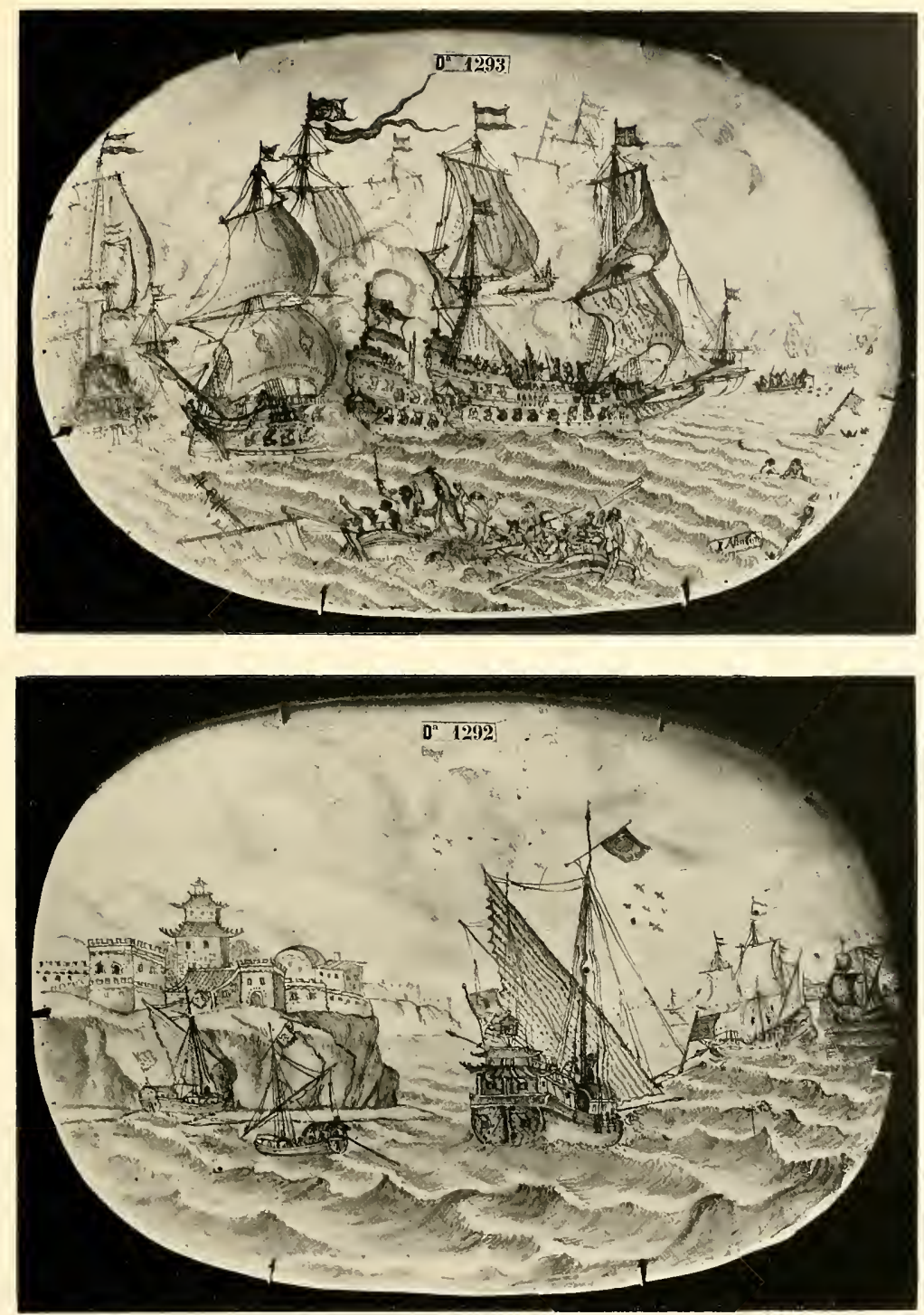


PLATE XXIV.

Fig. 37. Plate, blue-and-white, painted with a Dutch landscape.

Fig. 38. Plate, blue-and-white, painted with an italian landscape. Both unmarked. Ascribed to Frederik van Frijtom. Delft; second half of seventeenth century. D. Io ins. $(25.5 \mathrm{~cm}$.). (See page 72.)

Musées du Cinquantenaire, Brussels (Evenepoel Collection). 

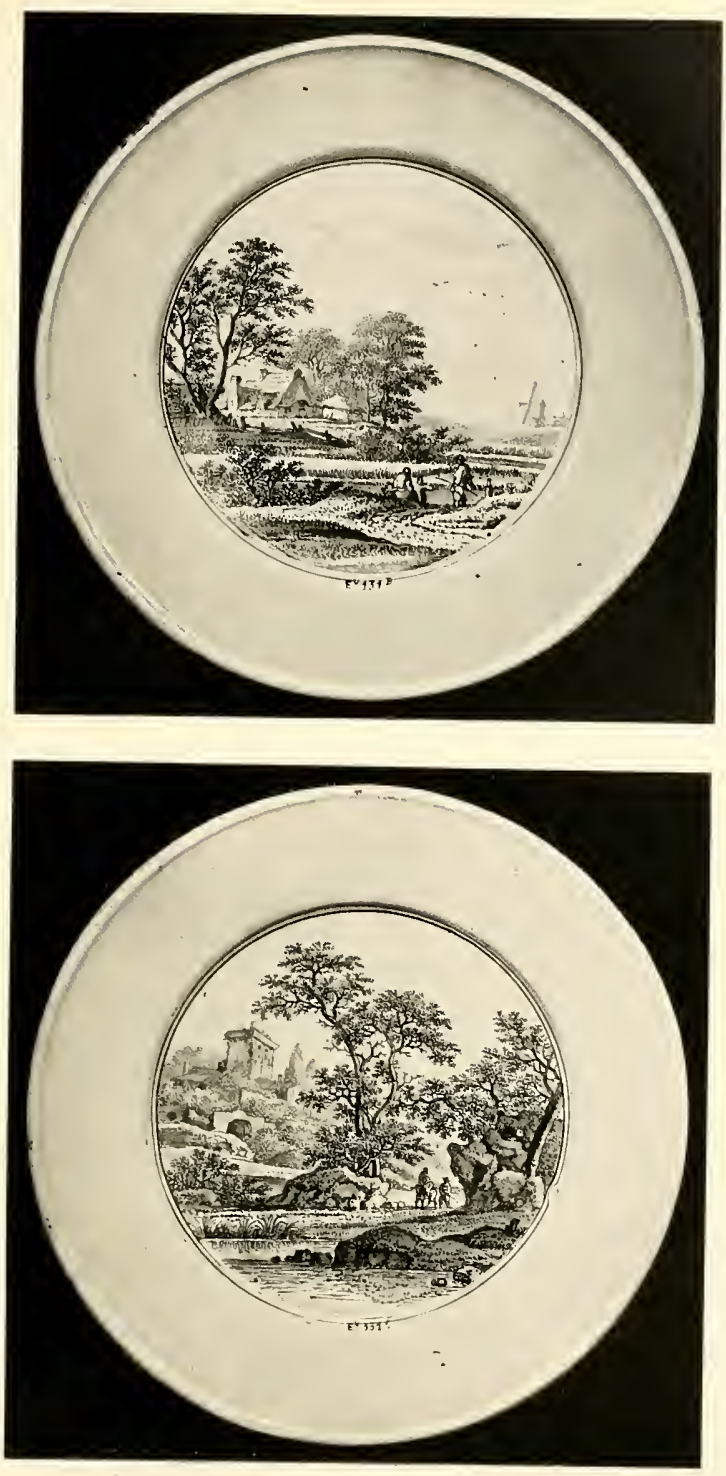


PLATE XXV.

Fig. 39. Octagonal Jug with silver lid; painted on a bluish white enamel in blue outlined in black trek with figures and plants in the Chinese style. Unmarked. Delft, probably made in the Hoppesteyn factory; second half of seventeenth century. H. 8 ins. (20.5 cm.). (See page 75.)

Nederlandsch Museum voor Geschiedenis en Kunst (Rijksmuseum), Amsterdam, No. 243.
Fig. 40. Vase, painted in blue outlined in black trek with floral sprays showing Chinese influence. Marked RHS. Delft, factory of Rochus Hoppesteyn; second half of seventeenth century.

H. 8 ins. (20.5 cm.). (See page 75.$)$ Nederlandsch Museum voor Geschiedenis en Kunst (Rijksmuseum), Amsterdan, No. 241. 

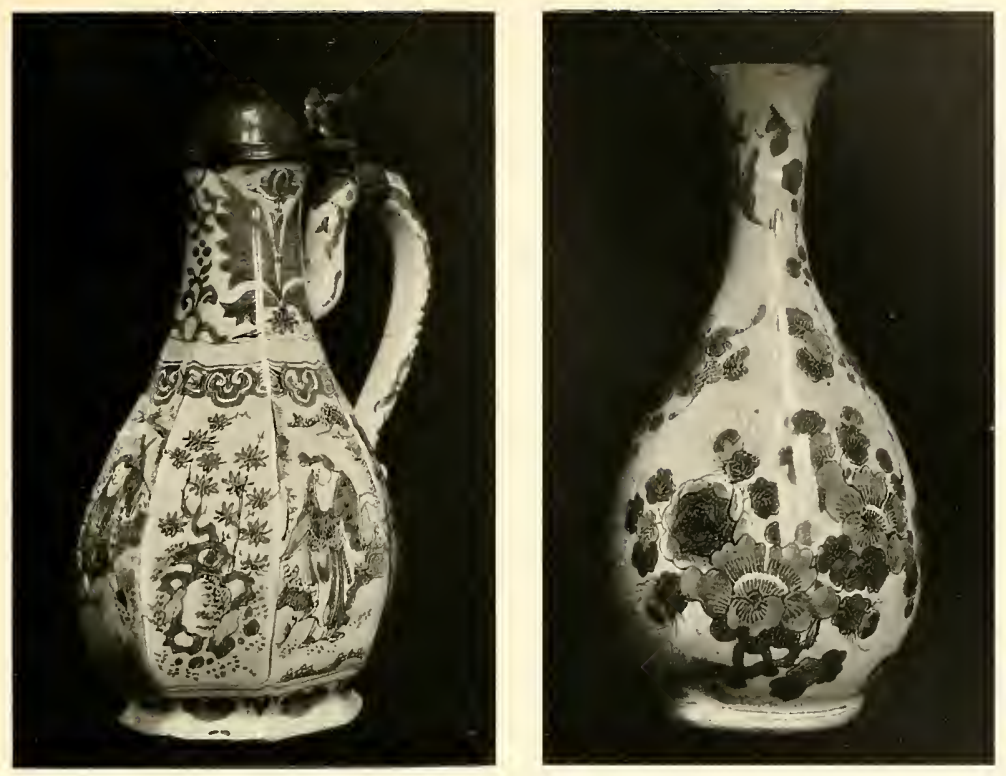


PLATE XXVI.

Fig. 41. Wig-stand painted in blue heavily outlined in deep manganese-purple with Chinese figures, in the style of porcelain of the late Ming dynasty. Mark, SVE in monogram. Delft, made by Samuel van Eenhoorn; second half of seventeenth century.

H. 78 ins. (1 $8.1 \mathrm{~cm}$.). (See page 75. )

Victoria and Albert Museum, London, No. C. 6611909 (Fitzenry Gift).

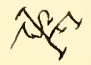




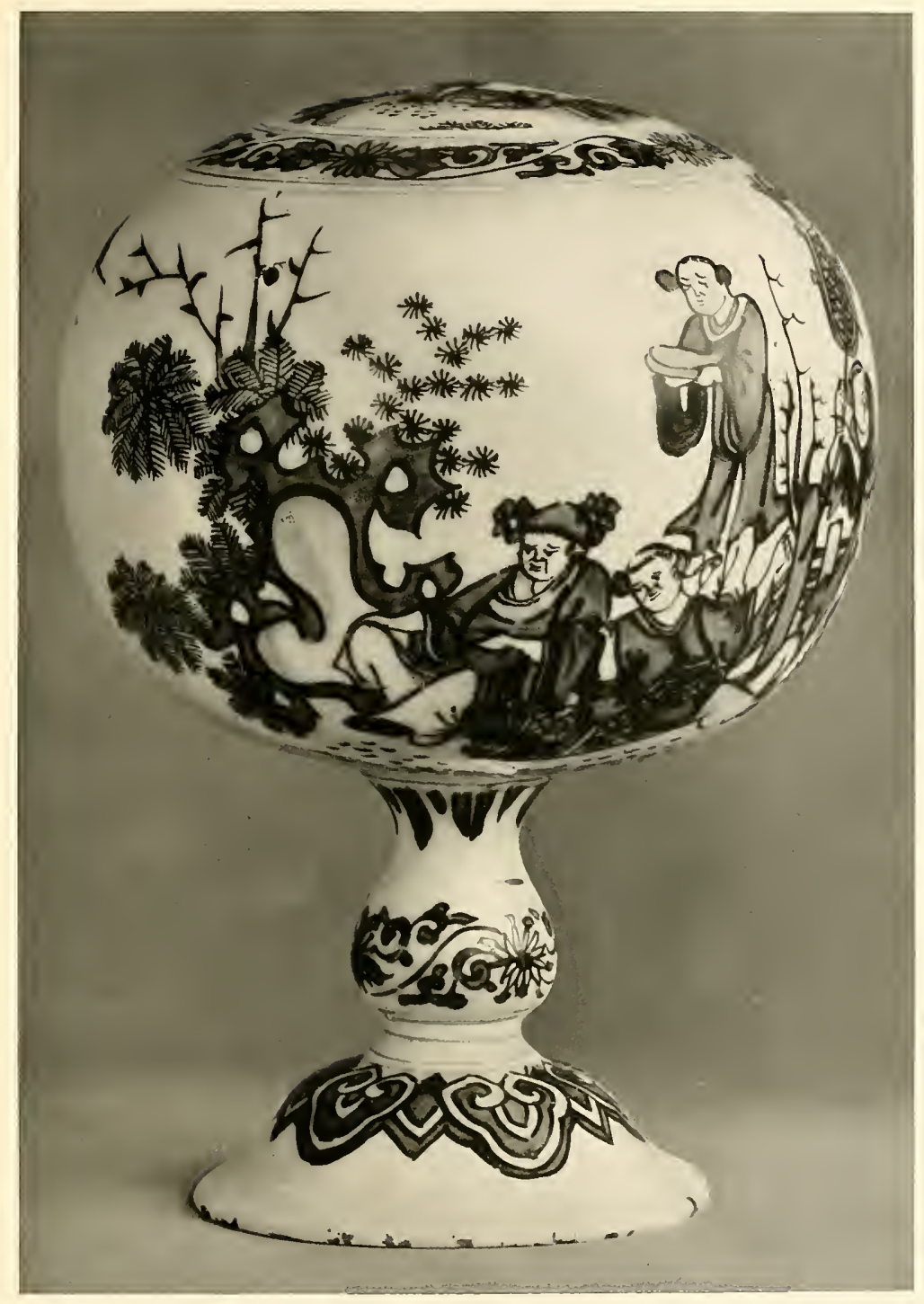




PLATE XXVII.

Fig. 42. Large Vase and Cover painted in blue outlined in manganese-purple with groups of Chinese figures in a landscape and floral borders. Mark, SVE in monogram. Delft, made by Samuel van Eenhoorn; second half of seventeenth century. H. 2 ft. $9 \frac{7}{8}$ ins. $(86 \mathrm{~cm}$.). (See page 75.$)$

Danske Kunstindustrimuseum, Copenhagen. 


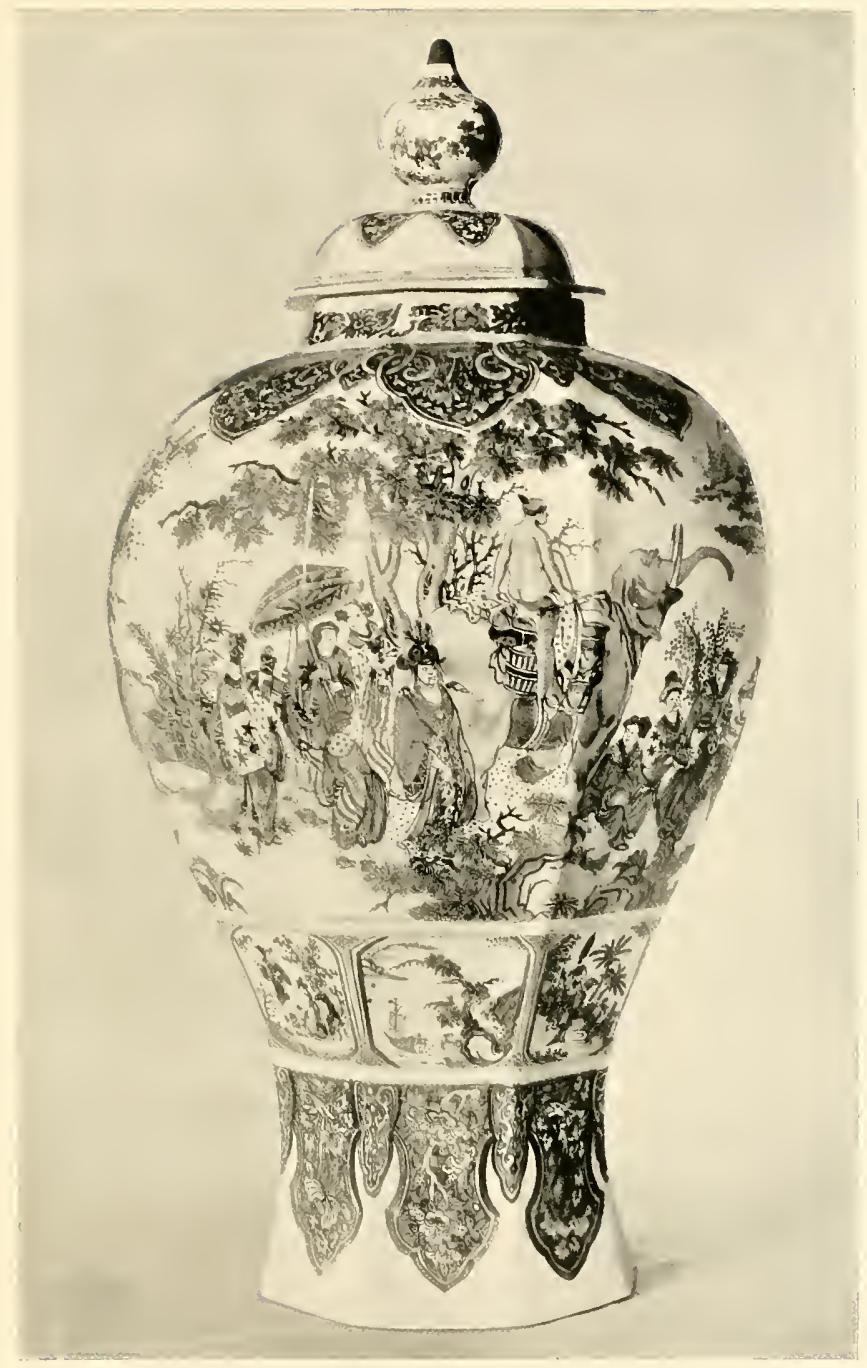




PLATE XXVIII.

Fig. 43. Pair of gourd-shaped bottles, painted in blue, outlined in dark blue treh, with naturalistic and formal flowers. Mark, AK in monogram. Delft, second half of seventeenth century. H. I2! ins. $(31 \mathrm{~cm}$.). (See page 69.)

Victoria and Albert Museum, London, Nos. C. 2369, 2370-1910 (Salting Collection).

Ac

V.1I

Fig. 44. Dish painted in blue, outlined in dark blue trek, with scattered flowers. Mark, LVE or LF in monogram. Delft, made by Lambertus van Eenhoorn or Louwijs Fictoor; late seventeenth or early eighteenth century. D. $19 \frac{1}{2}$ ins. $(49.5 \mathrm{~cm}$.). (See pages 79, 93.)

Victoria and Albert Uuseum, London, No, C. $647-1921$.<smiles>[CaH]</smiles> 

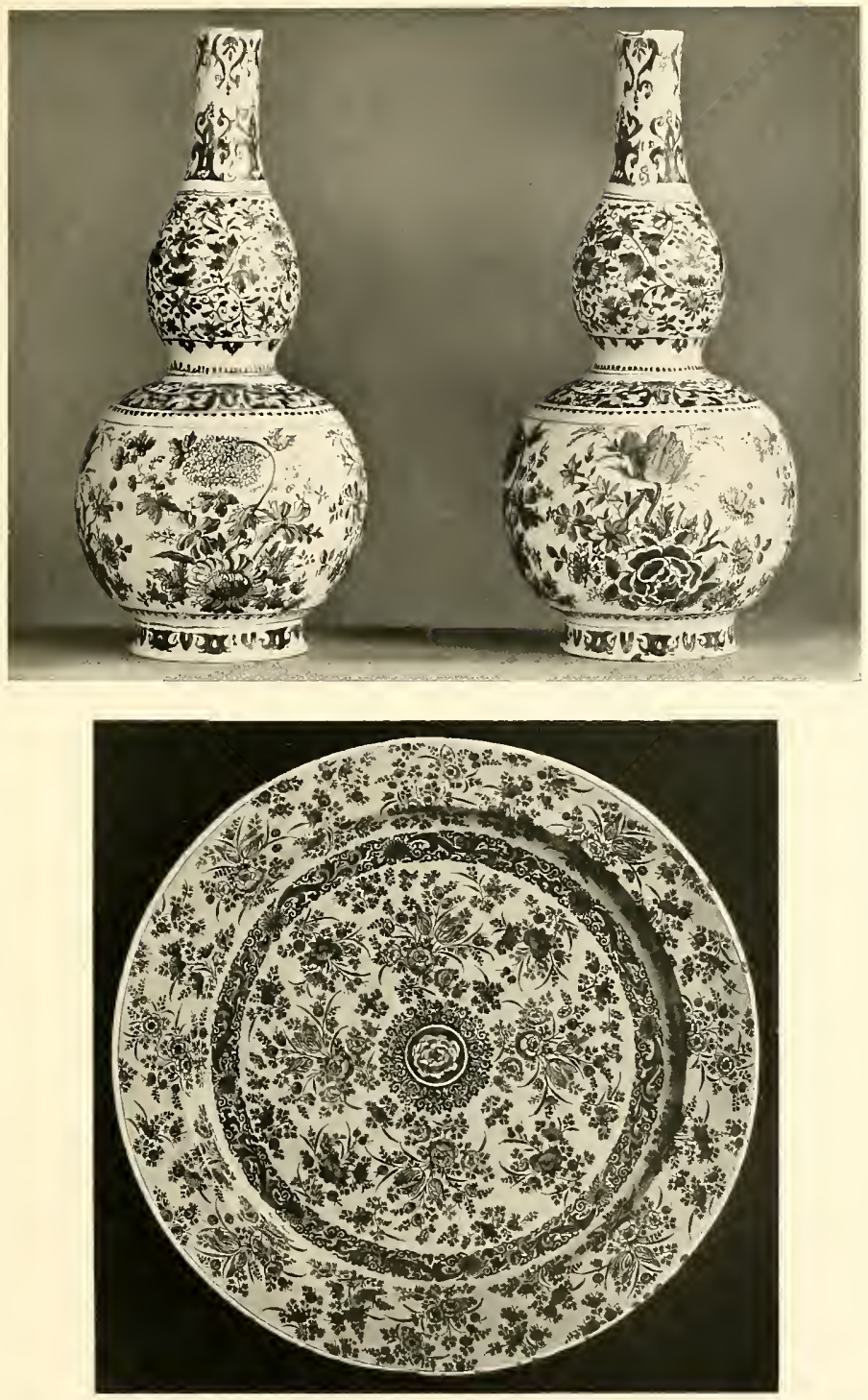

Fig. 45. Jug, painted in blue with a musicparty in an interior and guests arriving; on the neck, a lady and gentleman walking in a landscape. Mark, R. Delft, made at the factory at the sign of the "Rose" (de Roos), second quarter of eighteenth century. H. 9 ins. $(22.9 \mathrm{~cm}$.). (See page 87.$)$

Victoria and Albert Museum, London, No. 1004-

1853.

\section{R}

Fig. 46. Plate painted in bright blue, one of a set of twelve symbolising the signs of the Zodiac (Cancer). Signed on the back J. Thornhill fecit. Delph Aug. I7II. Painted by Sir James Thornhill or from his design; subsequently in the possession of his daughter, Mrs. Hogarth, and in the collection of Horace Walpole at Strawberry Hill,

Middlesex. Delft; dated 17II. D. 8 ins. $(20.3 \mathrm{~cm}$.). (See page 83.$)$

British Museum, London.

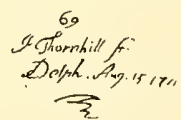



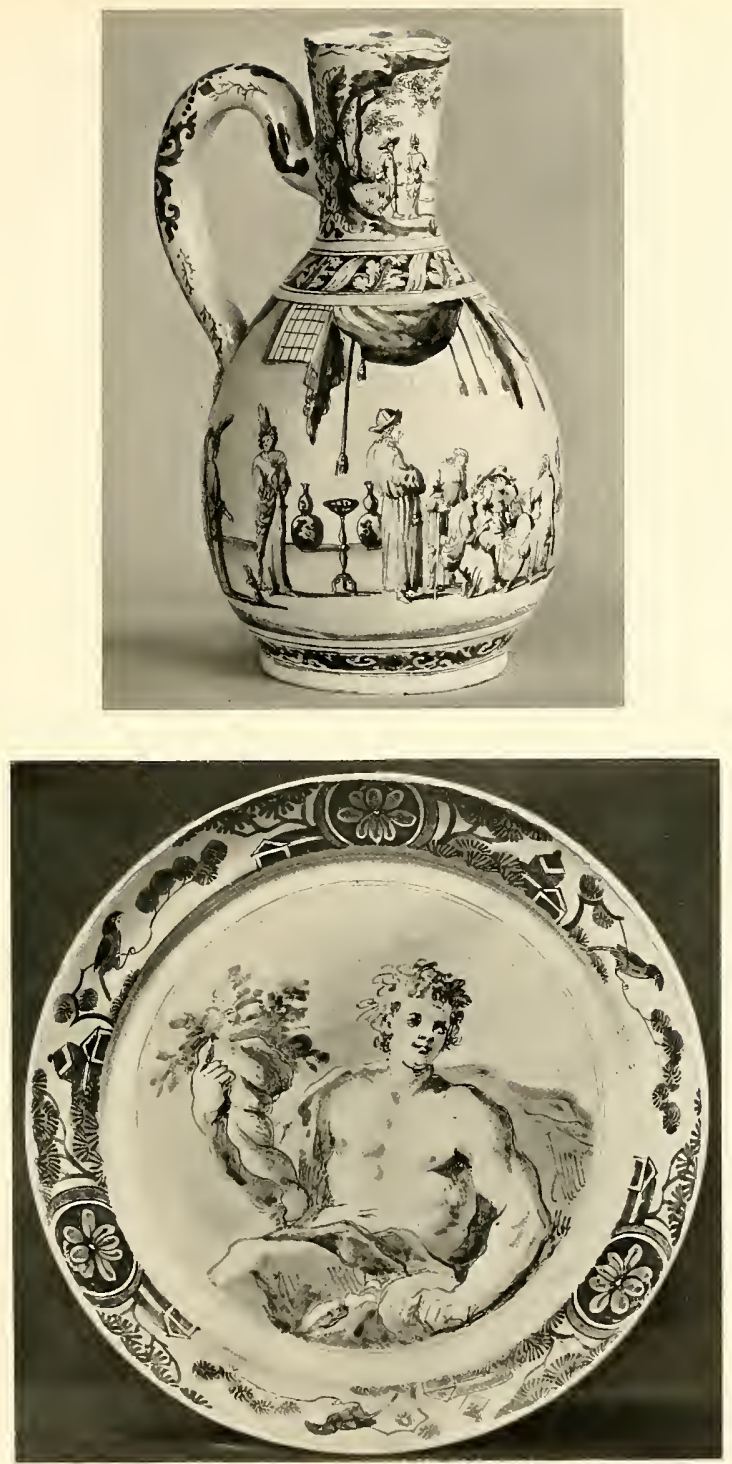


Fig. 47. Dish, blue-and-white, with scenes from the life of Christ in medallions reserved amongst foliated ornament with angeis; the subject of the large central medallion, Christ before Caiaphas, is copied from a print by Hendrik Goltzius. Mark, IVH. Delft; dated I729. D. I6 ins. $(40.5 \mathrm{~cm}$.). (See page 84. )

Nederlandsch Huseum voor Geschiedenis en Kunst (Rijksmuseum), Amsterdam, No. 270.

IVH

i>29

Fig. 48. Dish, blue-and-white, with Dutch landscapes in panels reserved amongst floral scrollwork; the largest, a view of Twisk near Enkhuizen, is copied from an engraving of 1726 . Signed I $74^{2}, 3$. v. Kuijk. Delft, painted by Michiel van Kuijk and dated $\mathbf{1} 742$.

D. 14 ins. $(35.6 \mathrm{~cm}$.). (See page 85.$)$

Tenbosch Collection, Liverpool. 

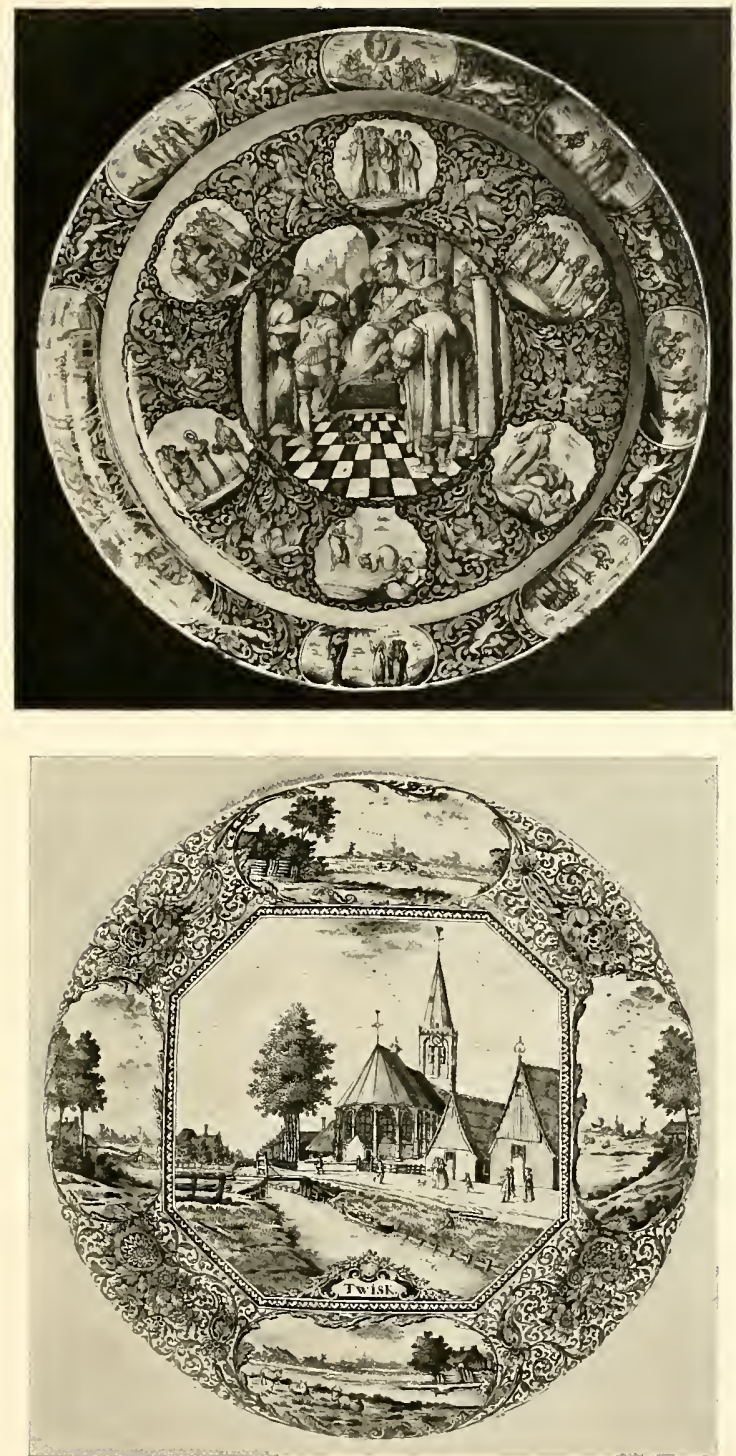


Fig. 49. Kettle and brazier, blue-and-white, with Chinese design of birds and

flowers in a garden. Unmarked. Delft; dated 1744. H. II $\frac{3}{8}$ ins.

(29 cm.). (See page 84.)

Nederlandsch Museum voor Geschiedenis en Kunst (Rijksmuseum), Amsterdam, No. 275.

Fig. 50. Dish, blue-and-white, with Chinese floral subjects in panels reserved amongst leafy scrollwork with amorini. Unmarked. Delft; first half of eighteenth century. D. $15 \frac{3}{4}$ ins. (39 cm.). (See page 85. )

Tenbosch Collection, Liverpool. 

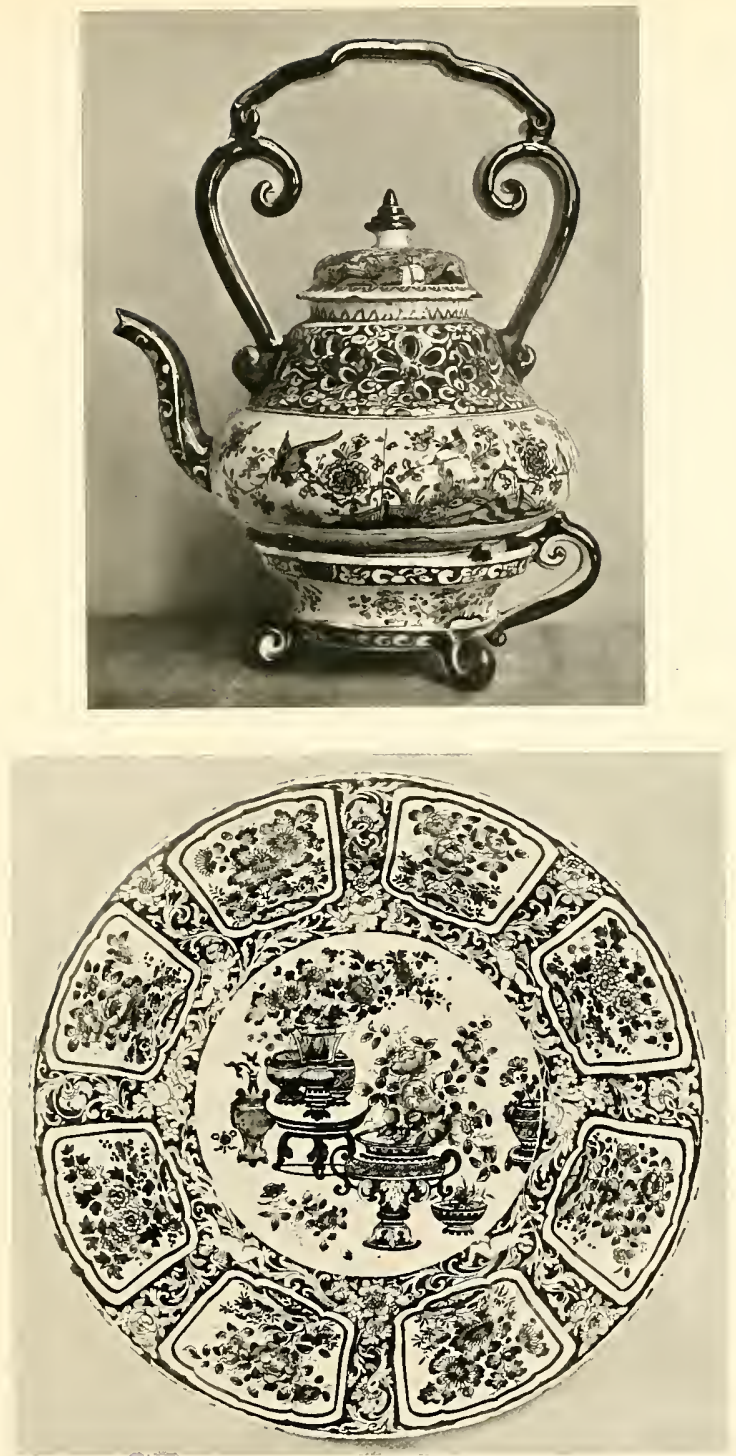


PLATE XXXII.

Fig. 5I, a and b. Violin painted in blue on one side with a ballroom scene, on the other with peasants dancing outside a tavern (the upper part of the neck restored). Unmarked. Delft; second quarter of eighteenth century. H. 25 ins. $(63 \mathrm{~cm}$.). (See page 87. )

Nederlandsch Museum voor Geschiedenis en Kunst (Rijksmuseum), Amsterdam, No. 299 (Loudon Collection). 

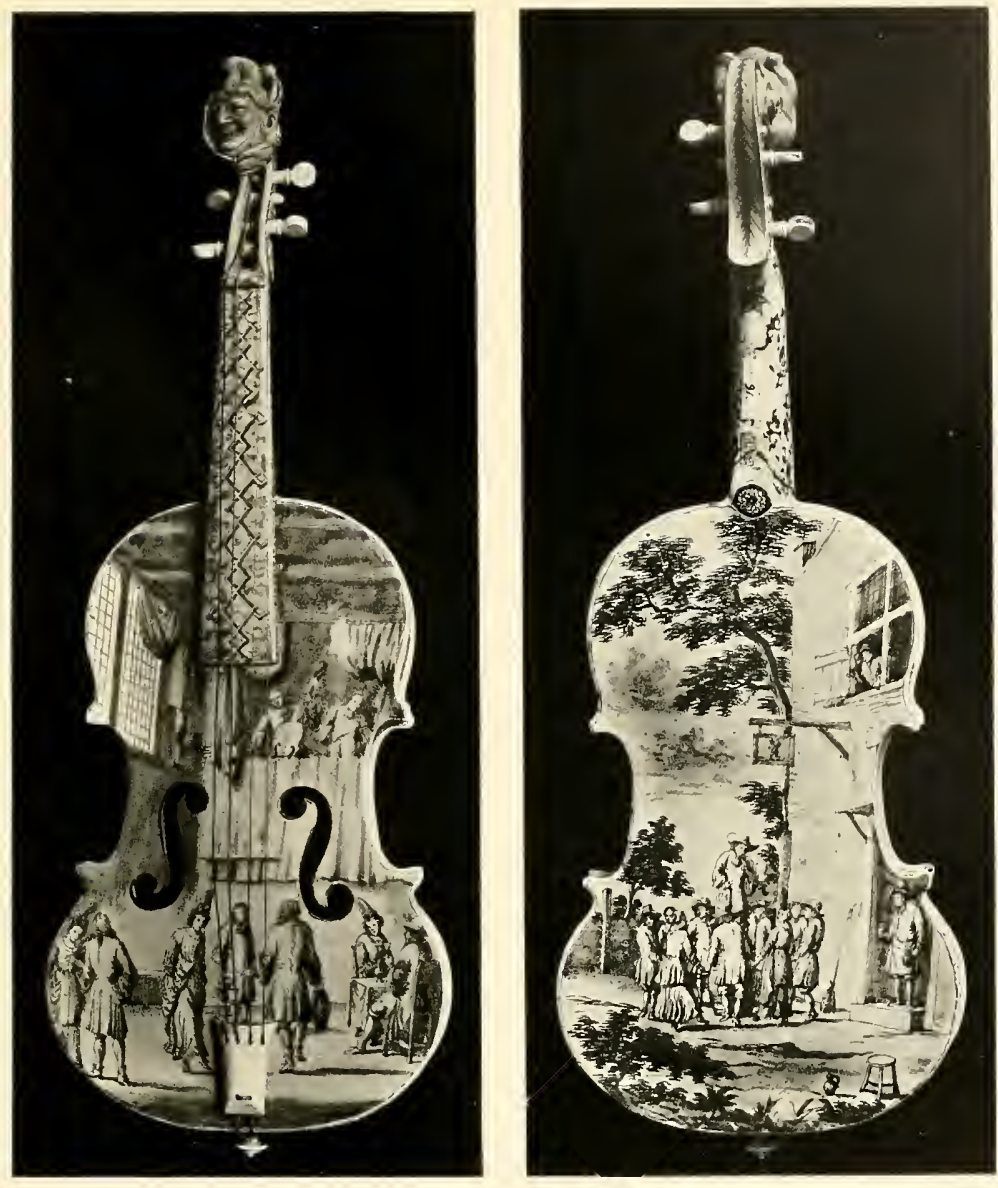

Fig. 52. Teapot, reeded, with Chinese plants and borders in blue, red, pale green and manganese-purple of the grand $\mathrm{feu}$, on white ground. Unmarked. Delft, style of the factories of Lambertus van Eenhoorn and Louwijs Fictoor; first quarter of eighteenth century. H. 4 ins. (12 cm.). (See page 93. .)

Nederlandsch Museum voor Geschiodenis en Kunst (Rijksmuseum), Amsterdam, No. 325 (Loudon Collection).

Fig. 53. Dish, reeded, painted in blue, red, yellow and green of the grand feu on a white ground with a design of flowers in panels adapted from Japanese (1mari) porcelain, the socalled "lightning" (bliksem) pattern. Mark, WK. Delft; first half of eighteenth century. W. $3_{3}^{\frac{5}{8}}$ ins. $(34.5 \mathrm{~cm}$.). (See page 98. )

Victoria and Albert Husezm (formerly in the Museum of Practical Geology), London, No. 4739-1901.

W 

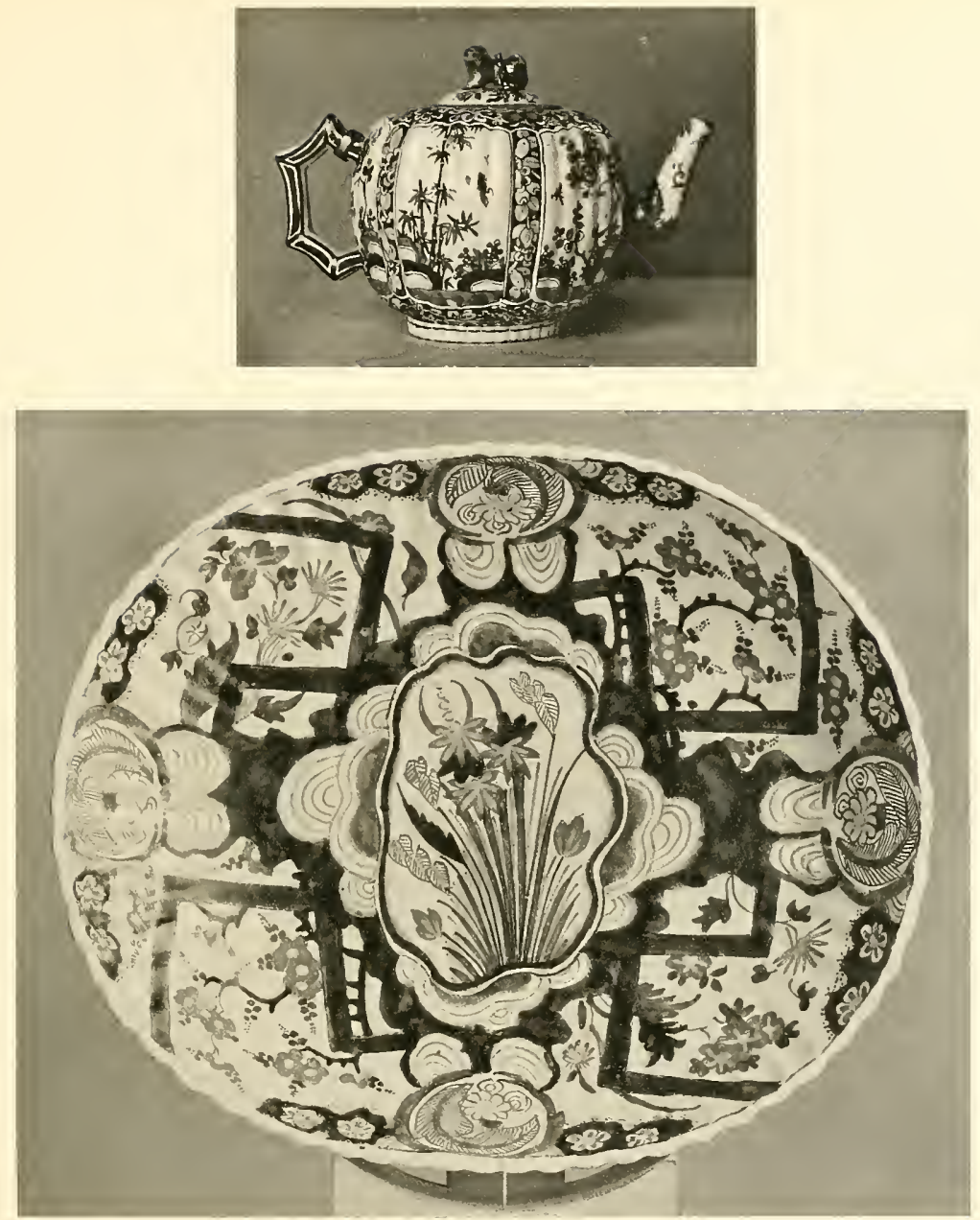



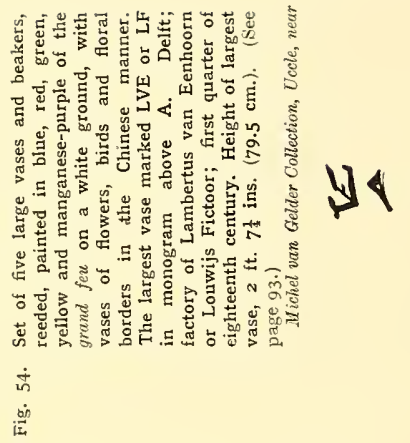




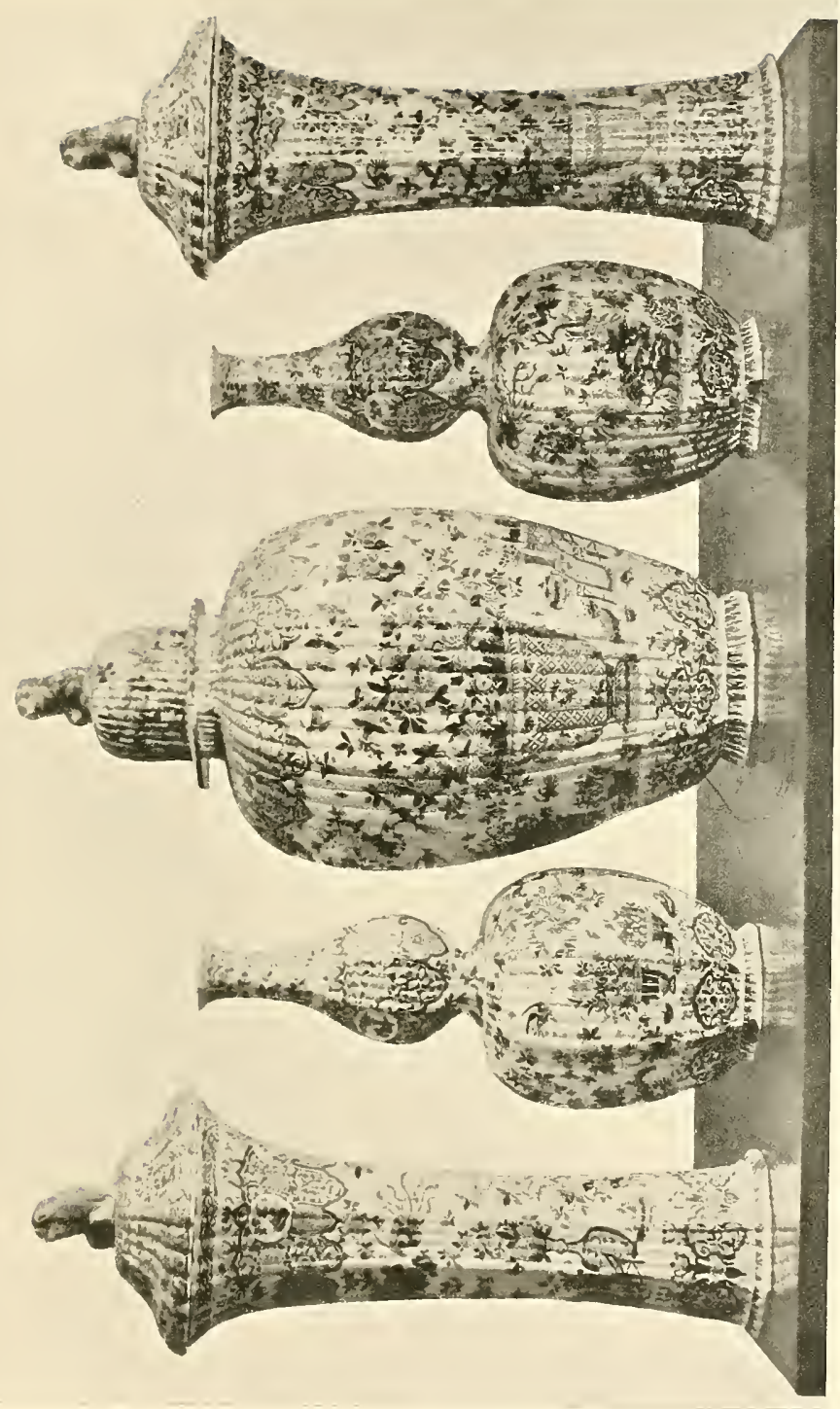




Fig. 55. Jug with metal lid, decorated with finely painted flowers of pseudoOriental character in red, blue, green and touches of manganese-purple of the grand fen on a white ground. Marked, GH. Delft; about 1700 .

H. $9{ }^{3}$ ins. $(25 \mathrm{~cm}$.$) . (Hee page 98$.)

Vederlundsch Museum worr Geschiedenis en Kunst

(Rijksmuseum), Amsterdum, No. 3t1.

\section{$\mathrm{CH}$}

112

ip

Fig. 56. Coffee-pot, reeded, with Chinese floral design in blue, red, pale green, manganese-purple and yellow of the grand feu on a white ground. Mark, LF in monogram above 3 and FDK. Delft, made by Louwijs Fictoor, proprietor of the "Double Bottle" (Dubbelde Schenkian) factory; first quarter of eighteenth century. H. Io ins. $(25.5 \mathrm{~cm}$.). (See page 93.$)$

Tederlandsch M use um rom Geschiedenis en Kunst (Rijks:nuswam). Amsterdam. No. 327 (Loudon ('nllection). 

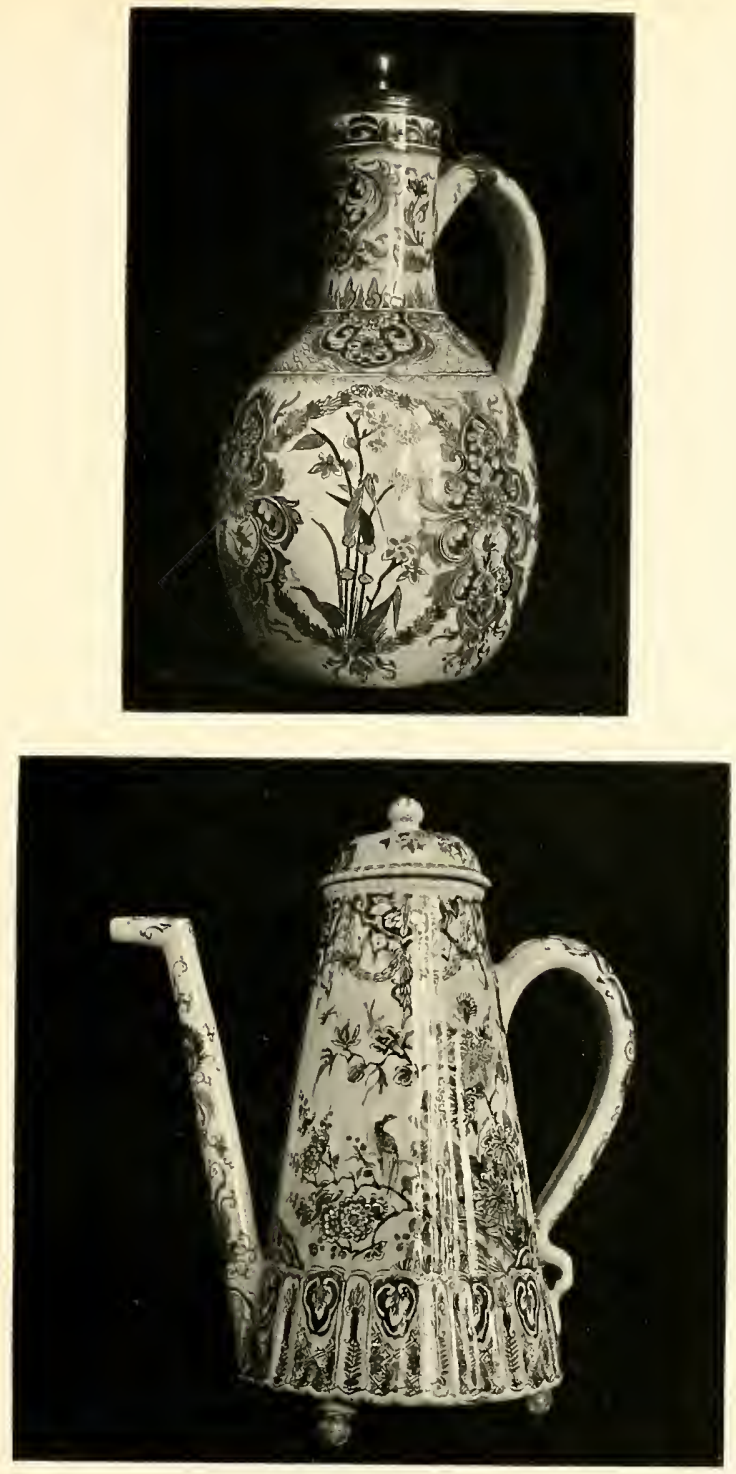

PLATE XXXV..

Fig. 57. Vase, ribbed, painted with floral ornament of Near Eastern character in blue, red, green, yellow and manganese-purple of the grond feu on a white ground. Mark, Roos. Delft, made at the "Rose" factory; about 1700 . H. $8 \frac{7}{8}$ ins. $(22.5 \mathrm{~cm}$ ). (See page 97.$)$

Nederlandsch Museum voor Geschiedenis en Kunst (Rijksmuseum), Amsterdam, No. 335.

Roos 


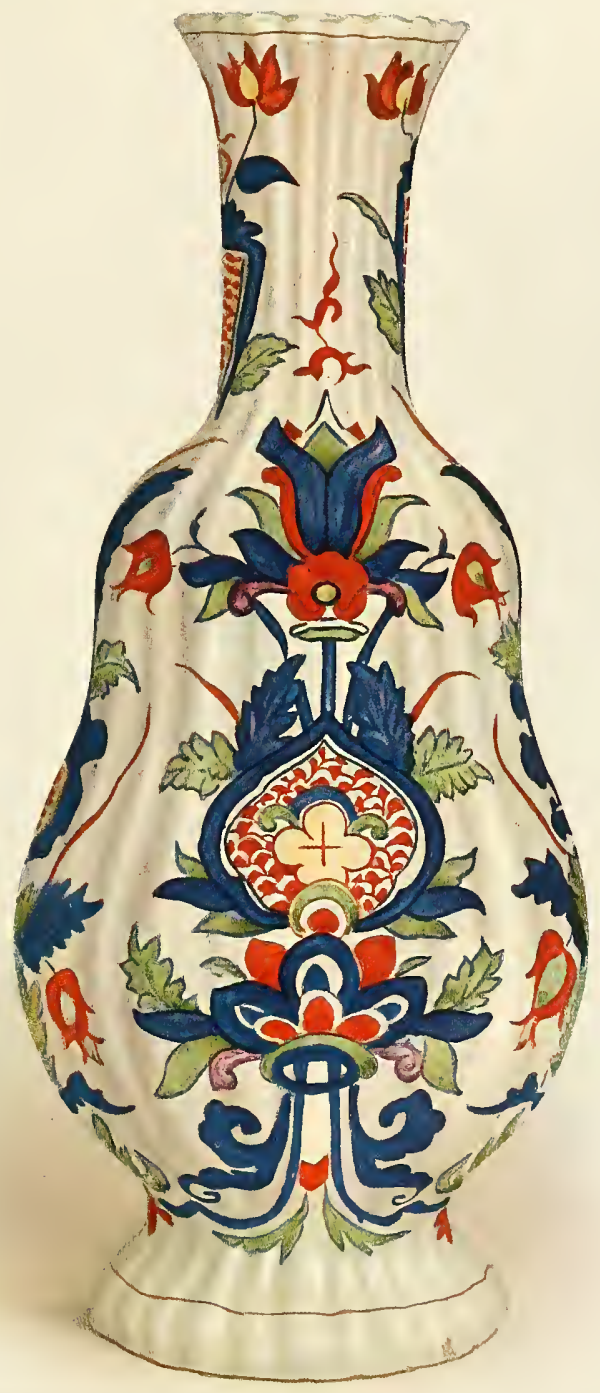




PLATE XXXVII.

Fig. 58. Set of three vases and two beakers, with Chinese floral ornament in red, blue, green and manganese-purple of the grand feu on a white ground. Mark, Roos. Delft, made at the "Rose" factory; early eighteenth century. Height of the largest vase, $15^{\frac{1}{2}}$ ins. ( $39.5 \mathrm{~cm}$.). (See page 97.)

Victoria and Albert Miseum, London, Nos. C. 247 to $251-1914$.

\section{Roos}



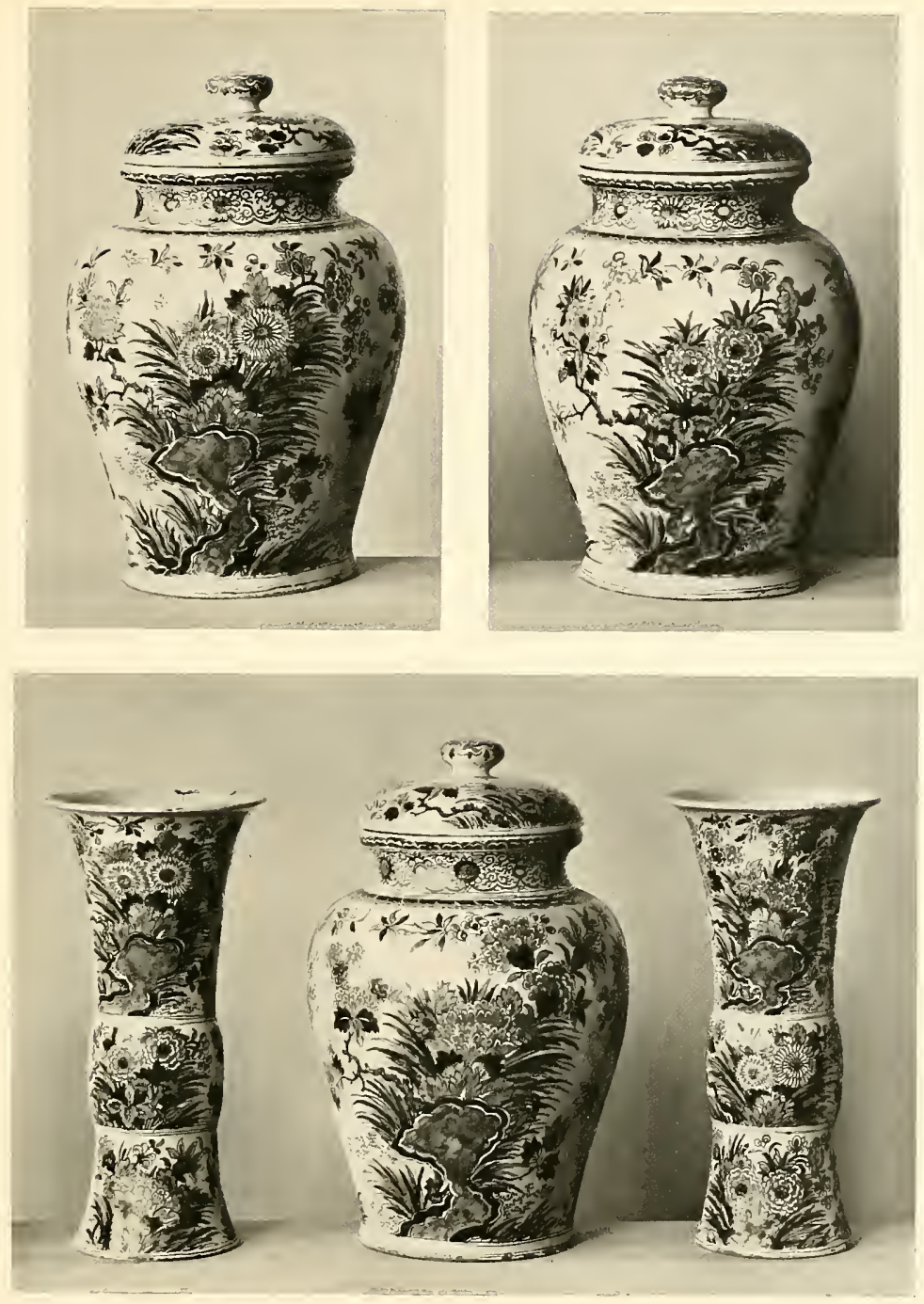


Fig. 59. Dish, painted in blue, red, green, manganese-purple, yellow and black of the grand feu on a white ground with Chinese animals and birds in landscapes between floral borders; the design adapted from famille verte porcelain of the reign of $\mathrm{K}$ 'ang $\mathrm{Hsi}$. Unmarked. Delft, probably made at the "Rose" factory; about 1700 or early eighteenth century (restored). D. $15^{3}$ ins. $(40 \mathrm{~cm}$.$) . (See page 97.)$

Nederlandsch Huseum voor Geschiedenis en hinnst (Rijksmuseum), Amsterdam. No. 337 (Loudon Collection).

Fig. 60. Dish painted in red, blue and yellowish green of the grand feu with scattered flowers and panelled border. Unmarked. Delft, perhaps made by Louwijs Fictoor or Lambertus van

Eenhoorn; first quarter of eighteenth century. D. 18 ins. $(45.5 \mathrm{~cm}$.). (See page 93.)

Michel van Gelder Collection, Uccle, near Brussels. 

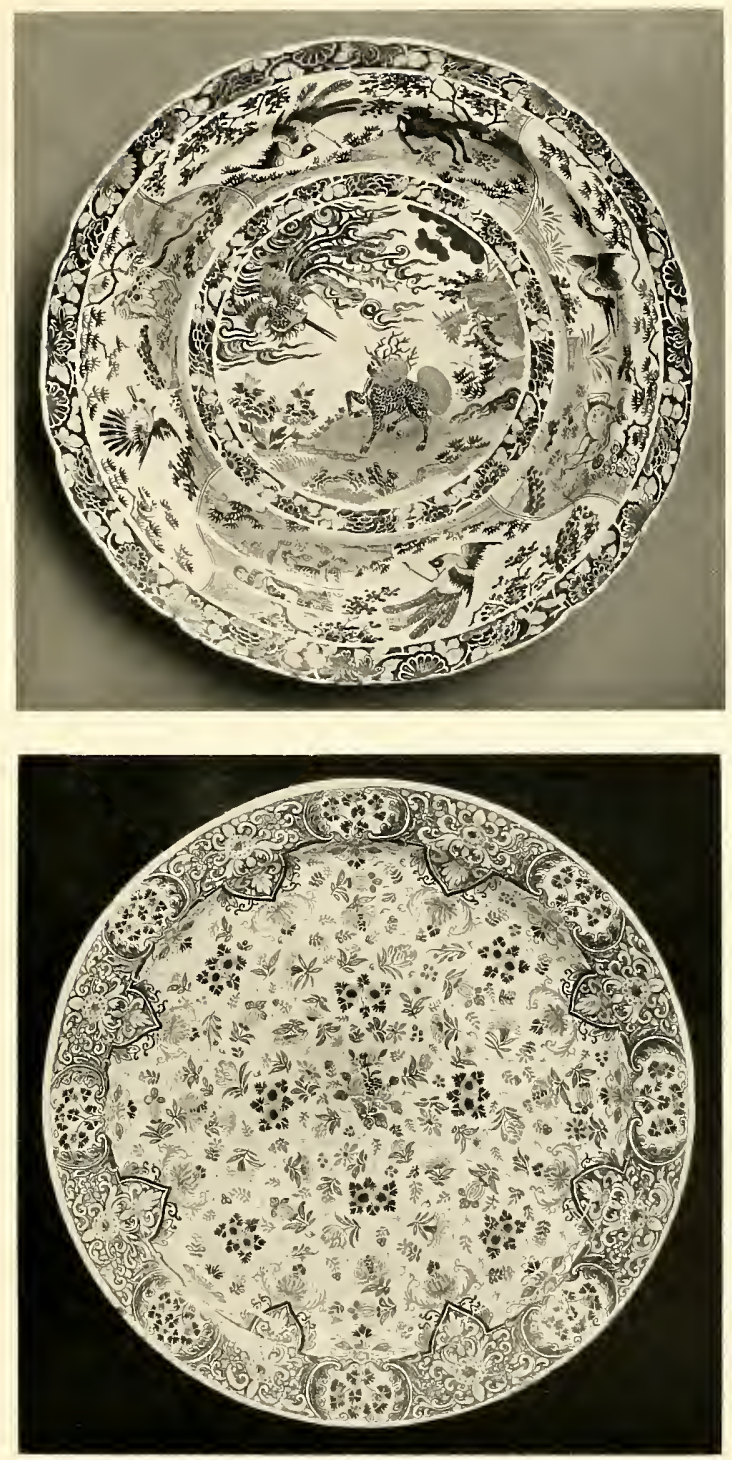


Fig. 6r. Wall-plaque, one of a pair painted in blue, red, green, manganese-purple and yellow of the grand feu on a white ground with Chinese flowering plants and birds within a border of floral ornament with reserved medallions. Mark, IVK. Delft; dated 7 Juni 1739. H. $141^{3}$ ins. $(37.5 \mathrm{~cm}$.). (See page 93.)

Nederlandsch $\boldsymbol{M}$ useum voor Geschiedenis en $K$ unst (Rijksmuseam), dmsterdam, No. 328 (Loudon Collection).

$711 N 1$

1739

$1 \vee K$

Fig. 62. Plate painted in colours of the grand fer on a white ground. In the middle, a group of Chinese crossing a bridge, in blue, with touches of red, bright yellow and green; on the rim, lealshaped panels with floral sprays in dark blue, red and manganese-purple on a yellow ground, separated by red diaper pattern. Unmarked. Delit; first quarter of eighteenth century.

D. ro ins. $(25.5 \mathrm{~cm}$.). (See page 98 .)

Hichel van Gelder Collection, Uccle, near Brussels. 

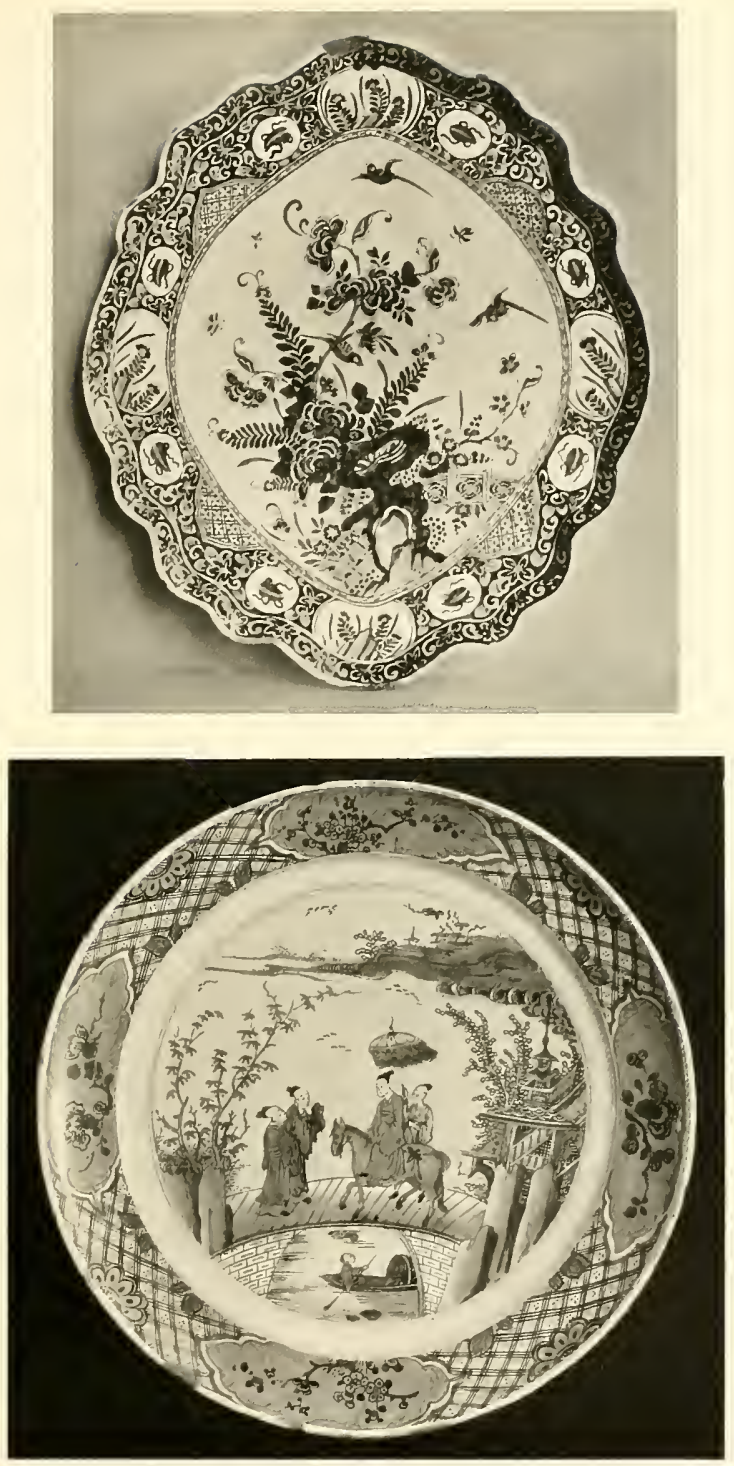

PLATE XL.

Fig. 63. Tile with a group of peasants in a hilly landscape, painted in grey and blue of various tones, pinkish buff, brown, yellow and green of the grand fcu. Ascribed to Gijsbert Verhaast. Delft; late seventeenth century. 9 ins. by 8 ins. (23 by $22 \mathrm{~cm}$.). (see page 98.$)$

I usée Cérumique, Sèves, No. 1378. 


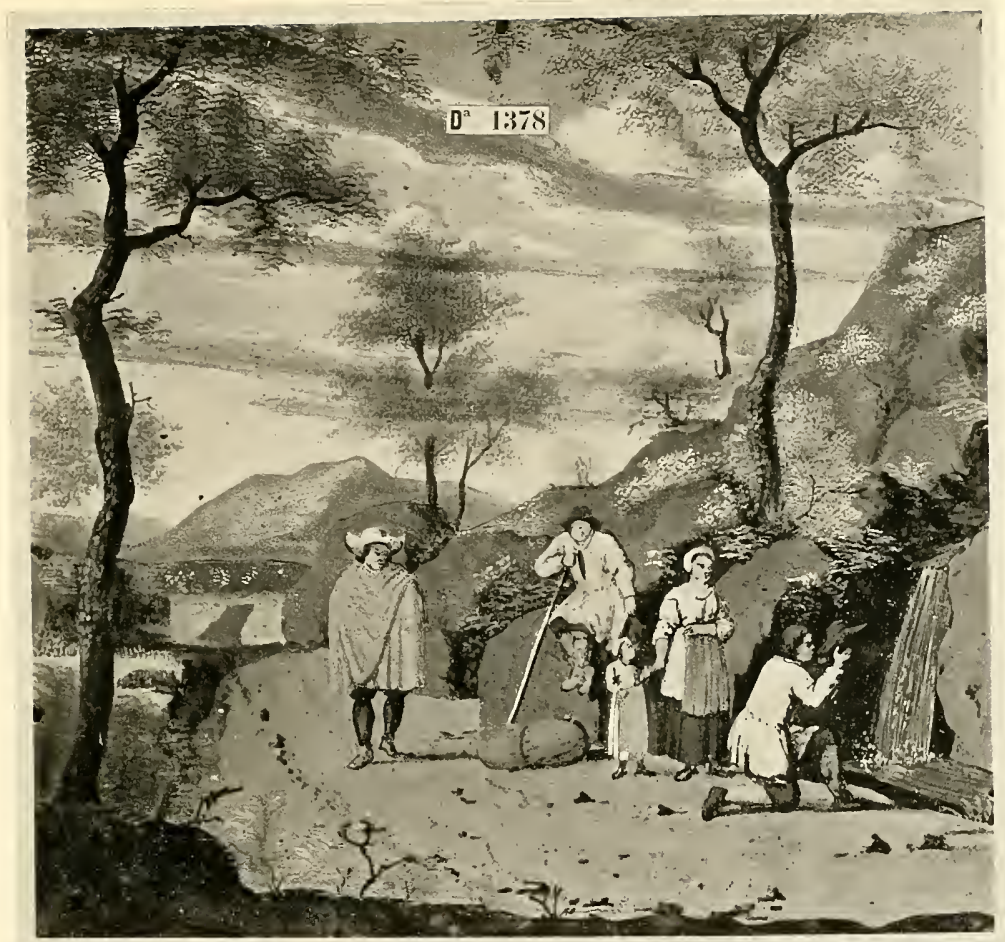




Fig. 65. Teapot, painted with floral ornanent in red, orange and greyish green of the grand feu in white reserves on a black ground. Mark, APK in monogram. Delft, made by Adriaen Pijnacker; first half of eighteenth century. H. $5_{8}^{1}$ ins. $(13 \mathrm{~cm}$.). (See page ro3.)

Vederlandsch Museum voor Geschiedenis en Kunst (Rijksmuseum), Amsterdam, No. 3.46 (Lomdom Collection).

$\mathbb{R}$

Fig. 66. Three octagonal vases, probably from a set of five or seven, reeded and painted with stylised floral designs in red, orange and greyish green of the grend feu in white reserves on a black ground. Mark, APK in monogram and No. 8. Delft, factory of Adriaen Pijnacker; first haif of eighteenth century. Height of largest vase $8_{5}^{5}$ ins. (22 cm.). (See page ro3.)

Clainpamain r'ollection, Lille.

\section{足 \\ N.}



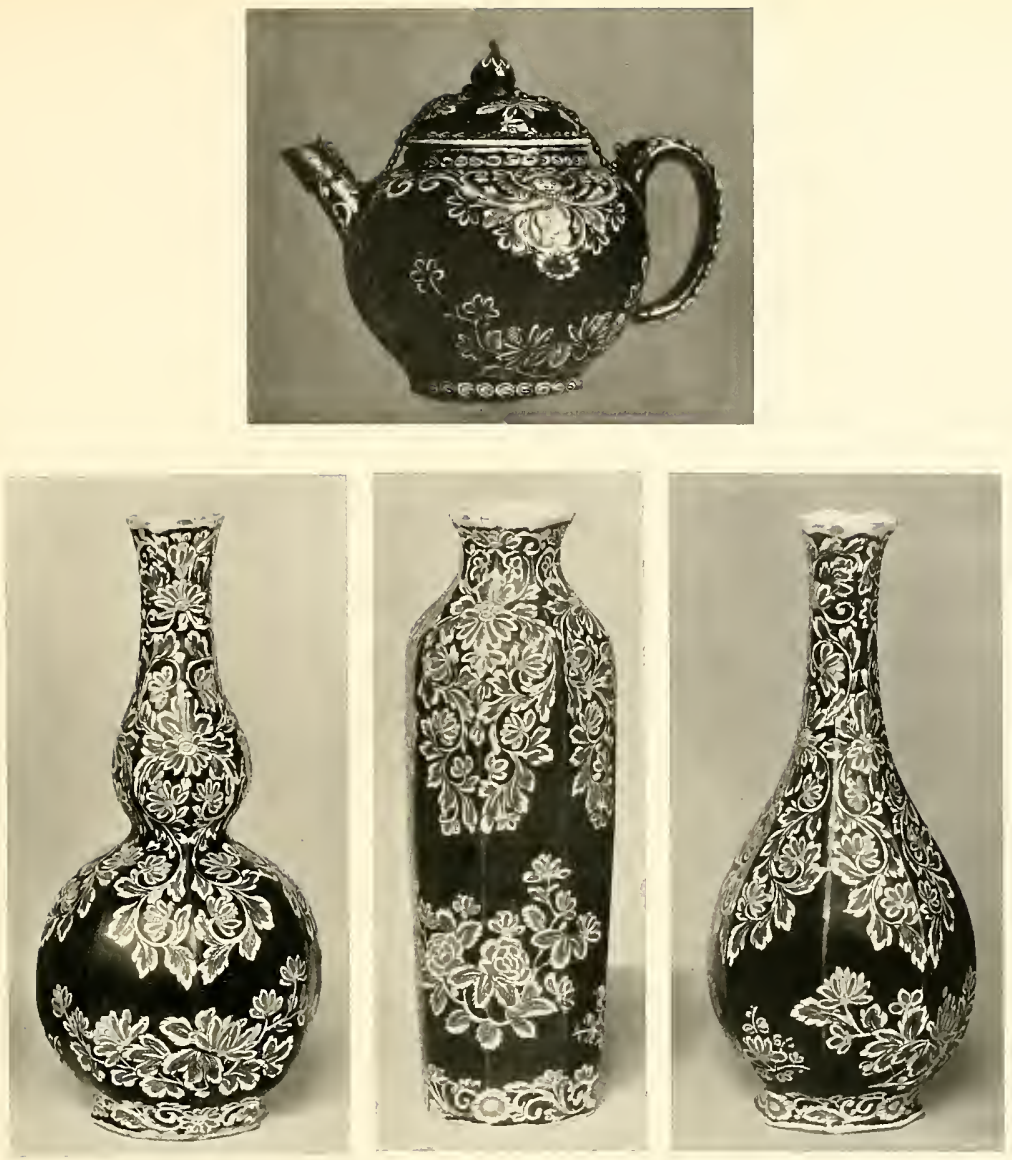


PLATE XL1J1.

Fig. 67. Wall-plaque covered with a black enamel and painted with flowers and a bird in blue, red, yellow, green and

white of the grand feu. Unmarked. Delft ; about 1700. H. Io ins. $(25.4$ cm.). (See page 103.)

Victoria and Albert Museum, London, No. 1291887. 


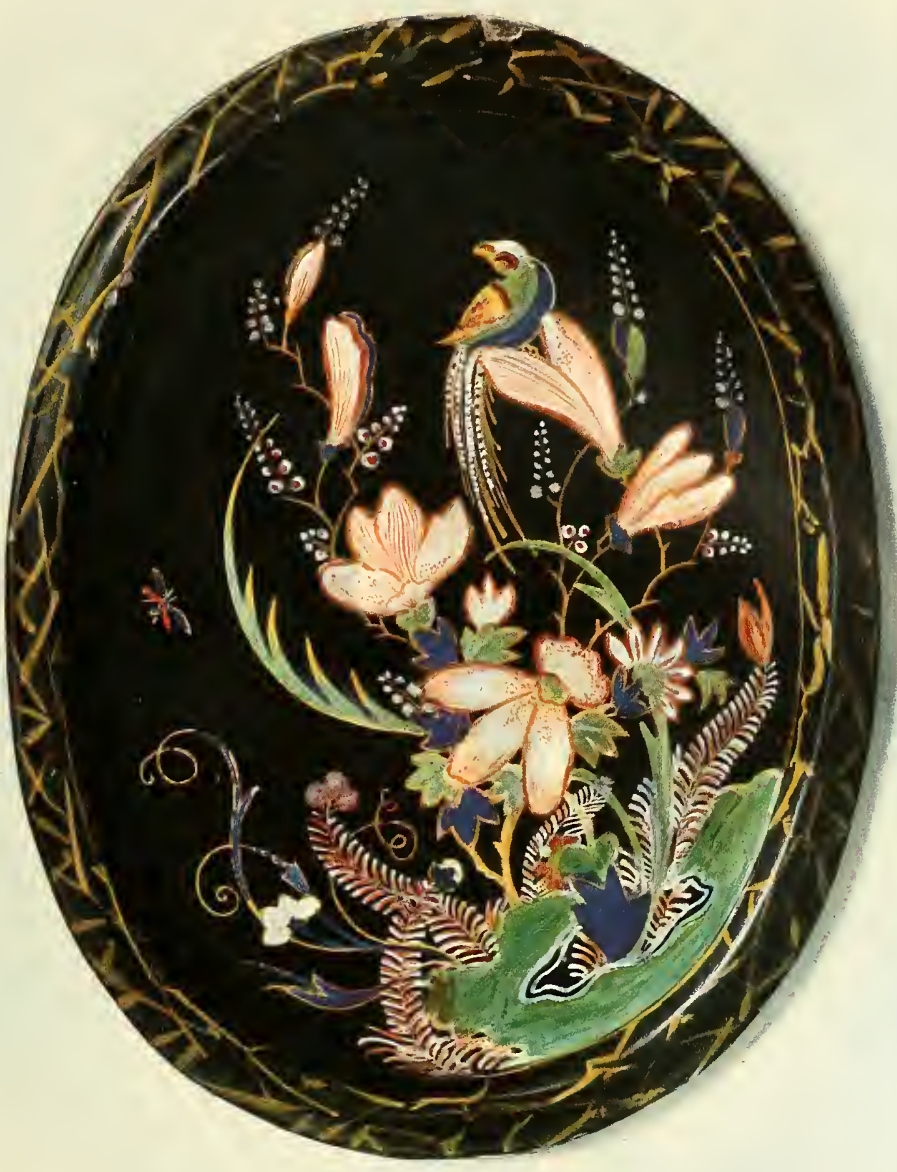




Fig. 68. Tea-caddy covered with a black enamel and painted over it with Chinese landscapes in yellow and green. Mark, LF or LVE in monogram. Delft, factory of Louwijs Fictoor or Lambertus van Eenhoorn; about r700. H. $3 \frac{7}{8}$ ins. $(9.9 \mathrm{~cm}$.$) .$ (See page ro3.)

Victoria and Albert Miseum, London, No. C. 23461910 (Salting Collection).<smiles>[TeH]</smiles>

Fig. 69. Plate covered with a black enamel and painted over it in yellow and green with a Chinese landscape. Unmarked. Delft, about $1700.8 \frac{7}{8}$ ins. $(22.6 \mathrm{~cm}$.). (See page 103.)

Victoria and Albert Vuseum, London. No, 126$188 \%$. 

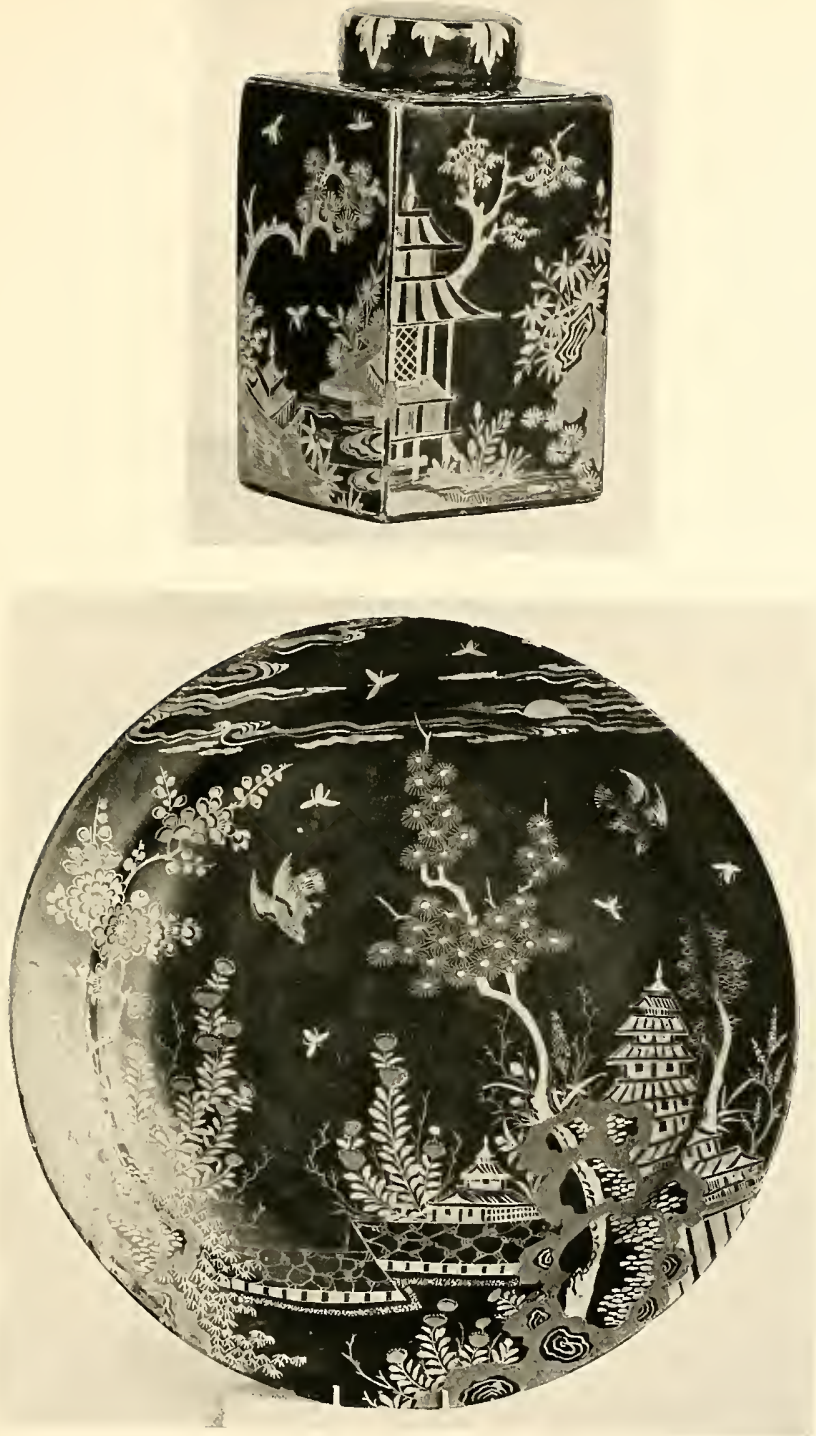

Fig. 7o. Jug with silver cover, covered with a mazarine-blue enamel and painted over it in yellowish green with flowers of Chinese style. Unmarked. Delft, made in imitation of Nevers faïence; eighteenth century. H. $8 \frac{?}{8}$ ins. $\{22.5$ cm.). (See page I04.)

Gemeentemuseum, The Hagne, No. 16s.

Fig. 71. Pair of Vases covered with a turquoiseblue enamel and painted over it with stylised flowers in yellow, green, reddish brown and white of the grand fert. Mark, D. Delft; eighteenth century. H. 10 ins. $(25.5 \mathrm{~cm}$ ). (See page r04.)

Nederlandsch Museum roor Geschiedenis en Kunst (Rijksmuseum), Amsterdam. No. 354 (Loudon Collection).

$D$ 

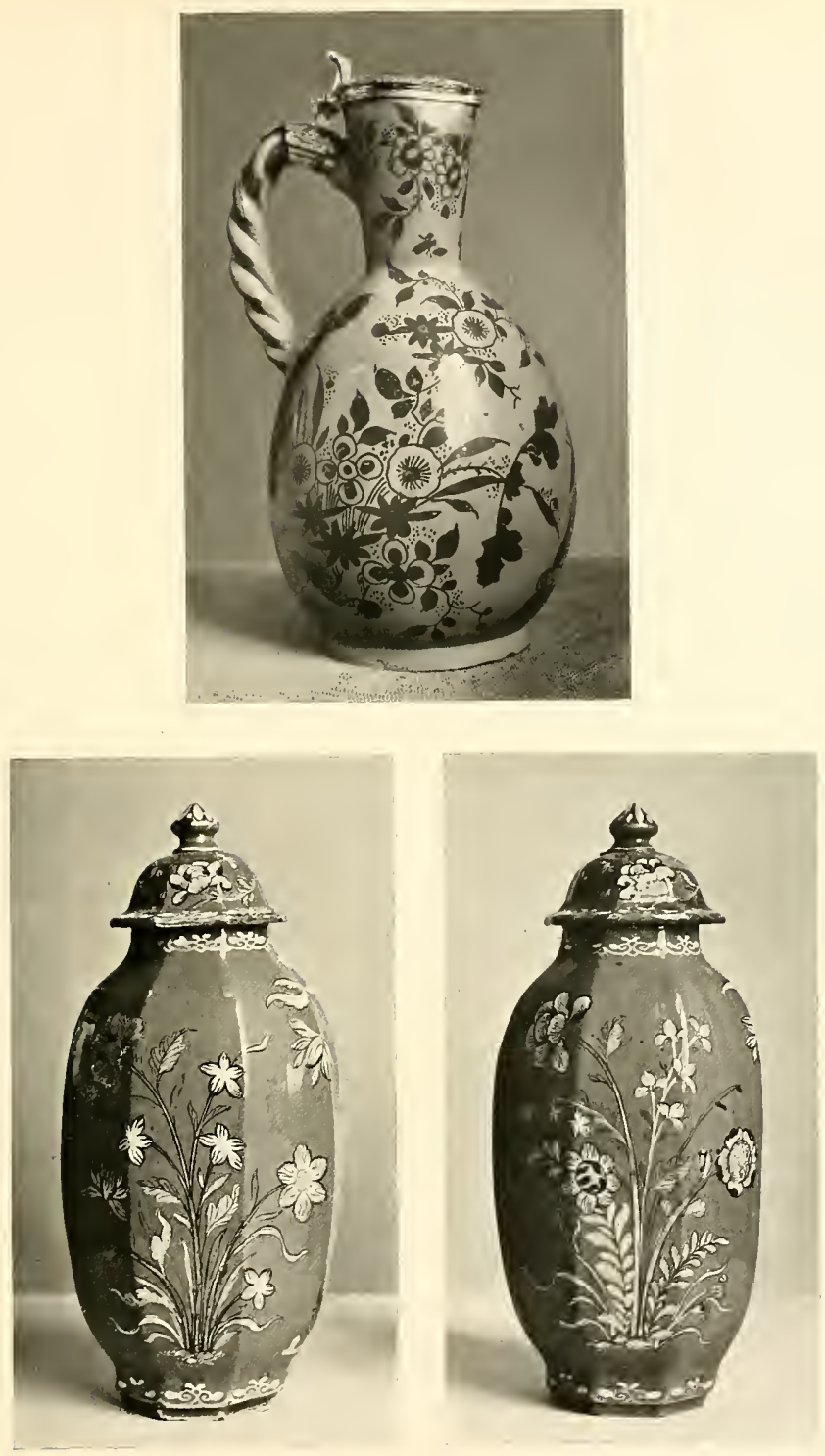


Fig. 72. Dish painted in red, blue, green, yellow and manganese-purple of the grand feu on a white ground with birds and a flowering tree, showing Chinese influence. Unmarked. Delft; eighteenth century. D. $138^{5}$ ins. (34.5 cm.). (See page I08.)

Vederlandsch Museum voor Geschiedenis en Kunst (Rijksmuseum), Amsterdam, No. 384 (Loudon Collection).

Fig. 73. Wall-plaque painted in blue, green, yellow, pink, manganese-purple and black of the grand feu on a white ground with two Chinese ladies. Unmarked. Delft; eighteenth century. H. Io 5 ins. (27 cm.). (See page I09.) Nederlandsch Muveum vwor Geschicdenis on Kunst (Rijksmuseum), Amsterdam, No. 129 . 

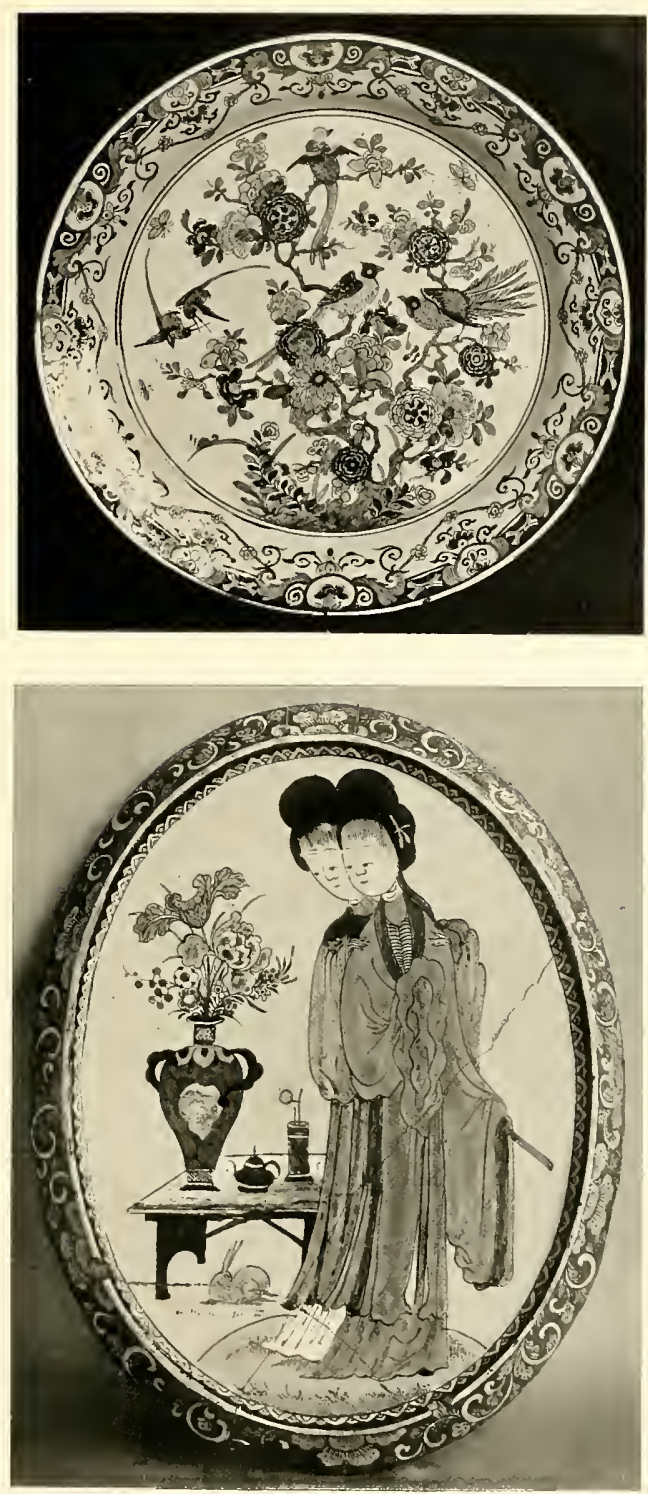


PLATE XLVII.

Fig. 74. Shallow bowl painted in imitation of famille verte Chinese porcelain of the reign of $\mathrm{K}$ 'ang $\mathrm{Hsi}$ with a group of ladies by a flowering tree, in grand feu colours on a white ground (washes of blue, green, yellow and pale manganese-purple outlined in red); dark manganese-purple is used to render the hair of the ladies. Unmarked. Delft; eighteenth century. D. $153^{3}$

ins. (40 cm.). (See page 108 .)

Victoria and Albert II useum, London. No. 150-

1887. 


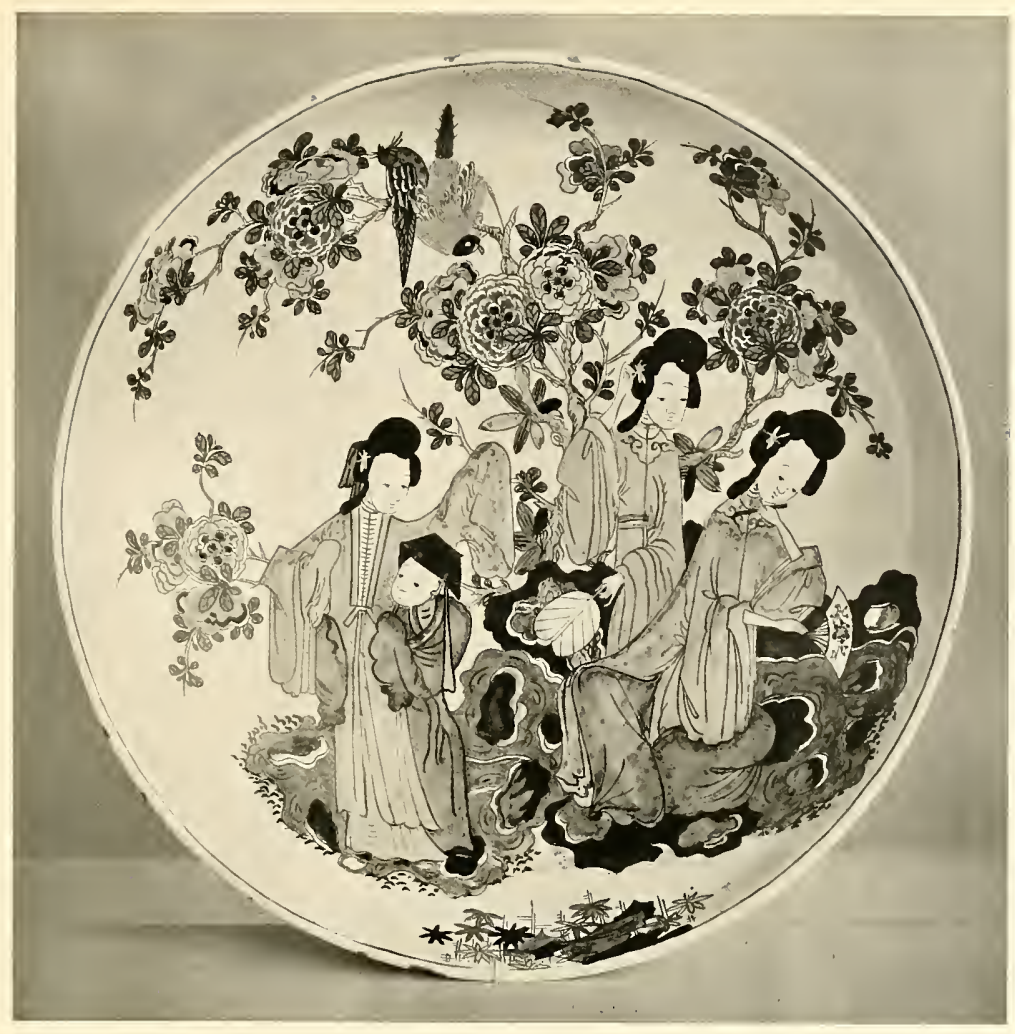




PLATE XLVIII.

Fig, 75. Dish painted in colours of the grand $f e x$ on a white ground; in the middle, a pastoral scene in blue alone, on the rim a floral pattern of Chinese character in red, manganese-purple, yellow, green and blue in reserve on a black ground. Unmarked. Delft; eighteenth century. D. $133^{3}$ ins. $(34.2 \mathrm{~cm}$.). (See page 107.)

Clainpanain Collection, Lille.

Fig. 76. Dish painted in colours of the grand fer on a white ground with a vase of flowers supoorted on a bracket of Louis XIV style and with a border of diaper ornament, amongst which are reserved medallions with lotus-flowers; the painting is chiefly in blue, with details in brownish red, green, yellow and manganese-purple. Unmarked. Delft; eighteenth century. D. $13 \frac{1}{2}$ ins. $(34.5 \mathrm{~cm}$.). (See page I 08 .)

Nederlandsch Museum voor Geschiedenis en Kunst (Rijksmuseum), Amsterdam, No. 388 (Loudon Collection). 

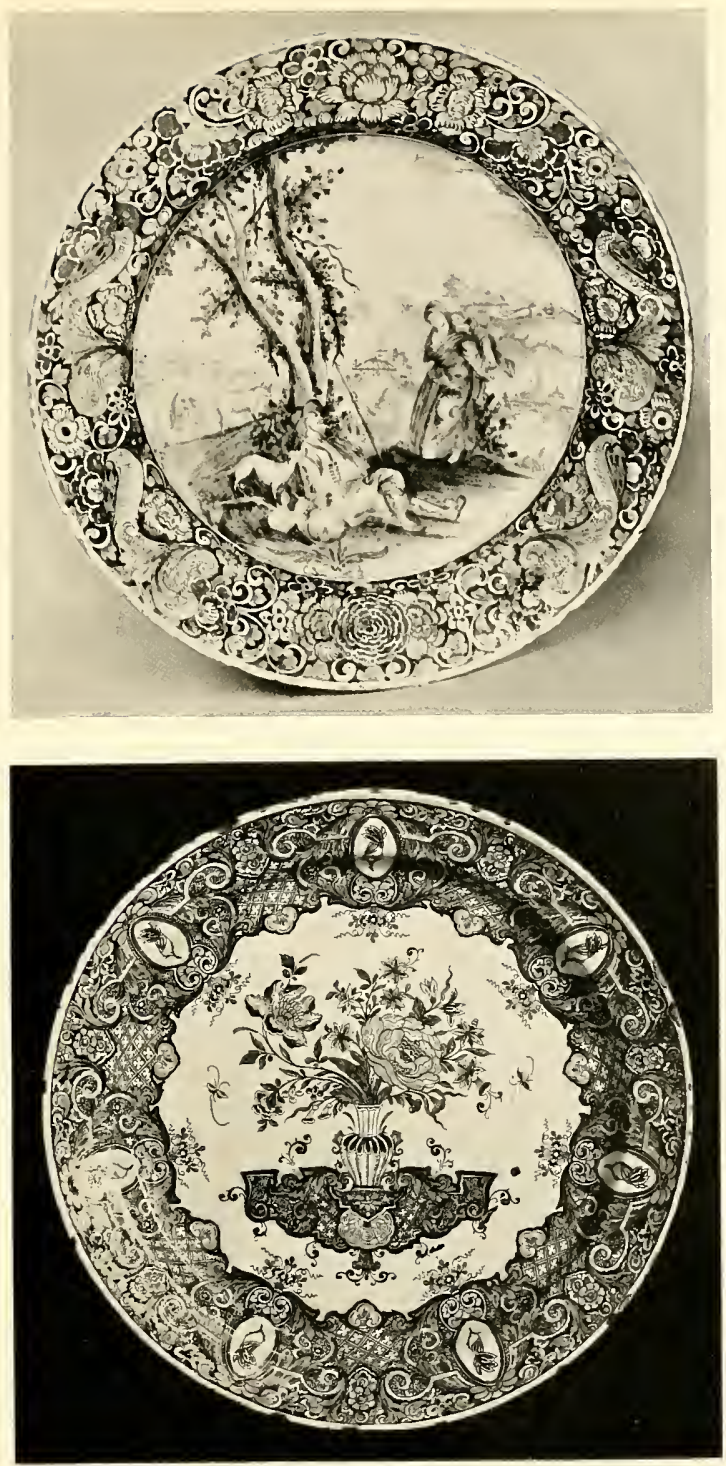


Fig. 77. Figure of a bagpipe-player sitting on a barrel, painted in green, reddish brown, liver-colour, yellow, black and blue of the grand feu on a white ground. Mark, an axe. Delft, factory of the "porcelain axe" (de Porceleyne Bijl); eighteenth century. H. Io 1 ins. $(26.8 \mathrm{~cm}$.). (See page III.)

Nederlandsch M useum voor Geschiedenis en Kunst (Rijksmuseum), Amsterdam, No. 457 (Loudon Collection).
Fig. 78. Figure of a horse jumping, one of a pair, painted in yellow, reddish brown, manganese-purple, blue and green of the grand feu on a white ground. Unmarked. Delft; eighteenth century. H. $9^{\frac{5}{8}}$ ins. $(24.5 \mathrm{~cm}$.). (See page III.)

Nederlandsch Museum voor Geschiedenis en Kunst (Rijksmuseum), Amsterdam, No. 461 (Loudon Collection).

Collection).

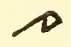

Fig. 79. Pair of slippers, painted with floral sprays in light red and blue of the grand feu on a white ground, in imitation of the rouille et bleu of Rouen. Unmarked. Delft, about 1700. L. 9 ins. $(23 \mathrm{~cm}$ ). (See page I04.)

Nederlandsch Huseum voor Geschivdenis en Kunst (Rijksmuseum), Amsterdan, No. 359 (Loudon Collection). 

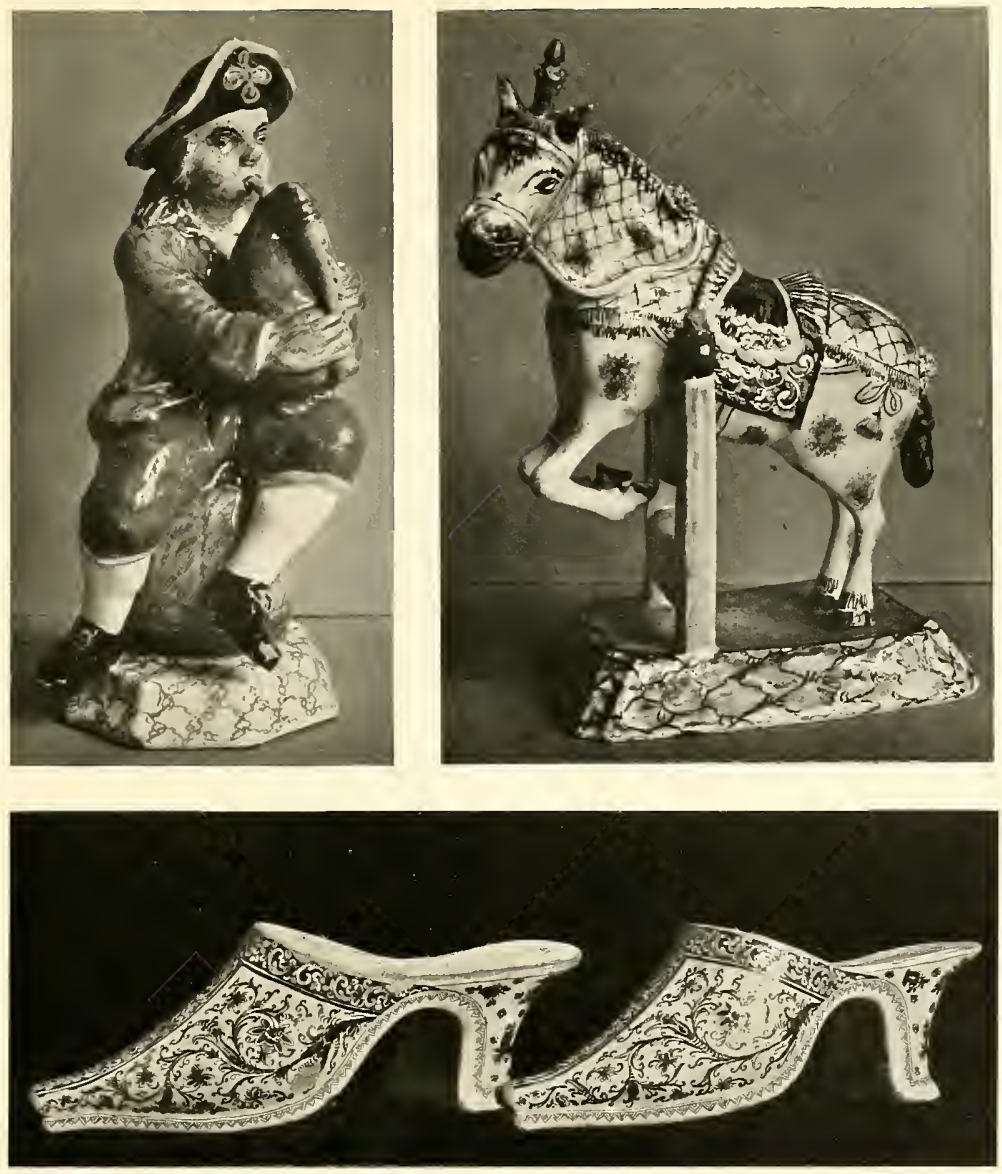


PLATE L.

Fig. 80. Figure of a cow, painted in blue, green, yellow, red and manganesepurple of the grand feu, the enamel bluish white. Unmarked. Delft; eighteenth century. H. 6 ins. ( $15 \mathrm{~cm}$.). (See page II I.)

Nederlandsch Huseum voor Geschiedenis en Kunst

(Rijksmuseum), Ansterdam, No. 462.

Fig. 81. Figure of a parrot perched on a ring, painted in blue, olive-green, yellow and manganese-purple of the grand fert. Unmarked. Delft; eighteenth century. H. 12 ins. $(30.6 \mathrm{~cm}$.). (See page III.)

Clainpanain Collection, Lille. 

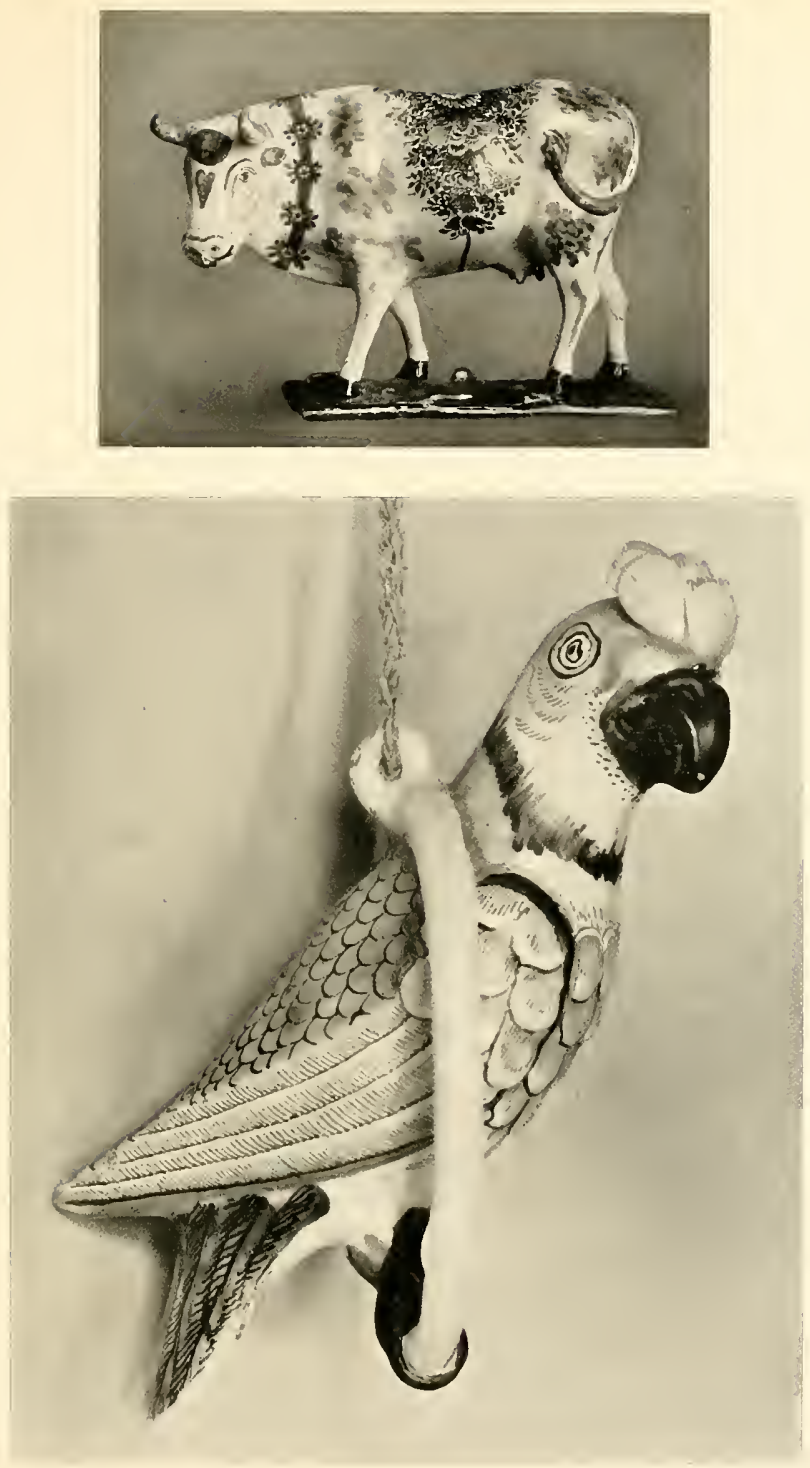


PLATE LI.

Fig. 82. Dish painted with floral ornament surrounding a rosette, showing only slight Chinese influence, in blue, red, green, yellow and manganese-purple of the grand feu on a white ground. Unmarked. Delft; eighteenth century. D. $13 \frac{3}{4}$ ins. $(35 \mathrm{~cm}$.). (See page I09.)

Nederlandsch Museum voor Geschiedenis en Kunst

(Rijksmuseum), Amsterdam, No. 397 . 


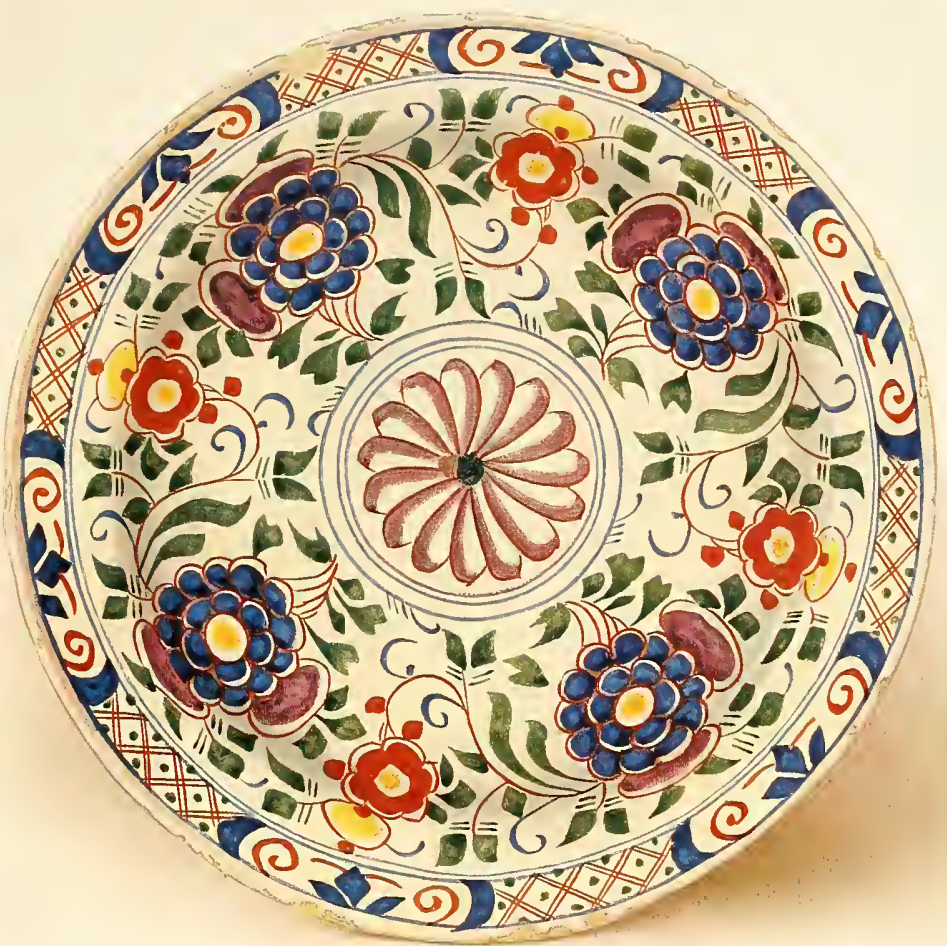




PLATE LII.

Fig. 83. Dish with floral design in blue, red, green, yellow and manganese-purple of the grand fcu on a white ground. Unmarked. Delft; eighteenth century. D. $13 \frac{1}{8}$ ins. $(33.5 \mathrm{~cm}$.), (See page rog.)

Nederlandsch Museum voor Geschiedenis en Kunst (Rijksmuseum), Amsterdam, No. 409.

Fig. 84. Bowl painted in blue, yellow and greyish green of the grand feu on a white ground with flowers and birds and the following inscription: Anno 1697 den 20 september is de vreede gesloten met Hollant spanjen engelant en vrancrijk. Unmarked. Delft, made to commemorate the peace of Ryswick, 1697 . D. $12 \frac{1}{8}$ ins. $(30.7 \mathrm{~cm}$.$) .$ (See page 99.)

Victoria and Albert Huseum, London, No. 1431905. 

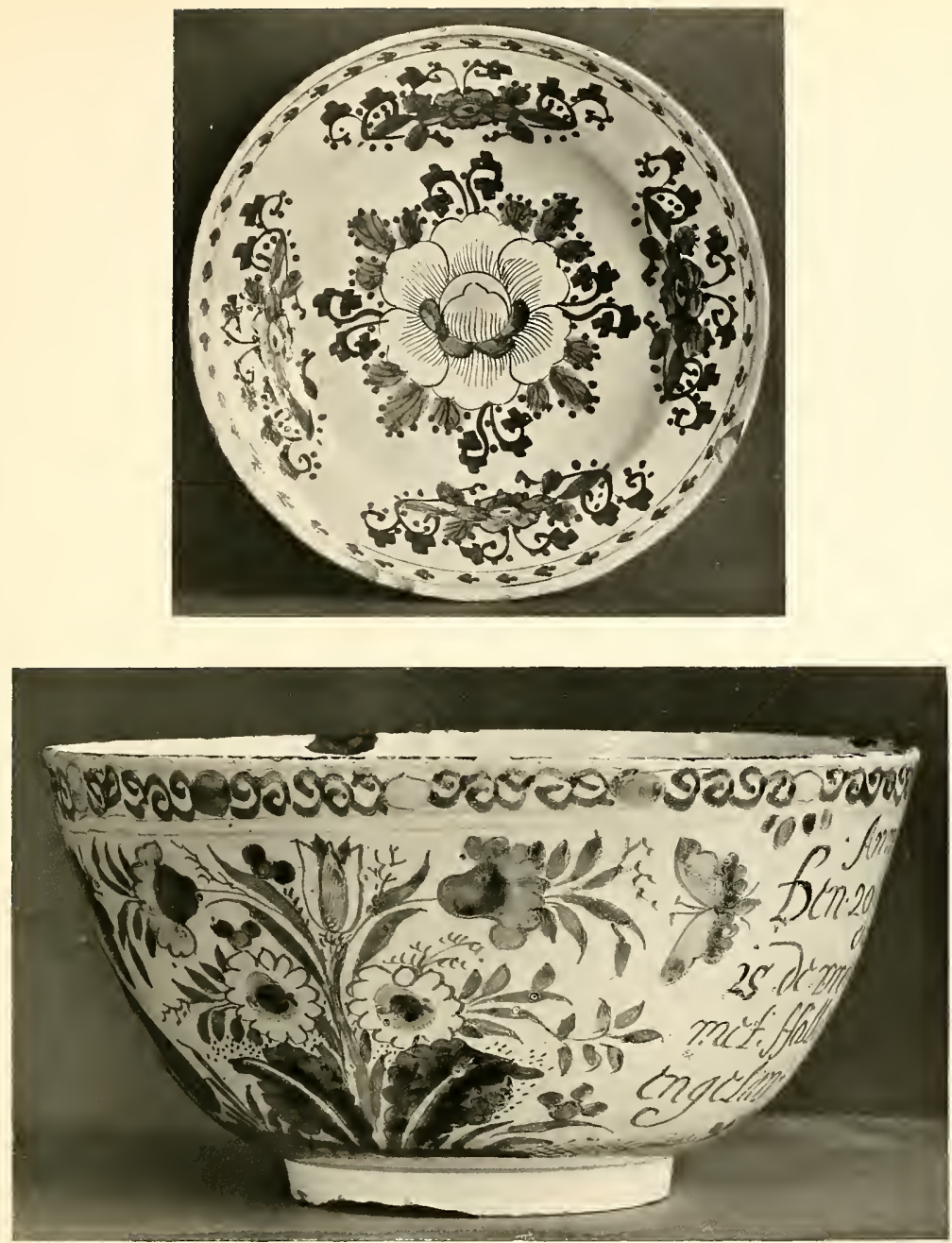


PLATE LIII.

Fig. 85 , a and b. Pair of oval plaques painted in soft colours, of the grand feu on a white ground (red, blue, yellow, green, manganese-purple and black). On each, within a polychrome Louis XIV framework, a figure of a drinker in purple; one of them holds a scroll inscribed $G$. Sachtleeven (probably the name of the engraver of the print that served as a copy). Unmarked. Delft; eighteenth century.

H. $8 \frac{5}{8}$ ins. (22 cm.). (See page 109.)

Nederlandsch Museum voor Gicschiedenis en Kunst (Rijksmuseum), Amstcrdam, No. 427 (Loudon Collection).

Fig. 86. Tile painted in brownish red, blue, yellow and green of the grand feu on a white ground with the arms of Orange. Marked $P$. Vizeer. Delft, dated 1765 . H. 54 ins. ( $13.5 \mathrm{~cm}$.). (See page 110.)

Nederlandsch Museum vor Geschiedenis en Kunst (Rijksmuseum), Amsterdam, No. 440 (Loudon Collection).

\section{$\uparrow$ Vizeer}



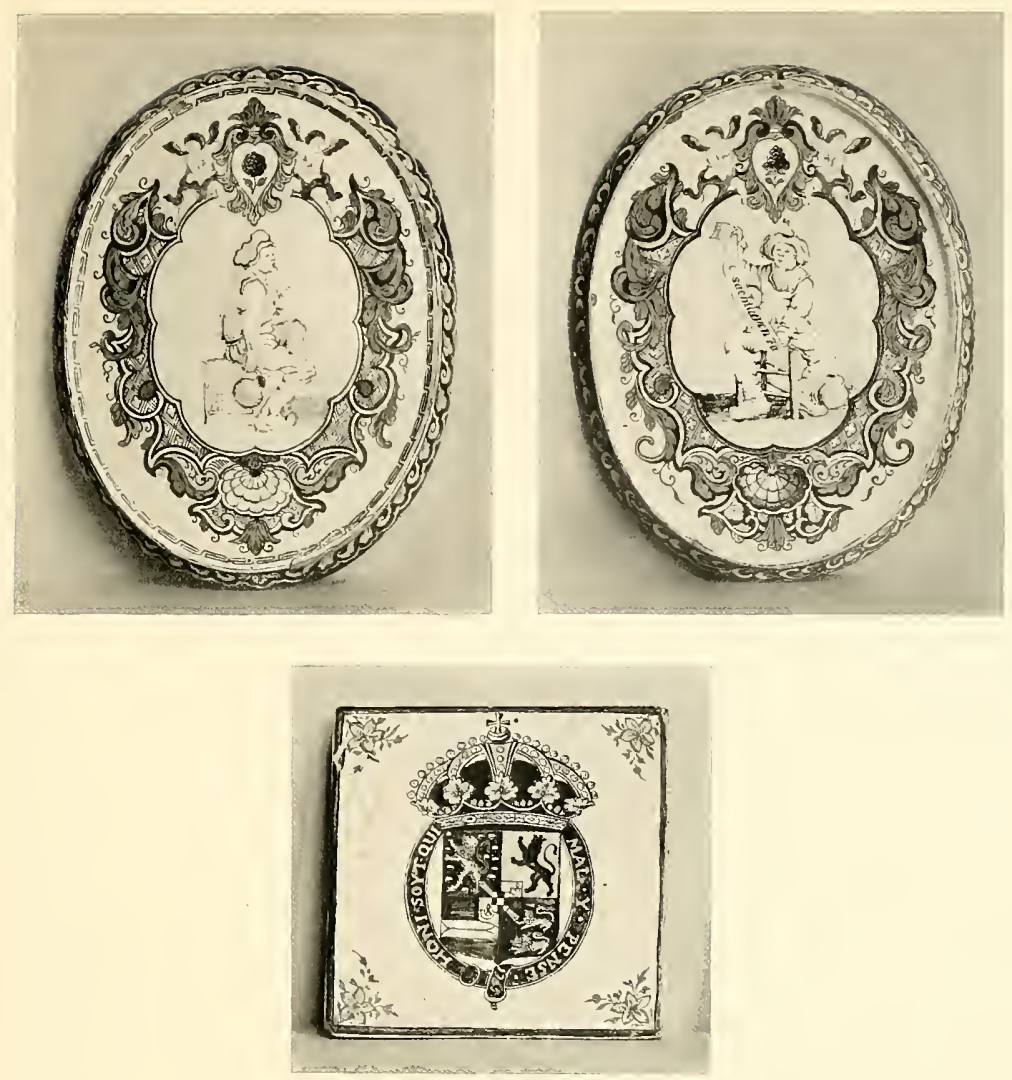


PLATE LIV.

Fig. 87. Money-box in three sections painted with Chinese flowers and European ornamental motives, in blue, touches of brownish red, yellow, green and black of the grand feu on a creamcoloured ground. Unmarked. Delft; eighteenth century. H. II $\frac{7}{8}$ ins. (30 cm.). (See page r I0.)

Nederlandsch Museum voor Geschiedenis en Kunst (Rijksmuseum), Amsterdam, No, $4 \$ 6$ (Loudon Collection). 


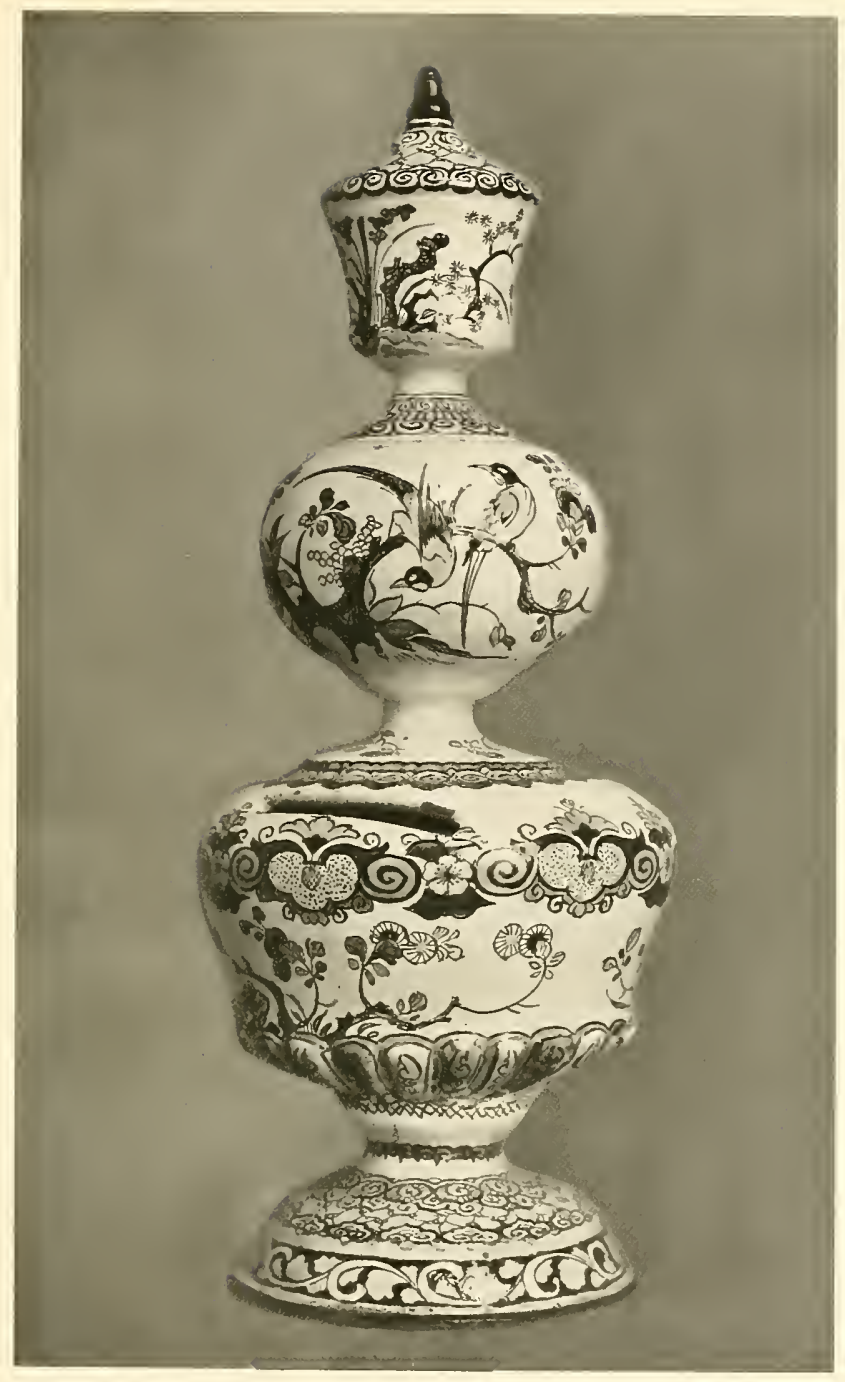




PLATE LV.

Fig. 88. Puzzle-jug painted with Chinese flowers in light brownish red, blue, yellow, green, manganese-purple and touches of black of the grand feu on a white ground. Unmarked. Delft; dated on the openwork neck 1758 . H. 8 g ins. (22 cm.). (See page 1 ro.)

Nederlandsch Museum voor Geschiedenis en Kunst (Rijksmuseum), Amsterdam, No. 413 (Loudon Collection).

Fig. 89. Tray painted with a vase of flowers in blue, red, yellow, orange, olive-green and pale manganese-purple. Unmarked. Delft; eighteenth century. W. II ins. $(27.9 \mathrm{~cm}$.). (See page IIO.)

Victoria and Albert Museum, London, No. 1461887. 

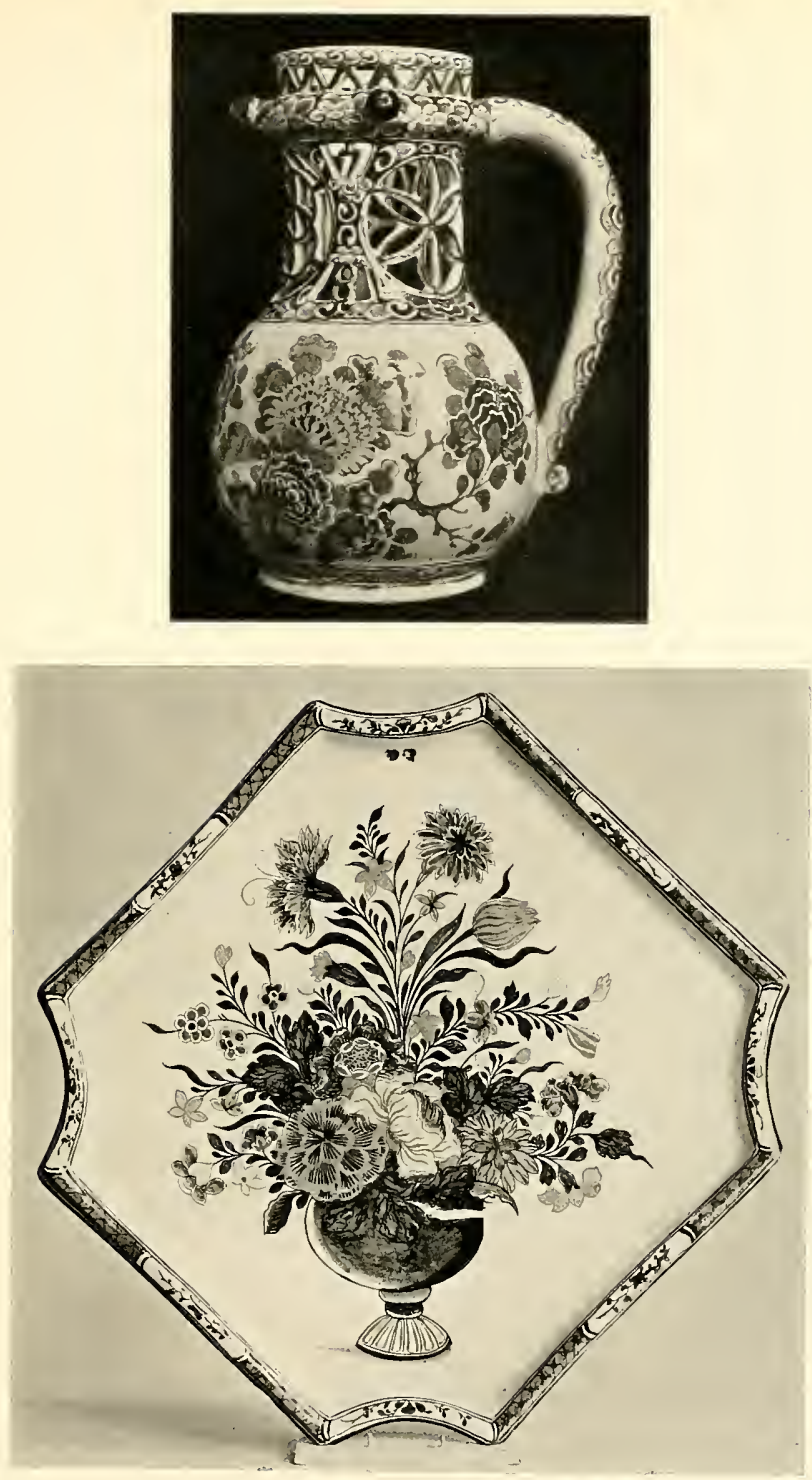

Fig. 9o. Tile-picture comprising $7^{8}$ tiles painted in blue, red, yellow, green, manganese-purple and black of the grand feu on a white ground; a Chinese landscape with figures, amongst them negroes rendered in a fine black pigment; probably based upon a woodcut original. Unmarked.

Delft; eighteenth century. H. $5 \mathrm{ft}$.

$6 \frac{1}{2}$ in. (I.69 m.). (See page II I.)

Nederlandsch Museum voor Geschiedenis en Kunst

(Rijksmuseum), Amsterdam, No. 476 (Loudon Collection). 


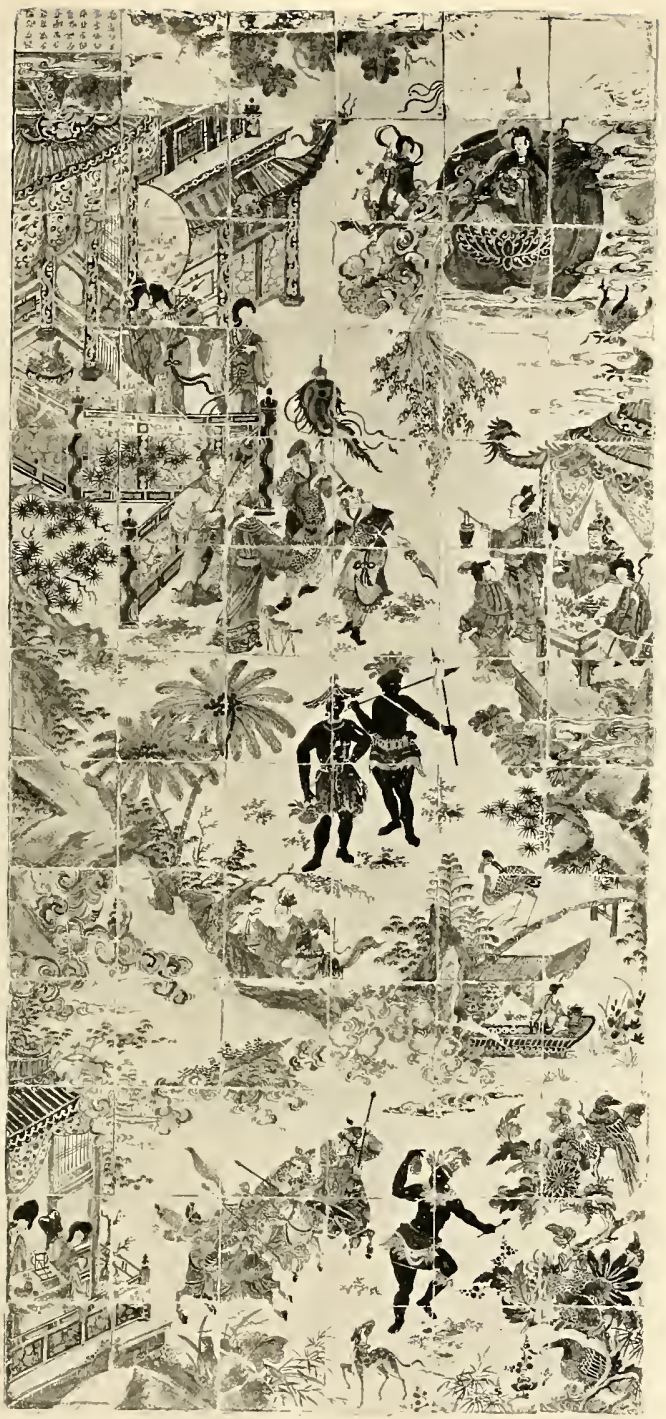




PLATE LVII.

Fig. 91. Jar painted on a bluish white ground in colours of the grand feu and muffiekiln combined (blue, red, olive-green and black outlined in black trek, with the addition of gilding of fine quality); decorated with small groups of Chinese figures. Mark, RHS. Delft, factory of Rochus Hoppesteyn; end of seventeenth century. H. 8 ins. $(20.5 \mathrm{~cm}$.). (See page I 15 .)

Nederlandsch Museum voor Geschiedenis en Kunst (Rijksmuseum), Amsterdam, No, 479 .

$\stackrel{+}{R}$

Fig. 92. Jar with cover painted with Chinese figures and formal borders on a white ground in colours of the grand feu and muffle-kiln (blue, red, black and gold). Mark, RHS. Delft, factory of Rochus Hoppesteyn; end of seventeenth century. H. $20 !$ ins. $(52 \mathrm{~cm}$.). (See page II 5 .)

Schlossmuseum, Berlin, No. 09,20.

20 

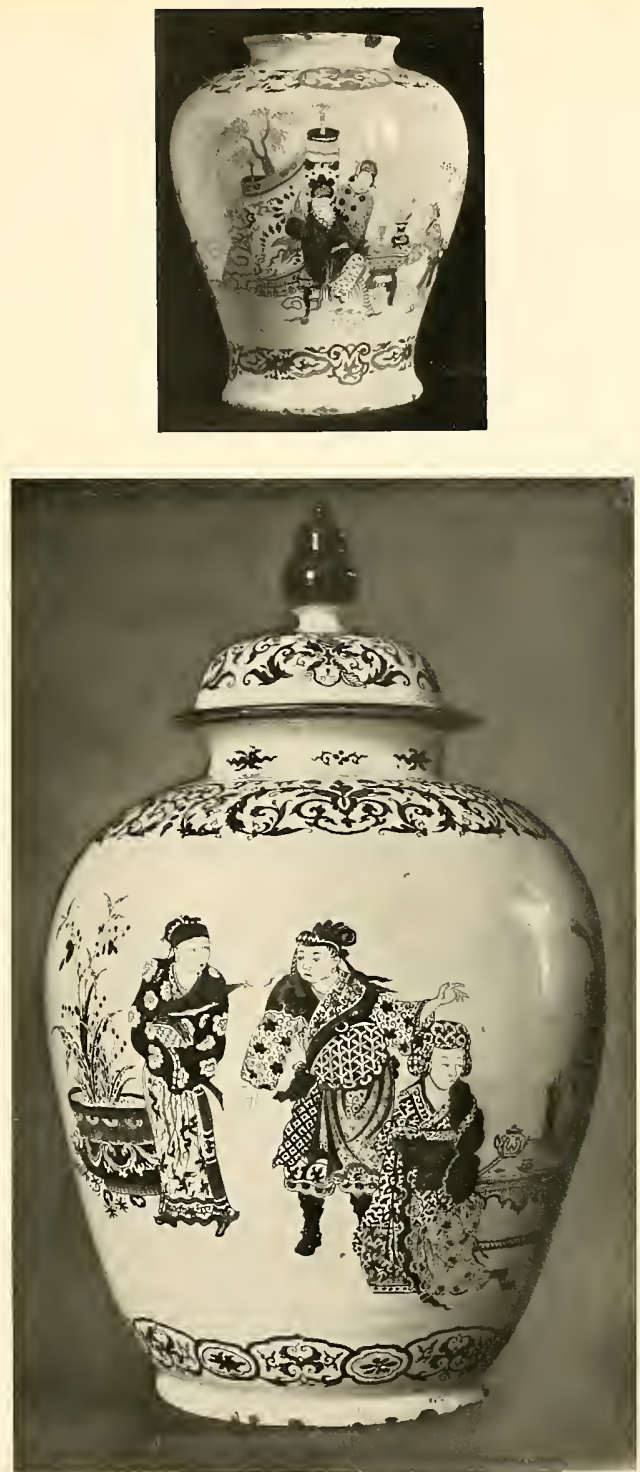


PLATE LVIII.

Fig. 93. Jug painted with Chinese figures on a white ground in colours of the grand fer and rnuffle-kiln (blue, brownish red, olive-green, black and gold, with black trek). Mark, RHS and a negro's head. Delft, factory of Rochus Hoppesteyn at the sign of the " Moor's Head " (het Moriaanshooft); end of the seventeenth century. H. Io ins.

(25 cm.). (See page I I6.)

Nederlandsch Museum voor Geschiedenis en Kunst (Rijksmuseum), Amsterdam, No. 479 (Loudon Collection). 


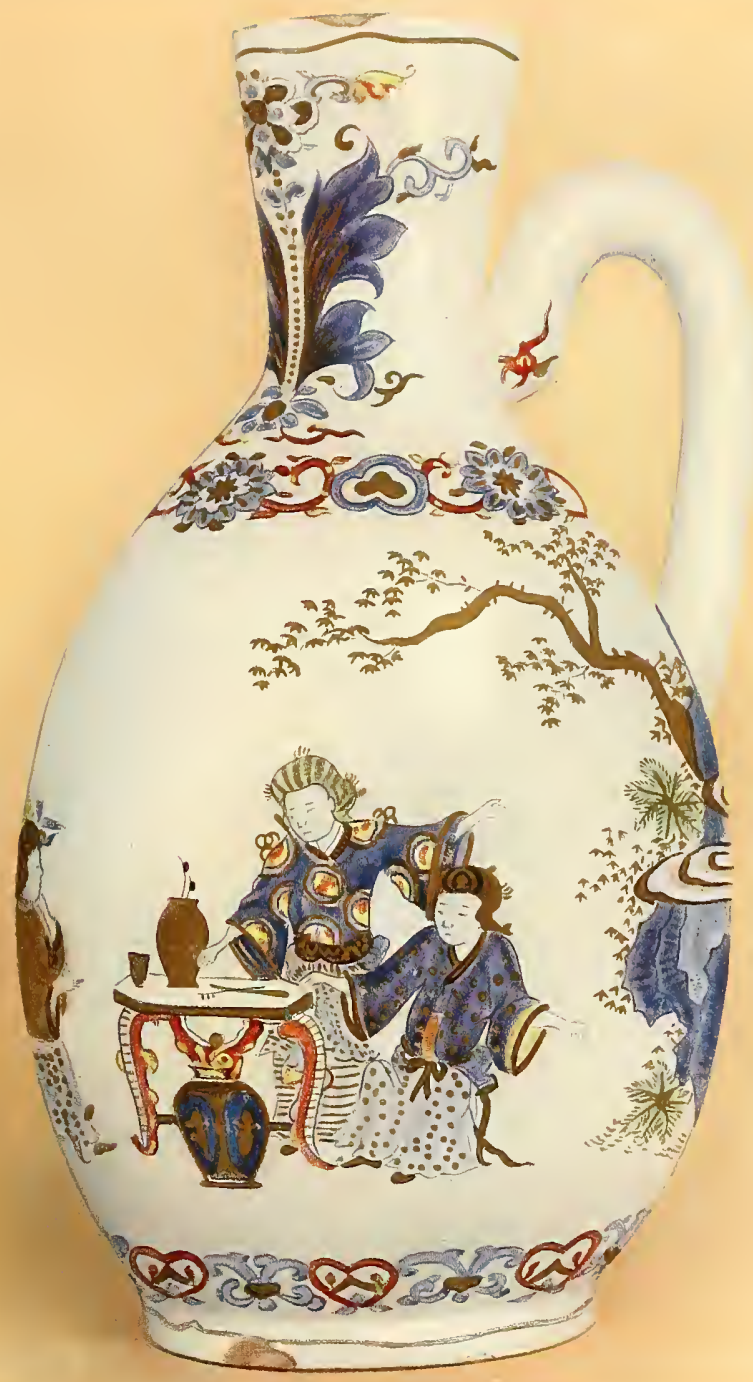





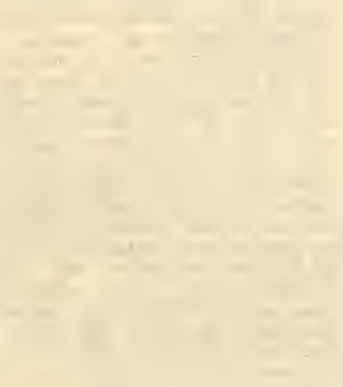


PLATE L]X.

Fig. 94. Jar painted on a white ground with a figure-subject in blue, forming a continuous frieze round the middle, perhaps depicting incidents from the life of Apollonius of Tyana. Above and below is scrollwork painted partly it grand feu, partly in mufflekiln, colours (manganese-purple, olive-green, blue and reddish brown, outlined in black trek, with gilding). Unmarked (the companion vases, similarly decorated, with the Labours of Hercules, are marked with the monogram IW). Delft, probably made at the factory of Rochus Hoppesteyn; about I7oo. H. $10 \frac{3}{4}$ ins. $(27.3 \mathrm{~cm}$.$) . (See page I 6$.

Musées du Cinquantenaire, Brussels (Erenepnel Collection). 


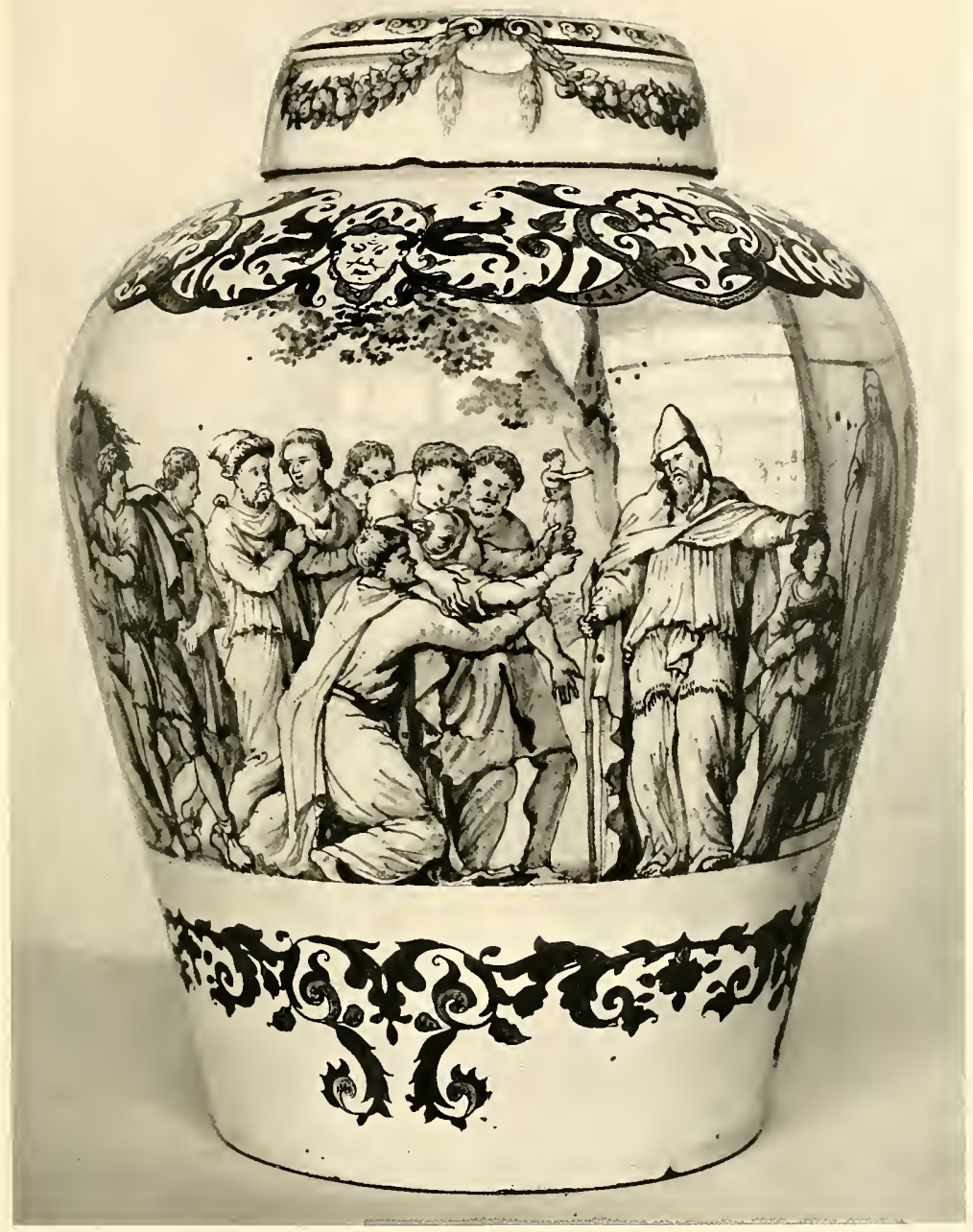



PLATE LX

Fig. 95, $a$ and b. Ewer with basin, reeded and painted with a design influenced by Japanese (Imari) porcelain, in grand feu and muffle-kiln colours (red, blue and gold) on a white ground. Mark, APK in monogram. Delft, factory of Adriaen Pijnacker; about 1700 or first half of eighteenth century. Ewer, H. Io $\frac{1}{2}$ ins. $(26.5 \mathrm{~cm}$.$) ; basin, W. 16$ ins. $(40.5$ cm.). (See page I I 8.)

Nederlandsch M useum roor Geschiedenis en Kunst (Rijksmuseum), Amsterdam, No. 485 (Loudon Collection).

层 

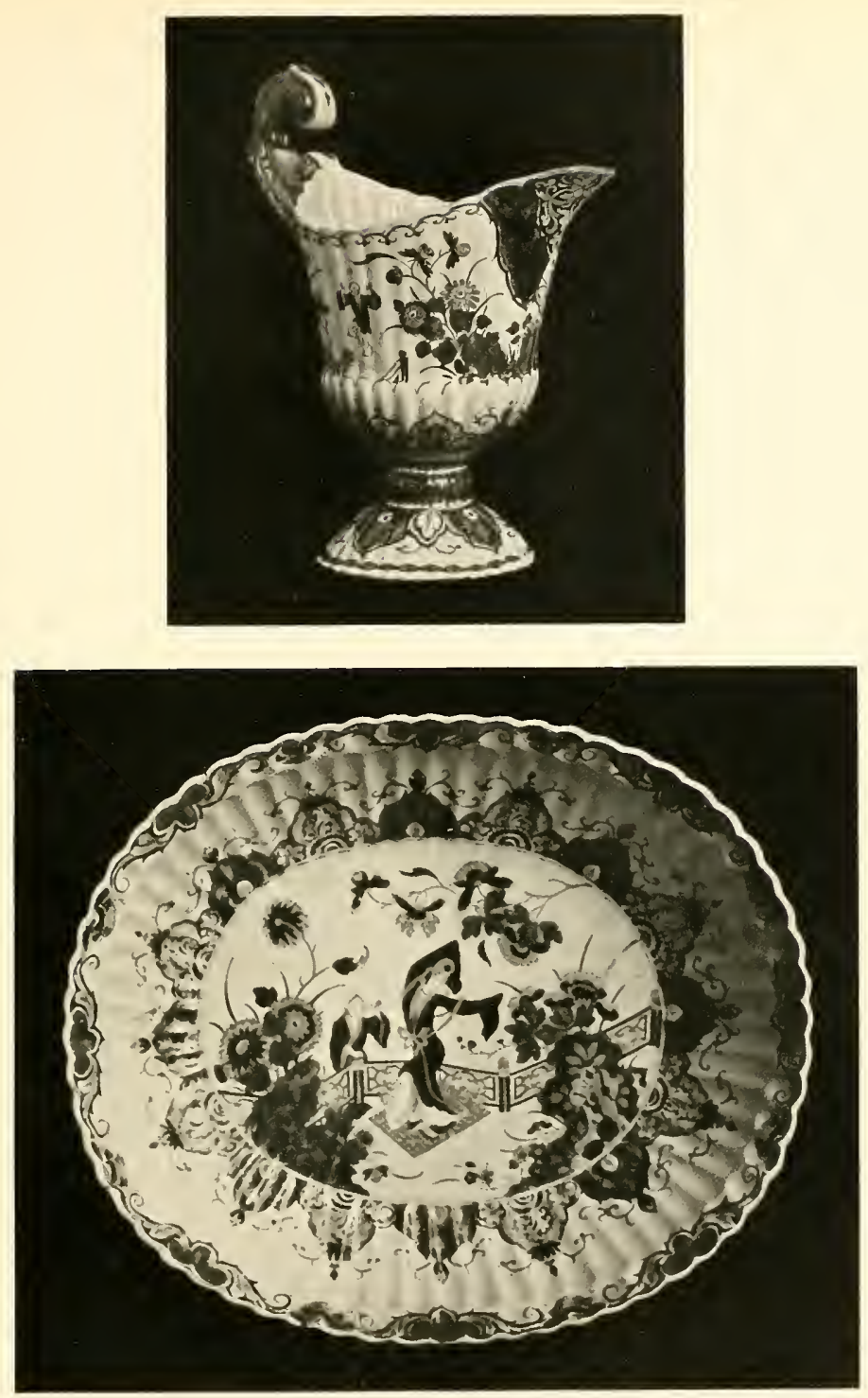


PLATE LXI.

Fig. 96. Dish painted with a floral design in imitation of Japanese (Imari) porcelain, in grand feu and muffle-kiln colours (red, blue, green and gold) on a white ground. Mark, APK in monogram. Delft, factory of Adriaen Pijnacker; first half of eighteenth century. D. 155 ins. $(39.5 \mathrm{~cm}$.). (See page 118 .)

Nederlandsch Museum voor Geschiedenis en Kunst (Rijksmuseum), Amsterdam, No. 492 (Loudon Collection).

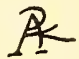




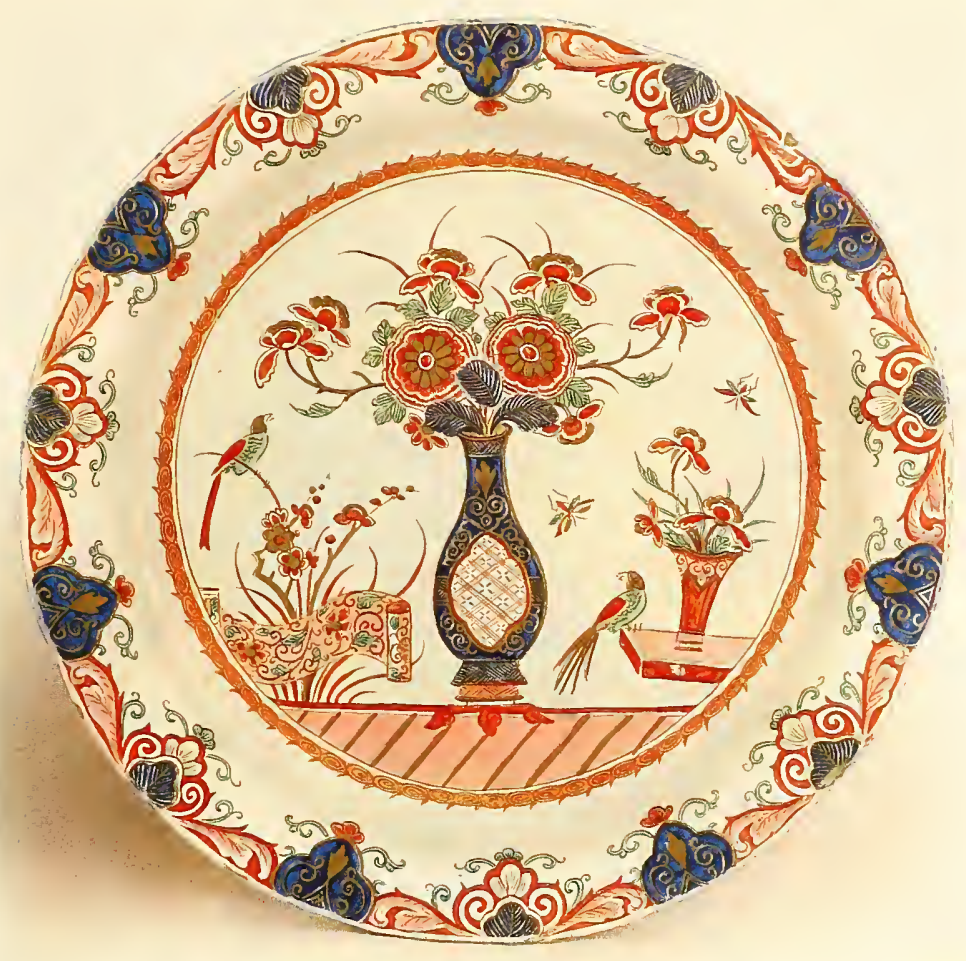




Fig. 97. Plate painted in grand fer and mufflekiln colours (blue, red and gold, with touches of turquoise-blue, grey and green) on a white ground, with the royal arms of England as borne from I7I4 to 1800 . Mark, APK is monogram. Delft, factory of Adriaen Pijnacker; eighteenth century. D. $8 \frac{1}{2}$ ins. $(21.5 \mathrm{~cm}$.). (Sce page II9.)

Musée des Arts Décoratifs, Paris (Doistun

Collection).

R

Fig. 98. Plate painted in grand feu and mufflekiln colours (blue, red, black, gold and touches of green) on a white ground, with the arms of Louis Alexandre de Bourbon, comte de Toulouse, as Admiral of France (I683-I737). Mark, APK in monogram. Delft, factory of Adriaen Pijnacker; middle of eighteenth century. D. $8_{2}^{1}$ ins. $(2 \mathrm{r} .5 \mathrm{~cm}$.$) . (See page rig.)$

$$
\text { Clainpanain Collection, Lille. }
$$

赵
Fig. 99. Plate painted in grand feu and mufflekiln colours (blue, red, green, purple, black and gold) on a white ground, with the arms of Frederick the Great, King of Prussia, 1740-1786, surmounted by a border with the eagles of Prussia and Brandenburg alternately; floral sprays on the back. Mark, APK in monogram. Delft, factory of Adriaen Pijnacker; middle of eighteenth century. D. $12_{r}^{3}$ ins. $(3 I .6 \mathrm{~cm}$.). (See page I I9.)

Gemeentemuseum, The Hague, No. 345.

\section{层}

n' 6 . 

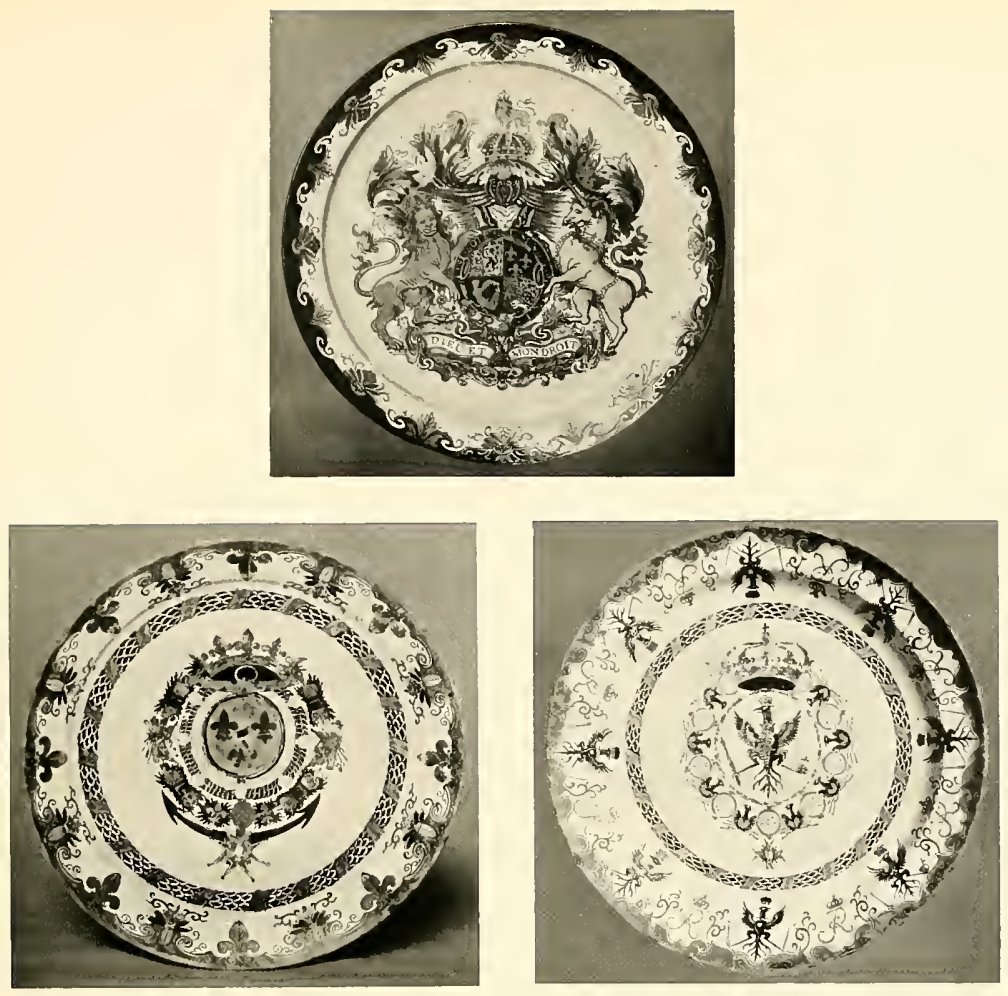


PLATE LXIII.

Fig. 100. Jug, with pewter-mounted lid, reeded and painted in imitation of Japanese (1mari) porcelain in muffle-kiln colours (red, blue, green, black and gold) on a white ground. Mark, APK in monogram. Delft, factory of Adriaen Pijnacker; middle of eighteenth century. H 81 ins. (2I cm.). (See page $x$ I 9 .)

Gemeentemuseum, The Hague, No. 355.

\section{A}

Fig. I01. Cruet-stand with bottles lettered 0 (Otie) and A (Azijn), for oil and vinegar, painted in imitation of Japanese (Imari) porcelain with figures and flowers in grand feu and muffle-kiln colours (red, blue, green, black and gold) on a white ground. Mark, APK in monogram. Delft, factory of Adriaen Pijnacker; first half of eighteenth century. H. 63 ins. ( $17 \mathrm{~cm}$.). (See page $1 \mathrm{r} 8$.)

Nederlandsch M useum voor Geschiedenis en Kunst

(Rijksmuseum), Amsterdam, No. 495 (Loudon Collection).

A 

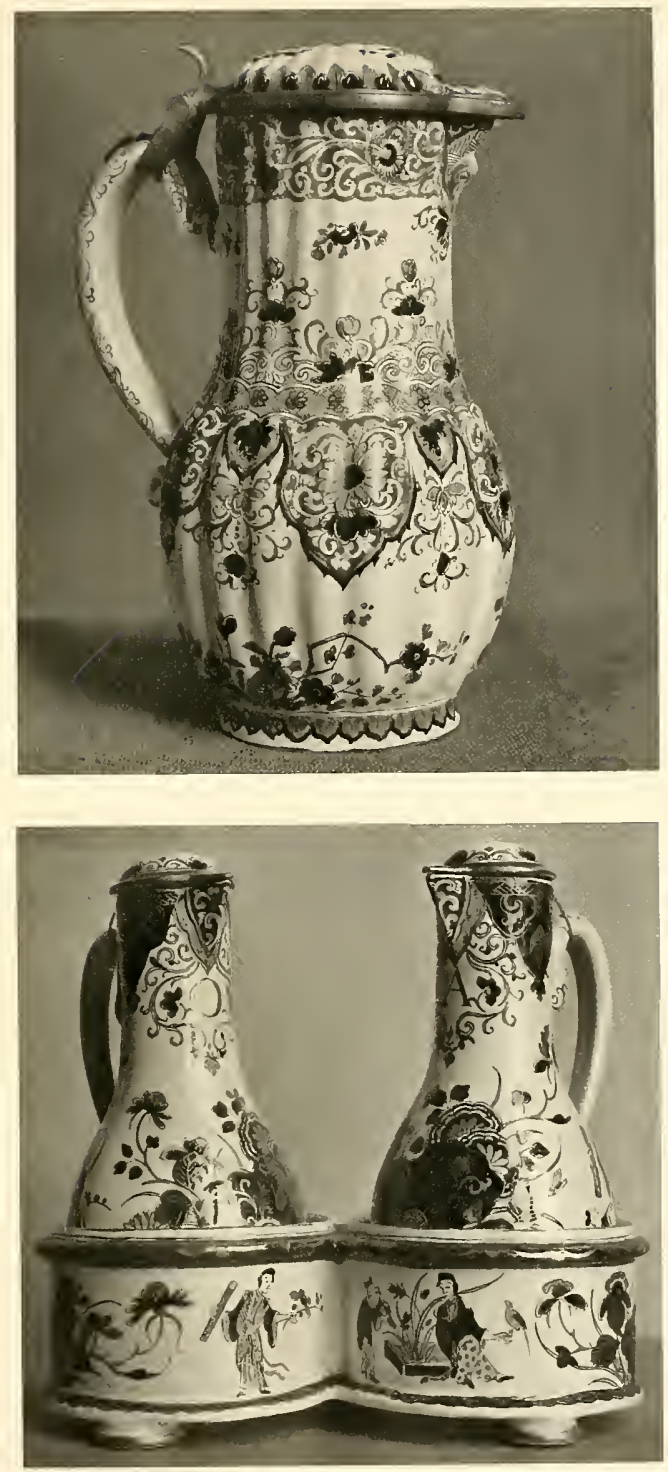




\section{PLATE LXIV.}

Fig. I02. Dish painted in grand feu and mufflekiln colours (red, blue, green, yellow, black, pink, lilac, grey and gold) on a white ground, with the subject of Europa and the Bull, after a print by Hendrik Goltzius, within an ornamental border. Mark, APK in monogram. Delft, factory of Adriaen Pijnacker; middle of eighteenth century. D, I5 $5^{\frac{3}{2}}$ ins. (40 cm.).

(See page Ir9.)

Nederlandsch Museum voor Geschiedenis en Kunst (Rijksmuseum), Amsterdam, No. 501 (Loudon Collection).

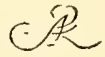

Fig. 103. Dish painted in grand feu and mufflekiln colours (red, purple, green, yellow, greyish blue and gold) on a white ground with a music-party; floral border. Unmarked. Delft; middle of eighteenth century. D. I5? ins. $(39 \mathrm{~cm}$.), (See page 124 .)

Misée des Arts Décoratifs, Paris (Doistau Collection). 

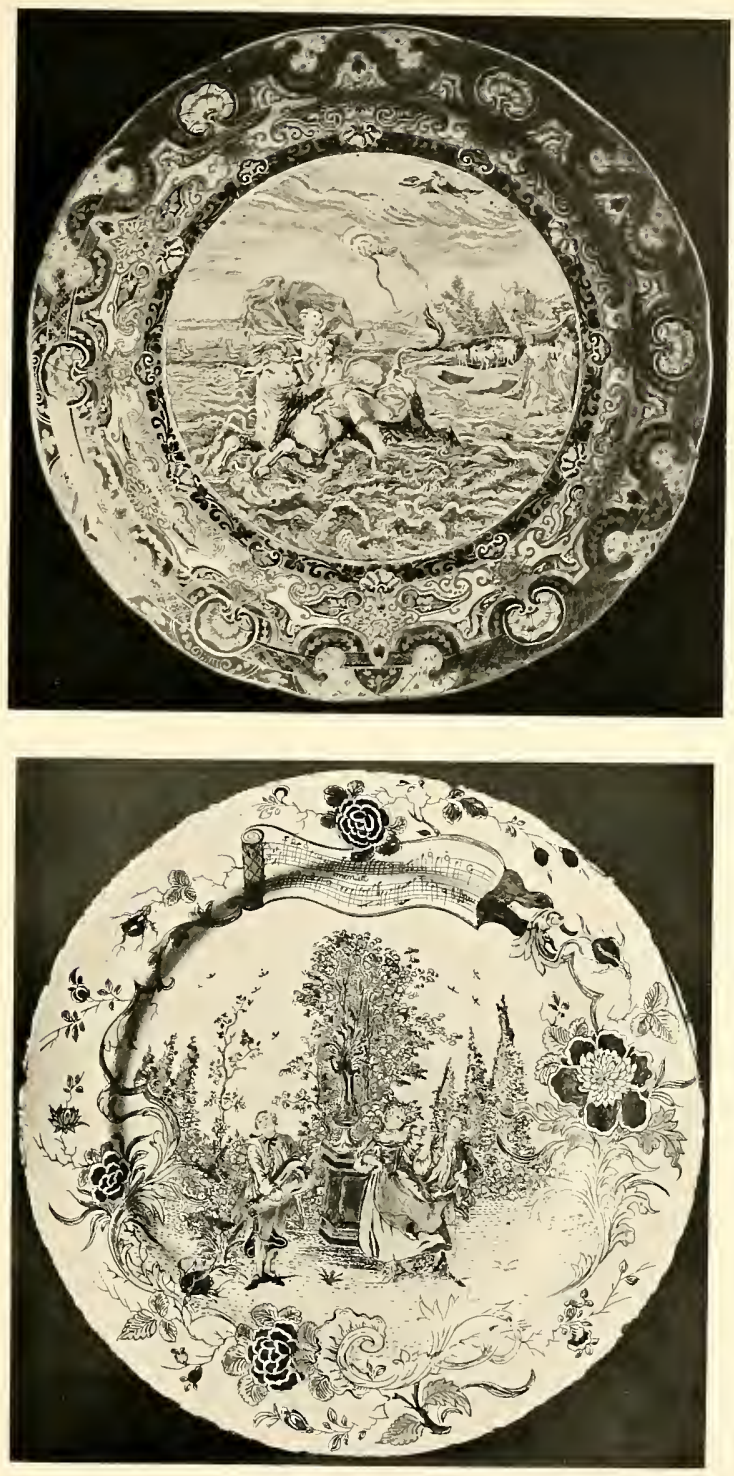



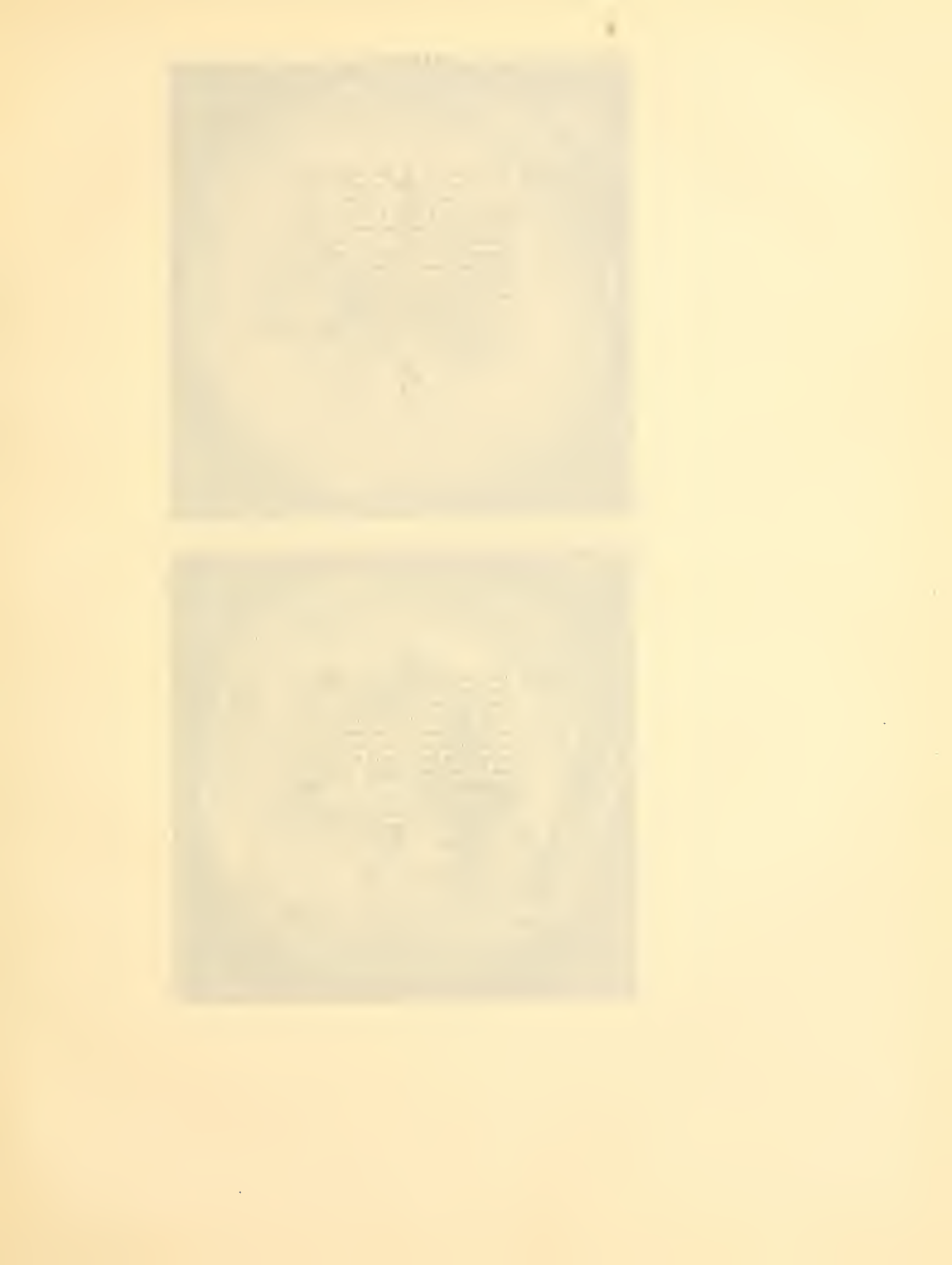


Fig. I04. Dish, painted in the muffle-kiln colours (red, green, purplish blue, liver-colour, black and gold) on a white ground, with a Chinese lady on a horse accompanied by four attendants on foot; the design is borrowed from Chinese porcelain of the famille verte, but with alteration of the colours. Mark, AR. Delft; middle of eighteenth century. D. II $\frac{7}{8}$ ins. $(30 \mathrm{~cm}$.). (See page I 24.)

Nederlandsch M useum voor Geschiedenis en Kunst (Rijksmuseum), Amsterdam, No. 522 (Loudon Collection).

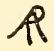

Fig. 105. Dish painted in colours of the mufflekiln (pinkish red, green, bluish green, yellow, brown, pale purplish blue, black and gold) on a white ground, with floral sprays, birds and in the background two figures; an imitation of Chinese porcelain of the famille rose. Unmarked. Delft; middle of eighteenth century. D. $13 \frac{3}{3}$ ins. (35 cm.). (See page 124.)

Nederlandsch Museum voor Geschiedenis en Kunst (Rijksmuseum), Amsterdam, No. 526 (Loudon Collection). 

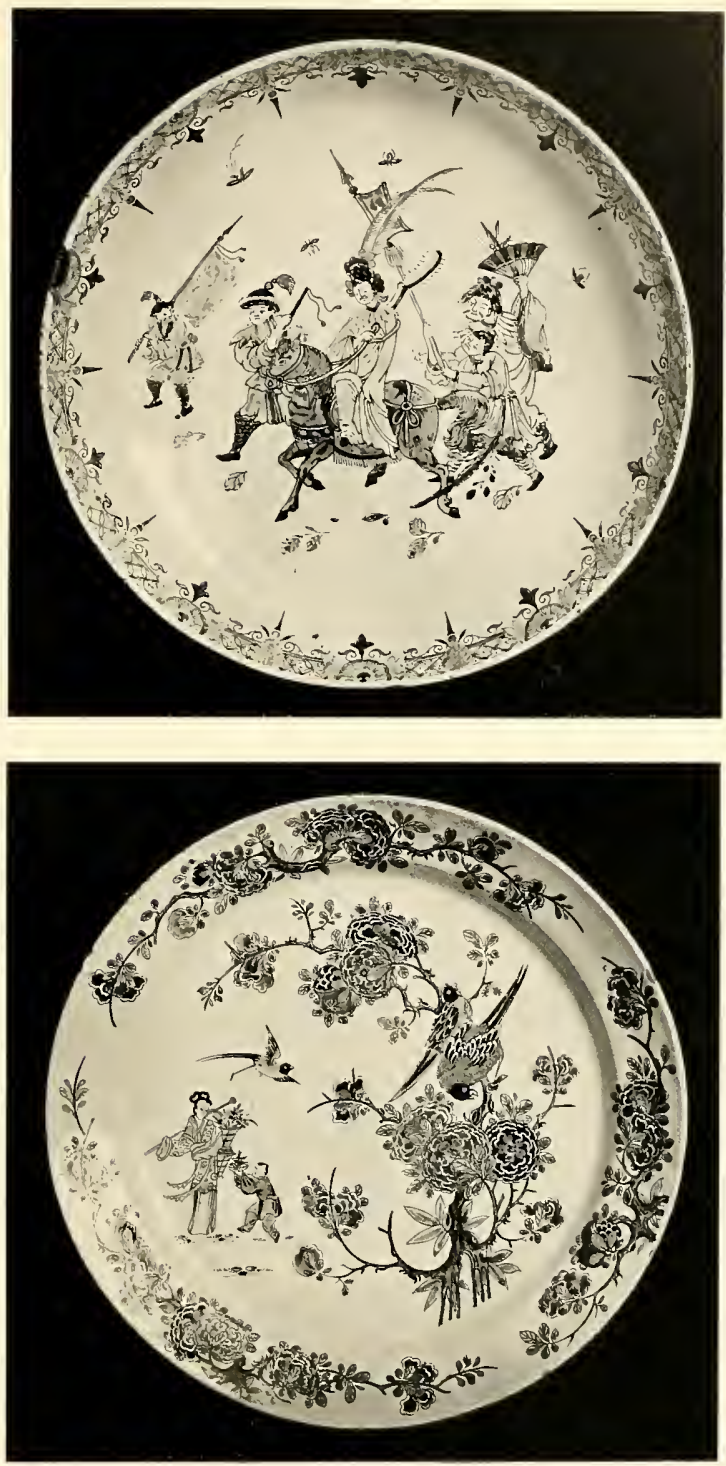


PLATE LXV1.

Fig. Io6. Miniature set of three vases and two beakers painted in grand feu and muffle-kiln colours (blue, red, green, purple and gold) on a bluish white ground, with floral decoration in the Japanese style. Unmarked. Delft middle of eighteenth century. Height, vases, $9 \frac{1}{2}$ ins. $(24 \mathrm{~cm}$.), beakers, 8 ins. $(20.5 \mathrm{~cm}$.). (See page 120.$)$

Nederlandsch Museum voor Geschiedenis en Kunst (Rijksmnseum), Ansterdam, No. s17 (Loudon Collection).

Fig. 107. Tea-tray painted in muffle-kiln colours (green, red, purplish blue, yellow and gold) on a white ground, with figures in a garden in imitation of Chinese famille verte porcelain. Unmarked. Delft; middle of eighteenth century. L. 161 ins. (41 cm.). (See page 124.)

Nederlandsch MIuseum voor Geschiedenis en Kunst (Rijksmusenm), Amsterdam, No. 523 (Loulon Collection). 

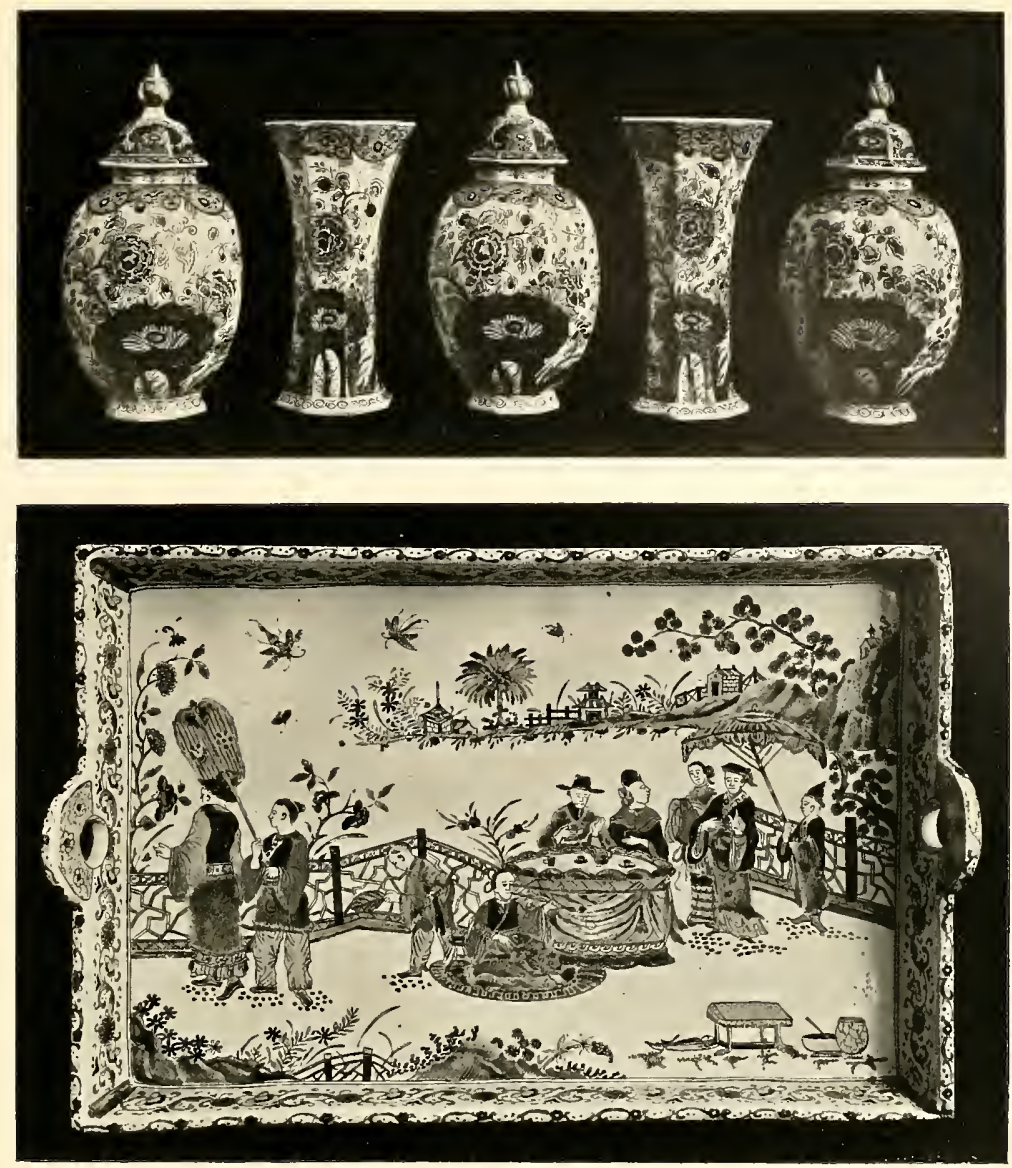


Fig. 108. Four tiles painted in muffle-kiln colours (red, blue, green, yellow, black and gold) on a white ground; on each is a basket of flowers in a medallion with formal ornaments in the surrounding angles. Delft; middle of eighteenth century. (See page I 25.) Museum Lambert van Meerten, Delft, No. A. 1194.

Fig. I09. Dish painted in muffle-kiln colours (red, pink, bluish lilac, yellow, green gold and black) on a white ground, with a landscape in the manner of Meissen porcelain and a baroque border. Unmarked. Delft; middle of eighteenth century. L. $12 \frac{3}{4}$ ins. (32.4 cm.). (See page 125.)

Victoria and Albert 11 useum, London, No. 1445 1853. 

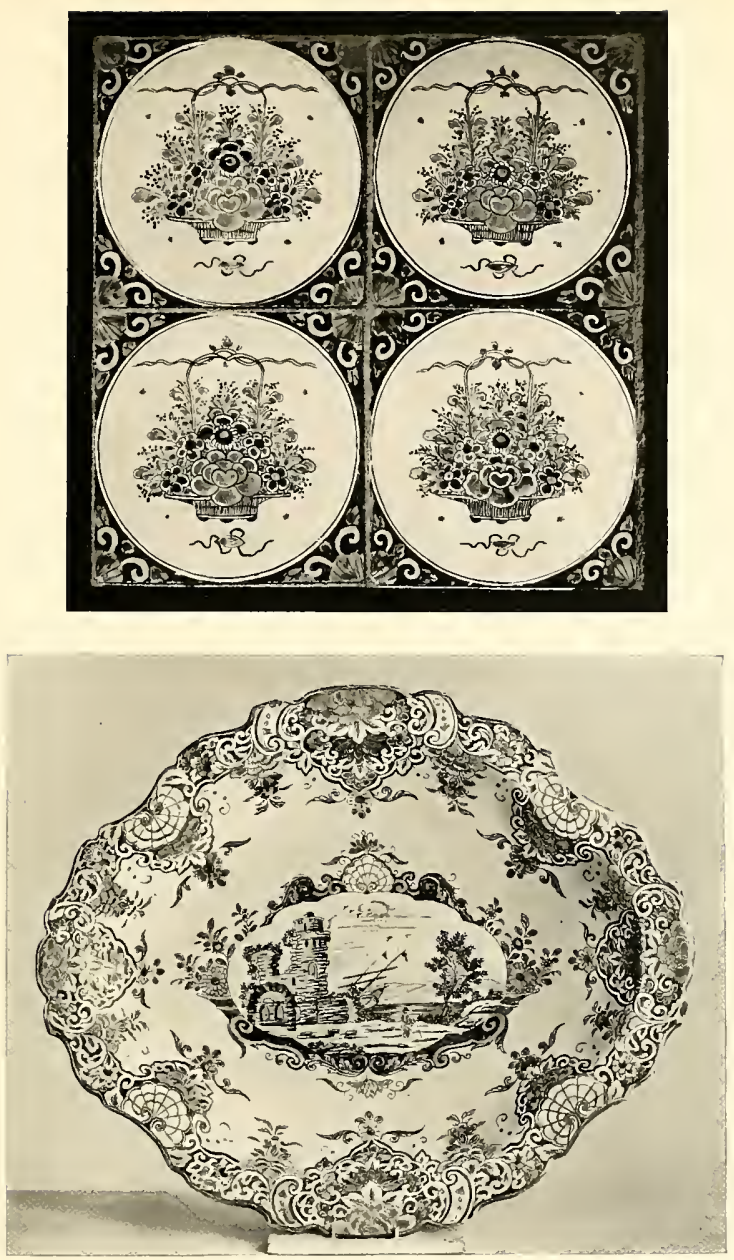


PLATE LXVIII.

Fig. I 10. Wall-cistern and wash-basin painted in muffe-kiln colours (pinkish lilac, red, yellow, green, purplish blue, black and gold) on a white ground, with landscapes within scrollwork and floral borders. Unmarked. Delft; middle of eighteenth century. Cistern, H. $17 \frac{1}{1}$ ins. $(43.5 \mathrm{~cm}$.), basin, W. $15 \frac{5}{8}$ ins. $(39.5 \mathrm{~cm}$.). (See page 125.)

Nederlandsch HI useum mor Geschiedenis en Kunst (Rijksmuseum), Amsterdam, No. 543 (Loudon Collection). 


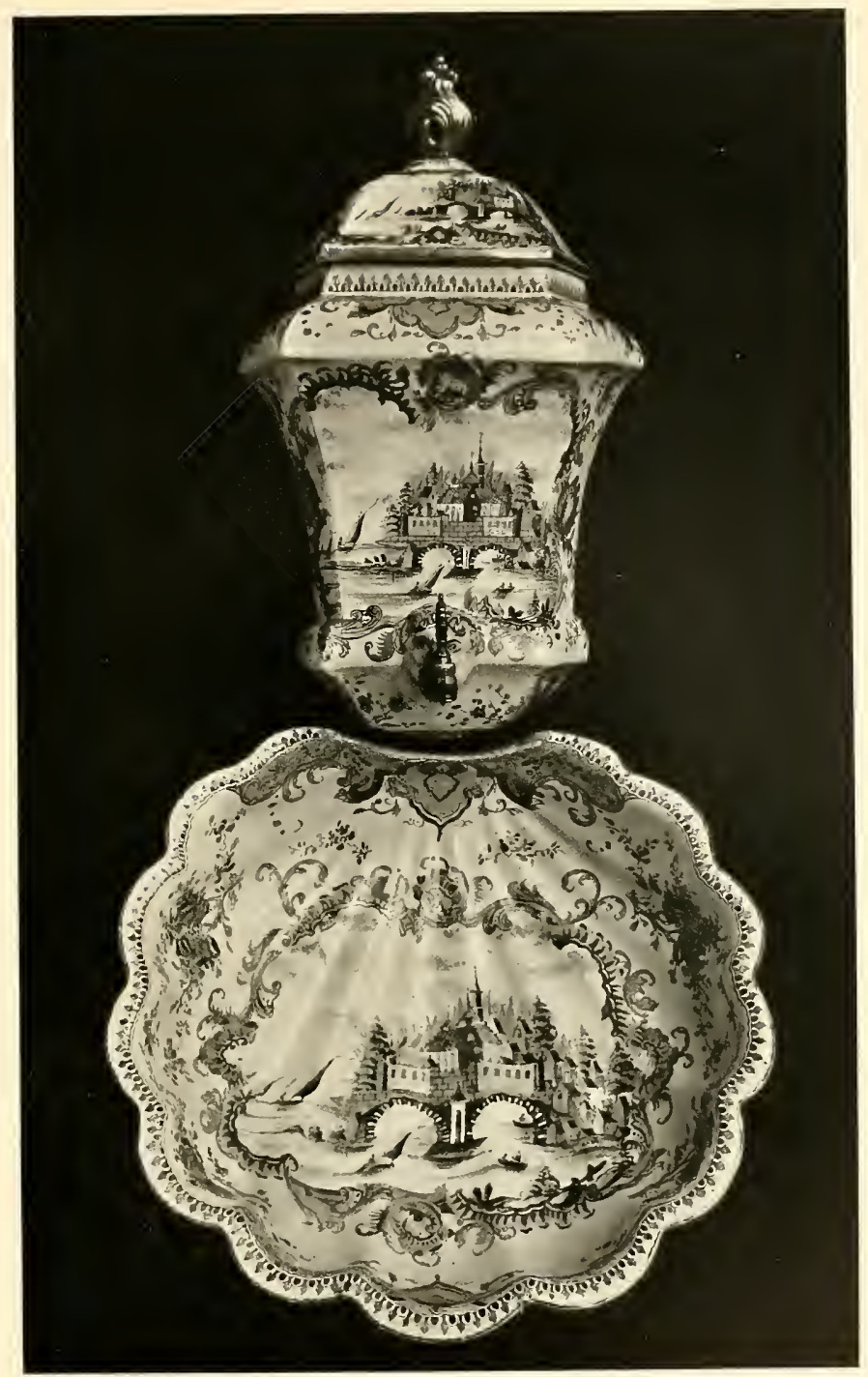



PLATE LXIX.

Fig. 111. Teapot of reddish brown earthenware with applied sprays of flowers, made in imitation of Chinese red stoneware. Mark, an impressed stamp with a fox and the name ARY DE MILDE. Delft, factory of Ary de Milde; second half of seventeenth century. H. $4 \frac{\pi}{2}$ ins. (II.5 cm.). (See page 129.)

Nederlandsch MI useum voor Geschiedenis en Kunst

(Rijksmuseum), Amsterdrm, No. 582.

Fig. I12. Coffee-pot painted in muffle-kiln colours on a white ground. Border of scale-pattern in crimson; below, a group of fruit in red, blue, green, yellow and pink; the legs picked out in brick red. Mark, a cock in red. Arnhem; about 1760. H. $13 \frac{3}{8}$ ins. $(34 \mathrm{~cm}$.$) . (See page 58$.)

Clainpanain Collection, Lille.

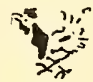



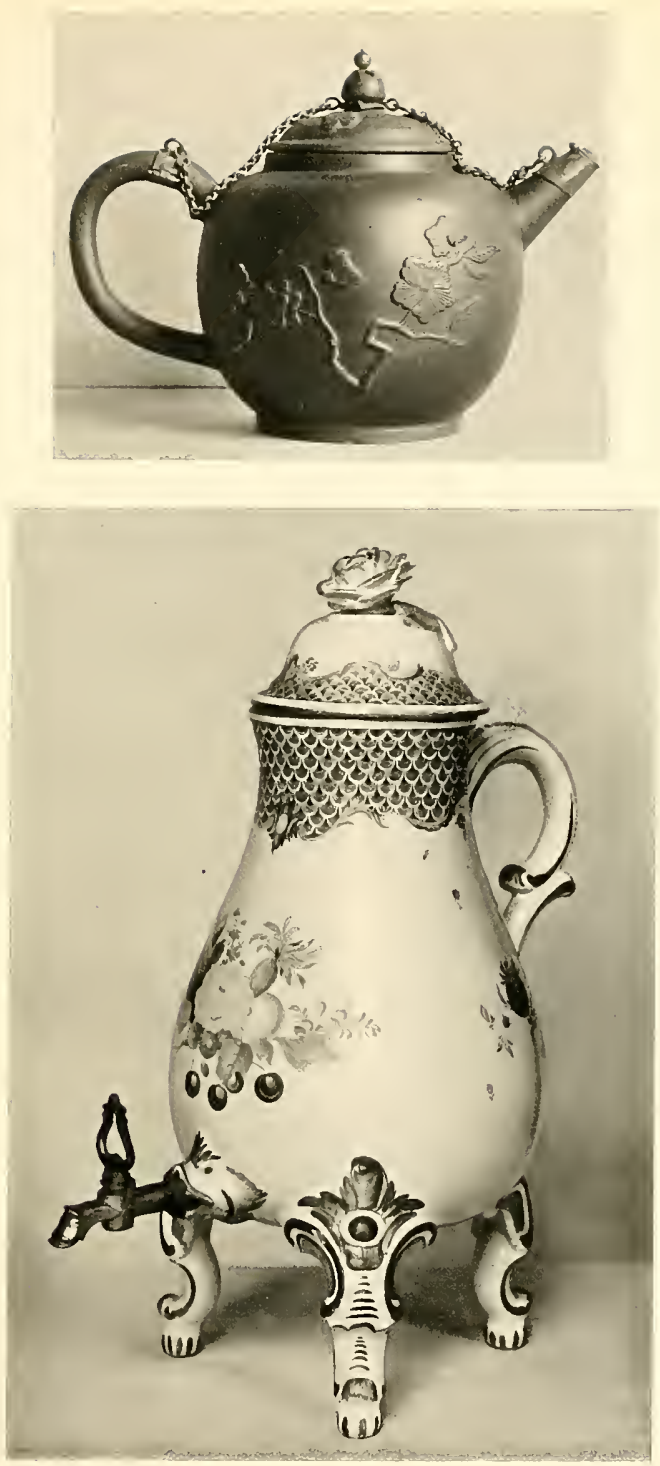





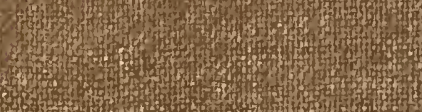

